
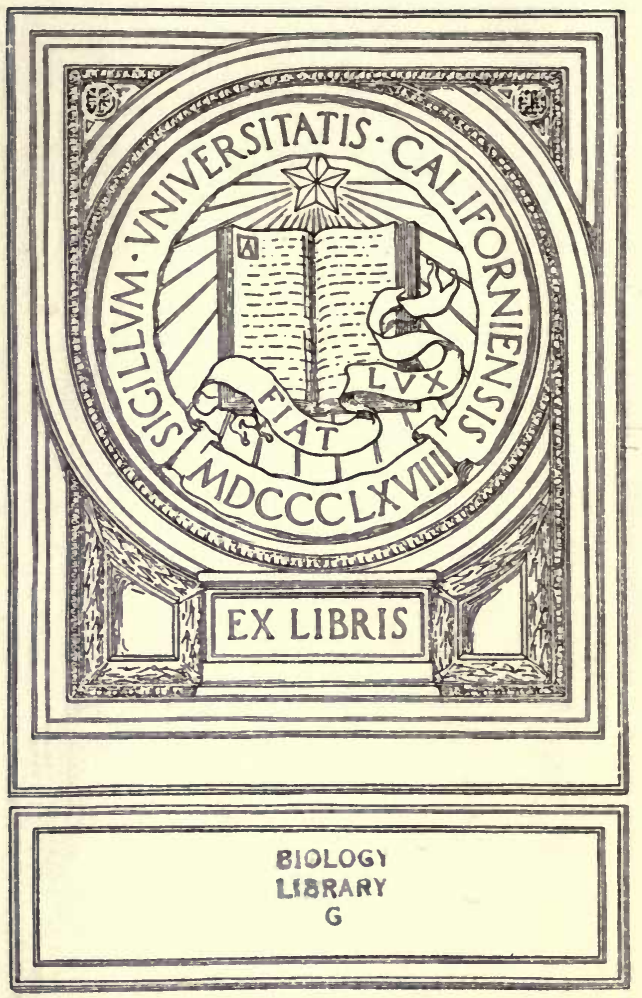




\section{LIFE AND HEALTH}

A TEXT-BOOK ON PHYSIOLOGY FOR HIGH SCHOOLS, ACADEMIES AND NORMAL SCHOOLS

B Y

ALBERT F. BLAISDELL, M.D. AUTHOR OF "CHILD'S BOOK OF HEALTH," "HOW TO KEEP WELL"

" OUR BODIES AND HOW WE LIVE," "PRACTICAL PHYSIOLOGY"

\section{GINN \& COMPANY}




\section{BLAISDELL'S \\ SERIES OF PHYSIOLOGIES}

By ALBERT F. BLAISDELL, M.D.

CHILD'S BOOK OF HEALTH

REVISED EDITION. In easy lessons for primary grades. List price, 30 cents.

HOW TO KEEP WELL

$\therefore$ REvised EuItion. A text-book on health for the lower grades. List price, 45 cents.

OUR BODIES AND HOW WE LIVE

REvisEd EDITION. An elementary text-book on physiolozy and hygiene for use in schools. List price, 65 cents.

\section{LIFE AND HEALTH}

A text-book on physiology and hygiene for high schools, academies, and normal schools. List price, 90 cents.

PRACTICAL PHYSIOLOGY

A text-book for higher schools. List price, \$1.10.

HOW TO TEACH PHYSIOLOGY

A handbook for teachers. List price, 10 cents.

GINN \& COMPANY Publishers

Entreed at Stationers' Hall

COPYRIGHT, 1902, 1910, BY

ALBERT F. BLAISDELL

ALL RIGHTS RESERVED

A 310.7 


\section{PREFACE}

THIs book is intended to serve as a text-book on physiology for such high schools, academies, and normal schools as provide two terms, and occasionally only one term, for this branch of study. For such secondary schools a shorter and simpler book than the author's Practical Physiology is needed. To meet this want the present book has been written.

The general plan of the author's larger book has been followed and a certain amount of its material and many of its expensive woodcuts have been utilized. The text has been simplified throughout and a large amount of new and instructive matter has been added.

In this book, as in all the other books of this series of school physiologies, the text has been supplemented by a large number of carefully graded and practical experiments. For the most part they are simple and can be performed with apparatus that is inexpensive and easily obtained.

The few facts which the young student is able to learn in school about the anatomy and physiology of the human body are of little value in themselves. Such facts, however, become of supreme importance and practical worth when they enable him to understand a few of the great laws of health and to apply them intelligently to his daily living. Hence the author has aimed to lay marked emphasis upon such points as bear directly upon personal health.

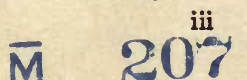


Special effort has been made to utilize in the text of the several chapters the latest teachings of modern hygiene regarding the nature and propagation of bacteria, the prevention and restriction of disease, and the preservation of health.

Sundry sections have been printed in smaller type. These may be omitted if it is deemed necessary to shorten the course in physiology.

This text-book complies fully with the laws of those states which require the study of the nature and the effects of alcohol, tobacco, and other narcotics upon the human system.

The author would acknowledge his indebtedness to Dr. Margaret B. Wilson of New York City for editorial assistance in revising the manuscript and reading the proof.

\section{A. F. BLAISDELL}

Boston, June, 1902

\section{PUBLISHERS' NOTE}

The author of this book has written an additional chapter (Chapter XV) on The Cause and Prevention of Tuberculosis, or Consumption. This has been done in accordance with the advice and suggestion of those educators and physicians who believe that pupils in our public schools should be taught the simplest facts concerning the cause and prevention of this dread disease. 


\section{CONTENTS}

CHAPTER I

INTRODUCTION

\section{CHAPTER II}

The Framework of the Body . . . . . . . . . . . $2 \mathrm{I}$

CHAPTER III

The Muscles

CHAPTER IV

Physical Exercise

CHAPTER V

FOOD AND DRINK . • . • . . . . . • • • 79

CHAPTER VI

The Digestion of Food

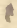
CHAPTER VII

The Blood and its Circulation . . . . . . . . I 36

CHAPTER VIII

RESPIRATION 161

CHAPTER IX

The Skin and the Kidneys . 184 
CHAPTER $\mathrm{X}$

The Nervous System PAGE

\section{CHAPTER XI}

The Special Senses

\section{CHAPTER XII}

The Throat and the Volce. . . . . . . . . . 276

\section{CHAPTER XIII}

The Preservation of Health . . . . . . . . . . 286

Bacteria, 286; The Prevention and Restriction of Disease, 295; The Care of the Sick Room, 298.

\section{CHAPTER XIV.}

First Aid to the InJURED . . . . . . . . . . 302

\section{CHAPTER XV}

The Cause and Prevention of Tuberculosis, or Consumptron 3i 7

APPENDIX . . . . . . . . . . . . . . . 333

GLOSSARY

INDEX . . . . . . . . . . . . . 353 


\section{LIFE AND HEALTH}

\section{CHAPTER I}

\section{INTRODUCTION}

1. Physiology in Schools. As a branch of study in our schools, physiology aims to make clear certain laws of health. Through a proper knowledge of these laws, and their practical application, we may hope to spend happier and more useful, because healthier, lives.

Hence, of all our school studies, no other should appeal to us with such peculiar force as does physiology, for it is the study of ourselves.

2. Questions which suggest themselves to the Thoughtful. Physiology appeals to us even from the first in a deeply personal way. Every thoughtful young person who takes up this study will now begin, even if he has never done so before, to ask himself a hundred questions about " the house in which we live."

Why is breathing so essential to our life, and why cannot we stop breathing when we try? Where within us, and how, burns the mysterious fire whose subtle heat warms us from the first breath of infancy till the last hour of life?

How is it that we can lift these curtains of our eyes and behold all the wonders of the world around us, then drop them, and though at noonday, be instantly in 
darkness? How does the minute structure of the ear report to us with equal accuracy the thunder of the tempest and the hum of the passing bee?

How can it be that the few articles of our daily food milk, bread, meats, and the like - build up our complex bodies, and by what strange magic are they transformed intó skin, teeth, bones, muscles, and blood?

These and hundreds of similar questions it is the province if physiology to answer.

3. The Profound Lessons taught by Physiology. The study of physiology is not only interesting and useful, but it should teach us some profound lessons. Every intelligent person should not only wish to acquire the knowledge how best to protect and preserve his body, but should feel a certain respect for an organism so wonderful as his physical frame. For our bodies are indeed not ourselves, but the frames that contain us, - the ships in which we, the real selves, are borne over the sea of life. He must be indeed a poor navigator who is not ever anxious so to direct his ship that it may escape the rocks of disease and premature decay, and that the voyage of his life may be long, pleasant, and successful.

Again, let us always keep in mind the thought that in studying physiology we are tracing in our bodies the myriad lines of marvelous skill and forethought as they appear in the work of the Divine Builder. However closely we study our bodily structure, we are, at best, but imperfect observers of the handiwork of Him who made us as we are.

4. Some Salient Facts concerning our Bodies. Even a very meager knowledge of the structure and action of our bodies reveals certain salient facts which must hold the attention of every thoughtful student. Thus, our bodies move 
themselves, either one part on another, or the whole body from place to place. The motive power is not from the outside world, but the energy of the movements exists in our bodies themselves.

Again, our bodies are continually breathing, that is, they take in oxygen from the surrounding air. They take in certain substances known as food, similar to those composing the body, which are capable through a process called oxidation, or through other chemical changes, of setting free a certain amount of energy.

Our bodies are continually making heat and giving it out to surrounding objects, the production and the loss of which are so adjusted that the whole body is warm, that is, of a temperature which is higher as a whole than that of surrounding objects.

Finally, our bodies are continually getting rid of so-called waste-matters, the most important of which are products of the oxidation of the material used as food, or of the substances which make up the organism.

5. The Main Features that distinguish Living Bodies. The living body, like the dead, is continually losing energy, but unlike the dead body is by means of food continually restoring its substance and replenishing its stock of energy. A great deal of energy thus stored up in the living body is utilized in doing mechanical work, that is, it is used in performing the various movements of the body. On the other hand, the energy set free in the dead body by oxidation and other chemical changes leaves the body for the most part in the form of heat. We shall learn later on that much of the energy which at last leaves the body as heat exists for a time within the living body in other forms than heat, though eventually transformed into heat. The dead body, left to itself, slowly decays, that is, it slowly 
combines with oxygen, slowly gives out heat, and therefore slowly loses its store of energy. Even a slight change in the surroundings of living bodies may rapidly, profoundly, and in special ways, affect not only the amount but the kind of energy set free. Thus the mere touch of a hair on some particular surface may lead to such a discharge of energy that a body previously at rest may be suddenly thrown into violent convulsions. This is especially true in certain diseases, for example, lockjaw.

The main problem we have to solve in the study of physiology is to ascertain how it is that our living bodies can renew their substance and replenish the energy which they are continually losing, and can, according to the nature of their surroundings, vary not only the amount but the kind of energy which they set free.

Hence, in all our future work, we must keep steadily in mind the two great fundamental divisions of physiology:

One which has to do with the renewal of substance and the replenishment of energy; the other which deals with the setting free of energy.

6. Life is Incessant Change. All living structures are subject to constant decay. Life is a condition of incessant changes, dependent upon two opposite processes, repair and decay. A considerable part of our bodies wastes every day, and the part which is wasted must be replaced. Thus our bodies are not composed of exactly the same particles from day to day, or even from one moment to another, although to all appearance we remain the same individuals. For instance, we are never of the same weight for two minutes together; but the change is so gradual, and the renewal of that which is lost may be so exact, that no difference can be noticed except at somewhat long intervals of time. 
7. The Metabolism of the Body. The process of building up the materials of the body from simpler materials is called anabolism.

The breaking down of the materials of the body into simpler substances is known as katabolism.

The entire series of changes that take place in the living body, beginning with the building up of its materials and ending with the casting out of wastes, is included in one word, metabolism.

The reduction of complex to simple substances results in the setting free of energy in the forms of heat and mechanical motion. Thus a complex substance, like a piece of muscle, or lean meat, is built up of many millions of molecules, each composed of a number of atoms arranged in a definite way. Force or energy was, of course, required for this regular arrangement of the atoms.

Now when this material is reduced by the process of oxidation to substances consisting of simpler molecules, such as carbon dioxide, urea, and water, the force stored up in the muscle as potential energy becomes manifest and is used as kinetic energy, or active life force.

8. Technical Terms defined. All living organisms may be studied from two points of view : first, as to their form and structure; second, as to the processes which go on within them.

The science which treats of all living organisms is called biology. It has naturally two divisions :

Morphology, which treats of the form and structure of living beings.

Physiology, which investigates their functions, or the special work done in their vital processes. The word physiology is from two Greek words ( $\phi \dot{v} \sigma \iota s$ and $\left.\lambda o^{\prime} \gamma o s\right)$ and means literally a talk or discourse about nature. 
The word anatomy, however, is usually employed instead of morphology. It is derived from two Greek words

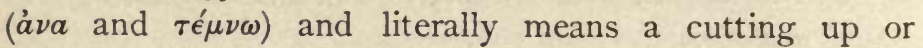
dissecting.

Human anatomy deals with the form and structure of the human body, and describes how the different parts are arranged, as learned by observation of the body as a whole, by dissection, and by the use of the microscope.

Histology, or "minute anatomy," is that part of biology which treats of the minute structure of the tissues of the body, as revealed by the microscope.

Human physiology describes the various processes that go on in the human body in health. It treats of the work done by the various parts of the body, and of the results of the harmonious action of the several organs.

Broadly speaking, physiology is the science which treats of the functions of living organized beings.

By the word function is meant the special work which an organ has to do.

An organ is a part of the body which does a special work. Thus the eye is an organ of sight, the stomach of digestion, and the lungs of breathing.

The word hygiene is often used in this branch of study. It treats of the health or physical welfare of the individual and of the community. Thus we speak of "personal hygiene," "public hygiene," "public health," and "sanitation."

We cannot understand the physiology of our bodies without some knowledge of their anatomy. An engineer could not understand the working of his engine unless he was well acquainted with all its parts, and the manner in which they were fitted together. So, if we are to understand the principles of elementary physiology, we must 
master a few of the main anatomical facts concerning the organs of the body before considering their special functions.

NotE. - A more accurate title for the subject-matter of this branch of study as now treated in text-books for elementary schools would be "Anatomy, Physiology, and Hygiene." By common usage, however, the word "Physiology" is quite generally used as a more condensed and convenient name.

\section{CHEMICAL COMPOSITION OF THE BODY}

9. Chemical Elements in the Body. All the various complex substances found in nature can be reduced by chemical analysis to about 70 elements, which cannot be further divided. By various combinations of these 70 elements all the substances known to exist in the world of nature are built up. When a human body is submitted to chemical analysis, it is found that the bones, muscles, teeth, blood, etc., may be reduced to a few chemical elements.

In fact, the human body is almost entirely composed of I 3 of the 70 elements, namely: oxygen, hydrogen, nitrogen, chlorine, fluorine, carbon, phosphorus, sulphur, calcium, potassium, sodium, magnesium, and iron. Besides these, a few of the other elements, as silicon and iodine, have been found; but they exist in extremely minute quantities.

Oxygen, hydrogen, and nitrogen, which are gases in their uncombined form, make up three-fourths of the weight of the whole human body. Carbon, which exists in an impure state in charcoal, forms more than one-fifth of the weight of the body. Thus, carbon and the three gases named make up about 96 per cent of the total weight of the body.

$\checkmark$ We must keep in mind that, with slight exceptions, none of these elements exist in their elementary form in the 
animal economy. They are combined in various proportions, the compounds differing widely from the elements of which they consist. Thus, oxygen and hydrogen unite to form water, and water forms more than two-thirds of the weight of the whole body.

10. Inorganic Salts. A large number of the elements of the body unite one with another by chemical affinity and form inorganic salts. Thus, sodium and chlorine unite and form chloride of sodium, or common salt. This is found in all the tissues and fluids, and is one of the most important inorganic salts the body contains. It is absolutely necessary for continued existence.

By a combination of phosphorus and oxygen with sodium, potassium, calcium, or magnesium, the various phosphates are formed. The phosphates of lime and soda are the most abundant of the salts of the body. For instance, they form more than half the material of the bones.

The special place of iron is in the coloring matter of the blood. Its various salts are also found in small quantities in the ash of bones, in muscles, and in many other tissues.

11. Organic Compounds. Besides the inorganic materials, there exists in the human body a series of compound substances formed by the union of the elements just described, which always require the agency of living structures for their formation. They are built up from the elements or from simple mineral compounds by plants, and are called organic compounds. Human beings and the lower animals take such of these organized materials as they require, and build them up into the materials of their own bodies, often forming still more highly organized forms in the process.

Whatever other elements they may contain the organic compounds of the body are invariably composed chiefly of carbon, hydrogen, and oxygen. 


\section{Introduction}

The principal organic compounds found in the body are usually divided into three great classes :

I. Proteids, or albuminous substances.

2. Carbohydrates (starches, sugars, and gums).

3. Fats.

The extent to which these three great classes of organic materials of the body exist in the animal and vegetable kingdoms, and are utilized for the food of man, will be discussed in the chapter on food (Chapter V).

12. The Proteids. The proteids, because they contain the element nitrogen while the others mentioned above do not, are frequently called nitrogenous, and the other two are known as non-nitrogenous substances.

The proteids, the type of which is egg albumin, or the white of egg, are found in muscle and nerve, in glands, in blood, and in nearly all the fluids of the body. A human body is estimated to contain on an average about i 8 per cent of albuminous substances.

In succeeding chapters we shall have occasion to refer to various proteids and substances allied to them as they exist in muscle (myosin), coagulated blood (fibrin), and bones (gelatin).

13. The Carbohydrates. The carbohydrates are formed of carbon, hydrogen, and oxygen, the last two in the proportion to form water. Thus, we have animal starch, or glycogen, stored up in the liver. Sugar, as grape sugar, is also found in the liver.

14. The Fats. The body of an average man contains about Io per cent of fats. These are formed of carbon, hydrogen, and oxygen, in which the latter two are not in the proportion to form water. The fat of the body consists of a mixture which is liquid at the ordinary temperature. 
It must not be supposed that the various chemical elements, as the proteids, the salts, the fats, etc., exist in the body in a condition to be easily separated one from another. Thus, a piece of muscle contains all the various organic compounds just mentioned, but they are combined, and in different cases the amounts vary. Again, fat may exist in the muscles even though it is not visible to the naked eye, and a microscope is required to show the minute fat droplets.

\section{THE MINUTE STRUCTURE OF THE TISSUES}

15. Protoplasm. The ultimate living substance of the body is called protoplasm. ${ }^{1}$

This material basis of all living things, whether plants or animals, is a mixture of various organic compounds, the chief of which, in all cases, are proteids.

16. Cells. When we carry back the analysis of an organized body as far as we can, we find every part of it made up of masses of protoplasm of various sizes and

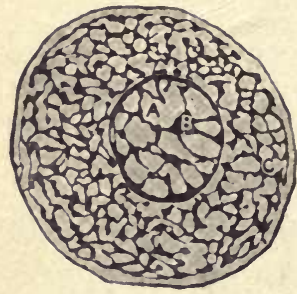

Fig. I. Diagram of a Cell.

$A$, nucleus; $B$, nucleolus ; $C$, protoplasm. (Highly magnified.) shapes. Such bodies are technically named cells. The white blood corpuscle is a typical cell having a nucleus and nucleoli. Every cell has the power of appropriating nutrient material, of dividing and subdividing so as to form new masses like itself. When not built into a tissue, it has the power of changing its shape and of moving from place to place, by means of the delicate projections, technically called processes, which it puts forth.

1 The word " protoplasm " must not be misunderstood to mean a substance of a definite chemical nature, or of an invariable morphological structure; it is applied to any part of a cell which shows the properties of life, and is therefore only a convenient abbreviation for the phrase, "mass of living matter." 
Every perfect cell consists of a cell-body and a nucleus. In brief, then, a cell is a nucleated mass of protoplasm endowed with the attributes of life. In this sense the term "cell" is
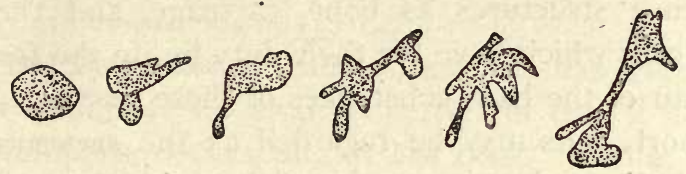

FIG. 2. Amœboid Movement of a Human White Blood Corpuscle.

(Showing various phases of movement.)

now used. Every tissue of the human body is formed through the agency of protoplasmic cells.

17. The Differentiation of Cells. The simplest forms of animal life are organisms consisting of only one cell. Thus, the amœba begins its life as a cell split off from its parent. This divides in its turn, and each half is a complete amœba. Organisms a little higher than the amoba consist of many cells. As we ascend in the animal scale the cells adapt themselves to perform certain definite functions and a division of labor occurs. Technically, the cells are said to undergo differentiation.

Cells having similar shape and function are grouped to form tissues, and tissues are grouped to form organs.

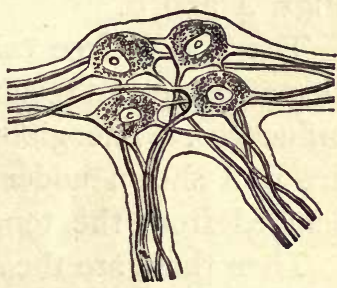

FIG. 3. Nerve Cells from the Gray Matter of the Cerebellum.

(Magnified 260 diameters.)

18. Cells and the Human Organism. If the human body be studied in its first stage of development, it is found to originate from a single nucleated cell. From this original cell, by growth and development, the body, with all its various tissues, is built up. Many fully formed organs, like the liver, consist chiefly of cells. Sometimes cells are modified 
to form fibers, such as those of tendon, muscle, and nerve. Later on we shall see that the white blood corpuscles exhibit all the characters of the amœba (Fig. 2). Even such dense structures as bone, cartilage, and the teeth contain cells which have for their duty in life the formation and repair of the hard substances of these tissues.

In short, cells may be regarded as the anatomical units of animal tissues, by the combination of which the body is built up.

In addition to the living cells, every tissue contains more or less of a lifeless substance between the cells called intercellular substance, which is produced at some time by the cells.

19. Kinds of Cells. Cells vary greatly in size, some of the smallest being only $\frac{1}{3500}$ of an inch or less in diameter. They also vary greatly in form, as may be seen in Figs. 4 and 6.

The typical free cell is usually globular in form, other shapes being the result of pressure or of similar modifying influences. The globular as well as the large flat cells are well shown under the microscope in a drop of saliva scraped from the tongue.

Then there are the columnar cells, found in various parts of the intestines and the respiratory passages. The latter cells sometimes have on the free surface delicate prolongations called cilia. Under the microscope they present a wavy appearance, like that of a field of grain when the wind blows over it (Fig. 6). There are, besides, cells known as spindle, stellate, and pavement cells, and others having various names suggested by their shapes.

Cells are also described as to their contents. Thus, fat cells and pigment cells are alluded to in succeeding sections. 
Cells may be described also with reference to their functions or location or the tissue in which they are found, as blood cells or corpuscles (Figs. 2 and 67), nerve cells (Fig. 3), and connective-tissue cells.

20. Vital Properties of Cells. Each cell has a life of its own. It manifests its vital properties in that it is born, grows, multiplies, decays, and at last dies. During its life it assimilates food, works, rests, and is capable of spontaneous motion and frequently of locomotion. Some cells live a brief life of $\mathrm{I} 2$ to 24 hours, as is probably the case with many of the cells lining the alimentary canal; others may live for years, as do the cells of cartilage and bone.

A most interesting power of the living cell
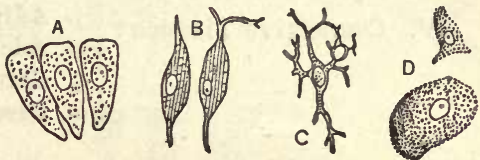

FIg. 4. Various Forms of Cells.

$A$, columnar cells found lining various parts of the intestines (called columnar epithelium); $B$, cells of a fusiform or spindle shape found in the loose tissue under the skin and in other parts (called connectivetissue cells); $C$, cell having many processes - such are found in some kinds of connective tissue; $D$, primitive cells composed of protoplasm with nucleus, and having no cell wall. All are represented about 400 times their real size. is motion, a beautiful form of which is found in ciliated epithelium (sec. 23). Cells may move actively and passively. In the blood the corpuscles are swept along by the current, but some of the white corpuscles are able to make their way actively through the tissues, as if guided by some sort of instinct. They protrude a portion of their protoplasm in the direction in which they wish to move and then draw the rest of the body towards this "pseudopodium," or false foot. The property of protoplasm which makes this movement possible is known as contractility. It is possessed in some degree by all protoplasm, but it is the characteristic property of the cells and fibers of muscle. 
THE PRINCIPAL TISSUES OF THE BODY

21. The Chief Tissues classified. The chief tissues which form the organs of the body may be classified as follows :

I. Nervous Tissues.

II. Muscular Tissues. (I. White and Elastic, Fibrous.

III. Epithelial Tissues. 2. Areolar or Cellular.

IV. Connective Tissues : $\left\{\begin{array}{l}\text { 3. Adipose or Fat. } \\ \text { 4. Adenoid or Retiform. }\end{array}\right.$

5. Cartilage.

6. Osseous or Bone.

The most important tissues, the nervous and muscular, the "master tissues," - are those by which the active life of

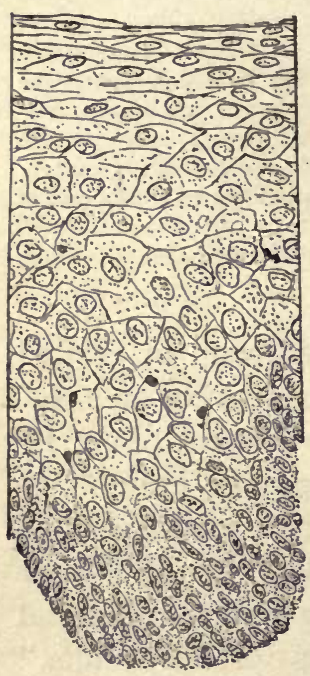

FIG. 5. Cross-Section of Squamous Epithelium from the Esophagus. the individual is carried on. These will be described in later chapters.

The remaining chief tissues - epithelial and connective - will now be briefly explained.

The osseous tissue, or bone, will be described in Chapter II.

\section{THE EPITHELIAL TISSUES}

22. Epithelium. Cells are associated and combined in many ways to form tissues. The distinctive character of every tissue depends on its structure, its mode of union, and the vital properties of its elements.

One of the simplest of the tissues is called epithelium, or surface-limiting tissue, and the cells are known as epithelial cells. 
23. Varieties of Epithelium. The various kinds of epithelial tissues are usually classified as squamous, glandular, and columnar.

The squamous, or pavement epithelium consists of very thin flattened scales which form the outer layer of the skin and the linings of the mouth. ${ }^{1}$

The glandular epithelium forms the essential parts of glands such as the liver and the glands of the skin.
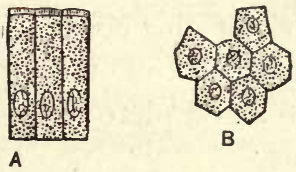

A
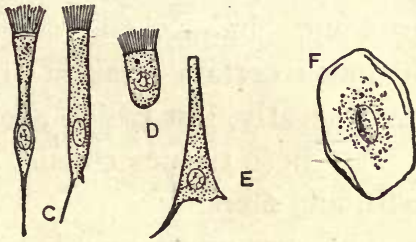

FIG. 6. Various Kinds of Epithelial Cells.

The ciliated epithelium (a variety of the columnar) is marked by the presence of very fine hair-like procęsses called cilia, which develop from the free end of the cell and exhibit a rapid whip-like movement as long as the cell is alive. This motion is always to and fro in the same direction, and serves to carry away mucus and even foreign particles in contact with the membrane on which the cells are placed.

This kind of epithelium is especially common in the air passages, where it serves to keep a free passage for the entrance and exit of air.

1 A variety of the smooth pavement epithelium, called endothelium, lines the heart and blood vessels and is the characteristic tissue of serous membranes, like the pleura and the peritoneum (secs. 167 and 213 ). 


\section{THE CONNECTIVE TISSUES}

24. Connective Tissues. ${ }^{x}$ The connective tissues serve to unite and bind together the different organs and tissues. Made up of fibers and cells, they form a sort of flexible framework of the body. They so pervade every portion of it that if all the other tissues were removed, we should still have a complete representation of the bodily shape in every part.

$\dot{x}$ In brief, the connective tissues may be said to serve as packing, binding, and supporting structures. This name includes certain tissues which to all outward appearance vary greatly, but which are properly grouped together.

All these tissues consist of a ground-substance or matrix, cells, and fibers.

The ground-substance is best seen in hyaline cartilage, where it has a glossy appearance. In bone it is infiltrated with the salts which give to the osseous tissue its hardness and make it seem so unlike other tissues.

Experiment I. To examine squamous epithelium. With an ivory paper-knife gently scrape the back of the tongue or the inside of the lips or cheek; place a tiny portion of the substance thus obtained upon a glass slide ; cover it with a thin cover-glass, and if necessary add a drop of water. Examine with the microscope, and the irregularly formed epithelial cells will be seen.

Experiment 2. To examine ciliated epithelium. Open a frog's mouth, and with the back of a knife-blade gently scrape a little of the membrane from the roof of the mouth. Transfer to a glass slide, add a drop of salt solution, and place over it a cover-glass with a hair underneath to prevent pressure upon the cells. Examine with a microscope under a high power. The cilia move very rapidly when quite fresh, and are therefore not easily seen. 
The cells are called connective-tissue corpuscles, cartilage cells, and bone corpuscles, according to the type of the

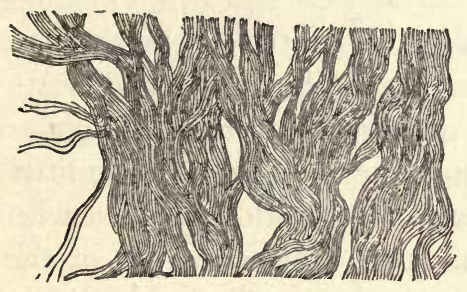

FIG. 7. White Fibrous Tissue. (Highly magnified.) tissues in which they occur. The fibrous connective tissues are composed of a matrix in which are imbedded the cells and two kinds of connective-tissue fibers, white and yellow or elastic. As the character of connective tissue depends largely on the arrangement of these fibers, they are worthy of special mention.

25. Connective Tissue with White Fibers. The white fibers of connective tissue consist of bundles of very delicate fibrils bound together by a small amount of cement substance into bundles varying in size. Between the fibrils protoplasmic masses (connective-tissue corpuscles) are found. These fibers may be so interwoven as to form a sheet, as in the periosteum of the bone, the fasciæ around muscles, and the capsules of organs; or they may be aggregated into bundles and form rope-like bands, as in the ligaments of joints and the tendons of muscles.

26. Connective Tissue with Yellow or Elastic Fibers. The yellow or elastic fibers of connective tissue are

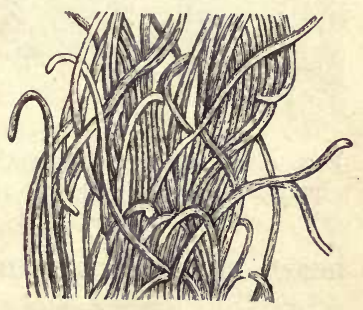

Fig. 8. Yellow Elastic Tissue.

(Highly magnified.) much stronger and coarser than those of the white. They are yellowish, tend to coil up like a broken spring, and are highly elastic. It is these fibers which give elasticity to the skin and to the coats of the arteries. Their typical 
form occurs in the ligaments which bind the vertebra together, in the true vocal cords, and in certain ligaments of the larynx.

27. Areolar or Cellular Tissue. This tissue, thus named by the older anatomists, consists of bundles of delicate fibers interlacing and crossing one another, forming irregular

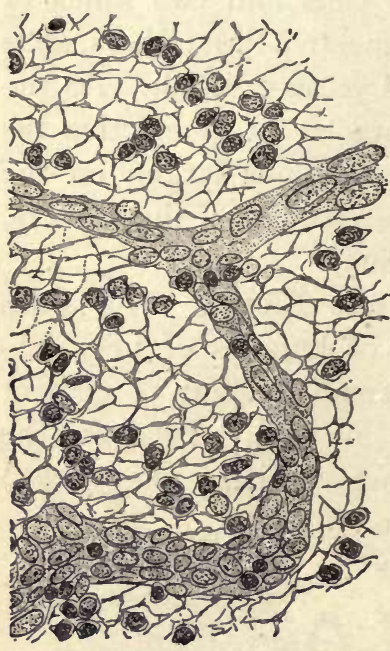

Fig. 9. Retiform Connective Tisșue from a Lymph Gland. spaces or meshes. These little spaces, in health, are filled with fluid that has oozed out of the blood vessels. The areolar tissue forms a protective covering for delicate and important organs.

$\times 28$. Adipose or Fatty Tissue. In almost every part of the body there is found a variable quantity of adipose or fatty tissue. Examined by the microscope, the fat cells are seen to be minute sacs of exceedingly delicate, structureless membrane filled with oil.

This tissue is usually plentiful beneath the skin, in the abdominal cavity, on the surface of the heart, in the marrow of bones, and elsewhere.

Experiment 3. To examine white fibrous tissue. Snip off a very minute portion from a tendon of a rabbit, or any small animal recently dead. Tease the specinen with needles, mount in salt solution, and examine under a high power. Note the course and characters of the fibers.

Experiment 4. To examine elastic tissue. Tease out a small piece of ligament from a rabbit's leg in salt solution; mount in the same, and examine as before. Note the curled elastic fibers. 
29. Adenoid or Retiform Tissue. This is a variety of connective tissue found in the tonsils, spleen, lymphatic glands, and allied structures. It consists of a very fine network of fibrils, around which are cells of various sizes.

30. Cartilage. Cartilage, or gristle, is a tough but highly elastic tissue. Under 1 the microscope it is seen to consist of a matrix, or base, in which nucleated cells abound, either singly or in groups.

Cartilage has sometimes the appearance of fine ground glass, when it is spoken of as hyaline. This kind of cartilage forms the early state of most of 2 the bones, and is also a permanent coating for the articular ends of long bones.

In other cases the matrix is almost replaced by white fibrous tissue. This is called white fibro-cartilage, and is found where great strength and a certain amount of rigidity are required, as in the disks between the bodies of the vertebræ, in the interior of the knee joint, in the wrist and other joints, and also in the lining of the grooves for various tendons.

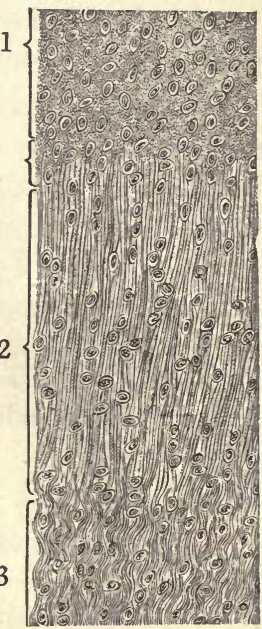

FIG. 10. Longitudinal Section of Cartilage.

I, hyaline cartilage; 2 , white fibro-cartilage; 3 , white fibrous connective tissue.

Again, there is between the cells a meshwork of yellow elastic fibers. This is called yellow or elastic fibro-cartilage, and is found in the gristle of the external ear, in the cartilage of the Eustachian tube, in the epiglottis and in other parts of the larynx. 


\section{ADDITIONAL EXPERIMENTS}

It may be well to postpone some of the experiments in histology until kindred topics are met with in the succeeding chapters.

For general directions and explanations and also suggestions for performing additional experiments, see the Appendix.

Experiment 5. To examine adipose tissue. Take a bit of fat from the mesentery of a rabbit. Tease the specimen in salt solution and mount in the same. Note the fat cells lying in a vascular meshwork.

Experiment 6. To examine blood corpuscles. Wind a piece of twine tightly around the last joint of a finger. Prick the skin with a clean needle. A drop of blood will flow. Spread it out on a piece of glass under a cover-glass and examine with the compound microscope. A large number of red corpuscles may be seen and a few colorless cells.

Experiment 7. To examine a typical nucleated cell. A colorless human blood corpuscle is a typical nucleated cell. Dilute a drop of fresh blood (to be obtained and examined as directed in the preceding experiment) with water, or, still better, with very dilute acetic acid. The spongy protoplasm of the colorless corpuscles swells up and becomes transparent. An internal rounded body becomes visible, which is the nucleus.

When the blood under the microscope is stained with carmine fluid, the nucleus is generally more deeply stained than the rest of the corpuscle. This may be done by placing a drop of carmine fluid on the slide close to the edge of the cover-glass and pressing a piece of blotting paper against the opposite edge of the cover-glass to absorb a little of the liquid.

Note to The Teacher. - The teacher is advised to use these two most excellent handbooks : Peabody's Laboratory Exercises in Anatomy and Physiology (H. Holt \& Co.); Brown's Physiology for the Laboratory (Ginn \& Company).

Reference should also be made to the Outline of Requirements in Anatomy, Physiology, and Hygiene for admission to Harvard University. 


\section{CHAPTER II}

\section{THE FRAMEWORK OF THE BODY}

x 31. The Bony Framework. The framework on which the body is built consists chiefly of a large number of bones, called the skeleton. There are in the adult human body about two hundred distinct bones. The teeth are not bones, but are a part of the structure of the skin.

The bones of the body give firmness, strength, and protection to the soft tissues and vital organs. They also form levers for the muscles to act upon, and thus render possible many complicated movements.

x 32. Chemical Composition of Bone. Bone is composed of earthy, or mineral matter (chiefly in the form of lime salts), and of animal matter (principally gelatin), in the proportion of two-thirds of the former to one-third of the latter. The proportion of earthy to animal matter varies with age. In infancy the bones are composed more largely of animal matter and are more easily deformed than in later life. Hence an infant's bones are not easily broken. In childhood the bones still contain a larger percentage of

The Study of the Skeleton in the Schoolroom. A human skeleton is almost a necessity in the study of bones and their action. To this intent, schools of a higher grade should be provided either with a mounted skeleton or with the separate bones. Oftentimes a loan of a complete skeleton or many of the bones can be secured of some medical man in the vicinity. In fact, there is no other way to study properly the structure and use of the bones and joints than by the bones themselves. 
animal matter than in more advanced life, and are therefore more liable to bend than to break; while in old age they contain a greater percentage of mineral matter, and are more easily broken.

Experiment 8. To show the mineral matter in bone. Put a large soup bone on a hot, clear fire, and let it remain there until it is at a

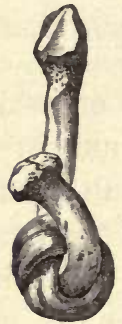

FIG. II. red heat. At first it becomes black from the liberation of the carbon of its organic matter, but at last it turns white. Let it cool. The animal matter has been burnt out, leaving the mineral, or earthy part, a white, brittle substance of exactly the same shape.

Experiment 9. To show the animal matter in bone. Add one-fourth of a cupful of muriatic acid to a quart of water, and place the mixture in a widemouthed bottle or glass fruit jar. Scrape and clean a chicken's leg bone, part of a sheep's rib, or any The Fibula tied other small slender bone. Soak the bone in the acid into a Knot mixture for a few days, adding a little more acid after the Mineral Matter has been dissolved by Acid. from time to time as the effervescence seems to have ceased. The mineral matter is slowly dissolved, and the bone, although retaining its original form, loses its rigidity and becomes pliable, and so soft as to be readily cut. If the experiment be carefully performed, a long, thin bone may even be tied into a knot.

\section{Physical Properties of Bone. A bone is not the} same in its structure in all parts. If we take a leg bone of a sheep, or a large end of beef shin bone, and saw it lengthwise in halves, we see two distinct structures. There is a compact tissue which seems hard and solid as stone forming the outside shell, and a honeycombed lighter tissue inside having the appearance of a beautiful trelliswork of thin bony plates. This spongy, or cancellous tissue occurs in the interior of bones, and chiefly at the joint ends. Not only is the cancellous tissue strong and light, but it has another advantage, - that of breaking shocks. 
It will also be seen that the shaft is a hollow cylinder, formed of compact tissue, enclosing a cavity called the medullary canal, which is filled with a soft, fatty substance called the marrow of the bone. The marrow is richly supplied with blood vessels, which enter the cavity through small openings in the compact tissue. In fact, all over the surface of bone are the openings of minute canals leading into the substance. One of these, especially constant and large in many bones, is called the nutrient foramen, and transmits a special artery to nourish the bone.

Experiment ro. Obtain a part of a beef shin bone, or a portion of a sheep's or a calf's leg, including if convenient the knee joint. Have the bone sawed in two lengthwise, keeping the marrow in place. Boil, scrape, and carefully clean one-half. Note the compact and spongy parts, shaft, etc.

Experiment II. Trim off the flesh from the second half. Note the pinkish-white appearance of the bone, the marrow, and the tiny specks of blood, etc. Knead a small piece of the marrow in the palm; note the oily appearance. Convert some marrow into a liquid by heating. Contrast this fresh bone with an old dry one.

NotE.-While waiting for class use, fresh bones should be kept in a cool place, carefully wrapped in a cloth moistened with listerine, dilute carbolic acid solution, or even glycerine solution - an ounce to one pint of water.

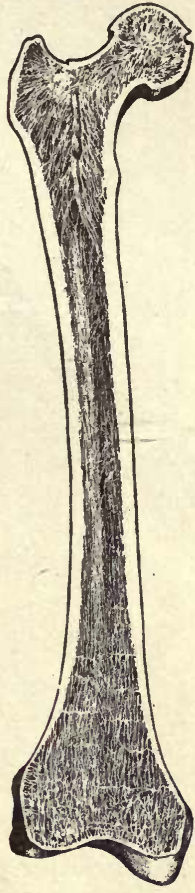

Fig. I 2. The Right Femur sawed in Two lengthwise.

(Showing arrangement of compact and cancellous tissue.)

34. The Periosteum. A fresh or living bone is invested with a delicate membrane called the periosteum. It adheres very closely to the bone, and covers every part except at 


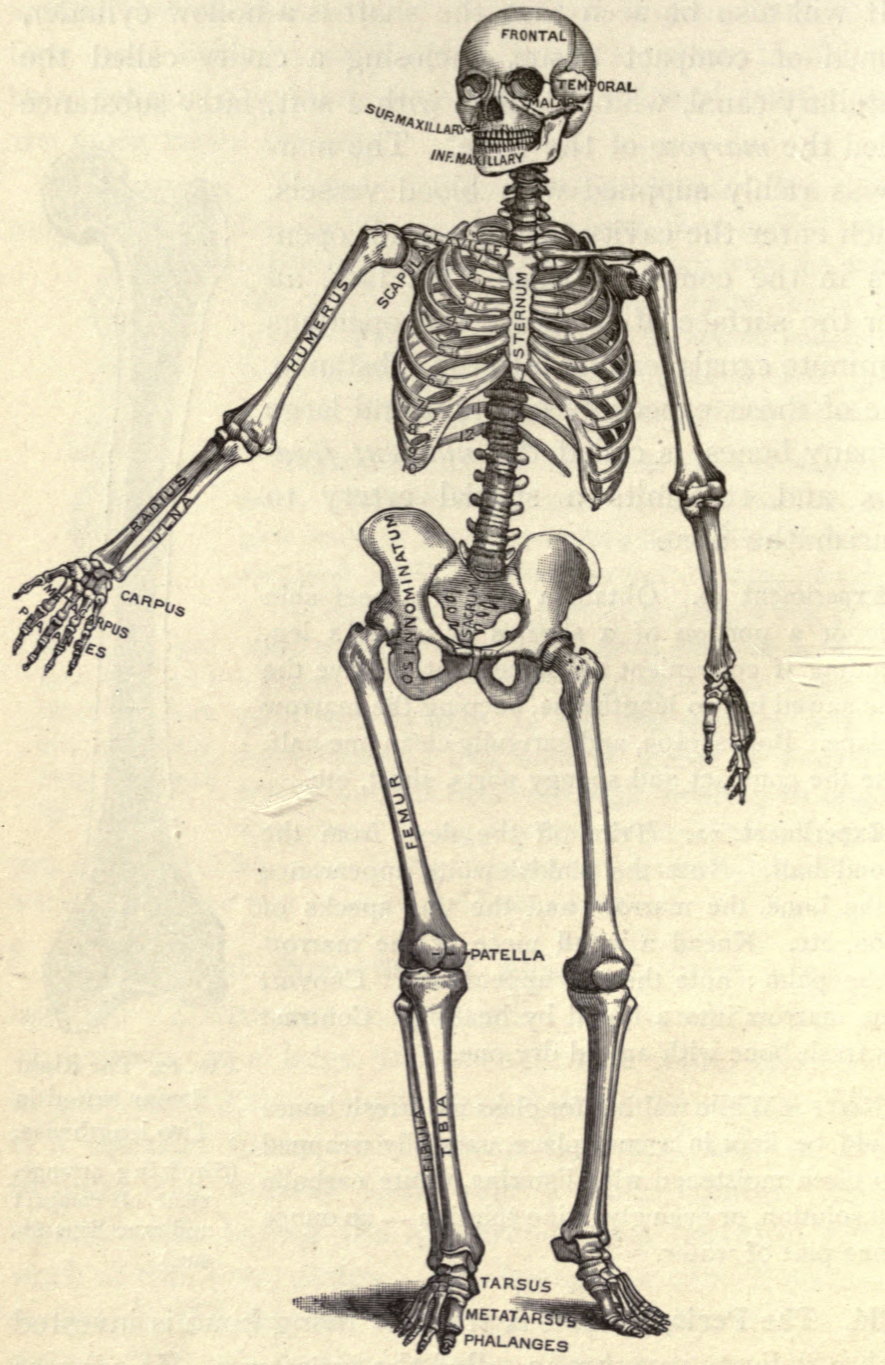

Fig. 13. The Skeleton. 


\section{The Framework of the Body}

the joints and where it is protected with cartilage. The periosteum is richly supplied with blood vessels, and plays an important part in the growth, formation, and repair of the outside of bone. If, therefore, the periosteum be detached from the surface of the bone by injury or disease, there is a risk that a layer of the subjacent bone will gradually lose its vitality and soon die. ${ }^{1}$

\section{Microscopic Structure of Bone.} If a very thin slice of bone be cut from the compact tissue and examined under a microscope, numerous minute openings are seen. ${ }^{2}$ Around these are arranged rings of bone, with little black bodies in them, from which radiate fine dark lines. These openings are sections of canals called Haversian canals, - after Havers, an English physician, who first discovered

1 The periosteum is often of great practical importance to the surgeon. Instances are on record where bones have been removed, leaving the periosteum, within which the entire bone has grown again. Some years ago Dr. James R. Wood, a famous surgeon in New York, removed the whole lower jawbone from a young woman, leaving the periosteum and even retaining in position the teeth by a special apparatus. The entire jawbone grew again, and the teeth resumed their original places as it grew.

${ }^{2}$ Mounted sections of bone and slides for the study of other elementary tissues may be readily procured of dealers in microscopical supplies:

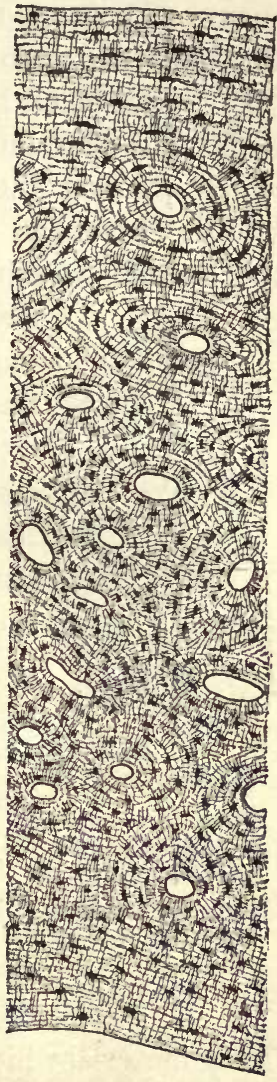

Frg. 14. Cross-Section from Shaft of a Long Bone.

(Little openings (Haversian canals) are see n, and around them are arranged rings of bone with little dark spaces, $\quad$ ac $u n a$, from which branch out fine dark lines, canaliculi.) 
them. They are tunnels left in the compact substance of the bone, through which run blood vessels for its nutrition. The black bodies are minute cavities called lacuna, while the fine lines are very minute canals, canaliculi, which connect the lacunæ and the Haversian canals.

The Haversian canals contain tiny blood vessels, while the lacunæ contain bone cells which have made the hard

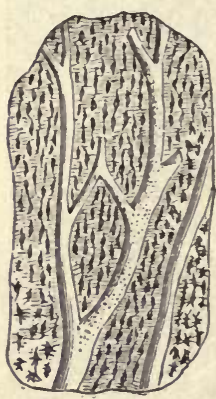

Fig. 15. Longitu- +36 . The Self-Formative Power of Bones. dinal Section of Thus bones are not dry, lifeless substances, Bone.

(The Haversian canals are seen branching and communicating with one another.) more of it if occasion should arise. Very fine branches from these bone cells pass into the canaliculi in growing bone. The canaliculi are far too small to allow the entrance of blood cells. They admit the passage of nothing but a thin liquid from the blood, the "plasma," which nourishes the bone and keeps it in a state fit for selfrepair when injured by disease or violence. but are the very type of activity and change. In life they are not only richly supplied with blood from the nutrient artery and from the periosteum covering the surfaces, but material of the bone and are ready to make they also contain countless little cells of living material which maintain an endless network throughout their whole structure.

Bones have, therefore, like all other living structures, a self-formative power, and draw from the blood the materials for their own nutrition.

In all respects bones are as much cared for as are the softer tissues of the body. 


\section{THE BONES OF THE HEAD}

$\times 37$. The Head, or Skull. The bones of the skeleton may be divided for convenience into those of the head, the trunk, and the limbs.

The bones of the head are described in two parts, - those of the cranium, or brain-case, and those of the face. Taken together, they form the skull.

38. The Cranium. The cranium is a dome-like structure, made up in the adult of eight distinct bones firmly locked together. These bones are :

\section{Frontal, \\ 2 Parietal, \\ -2 Temporal,}

I Occipital,

I Sphenoid,

I Ethmoid.

The frontal bone forms the forehead and front of the head.

The parietal bones form the sides and roof of the skull. The two bones make a beautiful arch to aid in the protection of the brain.

The temporal bones form the temples on either side. In each bone is the cavity containing three little bones which form a part of the organs of hearing.

The occipital bone forms the lower part, or base, of the skull, as well as the back of the head. Its lower part is pierced by a large oval opening called the foramen magnum, through which the spinal cord becomes continuous with the brain.

The sphenoid bone is so called because it is wedged in at the base of the skull between all the other bones of the cranium, and locks together fourteen different bones. It bears a fancied resemblance to a bat with extended wings and forms a series of girders to the arches of the cranium. 
The ethmoid bone is situated at the root of the nose and forms a part of the floor of the cranium. It is a remarkably light and spongy bone, and is so called because it is perforated with numerous holes like a sieve, through which the nerves of smell pass from the nose to the brain.

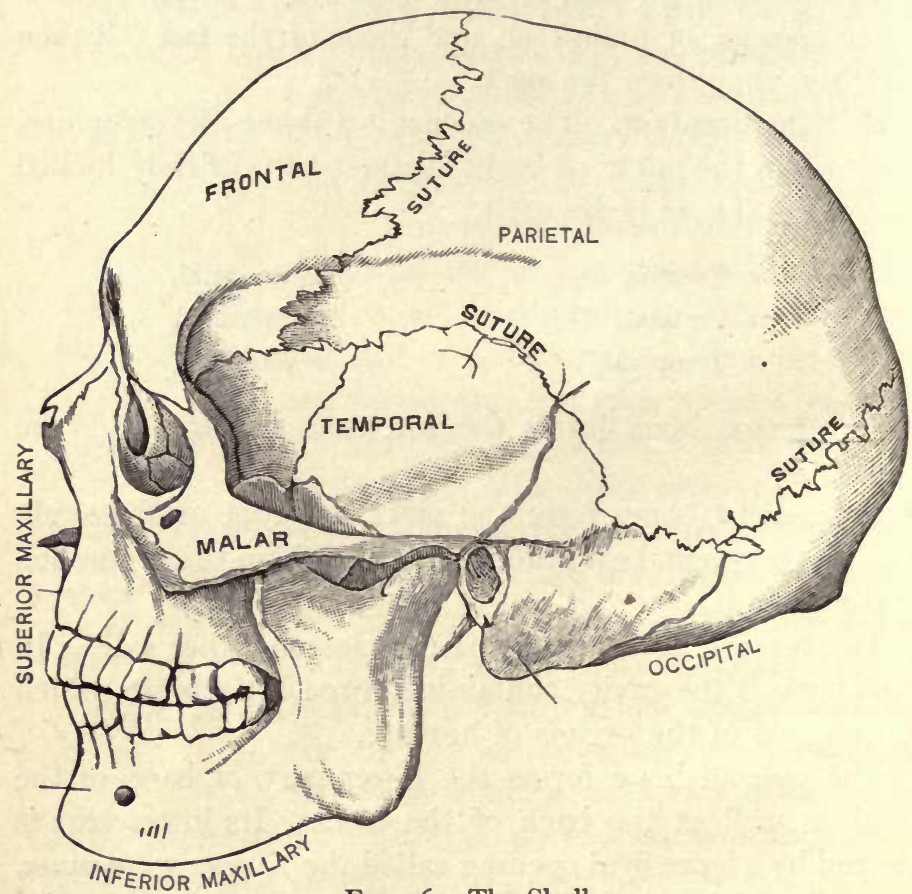

Fig. 16. The Skull.

39. The Face. The face is made up of fourteen bones, which, with the exception of the lower jaw, are, like those of the cranium, closely interlocked with one another. By this union these bones help form a number of cavities which contain most important organs. 
The bones of the face serve, to a marked extent, to give form to the human countenance. Upon these bones depend the build of the forehead, the shape of the chin, the size of the eyes, the prominence of the cheeks, the contour of the nose, and other peculiarities which are reflected in the beauty or ugliness of the face.

40. Bones of the Face. The bones of the face are :
2 Superior Maxillary,
2 Malar,
2 Nasal,
2 Lachrymal,

2 Palate,

2 Turbinated,

I Vomer,

I Lower Maxillary.

The superior maxillary or upper jawbones form a part of. the roof of the mouth and most of the floor of the orbits. In them is fixed the upper set of teeth.

The malar or cheek bones are joined to the upper jawbones, and help form the socketss of the eyes.

The nasal or nose bones are two very small bones between the eye sockets, which form the bridge of the nose.

In the inner angles of the orbit are the two small lachrymal bones.

The palate bones are behind those of the upper jaw and with them form the bony part of the roof of the mouth.

The inferior turbinated are spongy, scroll-like bones,

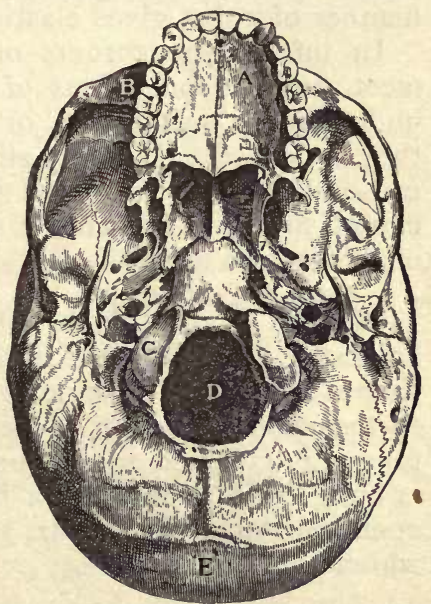

FIg. 17. The Base of the Skull.

$A$, palate process of upper jawbone; $B$, zygoma, forming zygomatic arch; $C$, condyle, for forming articulation with atlas; $D$, foramen magnum; $E$, occipital bone. 
which curve about within the nasal cavities so as to increase the surface of the air passages of the nose.

The vomer serves as a thin and delicate partition between the two cavities of the nose. It is so named from its resemblance to a ploughshare.

The largest bone in the face is the inferior maxillary, or lower jaw. It has a horseshoe shape and supports the lower set of teeth.

41. Sutures of the Skull. The edges of the bones of the outer shell of the skull are joined together in a peculiar and admirable manner. In adult life these edges, which are not unlike the teeth of a saw in appearance, fit into each other and grow together, suggesting the dovetailed joints used by the cabinet-maker. When united these serrated edges look almost as if sewed together; hence their name, sutures. This manner of union gives elasticity and strength to the skull.

In infants the corners of the parietal bones do not yet meet, and the pulsations of the brain may be seen and felt under these "soft spots," or fontanelles ("little fountains") as they are called. Hence a slight blow to an infant's head may cause serious injury to the brain. As old age creeps on, the cap of the skull becomes a solid dome of bone, with all trace of the sutures lost.

42. The Hyoid Bone. Under the lower jaw is a little horseshoe-shaped bone, called the hyoid bone, because it is shaped like the Greek letter upsilon $(Y)$. It really belongs to the skull, although it lies in the neck. The root of the tongue is fastened to the bend of the hyoid, and the larynx is hung from it as from a hook. This bone serves to keep open the top of the larynx, and to it are attached the muscles which move the tongue.

Experiment 12. To locate the hyoid bone. Allow the neck to rest in its natural position. Gently grasp with the thumb and forefinger the front of the throat, just above the "Adam's Apple." The hyoid bone can be plainly felt on a level with the lower jaw and about one inch and a half behind it. 


\section{THE BONES OF THE TRUNK}

${ }^{x}$ 43. The Bones of the Trunk. The bones of the trunk may be subdivided into those of the spinal column, the ribs, the sternum, and the hips.

The trunk includes fifty-three bones usually thus arranged :

I. Spinal Column, 26 bones : $\left\{\begin{aligned} 7 & \text { Cervical Vertebræ. } \\ \text { I2 } & \text { Dorsal Vertebræ. } \\ 5 & \text { Lumbar Vertebræ. } \\ \text { I } & \text { Sacrum. } \\ \text { I } & \text { Coccyx. }\end{aligned}\right.$

II. Ribs, 24 bones: $\begin{cases}\text { I } 4 & \text { True Ribs. } \\ \text { Io False Ribs. }\end{cases}$

III. Sternum. buasthone

IV. Two Hip Bones.

44. The Spinal Column. The spinal column, or backbone, is a most marvelous piece of mechanism. It is the central structure, to which all the other parts of the skeleton are adapted. It supports the head, encloses and protects the spinal cord, and forms the basis for the attachment of many important muscles, especially those which maintain the body in an erect position.

The spinal column consists of numerous separate bones, called vertebræ. The seven upper ones belong to the neck, and are called cervical vertebræ. The next twelve are the dorsal vertebræ; these belong to the back and support the ribs. The remaining five belong to the loins, and are called lumbar vertebræ.

Each vertebra has an opening through its center, and the separate bones so rest, one upon another, that these openings form a continuous canal from the head, to the 
lower part of the spine. The great nervous organ, known as the spinal cord, together with some of the nerves which are attached to it, extends from the cranium through the entire length of this canal.

Between the vertebræ are pads, or cushions of cartilage. These act as "buffers," and serve to give the spine strength and elasticity and to prevent friction of one bone on another. They also serve to break the effect of shock to the brain and the spinal cord from any sudden jar or injury of the limbs or the trunk.

* 45. The Sacrum and Coccyx. The spinal column rests on a strong mass of bone called the sacrum, or sacred-bone. It is composed of five vertebræ joined together, and is wedged in between the hip bones, forming the keystone of the pelvis. It is not easy to say why this bone was called "sacred." The reason generally assigned is that it was used in olden times in sacrifices.

Experiment 13. Run the tips of the fingers briskly down the backbone, and the spines of the vertebræ will be tipped with red so that they can be readily counted. Have the model lean forward with the arms folded across the chest; this will make the spines of the vertebræ more prominent.

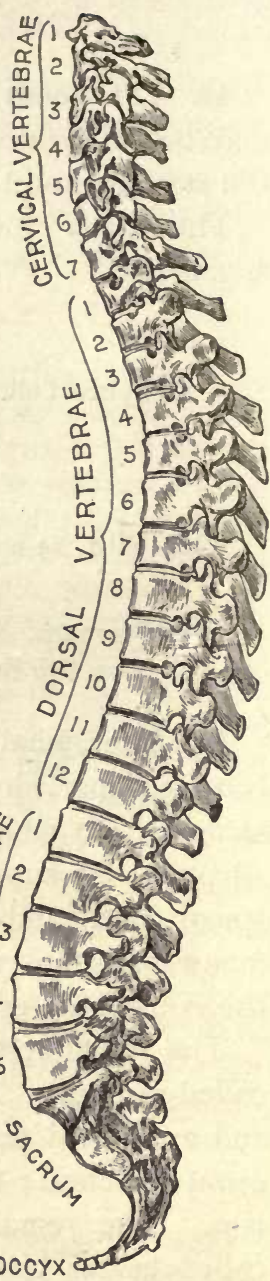

FIG. 18.

The Spinal Column. 
Joined to the lower end of the sacrum is the coccyx, a tapering series of little bones. It derives its name from a fancied resemblance to the beak of a cuckoo.

46. The Ribs. The barrel-shaped framework of the chest is in part composed of long, slender, curved bones, called ribs. There are twelve ribs on each side. Each pair is attached to a dorsal vertebra behind.

The first seven pairs, counting from the neck, are called the true ribs, and are joined by cartilages directly to the breastbone. The five lower pairs, called the false ribs, are not directly joined to the breastbone, but are connected, with the exception of the last two, with each other and with the last true ribs by cartilages. These elastic cartilages enable the chest to bear great blows

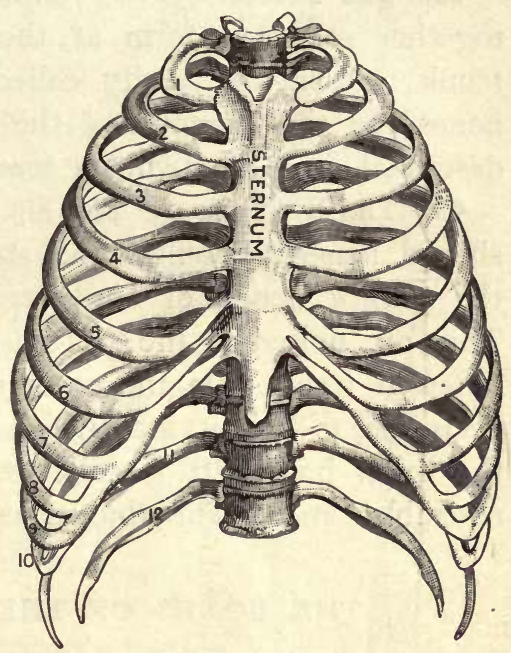

FIG. 19. Thorax.

(Anterior view.) with impunity. Thus a blow on the breastbone is distributed over fourteen elastic arches. The fowest two pairs of false ribs are quite free in front, and for this reason are often called "floating" ribs.

The ribs are not horizontal, but slope downwards from the backbone, so that when raised or depressed by the strong intercostal muscles, the size of the chest is alternately increased or diminished. This movement of the ribs, as we shall learn later, is of the utmost importance in breathing. 
47. The Sternum, or Breastbone. In shape the sternum, or breastbone, somewhat resembles an ancient dagger. It is a long, flat, narrow bone, forming the middle front wall of the chest. It is connected directly with all the true ribs, indirectly through cartilages with all the false ribs, except the "floating" ribs. It also gives attachment to the collar bones.

48. The Pelvis. Four immovable bones are joined together so as to form at the lower extremity of the trunk a basin-like cavity called the pelvis. These four bones are the sacrum and the coccyx, which have been described, and the two hip bones.

49. The Hip Bones. The hip bones are large, irregularly shaped bones, very firm and strong, and are often called the haunch bones, or nameless bones (ossa innominata). They are united to the sacrum behind and joined to each other in front. On the outer side of each hip bone is a deep cup, or socket, into which fits the rounded head of the thigh bone. It is called the acetabulum, because it resembles an ancient vinegar cup.

\section{THE BONES OF THE UPPER LIMBS}

50. The Bones of the Upper Limbs. Each of the upper limbs consists of the shoulder, arm, forearm, and hand.

The thirty-two bones of each upper limb are usually classified as follows :

$$
\begin{aligned}
& \text { Shoulder: }\left\{\begin{array}{l}
\text { Scapula, or shoulder-blade. } \\
\text { Clavicle, or collar bone. }
\end{array}\right. \\
& \text { Arm: . } \\
& \text { Forearm: } \begin{array}{l}
\text { Humerus, or arm bone. } \\
\text { Olna. } \\
\text { Radius. }
\end{array} \\
& \text { Hand:. }\left\{\begin{array}{l}
8 \text { Carpal, or wrist bones. } \\
5 \text { Metacarpal bones. } \\
14 \text { Phalanges, or finger bones. }
\end{array}\right.
\end{aligned}
$$


51. The Shoulder and Arm. The two bones of the shoulder, the scapula and the clavicle, serve to attach the arm to the trunk.

The scapula, or shoulder-blade, is a flat, triangular bone, lying on the upper

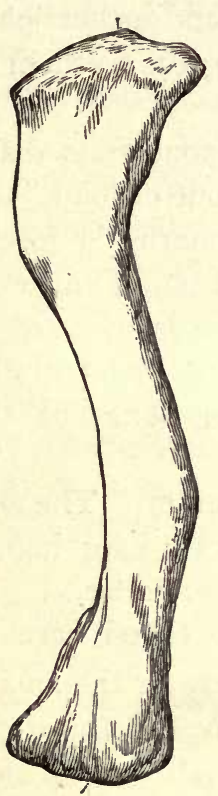

Fig. 20. Left Clavicle, or Collar Bone. (Anterior surface.) and back part of the chest, over the ribs. It consists of a broad, flat portion and a prominent ridge or spine. At its outer angle it has a shallow cup known as the glenoid cavity, in which plays the rounded head of the humerus.

The clavicle, or collar bone, so named from its resemblance to an ancient key, is a slender bone with a double curve like an italic $f$. It extends horizontally from the shoulderblade to the breastbone. It thus serves, like the keystone of an arch, to hold the shoulder-blade firmly in its place. Its chief use is to keep the shoulders wide apart, that the arm may enjoy a free range of motion. This bone

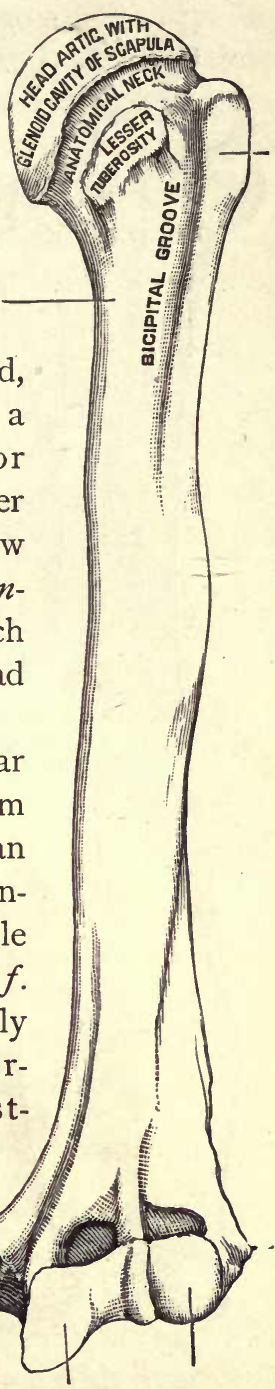

Fig. 21. Left Humerus. 


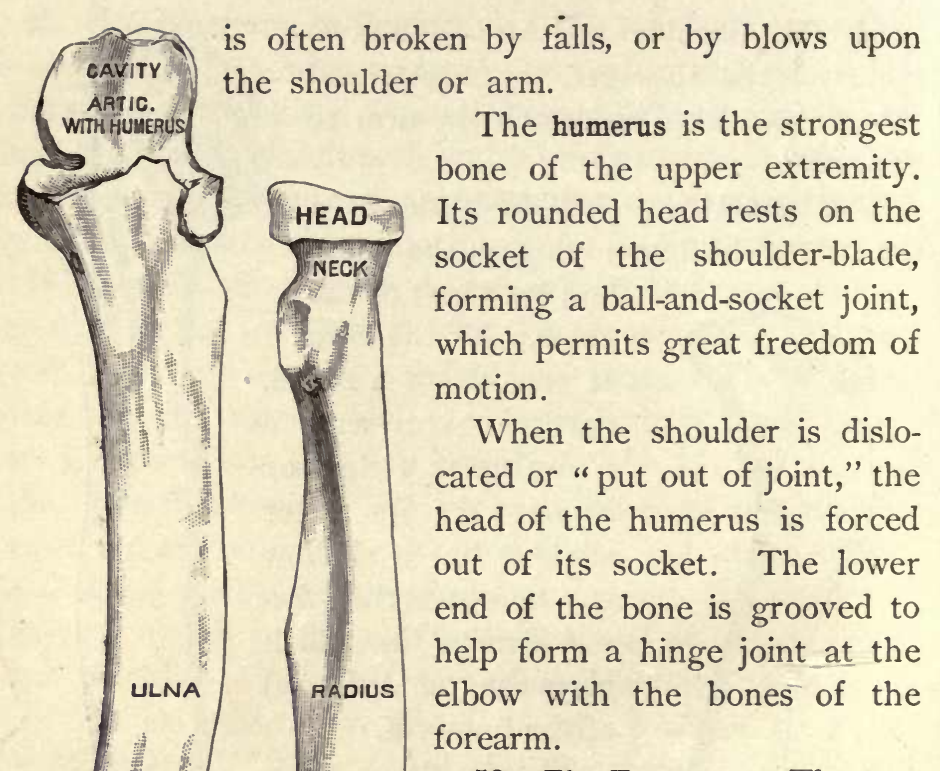

52. The Forearm. The forearm contains two long bones, the ulna and the radius.

The ulna, so called because it forms the elbow, is the longer and larger bone of the forearm, and is on the same side as the little finger. It is connected with the humerus by a hinge joint at the elbow. It is prevented from moving too far back by a hook-like projection called the olecranon process, which makes the sharp point of the elbow.

FIG. 22.

The radius is the shorter of 
the two bones of the forearm, and is so called from its resemblance to the spoke of a wheel. It is on the same side as the thumb. Its slender upper end articulates with the ulna and humerus; its lower end is wider and gives attachment in part to the bones of the wrist. This bone radiates or turns on the ulna, carrying the hand with it.

Experiment I4. Rest the forearm on a table, with the palm up (an attitude called supination). The radius is on the outer side and parallel with the ulna. If now, without moving the elbow, we turn the hand (pronation) as if to pick up something from the table, the radius may be seen and felt crossing over the ulna, while the latter bone has not moved.

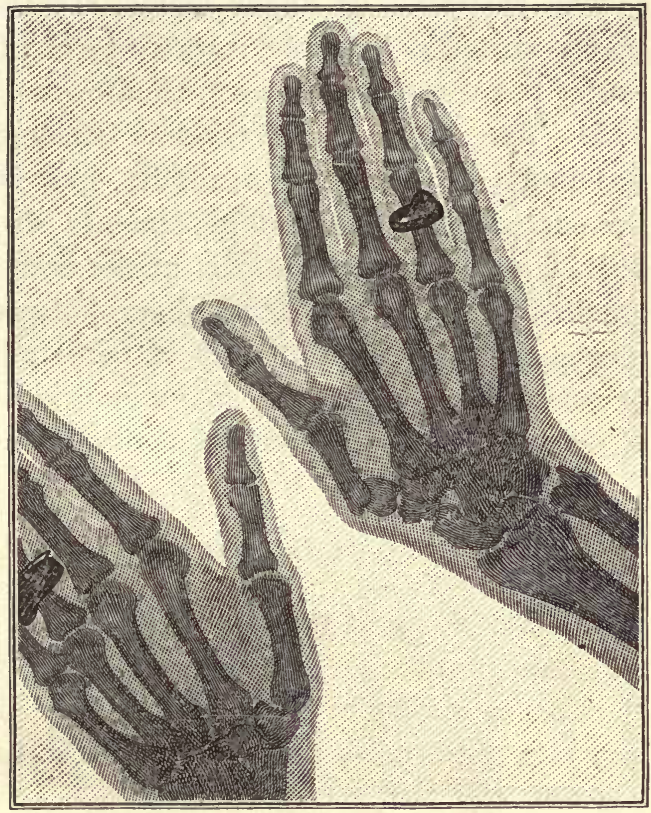

Fig. 23. Bones of the Hand and Wrist, as shown by an X-Ray Photograph. (Two rings are plainly shown.)

53. The Hand. The hand consists of twenty-seven separate bones, and is divided into three parts, the wrist, the palm, and the fingers.

The carpus, or wrist, consists of eight bones, arranged in two rows of four each, and bound together with ligaments which admit of ample flexibility. Thus the wrist is much 
less liable to be broken than if it were to consist of a single bone. The combined action of the carpal bones helps to give the hand much freedom of action.

The metacarpal or palm bones are the five long bones of the back of the hand.

The phalanges, or finger bones, are the fourteen small bones arranged in three rows to form the fingers. Each finger has three bones; each thumb, two.

× 54. The Hand as a Marvel of Mechanism. The hand has much strength and flexibility, and is thus enabled to accomplish the countless movements so necessary to our well-being. There, is no part of the body which cannot be reached by the hand. It is a marvel of precise and adapted mechanism, capable not only of performing every variety of work and of expressing many emotions of the mind, but of executing its orders with inconceivable rapidity.

\section{THE BONES OF THE LOWER LIMBS}

$X$ 55. The Bones of the Lower Limbs. The general structure and number of the bones of the lower limbs bear a striking similarity to those of the upper limbs. Thus, the leg, like the arm, is arranged in three parts, the thigh, the leg, and the foot.

The thirty bones of each lower limb are usually classified as follows :

Thigh: Femur, or thigh bone.

Leg: $\left\{\begin{array}{l}\text { Tibia, or shin bone. } \\ \text { Fibula, or splint bone. } \\ \text { Patella, or knee-cap. }\end{array}\right.$

Foot: $\left\{\begin{aligned} 7 & \text { Tarsal or ankle bones. } \\ 5 & \text { Metatarsal or instep bones. } \\ 14 & \text { Phalanges, or toe bones. }\end{aligned}\right.$ 
56. The Femur, or Thigh Bone. The longest and strongest of all the bones is the femur, or thigh bone. Its upper end has a rounded head which fits into the acetabulum, or the deep cup-like cavity of the hip bone, forming a perfect ball-and-socket joint. The rounded head fits so accurately into its socket that it may be retained by atmospheric pressure alone.

The shaft of the femur is strong, and is ridged and roughened in places for the attachment of the muscles. Its lower end is broad and irregularly shaped, having two prominences called condyles, the whole fitted for forming a hinge joint with the upper end of the shin bone.

$\times 57$. The Bones of the Leg. The leg, like the forearm, consists of two . bones. The tibia, or shin bone, is the long, three-sided bone forming the front of the leg. The sharp edge of the bone is easily felt just under the skin. It articulates with the lower end of the femur.

The fibula is a long, slender bone on the outer side of the leg, and is firmly fixed to the tibia at each end. Its lower end forms the outer projection of the ankle.

In front of the knee joint, imbedded in a thick, strong tendon,

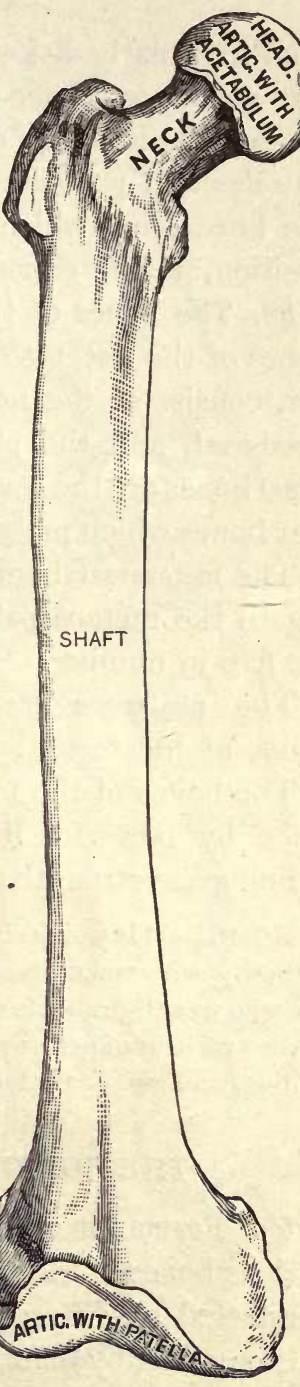

FIG. 24. Right Femur, or Thigh Bone. 
is an irregularly disk-shaped bone, the patella, or knee-cap. It increases the leverage of important muscles and protects the front of the knee joint, which is, from its position, much exposed to injury.

58. The Bones of the Foot. The bones of the foot, twenty-six in number, consist of the tarsal bones, the metatarsal, and the phalanges. The tarsal bones are the seven small, irregular bones which make up the ankle.

The metatarsal bones, corresponding to the metacarpals of the hand, are five in number.

The phalanges are the fourteen bones of the toes.

The bones of the foot are kept in place by powerful ligaments, combining great strength with elasticity.

NotE. - It is wonderful what habit and necessity will make the foot accomplish. We who wear tight boots can hardly believe it when we hear of persons carving, knitting, writing, and even painting with the toes.

\section{THE JOINTS}

59. Formation of Joints. The various bones of the skeleton are connected at different parts of their surfaces by joints, or articulations, which vary according to the FIG. 25. Right Tibia and Fibula. kind and the amount of motion.

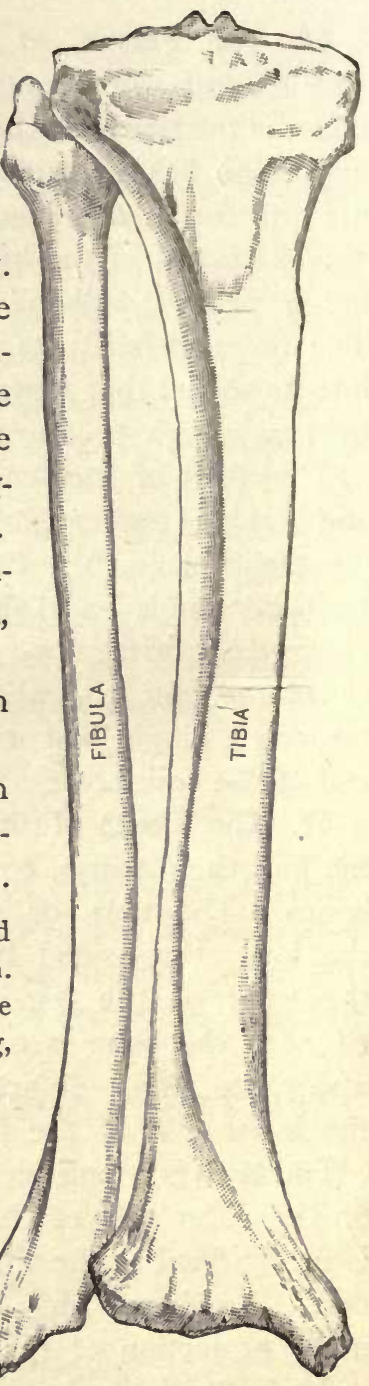


The principal structures which enter into the formation of a joint are: bone, cartilage, synovial membrane, and ligaments.

Bones make the chief element of all the joints, and their adjoining surfaces are shaped to meet the special demands of each joint. The joint-end of bones is coated with a thin layer of tough, elastic cartilage. This is also used at the edge of joint-cavities, forming a ring to deepen them. The rounded heads of bones which move in them are thus more securely held in their sockets.

Besides these structures, the muscles also help to maintain the joint-surfaces in their proper relation. Another essential to the action of the joints is the pressure of the outside air. This may be sufficient to keep the articular surfaces in contact even after all the muscles are removed. Thus the hip joint is so completely surrounded by ligaments as to be air-tight.

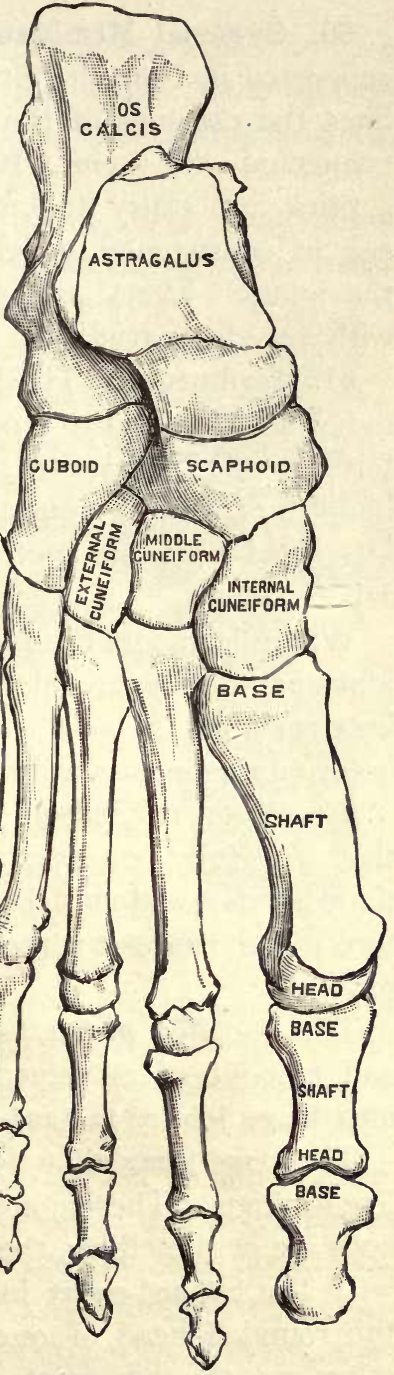

FIG. 26. Bones of Right Fooc. (Dorsal surface.) 
60. Synovial Membrane. A very delicate layer of cells supported by connective tissue, called the synovial membrane, lines the capsules of the joints and covers the ligaments connected with them. It secretes the synovia, or joint oil, a thick and glairy fluid, something like the white of a raw egg in consistency, which moistens the inner surfaces of the joints. Every part of a joint is thus enabled to run with very little friction.

61. Ligaments. The bones are held in place, and their movements limited to a certain extent, by bands of various forms, called ligaments. These are composed mainly of bundles of white fibrous tissue placed parallel to, or closely interlaced with, one another, and present a shining, silvery aspect.

While ligaments are pliable and flexible, permitting free movement, they are also wonderfully strong, tough, and inextensible. A bone may be broken, or its end torn off, before its ligaments are ruptured.

62. Different Kinds of Joints. It is only perfect joints that are fully equipped with the structures just mentioned. Some joints lack one or more, and are therefore called imperfect joints. Such joints allow little or no motion.

The so-called perfect joints vary according to the nature and amount of movement permitted. They are divided into hinge joints, ball-and-socket joints, and pivot joints.

The hinge joints allow forward and backward movements like a hinge. These joints are the most numerous in the body, as at the elbow, the ankle, and the knee.

In the ball-and-socket joints - a beautiful contrivancethe rounded head of one bone fits into a socket in the other, as the hip joint and the shoulder joint. These joints permit free motion in almost every direction. 
In the pivot joint a part of one bone fits into a notch in another. The best example of this is the joint between the first and second vertebræ. The radius moves around on the ulna by means of a pivot joint.

63. Uses of the Bones. The bones serve many important and useful purposes. The skeleton, a general framework, affords protection, support, and leverage to the other bodily tissues. Thus, the bones of the skull and of the chest protect the brain, the lungs, and the heart. The long bones of the limbs are levers to which muscles are attached.

Bones have many different shapes. Each bone is not only different from all the others, but is also curiously adapted to its particular place and use.

We have seen how the bones of the cranium are united by sutures, the better ta allow the delicate brain to grow, and to afford it protection from violence.

The complicated organ of hearing is protected by a winding series of minute apartments in the rock-like

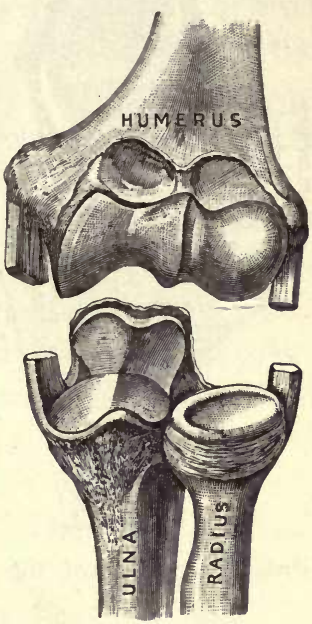

FIG. 27. Showing how the Ends of the Bones are shaped to form the Elbow Joint.

(The cut ends of a few ligaments are seen.) portion of the temporal bone. The socket for the eye has a jutting ridge of bone around it to guard this organ against injury. Grooves and canals, formed in hard bone, lodge and protect minute nerves and tiny blood vessels. The surfaces of bones are often provided with grooves, sharp edges, and rough projections, for the origin and insertion of muscles. 
64. How the Growth of Bones may be modified. Bones, as we have seen, are the seat of active vital processes throughout life, except perhaps in extreme old age. The final

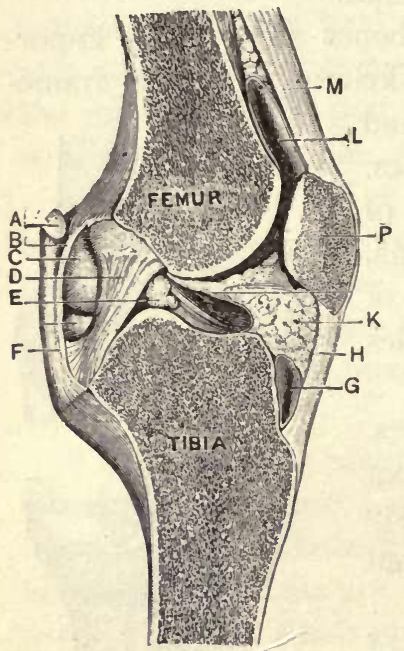

FIG. 28. Section of the Knee Joint.

(Showing its internal structure.)

$A$, tendon of the semi-membranotis muscle cut across; $B, F$, tendon of same muscle; $C$, internal condyle of femur; $D$, posterior crucial ligament; $E$, internal interarticular fibro-cartilage; $G$, bursa under knee-cap; $H$, ligament of kneecap; $K$, fatty mass; $L$, anterior crucial ligament; $M$, tendon of thigh muscles; $P$, patella.

knitting together of the ends of some of the bones with their shafts does not occur until somewhat late in life. For example, the separate bones of the sacrum do not fully knit into one solid bone until the twenty-fifth year. Hence the bones of young persons should not be subjected to the risk of undue violence from injudicious physical exercise, as in rowing, baseball, football, and bicycle riding. Moderate exercise, however, even in infancy, promotes the health of the bones as well as of the other tissues.

The bones are easily modified in their growth. Thus the continued pressure of some morbid deposit, as a tumor or an enlargement of an artery, may cause the absorption or distortion of bones as readily as of one of the softer tissues.

65. Sprains. A twist or strain of the ligaments and soft parts about a joint is known as a sprain, and may result from a great variety of accidents. When a person falls, the foot is frequently caught under him, and the twist comes upon the ligaments and other structures of the ankle. 
The ligaments cannot stretch, and so have to endure the wrench upon the joint. The result is a sprained ankle.

Next to the ankle, a sprain of the wrist is most common. A person tries, by throwing out his hand, to save himself from a fall, and the weight of the body brings the strain upon the firmly fixed wrist.

A sprain may be a slight affair, needing only a brief rest, or it may be severe and painful enough to call for the most skillful treatment by a surgeon. Lack of prompt and proper care in treating sprains is often the cause of a crippled ankle or knee.

66. Dislocations. A fall or a blow may bring such a sudden wrench or twist upon the ligaments as to force a bone out of place. This displacement is known as a dislocation. It should be treated by a surgeon at once. Any delay or carelessness may make a serious and painful affair of it, as the torn and bruised parts rapidly swell and become extremely sensitive.

67. Different Kinds of Fractures. The bones of the body are often fractured or broken. The simple fracture is the most common form, the bone being broken in a single place with no opening through the skin. When properly adjusted, the bone heals rapidly. When, besides the broken bone, there is an opening through the soft parts to the surface of the body, we have a compound fracture. This is a serious injury and calls for prompt surgical treatment.

68. How Bones are broken. Bones may be broken by direct violence, as when they are fractured at a certain point by some powerful force, as a blow from a baseball bat or a fall from a horse. Again, bones may be broken by indirect violence, as when a person, being about to fall, throws out his hand to save himself. The force of the 
fall on the hand often breaks the wrist, by which is meant usually the fracture of the lower end of the radius. This accident is common in winter from a fall or slip on the ice.

69. Treatment for Broken Bones. When a bone is broken a surgeon is needed to set it ; that is, to bring the broken parts into their natural position, and retain them by proper appliances.

With old people a broken bone is often a serious matter, and may cripple them for life, or prove fatal. A trifling fall, for instance, may cause a "broken hip." From the shock of such an injury, and the subsequent pain and exhaustion, an aged person may die in a few weeks.

In young people, however, the parts of a broken bone will knit together usually in three or four weeks after the fracture is reduced; while in adults six or even more may be required for firm union.

After a broken bone is strong enough to be used, it is fragile for some time, and great care must be taken, especially with children, that the injured parts may not be broken again before perfect union takes place.

70. The Effect of Alcohol upon the Bony Framework. During the entire period of bone growth the nutrition of the body should not be impaired. ${ }^{1}$ The bones should be furnished with all the materials necessary for a large and durable framework. Otherwise the body will be feeble and stunted in growth. This condition is seen in the stunted stature of young persons who have been underfed and overworked. It is believed that alcoholic liquors

1 Alcohol retards the growth of young cells and prevents their proper development. Alcohol in all its forms is particularly injurious to young persons, as it retards their growth and stunts both body and mind. This is the theory of Dr. Lionel S. Beale, a celebrated microscopist and thinker, and is quite generally accepted. - DR. ROGER S. TRACY of the New York Board of Health. 


\section{The Framework of the Body}

before maturity may produce a similar effect, hindering the full activity of bone cell-growth and thus preventing full development of the bones.

Surgeons recognize the fact that the broken bones of drunkards usually unite with greater difficulty than do those of the average patient. The use of alcoholic liquors is also one of the most frequent predisposing causes of the serious and painful disease known as gout, which often attacks the joints.

71. Effect of Tobacco upon the Bony Tissues. Powerful narcotics, like tobacco and opium, by retarding the activity of bone cell-growth, hinder the building up of the bodily frame. The formation of healthy bone tissue demands good, nutritious blood; but if this vital tissue is loaded with poisonous narcotics, the bones are defrauded of their proper building material.

\section{ADDITIONAL EXPERIMENTS}

Experiment 15. To illustrate the movement of torsion in the spine, or its rotation round its own axis. Sit upright, with the back and shoulders well applied against the back of a chair. Note that the head and neck can be turned as far as $60^{\circ}$ or $70^{\circ}$. Now bend forward, so as to let the dorsal and lumbar vertebræ come into play, and the head can be turned $30^{\circ}$ more.

Experiment 16. To show how the spinal vertebra make a firm but flexible column. Take twenty-four hard-rubber overcoat buttons, or the same number of coins, and pile them on top of one another. A thin layer of soft putty may be put between the coins to represent the pads of cartilage between the vertebræ. The most striking features of the spinal column may be illustrated by this simple apparatus.

Note. - As the succeeding chapters are studied, additional experiments on bones and their relation to other parts of the body will readily suggest themselves to the ingenious instructor or the thoughtful student. Such experiments may be utilized for review or other exercises. 
THE BONES OF THE BODY

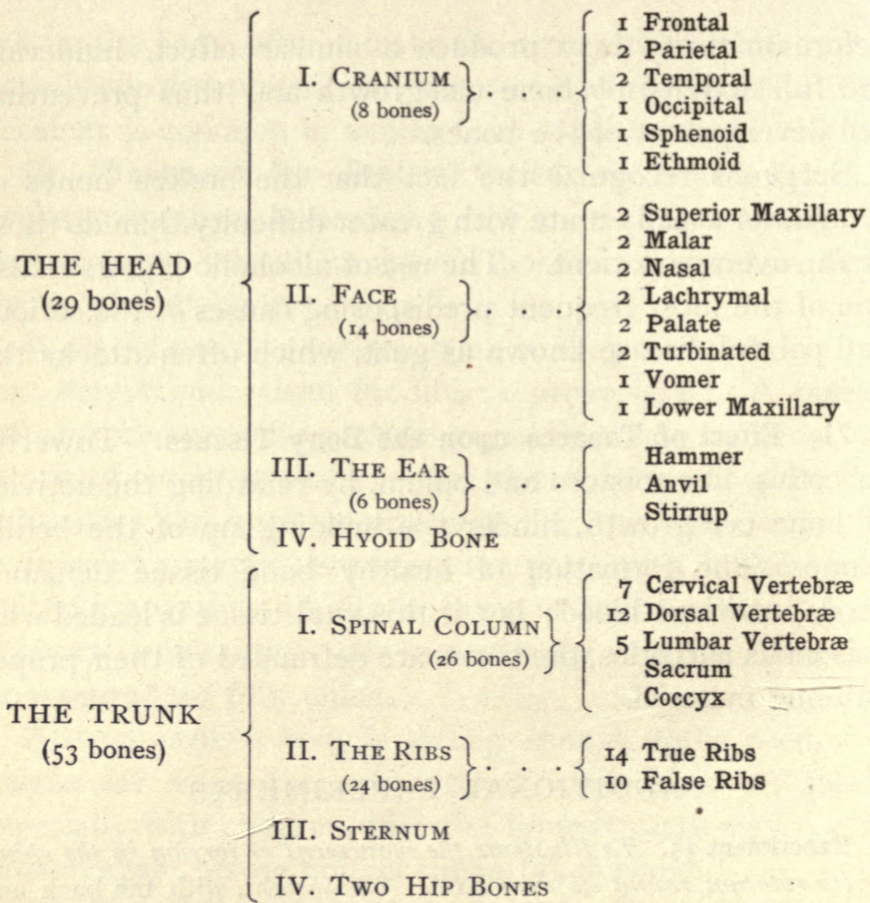
UPPER LIMBS (64 bones)
LOWER LIMBS (6o bones)
I. Shoulder . . . $\left\{\begin{array}{l}\text { Scapula } \\ \text { Clavicle }\end{array}\right.$
II. ARM . . . . Humerus III. FOREARM $\cdot\left\{\begin{array}{l}\text { Ulna } \\ \text { Radius }\end{array}\right.$ IV. HAND . . . $\left\{\begin{aligned} 8 & \text { Carpal } \\ 5 & \text { Metacarpal } \\ \text { I4 } & \text { Phalanges }\end{aligned}\right.$
I. Thigh . . . . Femur
II. LEG . . . . $\left\{\begin{array}{l}\text { Tibia } \\ \text { Fibula } \\ \text { Patella }\end{array}\right.$
III. FooT . . . $\left\{\begin{aligned} 7 & \text { Tarsal } \\ 5 & \text { Metatarsal } \\ \text { I } & \text { Phalanges }\end{aligned}\right.$ 


\section{CHAPTER III}

\section{THE MUSCLES}

72. Spontaneous Movements in Animals. Trees and stones never move unless acted upon by external force, while the infant and the tiniest insect can execute a great variety of movements. When the higher animals are at rest it is possible to observe some kind of motion in them. Even in the deepest sleep the beating of the heart and the motion of the chest never cease. In fact, the power to execute spontaneous movements is the most distinctive property of living animals.

All motion of our bodies is produced by means of muscles. Not only the limbs are moved by them, but even the movements of the stomach and of the heart are caused by muscles. Every part of the body which is capable of motion has its own special set of muscles.

173. The Two Great Kinds of Muscles. All the movements of the body as a whole are performed by muscles. These muscles make up the red flesh, well known to every one as the lean of butcher's meat, which, together with the fat, clothes the bony framework. We often call these voluntary muscles, because they are more or less subject to the control of the will.

The motion of the internal organs, as those of digestion, secretion, excretion, circulation, and respiration, are produced by muscles of another kind, that is, by muscles not usually under the control of the will. This work goes on 
quite independently of the will, and even during sleep. We frequently call the instruments of this activity involuntary muscles.

The former group, or skeletal muscles, from peculiarities revealed by the microscope, are more accurately known as striped or striated muscles. The latter group, or visceral

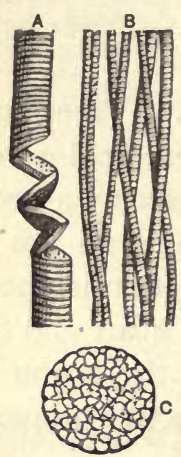

FIG. 29. Striated Muscular Fibers.

$A$, fiber separating into disks; $B$, fibrillæ (highly magnified); $C$, crosssection of a disk. muscles, from the smooth appearance which their cells present under the microscope, are called unstriated muscles.

Let us then remember the two kinds of muscles as the striated (often called voluntary) muscles, and the smooth, unstriated (often called involuntary) muscles.

74. Structure of the Striated Muscle. The main substance which clothes the bony framework of the body, and which forms about two-fifths of its weight, is the striated muscular tissue. These skeletal muscles do not cover and surround the bones in continuous sheets, but consist of separate bundles of flesh, varying in size and length.

Each muscle has its own set of blood vessels and nerves, and is enveloped in its own sheath of connective tissue, known as the perimysium. When this external wrapping is strong enough to be dissected off, it is known as fascia.

Muscles are not usually connected directly with bones, but by means of white, glistening cords or bands, called tendons.

75. Microscopic Structure of Striated Muscle. If a small piece of striated muscle be examined under a microscope it is found to be made up of bundles of fibers. Each fiber is enclosed within a delicate, transparent sheath, known as the sarcolemma. If one of these fibers be further examined 
under a very powerful microscope, it will sometimes be seen to consist of a great number of still more minute fibers, called fibrillæ. These fibers are also seen marked crosswise with dark stripes and can be separated at each stripe into disks. These cross-markings account for the name striped, or striated, muscle.

The fibrillæ, then, are bound together in a bundle to form a fiber, which is enveloped in its own sheath, the sarcolemma. These fibers, in turn, are further bound together to form larger bundles, called fasciculi, and these, too, are enclosed in a sheath of connective tissue. The muscle itself is made up of a number of these fasciculi bound together by an external wrapping (perimysium) of connective tissue.

76. Structure of the Unstriated Muscle. These muscles consist of ribbon-shaped bands which surround hollow, fleshy tubes or cavities. As they are never

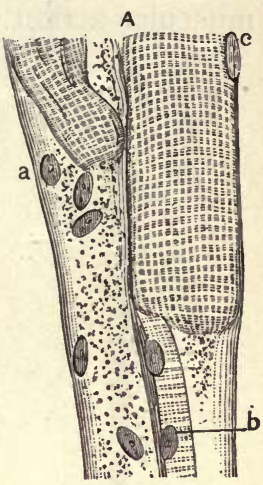

FIG. 30.

$A$, muscular fiber, showing stripes; $a, b$, and $c$, nuclei. (Highly magnified.) attached to bony levers, they have no need of tendons.

The microscope shows that these muscles consist not of fibers, but of long, spindle-shaped cells, united to form sheets or bands. They have no sarcolemma, stripes, or cross-markings like those of the striped muscles. Hence their name of unstriated, or unstriped, and smooth muscles.

Experiment 17. To show the gross structure of muscle. Take a small portion of a large muscle, as a strip of lean corned beef. Have it boiled until its fibers can be easily separated. Pick the bundles and fibers apart until they are so fine as to be almost invisible to the naked eye. Continue the experiment with the help of a hand magnifying glass or a microscope. 
77. Action of the Unstriated Muscles. The unstriated muscles respond to irritation much less rapidly than do the striated. The wave of contraction passes over them more slowly and more irregularly, one part contracting while another is relaxing. This may readily be seen in the muscular action of the intestines, called vermicular motion, or peristalsis. Irregular and excessive

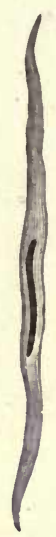

Fig. 31. A Spindle

Cell of Involuntary Muscle.

(Highly magnified.) contraction of the muscular walls of the bowels produces the cramp-like pains of colic.

Experiment 18. To show the general appearance of the muscles. Obtain the lower part of a sheep's or calf's leg, with most of the lean meat and the hoof left on. One or more of the muscles, with their bundles of fibers, fascia, and tendons, are readily made out with a little careful dissection.

The dissection should be made a few days before it is wanted and the parts allowed to harden somewhat in dilute alcohol.

In the stomach the contraction of these muscles produces the motion by which the food is churned about; in the arteries and veins they regulate the size of the channels through which the blood is driven along, and in the intestines they supply the force by which the partly digested food is mainly kept in motion.

$\sqrt{78}$. Muscular Contractility. The most characteristic property of muscle in the living state is its contractility, or the power of shortening when irritated by a stimulus, its volume or bulk remaining the same. In brief, when a muscular fiber contracts, it tends to bring its two ends closer together. 


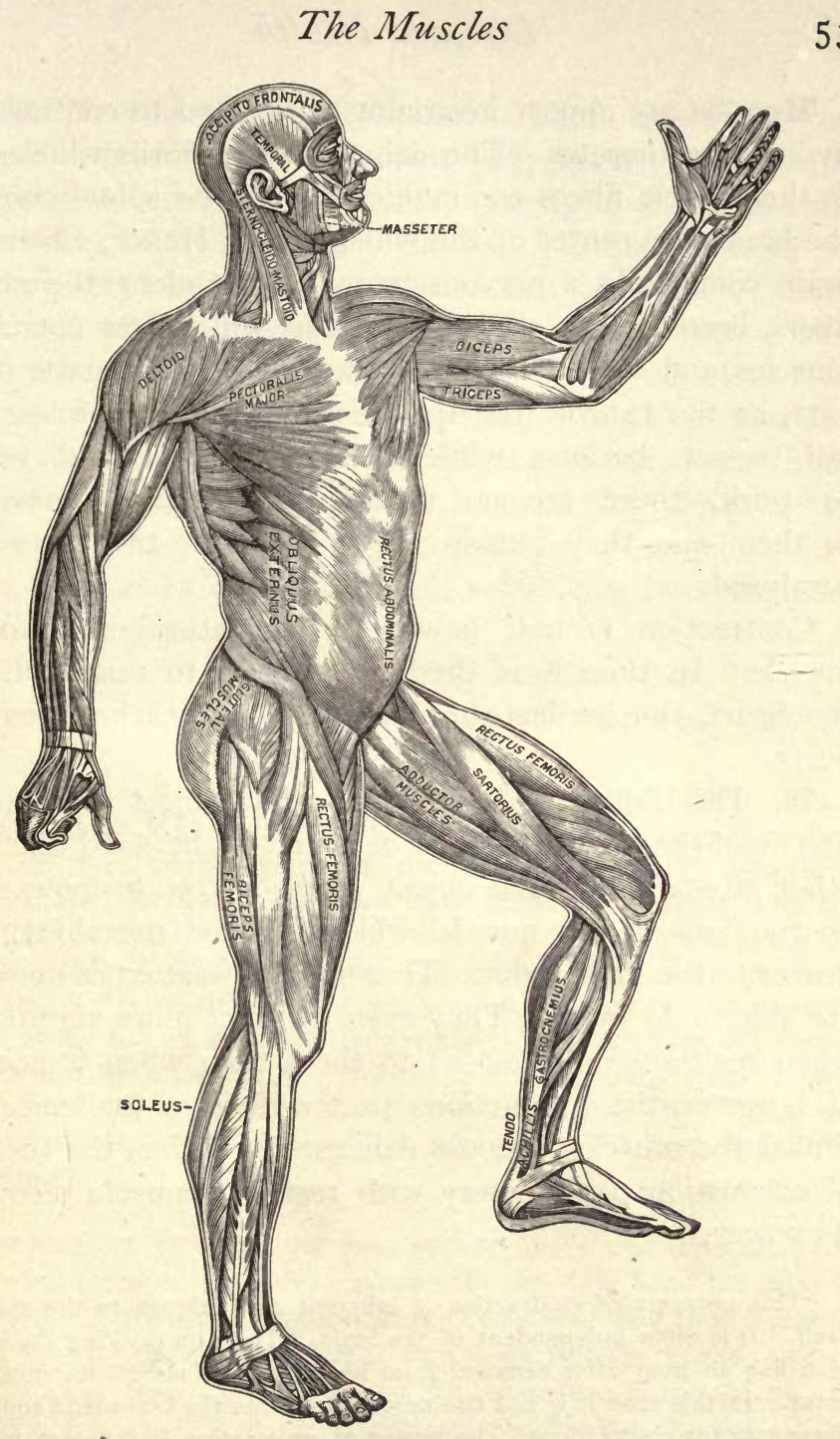

FIG. 32. Superficial Muscles of the Body. (Front view.) 
Muscles are almost invariably stimulated to contraction by a nervous impulse. The delicate nerve fibrils which end in the muscle fibers communicate with the spinal cord or the brain, the center of the will power. Hence, when the brain commands, a nervous impulse, sent along the nerve fibers, becomes the exciting stimulus which acts upon the muscles and makes them contract. ${ }^{1}$ If the nerves of a part, as the face or the leg, be severed the muscles will fail to act, because while they are intact and ready to work, there are no means of sending commands to them and they remain idle. In short, the parts are paralyzed.

Contraction is not, however, the natural state of a muscle. In time it is tired and begins to relax. Even the heart, the hardest-working muscle, rests between its beats.

N79. The Object of Contraction. The object of contraction is obvious. If one end of a muscle be fixed and the other attached to some object which is free to move, the contraction of the muscle will bring the movable body nearer to the fixed point. Thus by their contraction muscles are able to do work. They even contract more vigorously when resistance is opposed to them than when it is not. If, however, the contractions are too rapid or too long continued the muscles become exhausted. When the feeling of exhaustion passes away with rest, the muscle recovers its power.

1 This property of contraction is inherent and belongs to the muscle itself. It is often independent of the brain. Thus, on pricking the heart of a fish an hour after removal from its body, obvious contraction will occur. In this case it is not the nerve force from the brain that supplies the energy for contraction. The power of contraction is inherent in the muscle substance, and the stimulus by irritating the nerve ganglia of the heart simply affords the opportunity for its exercise. 
$\triangle$ 80. Various Kinds of Muscles. There are about four hundred muscles in the human body, all necessary for its various movements. They vary greatly in shape and size, according to their position and use. Some are from one to two feet long, others only a fraction of an inch. Some are long and spindle-shaped, others thin and broad, while still others form rings. Thus, some of the muscles of the arm and thigh are long and tapering, while the abdominal muscles are thin and broad. Again, the muscular fibers which surround and by their contraction close certain orifices, as those of the eyelids and lips, sometimes radiate like the spokes of a wheel, and sometimes form complete circles or ellipses.

The part of a muscle which remains fixed when it contracts is called its origin; the end connected with the movable part is its insertion.

81. How Muscles are named. Muscles are named according to their shape, position, division of origin or insertion, and their function. Thus we have the recti (straight) and the deltoid ( $\Delta$, delta), the brachial (arm), pectoral (breast), and the intercostals (between the ribs), so named from their position. Again, we have the biceps (two-headed), triceps (three-headed), and many others with similar names, so called from the points of origin and insertion. We find other groups named after their special use. The muscles which bend the limbs are called flexors, while those which straighten them are known as extensors.

Experiment 19. To show how muscles relax and contract. Lay your left forearm on a table; grasp with the right hand the mass of flesh on the front of the upper arm. Now gradually raise the forearm, keeping the elbow on the table. Note that the muscle thickens as the hand rises. This illustrates the contraction of the biceps, and is popularly called "trying your muscle." Reverse the act. Keep the elbow in position, bring the forearm slowly to the table, and the biceps appears to become softer and smaller, - it relaxes. 
82. Tendons and their Work. The fleshy parts of muscles are not usually connected directly with bones. The mass of flesh tapers off towards the ends, where the fibers pass into white, glistening cords, known as tendons.

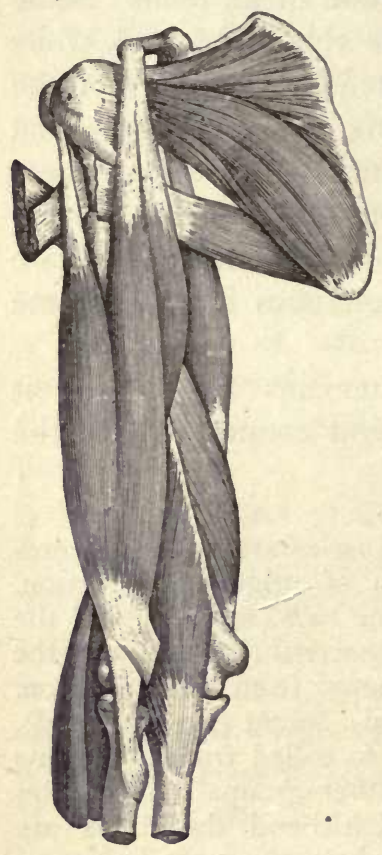

FIG. 33.

The Biceps Muscle dissected to show its Tendons.

These are commonly very strong, made up of white, fibrous tissue, and may be compared to ropes or cords which, when pulled, are made to act upon distant objects to which one end is fastened.

Tendons are most numerous about the larger joints, where they permit free action and yet occupy but little space. If we bend the arm or leg forcibly and grasp the inside of the elbow or knee joint, we can feel the tendons beneath the skin. The numerous tendons in the palm or on the back of the hand contribute to its marvelous dexterity.

The thickest and strongest tendon in the body is the tendon of Achilles, which connects the great muscles in the calf of the leg with the heel bone.

Experiment 20. Repeat Experiment 19 with other muscles. With the right hand grasp firmly the extended left forearm. Extend and flex the fingers vigorously. Note the effect on the muscles and tendons of the forearm. Grasp with the right hand the calf of the extended right leg, and vigorously flex the leg, bringing it near to the body. Note the contractions and relaxations of the muscles. 
83. Synovial Sheaths and Sacs. The rapid movement of the tendons over bony surfaces would soon produce an undue amount of heat and friction unless some means were provided to make the parts run smoothly. This is supplied by sheaths which form a double lining around the tendons. The opposed surfaces are lined with synovial membrane, the secretion from which moistens the sheaths in which the tendons move.

Little closed sacs, called synovial sacs, or bursæ, similarly lined and containing fluid, are also found in special places between two surfaces where much motion is required. Thus, there are two of these bursæ near the patella. Without these, the constant motion of the knee-pan in walking would produce undue friction and heat.

Experiment 21. Examine carefully the tendons in the parts dissected in Experiment 18. Pull on the muscles and the tendons, and note how they act to move the parts. This may be also admirably shown on the leg of a fowl or turkey obtained from a kitchen or from the market.

Obtain the hoof of a calf or sheep with one end of the tendon of Achilles still attached. Dissect it and test its strength.

Experiment 22. The tendons which bound the space behind the knee can be distinctly felt when the muscles which bend the knee are in action. On the outer side note the tendons of the biceps of the leg, running down to the head of the fibula. On the inside we feel three tendons of important muscles on the back of the thigh which flex the leg upon the thigh.

$\checkmark$ 84. The Mechanics of Motion. Levers. The active agents of bodily movements, as we have seen, are the muscles. All these movements, both of motion and of locomotion, are regulated according to certain fixed laws of mechanics. The bones, to which a great proportion of the muscles in the body are attached, act as distinct levers. The muscles supply the power for moving the bones, and the joints act as fulcrums or points of support. The weight of the limb, the weight to be lifted, or the force to be overcome, is the resistance. 
85. Examples of Levers in the Body. In mechanics three classes of levers are described, according to the relative position of the power, the fulcrum, and the weight, or the resistance. The movements of the bones can be referred to one or another of these three classes.

The head is supported on the atlas by a lever of the first class. The joint between the atlas and the skull is the fulcrum, the weight of the front of the head is the resistance. The power is behind, where the muscles from the neck are attached to the back of the skull. The object of this arrangement is to keep the head steady and balanced on the spinal column,
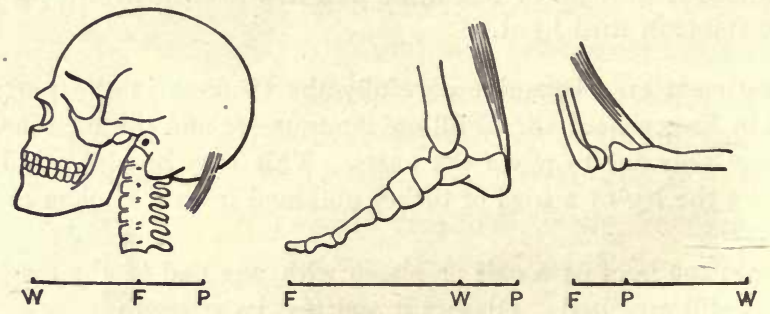

FIG. 34. Diagram illustrating Three Kinds of Lever Action.

$P$, fulcrum; $P$, power; $W$, weight. In the left-hand diagram the head is tilted back by the muscles of the neck. In the middle figure the toes rest on the ground, and the body is raised by the leg muscles. In the right-hand diagram the forearm is bent up by the biceps muscle.

and to move it backward and forward. Range and rapidity are here gained at the expense of power.

Standing on tiptoe is done by means of a lever of the second class. The toes in contact with the ground are the fulcrum, the power is the action of the muscles of the calf, and between these is the weight of the body transmitted down the bones of the leg to the ankle. Power is here gained at the expense of range of movement.

Levers of the third class are common in the body. In bending the forearm on the arm, familiarly known as "trying your muscle," the power is supplied by the biceps muscle attached to the radius, the fulcrum is the elbow joint at one end of the lever, and the resistance is the weight of the forearm and hand at the other end. 
86. Muscles of the Head and Neck. There are scores of tiny muscles about the head, face, and eyes, which by their alternate contractions and relaxations impart to the countenance those expressions which reflect the feelings and passions of the individual.

Two important muscles, the temporal, near the temples, and the masseter, or chewing muscle, are the chief agents in moving the lower jaw. They are very large in the lion, tiger, and other flesh-eating animals. On the inner side of each cheek is the buccinator, or trumpeter's muscle, which is largely developed in those who play on wind instruments. Easily seen and felt under the skin in thin persons, on turning the head to one side, is the sterno-cleido-mastoid muscle, which passes obliquely down on each side of the neck to the collar bone. This muscle is prominent in sculpture and painting.

Experiment 23. To illustrate how the muscles use the bones as levers. First, practice with a ruler, blackboard pointer, or any other convenient object, illustrating the different kinds of levers, until the principles are familiar. Next, illustrate these principles on the person, by making use of convenient muscles. Thus, lift a book on the toes, by the fingers, on the back of the hand, by the mouth, and in other ways.

Experiment 24. With the head slightly bent forward, grasp between the fingers and thumb of the right hand the edge of the left sterno-cleido-mastoid muscle, just above the collar bone. Raise the head and turn it from left to right, and the action of this important muscle is readily seen and felt.

87. Muscles of the Chest and Back. The chest is supplied with numerous muscles which move the ribs up and down in the act of breathing. A great fan-shaped muscle, called the pectoralis major, lies on the chest. It extends from the chest to the arm and helps draw the arm inward and 
forward. At the back of the shoulder a large, spread-out muscle passes upward from the back to the humerus. From its wide expanse on the back it is known as the latissimus dorsi ("broadest of the back"). When in action

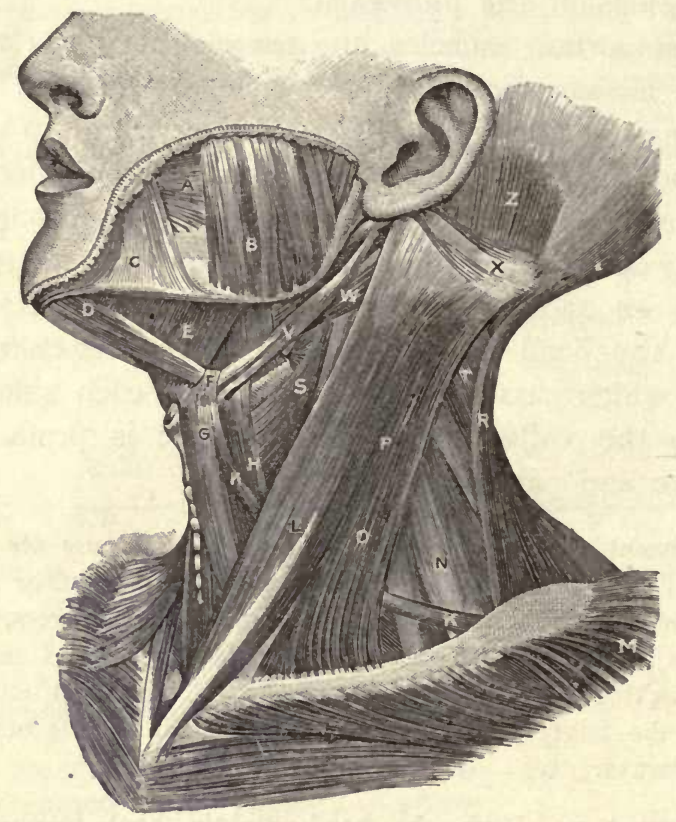

FIG. 35. Principal Muscles on the Left Side of Neck.

$A$, buccinator; $B$, masseter; $C$, depressor anguli oris; $D$, anterior portion of the digastric; $E$, mylo-hyoid; $F$, tendon of the digastric ; $G$, sterno-hyoid; $H$, sternothyroid; $K$, omo-hyoid; $L$, sternal origin of sterno-cleido-mastoid muscle; $M$, superior fibers of deltoid; $N$, posterior scalenus; $O$, clavicular origin of sterno-cleido-mastoid; $P$, sterno-cleido-mastoid; $R$, trapezius; $S$, anterior constrictor; $T$, splenius capitis ; $V$, stylo-hyoid; $W$, posterior portion of the digastric; $X$, fasciculi of ear muscles; $Z$, occipital.

it draws the arm downward and backward, or, if one hangs by the hands, it helps to raise the body. It is familiarly known as the "climbing muscle." 
88. Muscles of the Shoulder and Arm. The arm is raised from the side by a large triangular muscle on the shoulder, the deltoid, so called from its resemblance to the Greek letter delta, $\Delta$. The biceps, or two-headed muscle, forms a large part of the fleshy mass in front of the arm. Its use is to bend the forearm on the arm, an act familiarly known as "trying your muscle." Its direct antagonist is the three-headed muscle, called the triceps. This forms the fleshy mass on the back of the arm, its use being to draw the flexed forearm into a right line.

On the back and outside of the forearm are the extensors, which straighten the wrist, the hand, and the fingers. On the front and inside of the forearm are the flexors, which bend the hand, the wrist, and the fingers. If these muscles are worked vigorously, their tendons can be readily seen and felt under the skin.

89. Muscles of the Lower Extremities. Passing to the lower extremities, the thigh muscles are the largest and the most powerful in the body. In front a great, fourheaded muscle, quadriceps extensor, unites into a single tendon in which the knee-cap is set, and serves to straighten the knee, or when rising from a sitting posture helps elevate the body. On the back of the thigh are several large muscles which bend the knee, and whose tendons, known as the "hamstrings," are readily felt just behind the knee.

On the back of the leg the most important muscles, forming what is known as the calf, are the gastrocnemius and the soleus. The first forms the largest part of the calf. The soleus, so named from its fancied resemblance to a sole-fish, is a muscle of broad, flattened shape, lying beneath the gastrocnemius.

The tendons of these two muscles unite to form the tendon of Achilles, so called because that hero is said to have 
been invulnerable except at this point. The muscles of the calf of the leg have great power, and are constantly called into use in walking, cycling, dancing, and leaping.

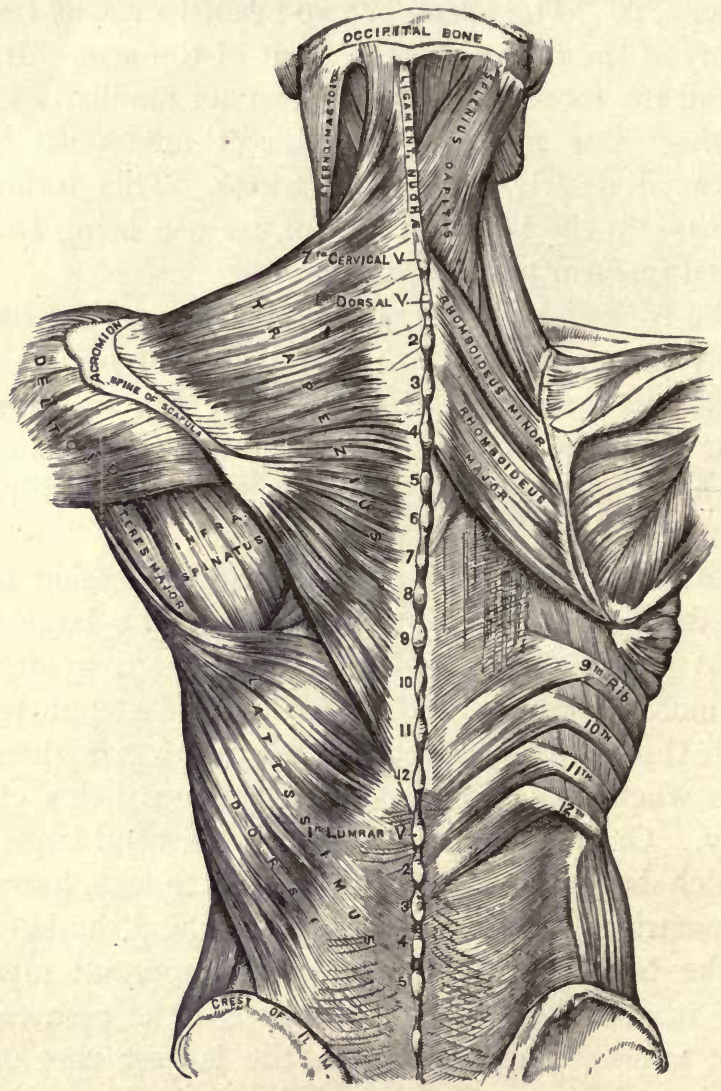

FIG. 36. A Few of the Important Muscles of the Back.

90. Effect of Alcoholic Beverages upon Muscular Work. Alcohol, even in small quantities, tends to depress the nervous centers, and thus indirectly relaxes the muscles. 
This is evident from the unsteady hand, the staggering gait, and the lack of general muscular control of those who are under the influence of strong drink.

Men under the influence of alcoholic liquor may do an increased amount of muscular work for a very few minutes, but such an increase is produced at the expense of energy which is needed in enduring sustained exposure or work. Men who are trained for athletic contests are strictly forbidden to use alcoholic beverages.

In brief, while a certain amount of energy may be derived from the oxidation of alcohol in the body, both experiment and observation seem to show that the sum total of benefit in the form of sustained muscular work is more than counterbalanced by the paralyzant effect of the alcohol upon the nervous system.

91. Effect of Tobacco on the Muscular Tissues. Tobacco tends to impair the energy of the muscular tissues as alcohol does, by its paralyzing effect upon the nervous centers. This applies especially to the young, in the growing age between twelve or fourteen and twenty, the very time when the healthy body is being well knit and compacted.

Hence many public and private schools, as well as our national naval and military academies, rigidly prohibit the use of tobacco by their students.

For the same reason, the statute laws in many states prohibit the sale of cigarettes to minor children.

Several directors of physical education in our colleges have clearly demonstrated by personal examination and recorded statistics that the use of tobacco among college students checks growth in weight, height, chest-girth, and, most of all, in lung capacity. 


\section{ADDITIONAL EXPERIMENTS}

Experiment 25. To examine the minute structure of voluntary muscular fiber. Tease, with two needles set in small handles, a bit of raw, lean meat, on a slip of glass, in a little water. Continue until the pieces are almost invisible to the naked eye.

Experiment 26. Place a clean, dry cover-glass, of about the width of the slip, over the water containing the torn fragments. Absorb the excess of moisture at the edge of the cover by pressing a bit of blotting paper against it for a moment. Place it on the stage of a microscope and examine with highest obtainable power, by light reflected upward from the mirror beneath the stage. Note the apparent size of the finest fibers ; the striation of the fibers, or markings of alternate dim and bright cross bands.

Texperiment 27. To show the ligamentous action of the muscles. Standing with the back fixed against a wall to steady the pelvis, the knee can be flexed so as almost to touch the abdomen. Take the same position and keep the knee rigid. When the heel has been but slightly raised a sharp pain in the back of the thigh follows any effort to carry it higher. Flexion of the leg to a right angle increases the distance from the lines. of insertion on the pelvic bones to the tuberosities of the tibia by two or three inches - an amount of stretching these muscles cannot undergo. Hence the knee must be flexed in flexion of the hip.

† Experiment 28. A similar experiment may be tried at the wrist. Flex the wrist with the fingers extended, and again with the fingers in the fist. The first movement can be carried to 90 per cent, the second only to 30 per cent, or in some persons up to 60 per cent. Making a fist had already stretched the extensor muscles of the arm, and they can be stretched but little farther. Hence, needless pain will be avoided by working a stiff wrist with the parts loose, or the fingers extended, and not with a clenched fist.

Note. - A description of an apparatus, illustrating the combined action of muscles and joints, may be found in the Outlines of Requirements for Harvard University. 
IMPORTANT MUSCLES OF THE BODY

Location

Name

Chief Function

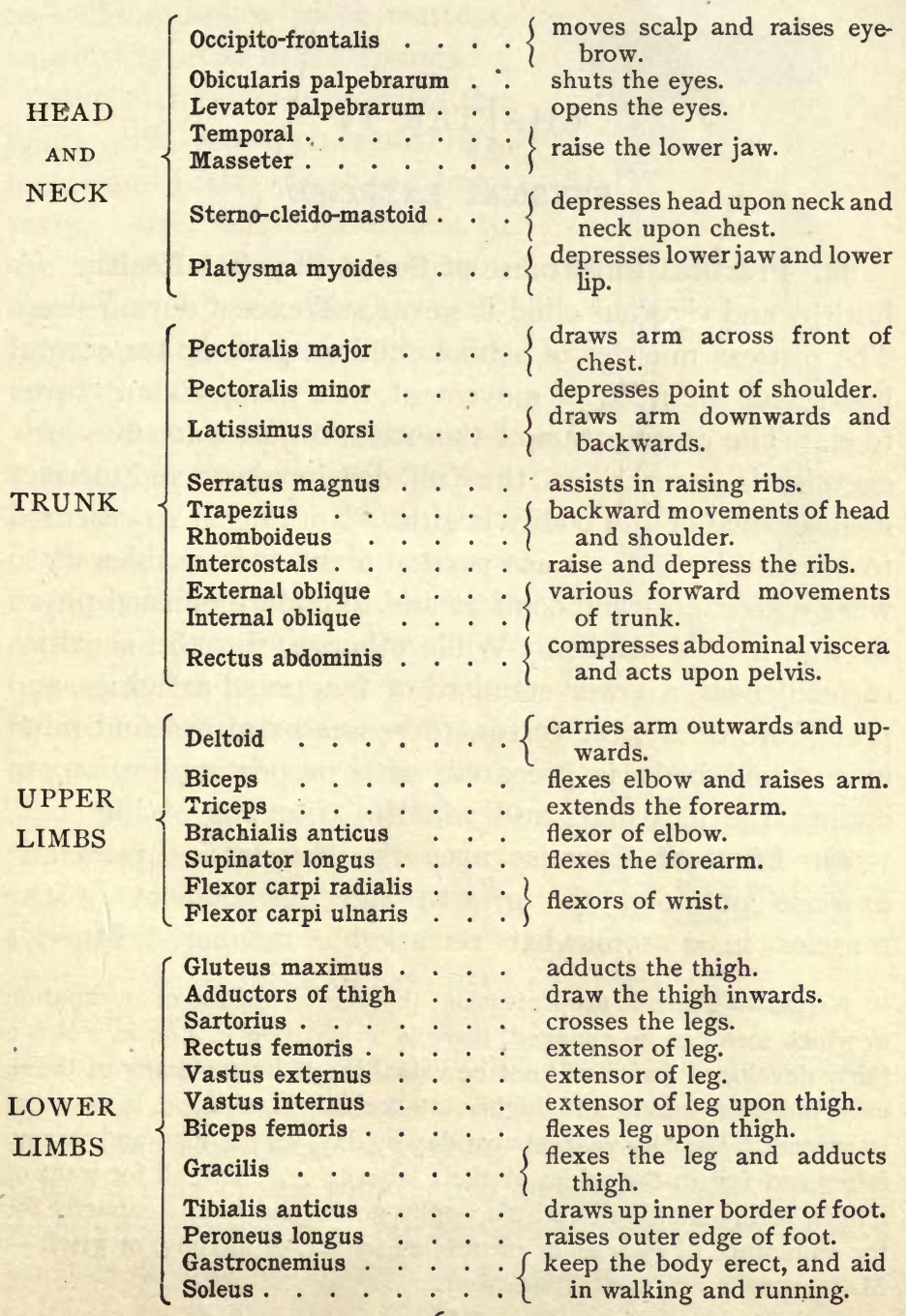




\section{CHAPTER IV}

\section{PHYSICAL EXERCISE}

92. Practical Importance of Sound Physical Health. A healthy and vigorous child is never still except during sleep. The restless muscles of school children pent up for several hours feel the need of movement, as a hungry man craves food. The gratification of this natural desire for muscular exercise is essential to the full development and perfect maintenance of the bodily health. Nothing is so essential to success in life as sound physical health. It enables us to work with energy and comfort and to endure unusual physical and mental strains. While others suffer the penalties of feebleness, a lower standard of functional activities, and premature decay, the fortunate possessor of a sound mind in a sound body is prepared, with proper application, to endure the hardships and win the triumphs of life.

93. Effect of Exercise upon the Muscles. Systematic exercise promotes the growth and development of the muscles in a somewhat remarkable manner. Muscles

Note. - There is no profession, there is no calling or occupation in which men can be engaged, there is no position in life, in which a fairly developed frame will not be valuable; there are many of these, even the most purely and highly intellectual, in which it is essential to success. Year by year, almost day by day, we see men and women falter and fail in the midst of their labors ; . . . and all for want of a little bodily stamina - a little bodily power and bodily capacity for the endurance of fatigue, or protracted unrest, or anxiety, or grief. MACLAREN's Physical Education. 
properly exercised not only increase in size, but are better enabled to get rid of any needless accumulation of fat, as well as useless waste matters, which may exist in the tissues.

Muscular exercise provides the joints with more powerful ligaments and better developed bony parts. After long confinement to the bed from disease, the joints have wasted ligaments, thin cartilages, and the bones are of smaller proportions.

94. Muscular Coördination and Physical Training. He who has been physically well trained has both a more economical and a more intelligent use of his muscles. He has acquired the art of causing his muscles to act in harmony. Movements once difficult are now carried on with ease. The power of coördination is increased, so that a desired end is attained with the least expenditure of physical force and nervous energy. In learning to row, play baseball, ride the bicycle, or in

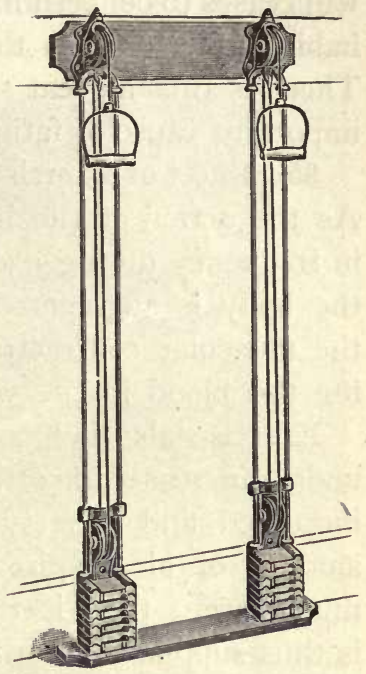

FIG. 37. The Standard Special Chest Weight.

(A convenient machine by means of which all the muscles of the body may be easily and pleasantly exercised, with sufficient variations in the movements to prevent monotony. A space about $6 \mathrm{ft}$. wide, $6 \mathrm{ft}$. deep, and $7 \mathrm{ft}$. high is required in exercising with this machine.) any other exercises, the beginner makes his movements in a stiff and awkward manner. He will use and waste more muscular force in playing one game of ball, or in riding a mile on his wheel, than an expert would in doing many times the work. He has not yet learned to balance one set of muscles against its antagonists. 
In time, however, acts which were first done only with effort, and by a conscious will, become automatic. The will ceases to concern itself. By what is called reflex action, habit is developed in the nerve centers of the spinal cord. There is thus a great saving of actual brain work, and one important cause of fatigue is removed.

95. Effect of Exercise on the Circulation and Respiration. As the action of the heart is increased both in force and in frequency during exercise, the flow of blood throughout the body is augmented. This results from the force of the muscular contractions which play their part in pressing the blood in the veins onward towards the heart.

Exercise also induces a more vigorous respiration, and under increased breathing efforts the lung capacity is increased and the size of the chest is enlarged. The amount of air inspired and expired in a given time is much larger than if the body were at rest. The blood is thus supplied with a much larger amount of oxygen from the air inhaled, and gives off to the air a corresponding excess of carbon dioxide and water.

96. Effect of Exercise on Digestion. Exercise stimulates and strengthens the organs of digestion. The appetite is improved, especially after exercise in the open air. The digestion is more complete, absorption becomes more rapid, the peristaltic movements of the bowels are promoted, and the circulation through the liver is more vigorous.

Ample exercise also checks the tendency so common with those who eat heartily, but lead sedentary lives, towards a torpid circulation in the larger digestive organs, especially in the stomach and the liver.

97. Exercise and the Bodily Temperature. Exercise increases the flow of blood through the small vessels of the skin, and thus increases the radiation of heat from 
the surface. If the exercise be vigorous and the weather hot, a profuse perspiration ensues, the rapid evaporation of which cools the body. The skin is thus a most important regulator of the bodily temperature, and prevents any harmful rise above the normal which would otherwise result from vigorous exercise.

98. Effect of Physical Training upon the Personal Appearance. Judicious and systematic exercise, if moderately employed, soon gives a more upright and symmetrical figure, and an easier and more graceful carriage. Rounded shoulders become square, an awkward gait disappears, and there is seen a graceful poise of the head and a bearing of the body which marks those whose muscles have been well trained. Exercise improves the condition of the tissues generally. They become more elastic, and in all respects sounder. 'The skin becomes firm, clear, and healthy.

The delicate, ruddy aspect of the complexion, the swing of the body and the bearing of the

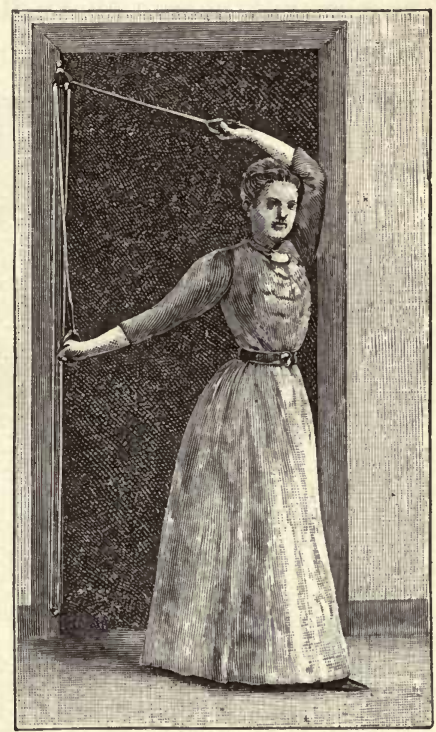

Fig. 38. Young Woman practicing at Home with the "Whitely Exerciser."

(From a photograph.) head and shoulders of young women whose physical training has been efficient are in marked contrast with the characteristics of those whose education in this respect has been neglected.

99. Unsuitable or Excessive Exercise. Exercise, like everything else which promotes our welfare, may be carried to excess. The words "excessive" and "unsuitable," when applied to muscular exertion, are relative terms, and apply to the individual rather than to the amount of work 
done. What may be excessive for one person might be beneficial to another.

Breathlessness is, perhaps, the most common effect of undue exertion. Let a middle-aged person, who is out of practice, run even a short distance, and he is soon troubled with his breathing. He pants, and his strength gives out.

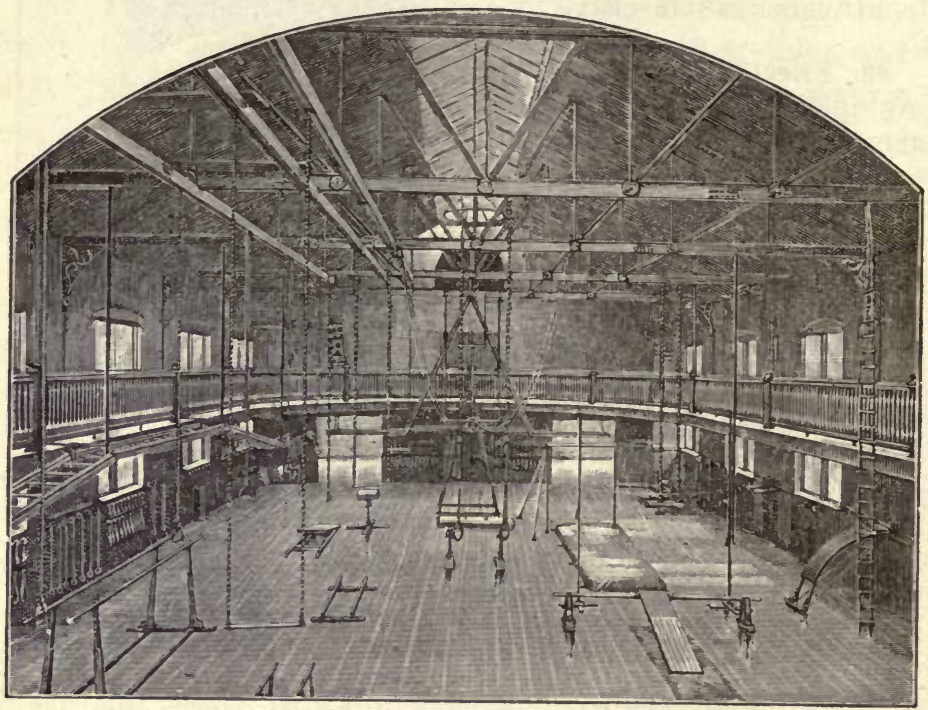

FIG. 39. A Well-Equipped Gymnasium.

(From a photograph.)

His chest, and not his legs, has failed him. He is said to be "out of breath."

The heart is often overstrained during violent exertion, as in lifting a great weight. Certain forms of heart disease are common with those whose occupations involve severe muscular effort, as professional athletes and oarsmen.

100. Results of Excessive Muscular Movements. The excessive repetition of muscular movements may lead to 
permanent contractions of the parts involved. Thus sailors, mechanics, and others frequently develop a rigidity of the tendons of the hand which prevents the full extension of the fingers. So stenographers, typewriters, telegraphers, and writers occasionally suffer from permanent contractions of certain muscles of the arm, known as writer's cramp.

101. Muscular Fatigue. We all know how tiresome it is to hold the arm outstretched horizontally even for a few moments. A single muscle, the deltoid, in this case does most of the work. Even in a vigorous man this muscle can act no longer than four to six minutes before the arm drops helpless. We may prolong the period by a strong effort of the will, but a time soon comes when no possible effort will enable us to hold out the arm. The muscle is said to be fatigued. It has by no means lost its contractile power, for if we apply a strong electric stimulus to it, the muscle will contract again. In brief, the functional power of a muscle has a definite limit, and in fatigue that limit is reached.

- 102. Results of Muscular Fatigue. The strength of the muscle, its physical condition, the work it has done, and the mental condition of the individual, all modify the state of fatigue. In those difficult acts which involve a special effort of the will, the question of nerve exhaustion is largely concerned.

Thus, the incessant movements in St. Vitus' dance result in comparatively little fatigue, because there is no association of the brain with the muscular,action. If a strong man should attempt to perform voluntarily the same movements, he would soon have to rest. None of the movements which are performed independently of the will, as the heart beats and breathing movements, ever involve the sensation of fatigue. 
As a result of fatigue the normal irritability of muscular tissue becomes weakened, and its force of contraction is lessened. There is, also, often noticed in fatigue a peculiar tremor of the muscles, rendering their movements uncertain. The stiffness of the muscles which occurs during severe exercise, or the day after, is a familiar result of fatigue.

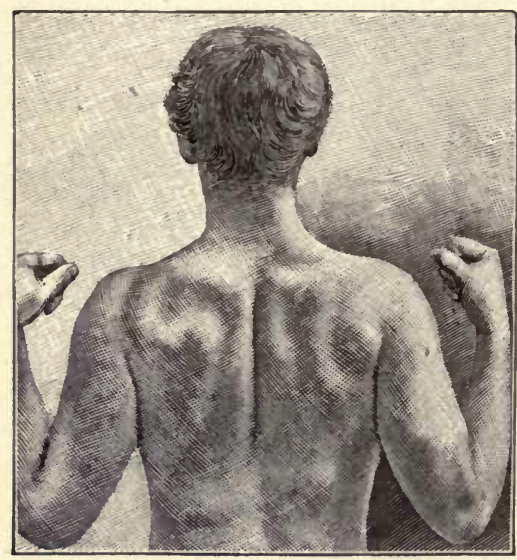

FIG. 40. Showing how the Muscles of the Back may be developed by a Moderate Amount of Dumb-Bell Exercise at Home.

(From a photograph of the living model.)

103. Fatigue serves as Nature's Warning. The sense of fatigue is Nature's warning to put us on our guard. It is a kind of regulator which serves. in the ordinary actions of life to warn us not to exceed the limits of useful exercise. Fatigue summons us to rest long before all the force of the motor organs has been expended, just as the sensation of hunger warns us that we need food, long before the body has become weak from the lack of nourishment.

104. A Period of Rest Necessary. Rest is necessary for the tissues, that they may repair the losses sustained in doing work. A period of rest must alternate with a period of activity. Even the heart has its periods of absolute rest to alternate with those of work. Were it not for this power to repair and renew its tissues, the body would soon be worn out.

The periods of rest should vary with the kind of exercise. Thus, exercise which produces breathlessness requires 
frequent but short rests. The trained runner, finding his respiration embarrassed, stops a moment to regain his breath. Exercises of endurance cause fatigue less quickly than those of speed, but require longer rest.

105. Amount of Physical Exercise required. The amount of physical exercise that can be safely performed by each person is a most important and practical question. No rule can be laid down, for what one person bears well may prove very injurious to another. To a certain extent, each must be guided by his own judgment. If, after taking exercise, we feel fatigued and irritable, are subject to headache and sleeplessness, or find it difficult to apply the mind to our work, it is plain that we have been taxing our strength unduly, and the warning should be heeded.

It may be laid down as a fairly safe rule that an adult of average height and weight, engaged in study or in any indoor or sedentary occupation, should take an amount of exercise equivalent to walking five or six miles a day. Growing children, as a rule, take more exercise than this, while most men working indoors take far less, and many women take less exercise than men. Exercise may be varied in many ways, the more the better; but as far as possible it should be taken in the open air.

106. Amount of Exercise modified by Circumstances. The proper amount of exercise must vary greatly with circumstances. Thus, age is an important factor in the problem. A young man may do with ease and safety what might be injurious to an older person. In youth, when the body is developing most rapidly, the judicious use of games, sports, and gymnastics is most beneficial.

Abundant evidence shows that physical development is most active from the thirtéenth to the seventeenth year; this manifests itself clearly by increase in weight. Hence, 
this period of life is of great importance in the physical development of the body. If at this age a boy or girl is subjected to undue physical strain, the development may suffer, the growth be retarded, and the foundation laid for future ill health.

107. Time for Exercise. It is not prudent to do hard work or take severe exercise just before or just after a full

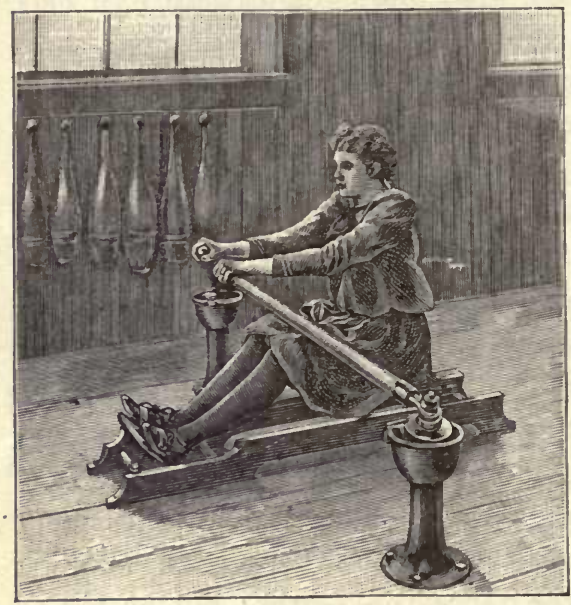

FIG. 4I. Student exercising in the School Gymnasium on the Rowing Machine. (From a photograph.) meal. While the stomach is busily digesting food vigorous exercise may prove injurious, and is apt to result sooner or later in dyspepsia. Hence the best time to take exercise is one or two hours after a meal.

On the other hand, severe exercise should not be taken on an empty stomach. Those who do much work or study before breakfast should first take a light lunch, just enough to prevent any faint feeling. With this precaution, there is no better time for moderate exercise than the early morning.

108. Walking, Running, and Jumping. Walking is generally regarded as the simplest and most convenient mode of taking exercise. When taken with a special object in view, it is the best and most pleasant of all physical 
activities. It is suited to individuals of all ages and occupations, and to residents of every climate.

In walking, the muscles of the entire body are brought into action, and the movements of breathing and the circulation of the blood are increased. The body should be erect, the chest thrown out, the head and shoulders held back, and the stride long and elastic. It is an excellent custom to add to the usefulness of this fine exercise by deep, voluntary inhalations of pure air.

Running as an exercise is beneficial to those who have kept themselves in practice and in sound condition. It brings into play nearly every muscle of the body, and thus serves to develop the power of endurance, as well as strength and capacity for rapid movement.

Jumping is usually an admirable and beneficial form of exercise. It brings into action many muscles without putting undue strain upon any particular group.

109. Skating, Swimming, and Rowing. Skating is a delightful and invigorating exercise. It calls into play a great variety of muscles, and is

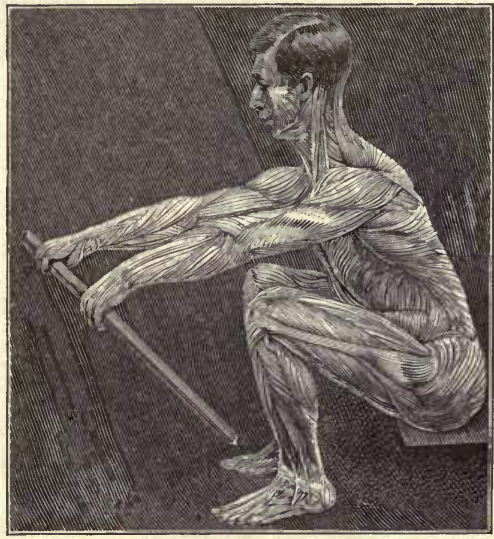

FIG. 42. Showing how Muscles may be developed in Rowing.

(Based upon a photograph from the living model.) beneficial at almost all ages. It strengthens the ankles and helps give an easy and graceful carriage to the body.

Every child above ten years of age should be taught to swim. The art, once mastered, is never forgotten. It 
calls into action a wide combination of muscles. This accomplishment, so easily learned, should be a part of our education, as it may be the means of saving one's own life or that of a companion.

In many respects rowing is one of the most perfect exercises at our command. It expands the chest, strengthens the body, and gives tone to the muscles of the abdomen. It is an admirable exercise for girls and women.

110. The Use of the Bicycle. The bicycle is at once the most useful and the most attractive machine ever devised for use and pleasure. Nothing has ever approached the wheel in tempting persons of all ages and occupations to go out of doors and take vigor ous exercise.

Bicycling does not bring into active use the leg muscles alone. It also produces a substantial increase in the circumference of the chest. It causes the arms and forearms to grow firmer and the muscles of respiration to become stronger and larger. In fact, the muscles of the whole body seem to improve in tone with this form of exercise.

111. Outdoor Games and Physical Education. While outdoor games are not necessary to maintain health, yet we can scarcely overestimate the value and usefulness of baseball, football, tennis, golf, and croquet in the physical development of young people. When played in moderation and under suitable conditions, they are most useful and beneficial exercises. They are played in the open air, and demand a great variety of vigorous muscular movement, with a considerable amount of skill and adroitness of action. These games not only involve healthful exercise, but tend to develop those manly and wholesome qualities which are essential to success in life.

112. Physical Exercises in School. Physical exercises of some sort should be provided for pupils in our schools, 
especially in large towns and cities, where there is little opportunity for outdoor games. These exercises should form a part of the regular course of study. The object should be the promotion of sound health rather than the development of muscle or the performance of feats of agility or strength. Exercises with dumb-bells and wands, or even without any apparatus, practiced a few times a day, for five minutes at a time, do a great deal of good. They relax the tension of body and mind, and introduce an element of pleasure into the routine of school life.

\section{Narcotics and Physical Exer-} cise. Recognizing the fact that alcoholic beverages and tobacco are so disastrous to efficiency in any system of physical training, instructors in physical culture rigidly forbid the use of these narcotics under all circumstances. While this principle is perhaps more rigorously enforced in training for athletic contests, it is insisted upon in teaching those who have in view only the maintenance of health.

\section{Practical Points about Physi-} cal Exercise. The main object in undertaking systematic and graduated

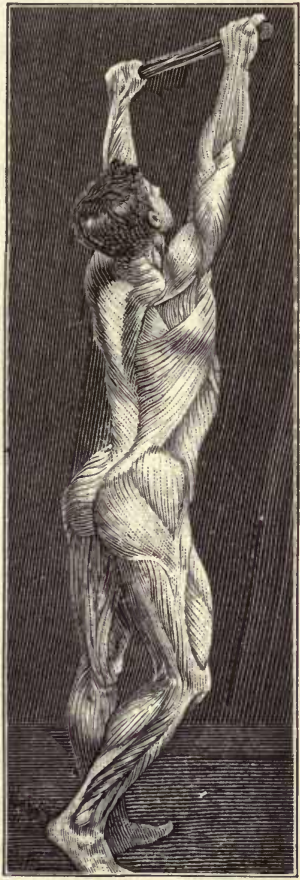

Fig. 43. Showing how the Muscles may be developed on the Trapeze or Horizontal Bar.

(Based upon a photograph from the living model.) physical exercises is not to learn how to do mere feats of strength and skill, but rather to fit one's self for the duties and the work of life. 
The most beneficial exercises ordinarily are the gentle ones, in which no strain is put upon the heart and the respiration. The special aim is to secure the equal use of all the muscles, not the development of a few.

Exercises which call for sustained effort, violent exertion, or sudden strain, are best avoided by those who have had no preparation or training.

After the more violent exercises, as baseball, football, a long ride on the bicycle, or even after a prolonged walk, a bath should be taken at the first convenient opportunity. Care should be taken to rub down thoroughly, and to change a part or all of the clothing. It is dangerous to stand about in clothes which are damp with perspiration.

Keep warmly clad after exercise, avoid chills, and always stop exercising as soon as fatigue is felt. Wear clothing which allows free play to all the muscles of the body. The clothing should be light, loose, and made of porous material.

In brisk walking keep the mouth shut, especially in cold weather, and breathe through the nose, regulating the pace so that it can be done without discomfort.

Note I. - Blackie's How to get Strong and how to stay so (New and Enlarged Edition of 1898 ) is full of wholesome advice and practical suggestions to those who may wish to practice health exercises at home.

Note 2. - One-half the struggle of physical training has been won when a boy can be induced to take a genuine interest in his bodily condition, - to want to remedy its defects, and to pride himself on the purity of his skin, the firmness of his muscles, and the uprightness of his figure. Whether the young man chooses afterwards to use the gymnasium, to run, to row, to play ball, or to saw wood, for the purpose of improving his physical condition, matters little, provided he accomplishes that object. - DR. D. A. SARGENT, Director of the Hemenway Gymnasium at Harvard University: 


\section{CHAPTER V}

\section{FOOD AND DRINK}

115. The Necessity for Food. In a general way the body may be compared to a steam engine in good working order. An engine consumes fuel to obtain from it the energy necessary to do its work; so, we consume within our bodies certain nutritious substances to obtain from them the energy necessary for our activities. Just as the energy for the working of the engine is obtained by the combustion of fuel, so the energy expended by our bodies in the form of muscular work or heat results from the combustion or oxidation within us of the food we eat. Unless this energy is provided for the body it will have but little power of doing work, and, like an engine without steam, must soon become motionless.

116. Waste made good by Food. A steam engine, from the first stroke of its piston rod, begins to wear out, and before long needs repair. All work involves waste. The engine, unless kept in thorough repair, would soon stop. So it is with our bodies. In their living cells chemical changes are constantly going on ; complex substances are being broken up into simpler combinations. It is impossible to move a single muscle, or even to think for one moment, without causing some substance in the muscular or brain tissue to become of no further use in the body.

In short, so long as the body maintains its activities, there must result a waste of substance which corresponds 
exactly to the amount of energy expended. This continual loss of substance must be made good by the introduction into the body of new material. This "new material" is the food we eat and is introduced into our bodies by means of the alimentary canal.

The process known as digestion, by which the food thus introduced is acted upon so that it can pass through the delicate walls of the alimentary canal into the blood and lymphatics, will be treated in Chapters VI and VII.

Meantime, let us learn something of the nature and composition of food, which is so essential to the welfare of the bodily tissues.

117. Classification of Foods. Foods may be conveniently divided into four great classes, to which the name foodstuffs, or alimentary principles, has been given.

\section{Proteids, or Nitrogenous Foods.}

II. Starches and Sugars, or Carbohydrates.

III. Fats and Oils.

IV. Inorganic or Mineral Foods, - Water, Salt.

118. Proteids, or Nitrogenous Foods. The proteids, frequently spoken of as nitrogenous foods, are rich in one or more of the following organic substances: albumin, casein, fibrin, gelatin, myosin, gluten, and legumin.

The type of this class of foods is egg albumin, well known as the white of an egg. The serum of the blood is very rich in albumin, as is lean meat. The curd of milk consists mainly of casein. Fibrin exists largely in blood and flesh foods. One of the chief constituents of muscular fiber is myosin. Gluten exists largely in the cereals, wheat, barley, oats, and rye. The proteid principle of peas and beans is legumin, a substance resembling casein. 
The principal proteid foodstuffs are milk, eggs, flesh foods of all kinds, fish, and the cereals among vegetable foods. Peas and beans are rich in proteids.

The essential use of the proteids, or nitrogenous foodstuffs, to the tissues is to supply the material from which new tissue is made or old tissue is repaired. They are also valuable to the body as sources of energy. Now, as proteids are the most important constituents of living matter, it is evident that proteid food is the essential element of all food. In short, if our diet contained no proteids, the tissues of the body would gradually waste away, and death would sooner or later result.

119. Starches and Sugars. The starches, sugars, and gums, also known as carbohydrates, enter largely into the composition of foods of vegetable origin. They contain no nitrogen, but only the three elements, carbon, hydrogen, and oxygen.

The starches are abundant in potatoes and the cereals, and in arrowroot, sago, and tapioca.

The sugars are also widely distributed substances, and include cane, grape, malt, maple, and milk sugars. To this group of carbohydrates also belong the gums and the cellulose or woody fibrous substance found in fruit, cereals, and all vegetables. Honey and molasses are likewise carbohydrates.

The starches and sugars are oxidized in the body, and a certain amount of energy is thereby liberated. The energy of muscular work and of the heat of the body comes largely from their oxidation.

120. Fats and 0ils. These include not only the ordinary fats of meat, but many animal and vegetable oils. They are rich in carbon and hydrogen, but contain little oxygen. The principal kinds of fat used as food are the fat of meat, 
butter, suet, and lard; but in many parts of the world various vegetable oils are largely used, as the olive, palm, cotton seed, cocoanut, and almond.

Weight for weight the fats and oils are more valuable than the carbohydrates as sources of energy, but the latter are more easily digested, and more easily oxidized in the body. An important use of fatty foods is for the maintenance of the bodily heat. The inhabitants of Arctic regions are thus enabled, by large use of the fat and oil from the animals they devour, to endure safely the severe cold.

121. Saline or Mineral Foods. The principal mineral foods are water, and the salts of lime, iron, magnesia, phosphorus, sodium, and potash. Except common salt and water, these substances are usually taken only in combination with other foods.

These saline matters are essential to health, and when they are not present in due proportion nutrition is disturbed. If a dog be fed on food freed from all salines, but otherwise containing proper nutrients, he soon suffers from weakness, after a time amounting to paralysis, and often dies in convulsions.

About two hundred grains of common salt are required daily by an adult, but a large proportion of this is contained in the organic food. Phosphate and carbonate of lime are obtained from milk and meats. Both are required for the bones and teeth. The salts of potash, which assist in purifying the blood, are obtained from vegetables and fruits. An iron salt is found in most foods, and sulphur in the yolk of eggs.

122. Water. Water is present in all foods. It is of use chiefly as a solvent, and while not strictly a food, is necessary to life. It enters into the construction of every 
tissue, and is constantly being removed from the body by every channel of waste. ${ }^{1}$

As a solvent water aids digestion, and as it forms about 80 per cent of the blood, it serves as a carrier of nutrient material to all the tissues of the body.

In brief, the presence of water in the tissues is a condition of all vital activity.

\section{IMPORTANT ARTICLES OF DIET}

123. Milk and Eggs. The value of milk as an article of diet cannot be overestimated. It affords nourishment in a very simple and convenient form. It is an ideal food, containing, in excellent proportions, all the elements necessary for growth and health in earlier youth.

Eggs are often spoken of as a typical natural food. The white of an egg is chiefly albumin, with traces of fat and salt; the yolk is largely fat and salts. Eggs furnish a convenient and concentrated food, and if properly cooked are usually readily digested.

124. Meats. The flesh of animals is one of our main sources of food. Containing a large amount of proteid, it is admirably adapted for building up and repairing the tissues of the body.

Beef contains less fat and is more nutritious than either mutton or pork. Mutton has a fine flavor and is easily digested. Veal and pork are less easily digested. Poultry and game are rich in phosphates.

1 The amount of water in various tissues of the body is given by the following table in parts of 1000 :

$\begin{array}{lrlllllr}\text { Enamel, } & 2 & \text { Skin, } & 720 & \text { Blood, } & 791 & \text { Serum, } & 959 \\ \text { Dentine, roo } & \text { Brain, } & 750 & \text { Bile, } & 864 & \text { Gastric juice, } & 973 \\ \text { Bone, } & 486 & \text { Muscle, } & 757 & \text { Blood plasma, 901 } & \text { Tears, } & 982 \\ \text { Fat, } & 299 & \text { Spleen, } & 758 & \text { Chyle, . } & 928 & \text { Saliva, } & 995 \\ \text { Liver, } & 693 & \text { Kidney, } & 827 & \text { Lymph, } & 958 & \text { Sweat, } & 995\end{array}$


125. Fish. Fish forms an important and most nutritious article of diet, as it contains almost as much nourishment as meat. The fish-eating races and classes are remarkably strong and healthy. As a rule, shellfish, except oysters, are not very digestible. Some persons are unable to eat certain kinds of fish, especially shellfish, without producing eruptions on the skin and other symptoms of mild poisoning.

126. Vegetable Foods. This is a large and important group of foods, and embraces a remarkable number of different kinds of diet. Vegetable foods include the cereals, garden vegetables, the fruits, and other less important articles. These foods supply a certain quantity of proteid and fat, but their chief use is to furnish starches, sugars, acids, and salts.

The vegetable foods, especially the cereals, indirectly supply the body with water, a great deal of which is absorbed by them in the process of cooking.

127. Proteid Vegetable Foods. The most important proteid vegetable foods are those derived from the grains of cereals and certain leguminous seeds, as peas and beans. The grains when ground make the various flours or meals. They contain a large quantity of starch, a proteid substance peculiar to them called gluten, and mineral salts, especially phosphate of lime. Wheat, oatmeal, and corn are most important articles of diet. Wheat flour contains starch, sugar, and gluten - nearly everything to support life except fat, in which it is very poor. Oatmeal is rich in proteids.

Corn meal is not only rich in proteid, but also in fat ; hence it is a most important and nutritious article of food. Rice, on the other hand, contains less proteid than any other cereal grain, and is the least nutritious. Peas and 
beans, distinguished from all other vegetables by their large amount of proteids, excel in this respect even beef, mutton, and fish. They take the place of meats with those who believe in a vegetable diet.

128. Non-Proteid Vegetable Foods. The common potato is the best type of non-proteid vegetable food. When properly cooked it is easily digested and makes an excellent article of diet. It is unfit for an exclusive food, but is best used with milk, meat, and other foods richer in proteid substances. Sweet potatoes, of late years extensively used as food, are rich in starch and sugar. Arrowroot, sago, tapioca, and similar foods are nutritious, and easily digested.

129. Non-Proteid Animal Foods. Butter is one of the most digestible of animal fats, wholesome, agreeable, and delicate in flavor, and is on this account much used as a food. Various substitutes have of late years come into use. These are made from animal fat, chiefly that of beef, and are known as butterine, oleomargarine, and by other trade names. These preparations, if properly made, are wholesome, and may be useful substitutes for butter.

130. Garden Vegetables. Various green, fresh, and succulent vegetables, such as celery, cabbages, beets, lettuce, and turnips, form an important part of our diet. They are of use not so much on account of their proteids, carbohydrates, or fats, which are usually small in quantity, as for the salts they supply, especially the salts of potash. The long-continued use of a diet without fresh vegetables often leads to a disease known as scurvy.

Vegetables are also used for the agreeable flavor possessed by many, and the pleasant variety and relish they give to the food. The undigested residue left by all green vegetables affords a useful stimulus to intestinal contraction. 
Explanation of the Graphic Chart. The graphic chart, on the opposite page, presents in a succinct and easily understood form the composition of food materials as they are bought in the market, including the edible and non-edible portions.

This chart has been rearranged and compiled from a monograph on "Foods and Diet" which may be found in the Yearbook of the United States Department of Agriculture for I 894 .

KEY : I, percentage of nutrients; 2 , fuel value of I pound in calories. The unit of heat, called a calorie, or gramme-degree, is the amount of heat which is necessary to raise one gramme (15.43 grains) of water one degree Centigrade (1. $8^{\circ} \mathrm{Fahr}$.). $A$, round beef; $B$, sirloin beef; $C$, rib beef; $D$, leg of mutton; $E$, sparerib of pork ; $F$, salt pork; $G$, smoked ham; $H$, fresh codfish ; $I$, oysters ; $J$, milk; $K$, butter; $L$, cheese; $M$, eggs; $N$, wheat bread; $O$, corn meal; $P$, oatmeal; $Q$, dried beans; $R$, rice; $S$, potatoes; $T$, sugar.

This table, among other things, shows that the flesh of fish contains more water than that of warm-blooded animals. It may also be seen that animal foods contain the most water, and vegetable foods, except potatoes, the most nutrients. Proteids and fats exist only in smail proportions in most vegetables, except beans and oatmeal. Vegetable foods are rich in carbohydrates, while meats contain none. The fatter the meat the less the amount of water. Thus, very lean meat may be almost four-fifths water, and fat pork only one-tenth water.

131. Fruits. Fruits - as oranges, strawberries, apples, grapes, and bananas - are a useful addition to our regular diet. They are cooling and refreshing, of agreeable flavor, and tend to prevent constipation. Their flavor and juiciness serve to stimulate a weak appetite and to give variety to the diet. If eaten in an unripe or an overripe state, fruits may occasion a disturbance of the stomach and bowels.

132. Condiments. The refinements of cookery, as well as the craving of the appetite, demand many articles which cannot be classed strictly as foods. They are called condiments, and as such may be used in moderation. They give flavor and relish to food, excite appetite, and promote digestion. 


\section{Food and Drink}

\section{COMPOSITION OF FOOD MATERIALS}

Nutritive ingredients, refuse, and fuel value

Nutrients.

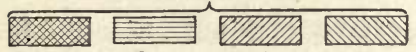

Protein.

Fats.

Carbo-

hydrates.

Non-Nutrients.
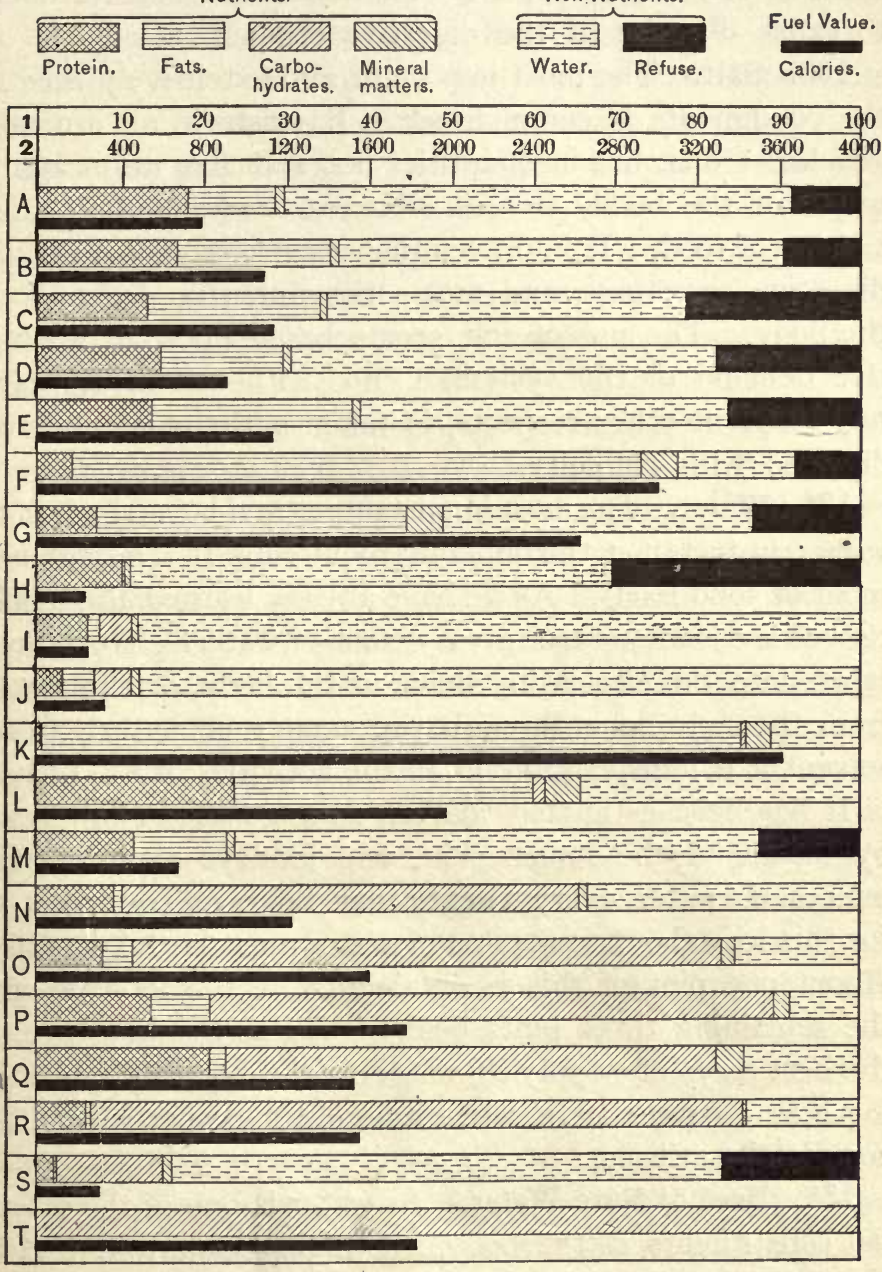

FIG. 44. Graphic Chart of the Composition of Food Materials. 
The more common condiments are salt, vinegar, pepper, ginger, nutmeg, cloves, and various substances containing ethereal oils and aromatics. Their excessive use is likely to cause disorder of the digestive organs.

133. Salt. The most important and extensively used of the condiments is common salt. It exists in all ordinary articles of diet, but in quantities not sufficient to meet the wants of the bodily tissues. Hence it is added to most articles of food. It improves their flavor, promotes certain digestive secretions, and meets the nutritive demands of the body. The use of salt seems based upon an instinctive demand of the system. Food without salt, however nutritious in other respects, is taken with reluctance and digested with difficulty.

134. Water. The most important natural beverage is pure water ; in fact, it is the only one required. It is a large element of solid foods. As we have already learned, the bodily tissues are made up to a great extent of water. Everything taken into the circulating fluids of the body, or eliminated from them, is done through the agency of water. As a solvent it is indispensable in all the activities of the body.

It has been estimated that an average-sized adult loses by means of the lungs, skin, and kidneys about eighty ounces of water every twenty-four hours. To make up for this loss about four pints of water must be taken daily. About one pint of this is obtained from the food we eat, the remaining three pints being taken as drink. One of the best ways of supplying water to the body is by drinking it in its pure state, when its solvent properties can be completely utilized.

135. Need of Pure Water. As water is one of the essential constituents of the body, it is highly important that it should be free from harmful impurities. If it contain the 
germs of disease, sickness may follow its use. Without doubt the most important factor in the spread of disease is, with the exception of impure air, impure water. It is the chief agent in the spread of typhoid fever. The evidence is likewise overwhelming that filthy water is an all-powerful agent in the spread of that terrible disease cholera.

136. Tea and Coffee. It has been estimated that onehalf of the human race now use tea, either habitually or occasionally. Its immoderate use is a prolific source of indigestion, palpitation of the heart, persistent wakefulness, and of other disorders. Persons who cannot use it without feeling its hurtful effects should leave it alone. It should not.be taken on an empty stomach, nor sipped after every mouthful of food.

Coffee often disturbs the rhythm of the heart and causes palpitation. Taken at night it often causes wakefulness. This effect is so well known that it is often employed to prevent sleep. Immoderate use of strong coffee may produce other harmful effects, such as muscular tremors, sick headache, palpitation, and various uncomfortable feelings in the cardiac region. Some persons cannot drink even a small amount of tea or coffee without these unpleasant effects. These beverages are unsuitable for young people.

137. Cooking. The art of cooking plays a very important part in the matter of health, and thus of comfort and happiness. Badly cooked and ill-assorted foods are often the cause of serious digestive disorders. Mere cooking is not enough, but good cooking is essential. Cooking enables food to be more readily chewed and more easily digested. Thus, a piece of meat when raw is tough and tenacious, but if cooked it loses much of its toughness, because the connective tissues are changed into a soft and jelly-like mass. Besides, the meat is more readily acted upon by the 
digestive fluids. Cooking also makes vegetables and cereals softer and enables the digestive juices readily to penetrate their substance.

Cooking improves or develops flavors in food (especially in animal foods), which tend to stimulate the appetite and the flow of digestive fluids.

Another important use of cooking is that it kills any minute parasites or germs in the raw food. The safeguard of cooking thus effectually removes some important causes of disease.

\section{ALCOHOL AND ALCOHOLIC BEVERAGES}

138. Alcoholic Beverages. There is a class of liquids so commonly and so widely used as beverages, and their effect upon the physical life is so far-reaching, so characteristic, and so dangerous, that their consideration demands special treatment in this chapter. We refer to alcoholic beverages, which on account of their great variety, their remarkable and widespread use, and their subtle and deleterious effects upon the bodily life, should enlist our earnest attention.

139. Properties of Alcohol. Alcohol is formed out of sugar by the process of fermentation. Sugar and alcohol, and many other substances of widely different natures, are built up of the same elements (carbon, hydrogen, and oxygen), but in varying proportions. For example, common or ethyl alcohol differs in chemical composition from fusel oil, one of the most poisonous of the alcohol series, only in the proportion of the same elements. Fermentation changes the combination of the elements composing sugar in such a way as to produce two very different compounds, alcohol and carbon dioxide. 
140. Nature of Fermentation. The ceaseless action of minute forms of plant life in bringing about the decomposition of the elaborated products of organized animal or vegetable structures is described in Chapter XIII.

All such work of vegetable organisms, whether going on in moulding cheese, in souring milk, in putrefying meat, in rotting fruit, or in decomposing fruit juice, is essentially one of fermentation. There are many kinds of fermentation, each produced by some special form of minute plant or micro-organism.

141. Alcoholic Fermentation. Let us now briefly turn our attention to that fermentation which results from the decomposition of sweet fruit, or other vegetable juices, which are composed largely of water, containing sugar and flavoring matters.

This special form of fermentation is known as alcoholic or vinous fermentation, and the minute germs, or microorganisms, that cause it are familiarly termed "alcoholic ferments." There are several varieties of these germs, classed by scientists as saccharomycetes, which are found on the surfaces and stems of fruit as it is ripening.

While the juice is in the fruit the conditions are less favorable for the work of the alcoholic ferments than for that of moulds. ${ }^{1}$ Hence fruit rots as a result of the work of moulds, which, growing within and upon it, cause its decomposition.

1 The work of some kinds of moulds may be apparent to the eye, as in the growths that form on old leather and stale bread and cheese. That of others goes on unseen, as when acids are formed in stewed fruits. Concerning the work of the different kinds of moulds, Troussart says: "Mucor mucedo devours our preserves; Ascophora mucedo turns our bread mouldy; Molinia is nourished at the expense of our fruits; and Chatomium chartatum develops itself in books and on their bindings, when they come in contact with a damp wall." - TroussarT's Microbes, Ferments, and Moulds. 
But when fruit is crushed and its juice pressed out, the minute germs, or micro-organisms, are carried into it, where they absorb the sugar, which is for them as well as for man a source of energy. By so doing they cause a breaking up of the sugar and a rearrangement of its atoms.

Two new substances result from this decomposition of sugar ; viz., carbon dioxide, which escapes as bubbles of gas into the surrounding air, and alcohol, which remains in the fluid. Now we must remember that fermentation entirely changes the nature of the substance fermented. This law holds good for all forms of decomposition. Before alcoholic fermentation the fruit juice was wholesome and beneficial; after fermentation it contains a liquid commonly known as alcohol, which changes the previously wholesome fruit juice into an intoxicating beverage.

Experiment 29. To illustrate yeast fermentation. Dissolve onefourth of a compressed yeast cake in half a cup of warm water; stir well. Now add two tablespoonfuls of molasses to a pint of warm water. Pour the first mixture into the second and shake well. Place mixture in a wide-mouthed, loosely stoppered quart bottle or quart glass. Note color of the mixture, its taste and smell.

Place the mixture on shelf near the kitchen fire or in any place where temperature is from $70^{\circ}$ to $95^{\circ} \mathrm{Fahr}$. After several hours, watch for evidence that the yeast is "working." Note the bubbles rising through the liquid, due to the splitting up of the sugar into carbon dioxide and alcohol. The alcohol formed by the yeast can be separated by distillation.

Experiment 30. After the mixture is "working," shake and pour a little into a bottle and place it in the ice chest or in ice water for an hour. Note the effect on the "working."

142. The more Common Fermented Beverages. Taking advantage of the great law of fermentation which dominates the realm of nature, man has devised means to manufacture various alcoholic beverages from a great variety of vegetable 
substances, as ripe grapes, pears, apples, and other fruits, cane juices, corn, the malt of barley, rye, wheat, and other cereals.

The process differs according to the substance used and the manner in which it is treated, but the ultimate outcome is always the same, viz., the production of a beverage containing a greater or less proportion of alcohol.

The more common alcoholic beverages produced by vinous fermentation are beer, wine, and cider.

The use of these drinks costs the world every year thousands of valuable lives and an inestimable loss of physical and mental working ability, besides a vast amount of crime and immorality. It is the nature of the álcohol which these drinks contain to create an increasing appetite for more alcohol, and to weaken the self-control necessary for resisting the appetite.

143. Distilled Liquors. When any kind of fermented liquor is heated, the vapor which first comes off contains much of the alcohol. Now if this alcoholic vapor be collected and cooled it takes the form of a much stronger liquid alcohol.

This process is known as distillation, and the product is called distilled liquor.

The more common distilled liquors are brandy, rum, whisky, and gin ; they are more harmful and dangerous than beer, wine, and cider, because they contain more alcohol.

144. The Effects of Small Quantities of Alcohol. Careful experiments show that the greater part of the alcohol of ordinary beverages, when used in small or moderate quantities, is burnt up or oxidized within the body. A small per cent of this alcohol may, however, be excreted unchanged in the breath and from the kidneys. Observations show that alcohol thus oxidized yields a certain amount of heat energy, 
as the oxidation of starch and sugar in the body yields energy; but the result to the body is quite different from that of the oxidation of foods. The energy yielded by foods makes the body warmer, while that gained from alcohol may be more than counterbalanced by the greater loss of heat resulting from the dilatation of the cutaneous blood vessels from the effect of the alcohol upon the nerves in the skin.

In brief, the oxidation of ordinary food makes the body better able to work and keep warm; the oxidation of alcohol makes the body less able to work and keep warm. Repeated test experiments have shown that alcohol decreases the amount of muscular work and lowers the quality of mental work done within the period of its influence. Its action is, therefore, antagonistic to the true purpose of food, while it is in harmony with the action of poisons.

145. Alcohol not a Food. Because alcohol in small quantities is oxidized within the body and supplies energy, it by no means follows that it is a food in the ordinarily accepted sense in which the word "food" is used. Under these conditions many harmful substances, as ether, chloroform, and morphine, would be classed as foods, for they are oxidized within the body and furnish a certain amount of energy. From a purely scientific and technical point of view alcohol may, therefore, liberate its energy within the body; but as this is at the expense of other essential requirements of a food, there are clearly no logical grounds for calling it a food in the ordinary and accepted meaning of the term. An actor is not a king because for a brief hour he walks the stage in royal dress and speaks majestic words.

Definitions of the word "food" are not always expressed in the same terms, but all definitions substantially accepted 
by the scientific world assume that a food, when properly taken, serves to build up and repair the body and to supply it with energy for its warmth and work, without injury to the tissues.

Until it is proved that the sum total of the effect of ingested alcohol is useful rather than harmful to the maintenance of the animal economy, it seems more logical, certainly less misleading, to accept the classification of standard authorities and class alcohol as a powerful drug, - a narcotic poison rather than a food.

In fact, when we stop to think of the possibilities involved in the ingestion of even a very small quantity of alcohol, the idea of calling it a food appears like a contradiction of terms.

146. Alcohol as a Poison. Alcohol, the product of vinous fermentation, the deleterious element, the "toxin," of minute germs known as the saccharomycetes, is a poison. The chief toxic element in all kinds of alcoholic liquors is ethylic or ordinary alcohol, although amylic alcohol, or "fusel oil," is found in raw whisky.

Ethylic alcohol is a distinct substance of definite chemical composition and affinities, and as a poison is second to none in its subtle and profound effect upon the bodily tissues. The chemical nature of ethylic alcohol cannot be lost in the smallest quantity, but must in every qualitative analysis remain the same, so long as by progressive division its substance as such still exists, even down to the last molecule.

In brief, let us then remember that alcohol acts as a true poison, whether we breathe in its vapor, swallow the liquid in dilute form, or have it injected into the cellular tissue by means of a hypodermic needle. It does not alter the inherent poisonous property of alcohol because when taken 
in small quantities or in dilute forms its deleterious effects upon the bodily life may not for a time be obvious. ${ }^{1}$ Arsenic and lead are no less poisons because it may take many days before their toxic effects upon the tissues are clearly exhibited.

\section{ADDITIONAL EXPERIMENTS}

Experiment 3r. As a type of the group of proteids we take the white of egg, - egg-white or egg albumin. Break an egg carefully, so as not to mix the white with the yolk. Drop about half a teaspoonful of the raw white of egg into half a pint of distilled water. Beat the mixture vigorously with a glass rod until it froths freely. Filter through several folds of muslin until a fairly clear solution is obtained.

Experiment 32. To a small quantity of this solution in a test tube add strong nitric acid; and boil. Note the formation of a white precipitate, which turns yellow. After cooling, add ammonia, and note that the precipitate becomes orange.

Experiment 33. Add to the solution of egg albumin excess of strong solution of caustic soda (or potash), and then a drop or two of very dilute solution (I per cent) of copper sulphate. A violet color is obtained, which deepens on boiling.

Experiment 34. Boil a small portion of the albumin solution in a test tube, adding drop by drop dilute acetic acid ( 2 per cent) until a flaky coagulum of insoluble albumin separates.

1 Alcohol is a poison. So is strychnine; so is arsenic; so is opium. It ranks with these agents. Health is always in some way or other injured by it; benefited by it - never. - SIR ANDREW CLARK, M.D., one of the most eminent physicians of our day.

Alcohol, even when diluted, as in wine, beer, and cider, is a poison which changes pathologically the tissues of the body and leads to fatty degeneration. - DR. August Forel, formerly Professor of Psychiatry in the University of Zurich.

A very large number of people are dying day by day, poisoned by alcohol, but not supposed to be poisoned by it. - SiR WILliam Gull, M.D., F.R.S., Consulting Physician to Guy's Hospital, London. 
Experiment 35. Moisten some flour with water until it forms a tough, tenacious dough; tie it in a piece of cotton cloth, and knead it in a vessel containing water until all the starch is separated. There remains on the cloth a grayish white, sticky, elastic "gluten," made up of albumin, some of the ash, and fats. Draw out some of the gluten into threads and observe its tenacious character.

Experiment 36. Use fresh cow's milk. Examine the naked-eye character of the milk. Test its reaction with litmus paper. It is usually neutral or slightly alkaline.

Experiment 37. Examine with the microscope a drop of milk, noting numerous small, highly refractive oil globules floating in a fluid.

Experiment 38. Take one or two teaspoonfuls of fresh milk in a test tube; heat it until it is lukewarm, and add a small quantity of liquid rennet. Note that the whole mass curdles in a few minutes, so that the tube can be inverted without the curd falling out. Soon the curd shrinks and squeezes out a clear, slightly yellowish fluid, the whey.

Experiment 39. Place some Fehling's solution (which can be obtained readily at the drug store, or tablets may be bought which answer the same purpose) in a test tube, and boil. If no yellow discoloration takes place, it is in good condition. Add a few drops of grape or milk sugar solution and boil, when the mixture suddenly turns to an opaque yellow or red color.

Experiment 40. Mix an even teaspoonful of wheat flour, Indian meal, oatmeal, or rye meal with an equal volume of ether. ${ }^{1}$ Stir carefully and filter mixture after it has stood for fifteen minutes to get rid of the ether odor. Evaporate some of the filtrate on a watch glass. A greasy residue is left, which may be shown by rubbing it on a piece of tissue or rice paper.

1 Benzine may be used instead of ether, as it is much cheaper and more readily obtained. As its vapor, as well as that of ether, is highly inflammable, the greatest caution must be exercised not to handle it near a flame or a hot stove. 


\section{CHAPTER VI}

\section{THE DIGESTION OF FOOD}

× 147. How Waste is made good by Food. As we have learned in a previous chapter, our bodies are subject to continual waste, which occurs in no one part alone, but in all the tissues.

Now the liquid part of the blood comes into direct contact with every one of these tissues, the ultimate cells of which are constantly being bathed by this nutritive fluid, which brings to them the material needed for their renewal. These cells are able to select from the fluid of the blood whatever they require to repair their waste and to provide for their renewed activity.

To keep the blood from becoming impoverished the materials which it is constantly losing must be supplied from some source outside of the body. This necessitates the ingestion of articles which are known as food.

The most important and complicated process by which food is made ready to pass into the blood is known as digestion, and the organs concerned in bringing about this marvelous change in the food are the digestive organs.

148. The Digestive Organs in General. The digestive apparatus of the human body consists of the alimentary canal and tributary organs which, although outside of this canal, communicate with it by ducts.

The alimentary canal consists of the mouth, the pharynx. the œsophagus, the stomach, and the intestines. 


\section{The Digestion of Food}

Other digestive organs which are tributary to this canal, and discharge their secretions into it, are the salivary glands, ${ }^{1}$ the liver, and the pancreas.

The digestive process may be subdivided into three steps, which take place respectively in the mouth, in the stomach, and in the intestines.

149. The Mouth. The mouth is the cavity formed by the lips, the cheeks, the palate, and the tongue. Its bony roof is made up of the upper jawbone on each side in front, and of the palate bones behind. This is the hard palate.

The mouth continues behind into the throat, the separation between the two being marked by fleshy pillars which arch up from the sides to form the soft palate. In the middle of this arch there hangs from its free edge a little lobe called the uvula (Figs. 45 and $5 \mathrm{I}$ ).

On each side where the pillars begin to arch is an almond-shaped body known as the tonsil. When we take cold one or both of the tonsils may become inflamed, and so swollen as to obstruct the passage into the throat.

150. Mastication, or Chewing. The first step in the process of digestion is chewing, or mastication, the cutting and grinding of the food by the teeth. While the food is

1 Glands. Glands are organs of various shapes and sizes, whose special work it is to separate materials from the blood for further use in the body, the processes being known as secretion and excretion. The means by which secretion and excretion are effected are, however, identical.

The essential parts of a gland are a basement membrane, on one side of which are found the secreting cells, on the other the blood current, flowing in exceedingly thin-walled vessels known as the capillaries. The cells are able to select from the blood whatever material they require, which they elaborate into their particular secretion.

In Fig. 47 is illustrated, diagrammatically, the structure of a few typical secreting glands. The continuous line represents the basement membrane. The dotted line represents the position of the cells on one side of the basement membrane. The irregular lines show the position of the blood vessels. 
thus being crushed it is moved to and fro by the varied movements of the tongue, so that every part of it may be mixed with saliva.

151. The Teeth. The teeth are attached to the upper and lower maxillary bones by roots contained in sockets in the

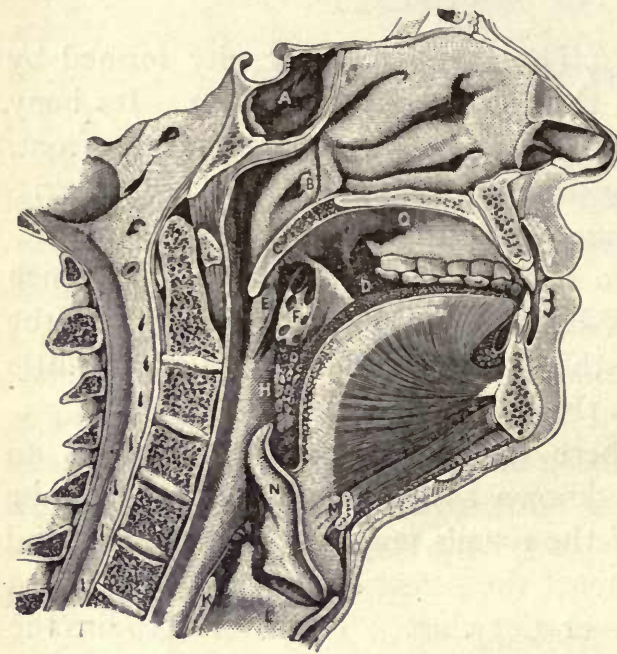

FIg. 45. Cavities of the Mouth, Pharynx, etc.

(Section in the middle line designed to show the mouth in its relations to the nasal fossæ, the pharynx, and the larynx.)

$A$, sphenoidal sinus ; $B$, internal orifice of Eustachian tube; $C$, velum palati; $D$, anterior pillar of soft palate; $E$, posterior pillar of soft palate; $F$, tonsil ; $H$, lingual portion of the pharynx ; $K$, lower portion of the pharynx; $L$, larynx; $M$, section of hyoid bone; $N$, epiglottis; $O$, palatine arch. jaws. Each tooth consists of a crown, the visible part, and one or more fangs, buried in the sockets. There are in adults thirty-two teeth, sixteen in each jaw.

Teeth differ in name according to their form and the uses to which they are specially adapted. Thus, at the front of the jaws there are incisors, or cutting teeth, two on each side. The incisors divide the food and are well developed in rodents, as squirrels, rats, and beavers.

Next come the canines, or cuspids, two in each jaw, so called from their resemblance to the teeth of dogs and other flesh-eating animals. The upper two are often called eye teeth, and the lower two, stomach teeth. 


\section{The Digestion of Food}

IOI

Next behind the canines follow, on each side, two bicuspids. The three hindmost teeth in each jaw are the molars, or grinders. The last molars are known as the "wisdom teeth" (Figs. 46 and 5 I).

×152. Development of the Teeth. The teeth just described are the "second," or permanent set, which succeeds the temporary, or milk teeth. The latter are twenty in number, five on each side of each jaw, that is, two incisors, one canine,

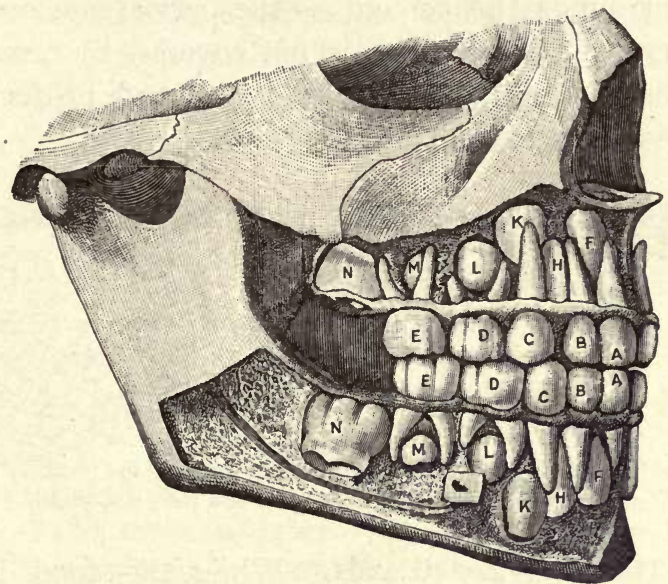

Fig. 46. Temporary and Permanent Teeth together.

Temporary teeth: $A$, central incisors; $B$, lateral incisors ; $C$, canines; $D$, anterior molars; $E$, posterior molars. Permanent teeth: $F$, central incisors; $H$, lateral incisors; $K$, canines ; $L$, first bicuspids ; $M$, second bicuspids; $N$, first molars.

and two molars. The milk teeth appear during the first and second years, and last until about the sixth or seventh year, from which time until the twelfth or thirteenth year they are gradually pushed out, one by one, by the permanent teeth. The roots of the milk teeth are much smaller than those of the second set.

153. Structure of the Teeth. If we should saw a tooth down through its center we should find in the interior 
a cavity. This is the pulp cavity, which is filled with the dental pulp, consisting chiefly of nerves and blood vessels. Irritation of this delicate pulp, due to the decay of the dentine, gives rise to toothache (Fig. 48).

Surrounding the cavity on all sides is the hard substance known as the dentine, or ivory. Outside the dentine of the root is a substance closely resembling bone, called cement. The root is held in its socket by fibrous membrane which surrounds the cement as the periosteum does bone.

The crown of the tooth is not covered by cement, but by the hard enamel, which forms a strong protection for the exposed part.

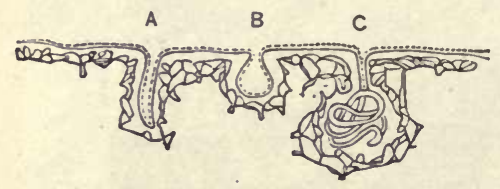

FIG. 47. Diagram of the Structure of Secreting Glands.

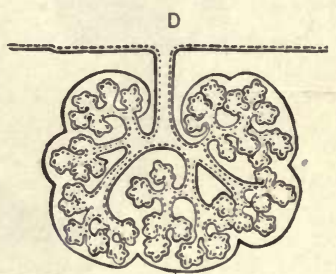

$A$, simple tubular gland; $B$, gland with mouth shut and sac formed; $C$, gland with a coiled tube; $D$, plan of part of a racemose gland.

154. The Salivary Glands. While the food is being chewed it is moistened with a fluid called saliva, which flows from six little glands, three on each side of the mouth. The parotid is situated in front of the ear. In the disease known as "mumps," common in childhood, this gland becomes inflamed and swollen. The submaxillary gland is placed on the inner side of the lower jaw ; the sublingual is on the floor of the mouth, between the tongue and the gums. Each gland opens into the mouth by a little duct (Fig. 49).

155. The Saliva. The saliva is a colorless liquid without taste or smell. Its principal constituent, besides water, is a ferment called ptyalin, which has the remarkable 
property of being able to change starch into a form of cane sugar known as maltose.

Thus, while the food is being chewed, another process is going on by which starch is changed into sugar. The saliva moistens the food, thus fitting it for swallowing, and it also aids in speech by keeping the mouth moist.

The activity of the salivary glands is largely regulated by their abundant supply of nerves. Thus, the saliva may flow into the mouth, even at the sight, smell, or thought of food. This is popularly known as "making the mouth water." The flow of saliva may be checked by nervous influences, as sudden terror and undue anxiety.

Experiment 4r. To show the action of saliva on starch. Saliva for experiment may be obtained by chewing a piece of India rubber and collecting the saliva in a test tube. Observe that it is colorless and either transparent or translucent, and when poured from one vessel to another is glairy and more or less adhesive. Its reaction is usually alkaline to litmus paper.

Experiment 42. Make a thin paste from pure starch or arrowroot and boil it for a minute. Dilute a little of the saliva with five volumes of water. Label three test tubes $A, B$, and $C$. In $A$, place starch paste ; in $B$, saliva ; and in $C$, one volume of saliva and three volumes of starch paste. Place them for ten minutes in a water bath at about $104^{\circ} \mathrm{Fahr}$., or in any place where the temperature is about that of the body.

Test portions of all three for sugar, by means of Fehling's solution or tablets. ${ }^{1} A$ and $B$ give no evidence of sugar. $C$ gives a yellow or red deposit of cuprous oxide, thereby proving that starch is thus converted into sugar by the saliva. This is done by the ferment ptyalin contained in saliva.

1 Tablets and other material for Fehling's test and additional tests for sugar can be purchased or ordered at any drug store.

The practical details of these, and other tests which assume some knowledge of chemistry, may be taught orally by the teacher or learned from some manual on the subject. 
156. The Pharynx. The pharynx forms a sac, into which the mouth opens. Just above the mouth are the two posterior passages into the nose. There are also little

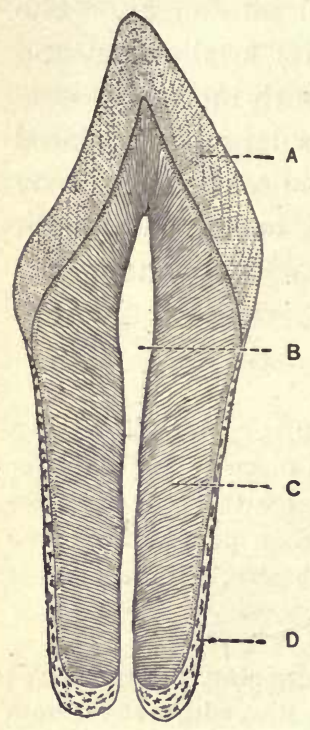

FIG. 48. Longitudinal Section of a Tooth. $A$, enamel; $B$, pulp cavity ; $C$, dentine; $D$, cement. openings, one on each side, from which begin the Eustachian tubes, which lead upward to the cavities in the interior of the ear.

The windpipe opens downward from the pharynx, but this communication can be shut off by a little plate or lid of cartilage, the epiglottis. During the act of swallowing this closes down over the entrance to the windpipe, and the windpipe rises up to meet the lid. This prevents the food from passing into the air passages (Figs. 45 and $5 \mathrm{I}$ ).

Experiment 43. Open the mouth wide; press down the back of the tongue gently with the handle of a teaspoon. With the aid of strong sunlight and a hand mirror the epiglottis may be seen.

$\times$ 157. The Esophagus. The œsophagus, or gullet, is a tube about nine inches long, reaching from the throat to the stomach. It lies behind the windpipe, pierces the diaphragm, which is between the chest and the abdomen, and opens into the stomach. It has in its walls muscular fibers, which, by their wave-like contractions, grasp the successive masses of food as they pass downwards and force them into the stomach.

158. Deglutition, or Swallowing. The food, having been well chewed and mixed with saliva, is now a soft, pasty mass, ready to be swallowed. The tongue gathers it up and 
forces it backwards between the pillars of the fauces into the pharynx. There is only one pathway for the food to travel, and that is down the osophagus.

The slow descent of the food may be seen if a horse or dog be watched while swallowing. Even liquids do not fall or flow down the food passage. Hence it is that acrobats are able to drink while standing on their heads, and that a horse drinks with his mouth below the level of the stomach. The food is under the control of the will until it has entered the pharynx; all the later movements are involuntary.

Experiment 44. Place the fingers on the "Adam's apple." Pretend to swallow something, and you can feel the upper part of the windpipe and get a very fair idea of the action of the epiglottis and the closing of its lid, thus covering the entrance and preventing the passage of food into the windpipe.

\section{The Stomach. The stomach}

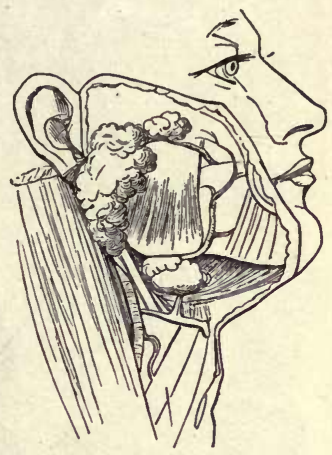
is the most dilated portion of the Fig. 49. Section of Face. alimentary canal and the principal organ of digestion. Its form is not

(Showing the parotid and submaxillary glands.) easily described. It has been compared to a bagpipe, which it resembles somewhat when moderately distended (Fig. 52).

We may describe the stomach as a pear-shaped bag, with a capacity of about four pints. It lies chiefly on the left side of the abdomen, under the diaphragm, and protected by the lower ribs.

The orifice by which the food enters the stomach is called the cardiac opening, because it is near the heart. The opening by which the food leaves the stomach and where the 


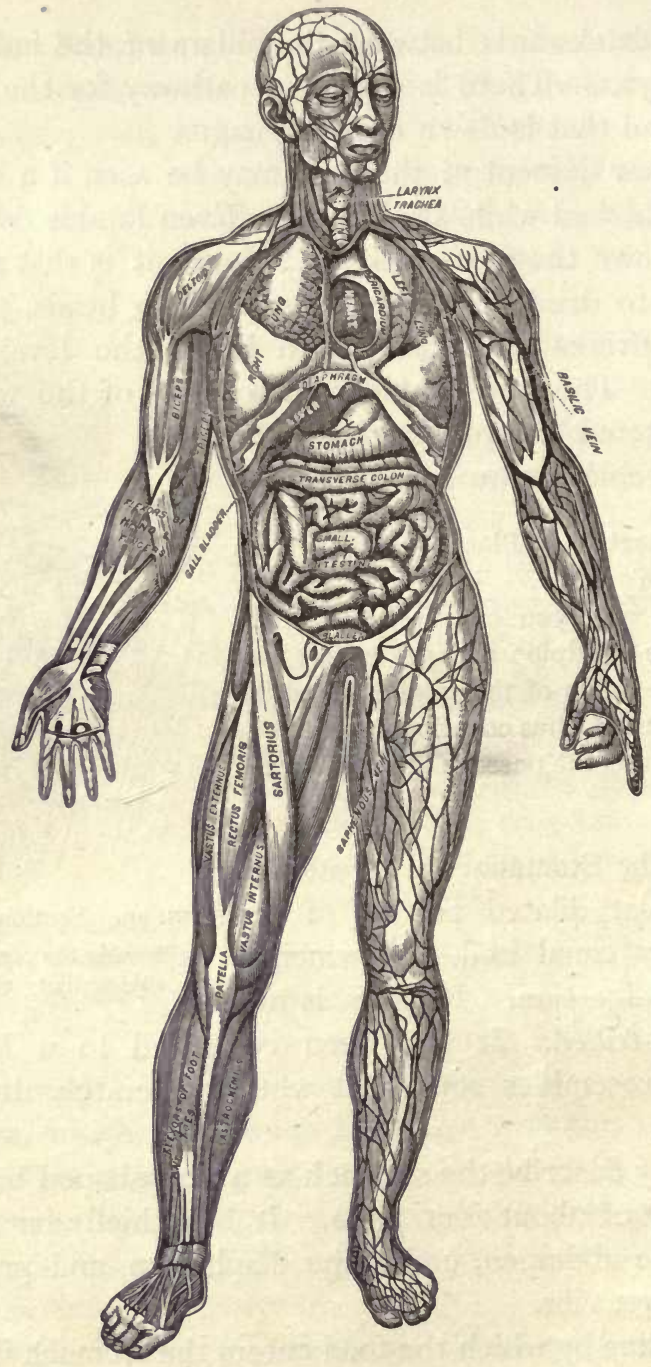

Fig. 50. Showing the Principal Organs of the Thorax and Abdomen in situ.

(The principal muscles are seen on the left, and superficial veins on the right.) 
intestine begins is known as the pyloric orifice. It is guarded by a kind of valve, known as the pylorus, or gatekeeper.

160. Coats of Stomach. The walls of the stomach are formed of four coats, known successively from without as serous, muscular, submucous, and mucous. The outer coat is the serous membrane which lines the abdomen, the peritoneum (sec. I67). The second coat is muscular, having three sets of involuntary muscular fibers. The third coat (submucous) is made up of loose connective tissue. Lastly, the mucous coat, a moist, pink, inelastic membrane, completely lines the stomach. When the stomach is not distended the mucous layer is thrown into folds presenting a corrugated appearance.

\section{y 161. The Gastric Glands.}

If we were to examine with a hand lens the inner surface of the stomach, we should find it covered with little pits, or depressions. These are the openings of the gastric glands (Fig. 53).

Soon after food enters the stomach, drops of fluid, known as gastric juice, collect at the mouths of these

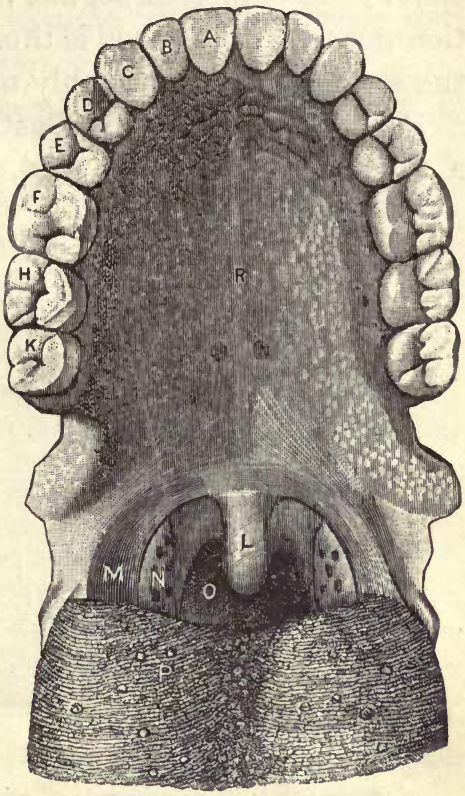

FIg. 51. A View into the Back Part of the Adult Mouth.

(The head is represented as having been thrown back, and the tongue drawn forward.)

$A, B$, incisors; $C$, canine ; $D, E$, bicuspids ; $F, H, K$, molars; $M$, anterior pillar of the fauces; $N$, tonsil; $L$, uvula ; $O$, upper part of the pharynx; $P$, tongue drawn forward; $R$, linear ridge, or raphe.

glands and trickle down its walls to mix with the food and to aid in its digestion. 
162. Digestion in the Stomach. When the food, thoroughly mixed with saliva, has entered the stomach, the cardiac end of that organ is closed, as well as the pyloric valve, and the muscular walls contract on the contents. A spiral wave of motion begins, becoming more rapid as digestion goes on. The food is thus constantly churned about in the stomach and thoroughly mixed with the gastric juice.

163. The Action of the Gastric Juice. The gastric juice is a thin, almost colorless fluid, with a sour taste and odor.

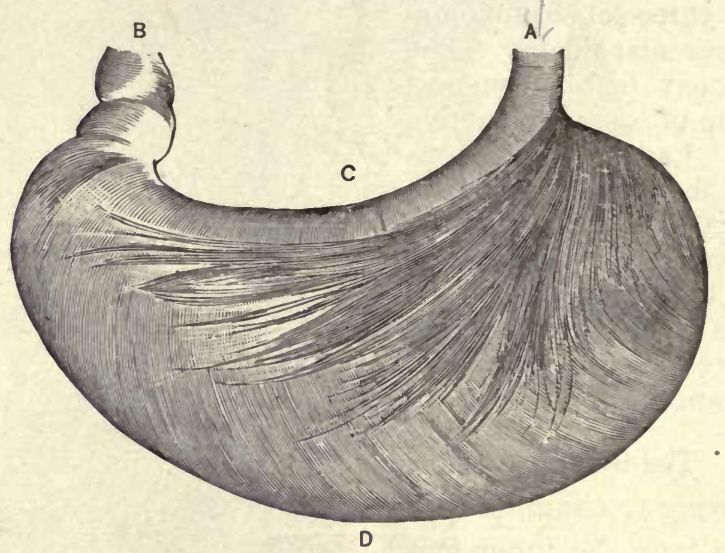

FIG. 52. The Stomach.

$A$, cardiac end; $B$, pyloric end; $C$, lesser curvature; $D$, greater curvature.

Its reaction is distinctly acid. Its chief constituents are two ferments called pepsin and rennin, free hydrochloric acid, mineral salts, and 95 per cent of water.

Pepsin, the most important constituent of the gastric juice, has the power of dissolving the proteid foodstuffs, converting some into what are called peptones, which are both soluble and capable of filtering through membranes.

Pepsin can do this only in the presence of an acid. Hence the importance of the hydrochloric acid of the gastric juice. 
The gastric juice has no action on starchy foods, neither does it act on fats, except to dissolve the albuminous walls of the fat cells. The fat itself is thus set free in the form of minute globules.

y 164. Passage of the Food into the Intestines. The contents of the stomach now assume the appearance and the consistency of a thick soup, usually of a grayish color, known as chyme.

After a variable time, from one to four hours, the chyme begins to move on in successive portions into the next part of the alimentary canal. The ring-like muscles of the pylorus relax at intervals to allow the muscles of the stomach to force the partly digested mass into the small intestines. This action is frequently repeated, until even

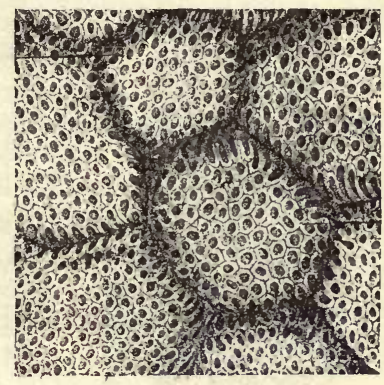

FIG. 53. Pits in the Mucous Membrane of the Stomach, and Openings of the Gastric Glands.

(Magnified 20 diameters.) the indigestible masses which the gastric juice cannot break down are crowded out of the stomach into the intestines. From three to four hours after a meal the stomach is again quite emptied.

A certain amount of this semiliquid mass, especially the peptones, is at once absorbed, making its way through the delicate vessels of the stomach into the blood current. × 165. The Small Intestine. At the pyloric end of the stomach the alimentary canal becomes again a slender tube, about twenty feet long, called the small intestine. It is divided, for convenience of description, into three parts.

The first part is called the duodenum, because it is about twelve fingers' breadth long, that is, about eight inches. 
Into this portion opens the bile duct from the liver and the duct from the pancreas, which first unite and then enter

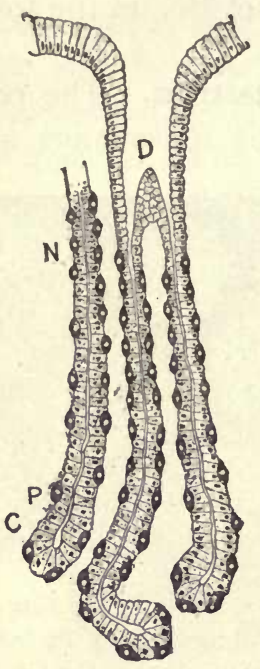

FIG. 54.

(A highly magnified view of a peptic or gastric gland, which is represented as giving off branches. It shows the columnar epithelium of the surface dipping down into the duct $D$ of the gland, from which two tubes branch off. Each tube is lined with columnar epithelial cells, and there is a minute central passage with the "neck" at $N$. Here and there are seen other special cells, called parietal cells, $P$, which are supposed to produce the acid of the gastric juice. The principal cells are represented at $C$.) the intestine as a common duct.

The next portion of the intestine is called the jejunum, because it is usually empty after death.

The remaining portion, known as the ileum, terminates in the right iliac region, and opens into the large intestine. This opening is guarded by the ileo-cæcal valve, a kind of movable partition provided with a button-hole slit. This valve permits the passage of material from the small to the large intestine, but prevents its backward movement.

Experiment 45. To show that pepsin and acid are necessary for gastric digestion. Take three beakers, or large test tubes; label them $A, B, C$. Put into $A$ water and a few grains of powdered pepsin. Fill $B$ two-thirds full of dilute hydrochloric acid (one teaspoonful to a pint), and fill $C$ two-thirds full of dilute hydrochloric acid and a few grains of pepsin. Put into each a small quantity of well-washed fibrin, and place them all in a water bath at $104^{\circ} \mathrm{Fahr}$. for half an hour, or in any other warm place.

Examine them. In $A$, the fibrin is unchanged; in $B$, the fibrin is clear and swollen up; in $C$, it has disappeared, having first become swollen and clear, and completely dissolved, being finally converted into peptones. Therefore, both acid and ferment are required for gastric digestion. 
166. The Coats of the Small Intestine. Like the stomach, the small intestine has four coats, the serous, muscular, submucous, and mucous. The serous is the peritoneum. By the contraction of the muscular coat the food is forced along the bowel. The blood vessels and nerves are distributed in the submucous coat. The inner, or mucous surface, has a fine, velvety feeling, due to a countless number of tiny, thread-like projections called villi. They stand up somewhat like the "pile" on velvet. It is through these villi that the digested food passes into the blood.

The inner coat of a large part of the small intestine is thrown into numerous transverse folds called valvula conniventes. These serve to increase the extent of the surface of the bowels and to delay mechanically the progress of the intestinal contents.

167. The Peritoneum. The intestines do not lie in a loose mass in the abdominal cavity. Lining the walls of this cavity, just as in a general way a paper lines the walls of a room, is a delicate serous membrane called the peritoneum. It envelops, in a greater or less degree, most of the viscera in the cavity, and forms folds by which they are connected with one another, or are attached to the posterior wall. Its arrangement is therefore very complicated. When the peritoneum comes in contact with the large intestine, it passes over it just as the paper of a room would pass over a gas

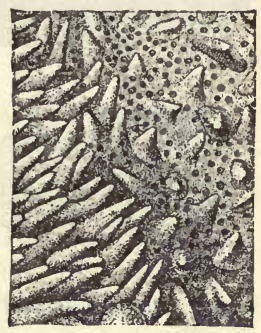

FIG. 55. A Small Portion of the Mucous Membrane of the Small Intestine.

(Villi are seen surrounded with the openings of the tubular glands. Magnified 20 diameters.) pipe which ran along the surface of the wall, and in passing over it binds it down to the wall of the cavity.

The small intestines are suspended from the back wall of the abdomen by a double fold of the peritoneum, called the mesentery. The bowels are also protected from external cold by several folds of this membrane loaded with fat. This is known as the great omentum.

4 168. The Large Intestine. The large intestine begins in the right iliac region and is about five or six feet long. It is much wider than the small intestine, which opens into 
the side of the large intestine a short distance beyond the beginning of the latter. A blind pouch, or dilated pocket, is thus formed at the place of junction, called the cæcum.

The large intestine passes upwards on the right side as the ascending colon, until the underside of the liver is
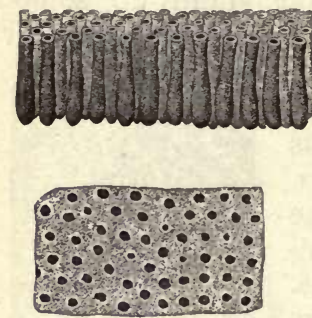

Fig. 56. Sectional View of Intestinal Villi.

(Black dots represent the glandular openings.) reached, where it passes to the left side as the transverse colon, below the stomach. It there turns downward as the descending colon, and making an S-shaped curve, the sigmoid flexure, ends in the rectum.

169. The Vermiform Appendix. Attached to the cæcum, and completing its blind end, is a worm-shaped tube, about the thickness of a lead pencil, and from three to four inches long, called the vermiform appendix. It is of no use in man, but in many of the lower animals it is much larger, and serves as an important digestive pouch. This tube is of great surgical importance, from the fact that it is subject to severe inflammation, often resulting in an internal abscess, which is always dangerous and may prove fatal.

Inflammation of the appendix is known as appendicitis, - a name quite familiar on account of the many surgical operations performed of late years for its relief.

+170. The Liver. The liver is a large, reddish-brown organ, situated just below the diaphragm and on the right side. It is the largest gland in the body and weighs from fifty to sixty ounces.

The liver is almost wholly covered by the ribs. In tight lacing it is often forced downward, out from the cover of the ribs, and thus becomes permanently displaced. As a result, other organs in the upper abdomen and pelvis are crowded together and also become displaced and distorted. 
171. The Hepatic Lobules. When a small piece of the liver is examined under a microscope it is found to be made up of masses of many-sided minute bodies, each about $\frac{1}{1200}$ of an inch in diameter, called hepatic or liver cells. The active work of the liver is done in the hepatic cells.

Each group of cells is called a lobule, and they give to the liver its coarse granular appearance when torn across. Each lobule is attached to a branch of the hepatic vein, the large vein which carries the blood away from the liver. The lobules are polyhedral in shape, with their cells arranged in rows, radiating from the center to the circumference. Minute channels separate the cells one from another and unite in a main duct leading from the lobule.

$x$ 172. The Portal Vein. There is a large vessel, called the portal vein, which during digestion brings to the liver blood heavily laden with the products of digestion, absorbed from the stomach and intestines. On entering the liver this great vein conducts itself as if it were an artery. It divides and subdivides into smaller and smaller branches, until it ends in a network of capillaries within that grgan.

173. The Bile. We have in the liver, on a grand scale,

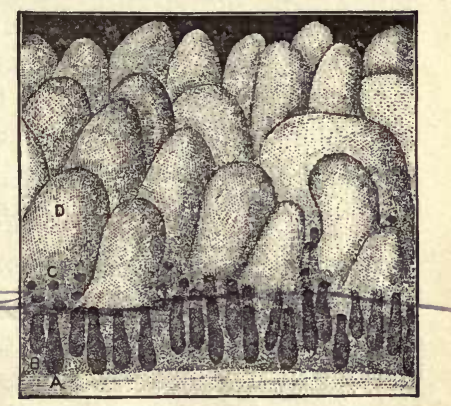

FIG. 57. Tubular Glands of the Small Intestines.

$A, B$, tubular glands seen in vertical section with their orifices at $C$ opening upon the membrane between the villi ; $D$, villus. (Magnified 40 diameters.) exactly the same conditions that obtain in the smaller and simpler glands. The thin-walled liver cells take from the blood brought to them by the portal vein certain materials 
which they elaborate into an important digestive fluid called the bile. ${ }^{1}$

This newly manufactured fluid is then carried away from the liver in little canals, called bile ducts, which gradually unite and form at last one main duct, known as the hepatic duct. It passes out on the underside of the liver, and as it approaches the intestine it meets at an acute angle the cystic duct proceeding from the gall bladder and forms with it the common bile duct, which opens obliquely into the horseshoe bend of the duodenum.

The cystic duct leads back to the under surface of the liver, where it expands into a sac capable of holding about two ounces of fluid, known as the gall bladder (Fig. 58).

Experiment 46. To show the action of bile. Obtain from the butcher some ox bile. Note its bitter taste, peculiar odor, and greenish color. It is alkaline or neutral to litmus paper. Pour it from one vessel to another, and note that strings of mucin (from the lining membrane of the gall bladder) connect one vessel with the other. It is best to precipitate the mucin by acetic acid before making experiments, and to dilute the clear liquid with a little distilled water.

Experiment 47. Test for bile pigments. Place a few drops of bile on a white porcelain slab. With a glass rod place a drop or two of strong nitric acid near the drop of bile; bring the acid and bile into contact. Notice the succession of colors, beginning with green, and passing into blue, red, and yellow.

Experiment 48. To show the action of bile on fats. Mix three teaspoonfuls of bile with one-half a teaspoonful of almond oil or sweet oil. Shake well, and keep the tube in a water bath at about $100^{\circ} \mathrm{Fahr}$. A very good emulsion is obtained.

1 The human bile when fresh is generally of a golden-yellow color and of extremely bitter taste. It is slightly alkaline in reaction and contains a great deal of pigment matter. When it has been vomited it is distinctly yellow, because of its action on the gastric juice. About one pint of bile is secreted in twenty-four hours. 
The bile, thus prepared in the depths of the liver by the liver cells, is carried away by the bile ducts, and may pass directly into the intestines to mix with the food. If, however, digestion is not going on, the mouth of the bile duct is closed, and in that case the bile is carried by the cystic duct to the gall bladder. Here it remains until such time as it is needed.

X74. The Blood Supply of the Liver. We must not forget that the liver itself, being a large and important organ, requires the constant nourishment of arterial blood to do its work. This is furnished by the blood brought to it by a great branch direct from the aorta, known as the hepatic artery, minute branches of which, in the form of capillaries, spread themselves around the liver lobules (Fig. 59).

The blood, having done its work and being now laden with impurities, is picked up by minute veinlets, which unite again and again till they at last form one great trunk called the hepatic vein. This carries the impure blood from the liver, and finally empties it into the vena cava inferior, one of the large veins of the body.

After the blood brought by the portal vein to the liver has been robbed of its bile-making materials, and otherwise acted upon, it is collected by the veinlets that surround the lobules and finds its way with other venous blood into the hepatic vein.

In brief, blood is brought to the liver and distributed through its substance by two distinct channels, - the portal vein and the hepatic artery, - but it leaves the liver by one channel, - the hepatic vein.

175. The Highly Important Work done by the Liver. We have thus far studied the liver only as an organ of secretion, the work of which is to elaborate a complex fluid, called bile, for future use in the process of digestion. This is, 
however, only one of its functions, and perhaps not the most important. In fact, the liver has many and complicated tasks to perform, some of which are not fully understood.

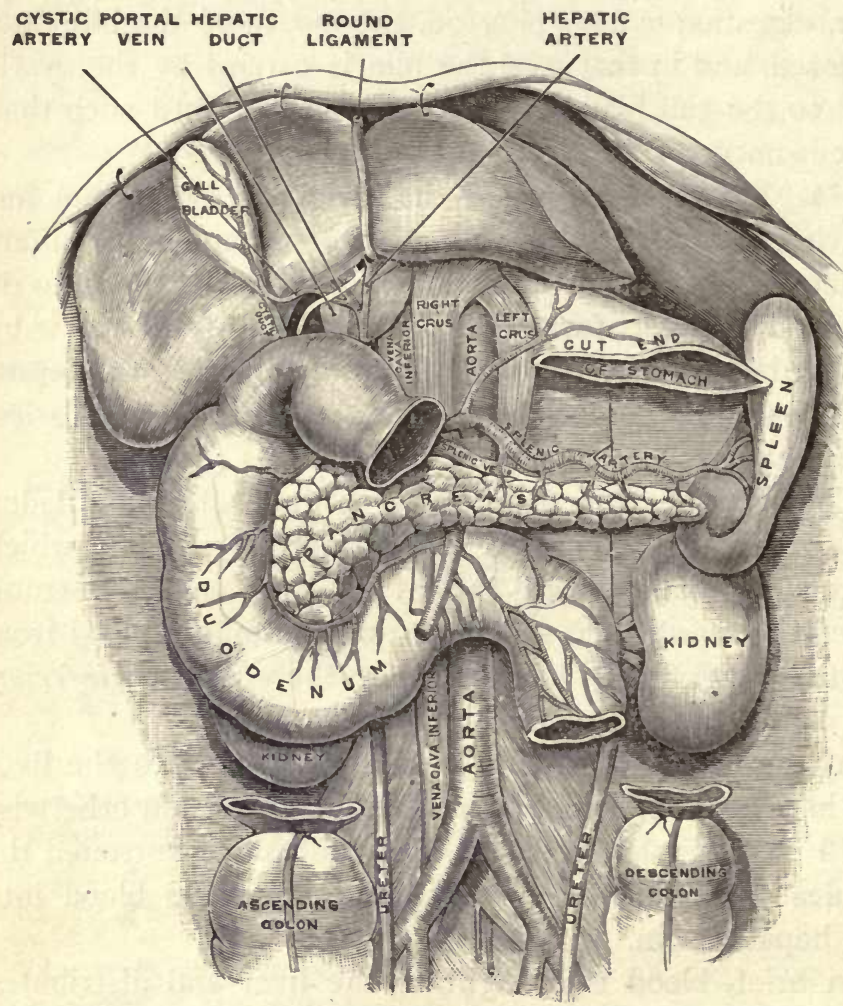

FIG. 58. Showing the Relations of the Duodenum and Other Intestinal Organs.

(A portion of the stomach has been cut away and the liver drawn up.)

The bile is not wholly a digestive fluid, but it contains also materials which are separated from the blood to be cast out of the body before they work mischief. Thus the liver ranks above all others as an organ of excretion; that 
is, it separates from the blood material that is of no further use to the body and casts it out.

Of the various ingredients of the bile, only the bile salts are of use in digestion. When mixed with pancreatic juice they play an important part in aiding the emulsification and saponification of fats and their subsequent absorption.

176. Glycogenic Function of the Liver. The third function of the liver is different from those already described. It is found that the liver of an animal well and regularly fed, when examined soon after death, contains a quantity of a carbohydrate substance not unlike starch. This substance, extracted in the form of a white powder, is really an animal starch. It is called glycogen, or liver sugar, and is easily converted into grape sugar or dextrose.

The hepatic cells appear to manufacture this glycogen and to store it up from the products of digestion brought by the portal blood. It is also thought that the glycogen thus deposited and stored up in the hepatic. cells is little by little changed into sugar. Then, as it is wanted, the liver deals out this stored-up material by carrying it to the tissues, as their needs demand, to supply them. with material which can be oxidized to yield heat and motion.

177. Formation of Urea by the Liver. There is evidence to show that the liver has the power to make urea as well as glycogen. Urea is the nitrogenous waste product which results from the breaking down of proteid. An excess of proteid food is probably broken up in the liver into glycogen and urea. The glycogen is utilized, as we have stated, and the urea is got rid of through the kidneys.

178. The Pancreas. The pancreas, or sweetbread, is a gland from six to eight inches long, weighing from three to four ounces, and is often compared in appearance to a dog's tongue. 
The pancreas lies behind the stomach, across the body, from right to left, with its large head embraced in the horseshoe bend of the duodenum. Its main duct enters the duodenum in company with the common bile duct.

+ 179. The Action of Pancreatic Juice. The pancreas secretes an alkaline digestive fluid called the pancreatic juice. Combined with bile, this fluid acts upon the large drops of fat which pass from the stomach into the duodenum, and either emulsifies or saponifies them. Emulsified fats consist of particles sufficiently minute to permit of their absorption into the blood. Saponification is a chemical change in which the fat is broken up into glycerine and a fatty acid, the latter combining with an alkali to form a soap.

This most important digestive fluid also produces on starch an action similar to that of saliva, but much more powerful. During its short stay in the mouth, very little starch is changed into sugar, and in the stomach the action of the saliva is soon arrested. Now, the pancreatic juice takes up the work in the small intestine and changes the greater part of the starch into sugar. Nor is this all, for it also acts powerfully upon the proteids not acted upon in the stomach, and changes them into peptones that do not differ materially from those resulting from gastric digestion.

The pancreatic juice is able to assist in digesting all three kinds of foodstuffs because it contains three ferments: trypsin, acting on proteids; amylopsin, acting on starches; and steapsin, acting on fats.

+180. Digestion in the Small Intestines. After digestion in the stomach has been going on for some time, successive portions of the semidigested food begin to pass into the duodenum. The pancreas now takes on new activity, and a copious flow of pancreatic juice is poured along its duct 
into the intestines. As the food is pushed along over the common opening of the bile and pancreatic ducts, a great quantity of bile from the reservoir, the gall bladder, is poured into the intestines. These two digestive fluids are now mixed with the chyme and act upon it in the remarkable manner just described.

Experiment 49. To show the action of pancreatic juice on oils or fats. Put two grains of pancreatin into a test tube. Add half a teaspoonful of warm water, and shake well for a few minutes; then add a tablespoonful of sweet oil ; shake vigorously.

A creamy, opaque mixture of the oil and water, called an emulsion, will result. This will gradually separate upon standing, the pancreatic extract settling in the water at the bottom. When shaken it will again form an emulsion.

Experiment 50. To show the action of pancreatic juice on starch. Put two tablespoonfuls of smooth starch paste into a goblet, and while still so warm as just to be borne by the mouth, stir into it two grains of the extract of pancreas. The starch paste will rapidly become thinner, and gradually change into soluble starch, in a perfectly fluid solution. Within a few minutes some of the starch is converted through intermediary stages into maltose and then into glucose. Use the Fehling test for sugar.

Experiment 5r. To show the action of pancreatic juice on the albuminous ingredients (casein) of milk. Into a half-pint bottle (an infant's nursing bottle will answer and is easily obtained) put two tablespoonfuls of cold water; add one grain of pancreatin, and as much baking soda as can be taken up on the point of a penknife. Shake well, and add four tablespoonfuls of cold, fresh milk. Shake again. Now set the bottle into a basin of hot water (as hot as one can bear the hand in), and let it stand for about forty-five minutes.

While the milk is digesting, take a small quantity of milk in a goblet, and stir in ten drops or more of vinegar. A thick curd of casein will be seen.

Upon applying the same test to the digested milk, no curd will be made. This is because the pancreatic ferment (trypsin) has digested the casein into "peptone," which does not curdle. 
The inner surface of the small intestine also secretes a liquid called intestinal juice, the precise functions of which are not known. The chyme, thus acted upon by the different digestive fluids, resembles a thick cream and is now called chyle. The chyle is thrust along the small intestine by the contractions of its muscular walls.

+ 181. Digestion in the Large Intestines. Digestion does not occur to any great extent in the large intestines. The food enters this portion of the digestive canal through the ileo-crcal valve and travels through it slowly. The remains of the food now become less and less fluid, and consist of undigested matter which has escaped the action of the several digestive juices, or which has withstood their influence. Driven onward by the contractions of the muscular walls, the waste material at last reaches the rectum, from which it is voluntarily expelled from the body.

\section{ABSORPTION}

$x$ 182. Absorption. While food remains within the alimentary canal it is outside of the body, so far as nutrition is concerned. To be of any service the food must be absorbed by the blood.

The efficient agents in absorption are the blood vessels and the lymphatics. The process by which the nutritious material enters the blood is called absorption. It is a process not confined, as we shall see, simply to the alimentary canal, but one that is going on in every tissue. The vessels by which the process of absorption is carried on are called absorbents, or lymphatics.

183. Absorption by the Mouth and Stomach. The lining of the mouth and œsophagus is not well adapted for absorption. That this does occasionally occur, however, 
is shown by the fact that certain poisonous chemicals, like cyanide of potash, if kept in the mouth for a few moments, will cause death. While we are chewing and swallowing our food, no doubt a certain amount of water and common salt, together with sugar which has been changed from starch by the action of the saliva, gains entrance to the blood.

In the stomach, however, absorption takes place with great aetivity. The semiliquid food is separated from the enormous supply of blood vessels in the mucous membrane

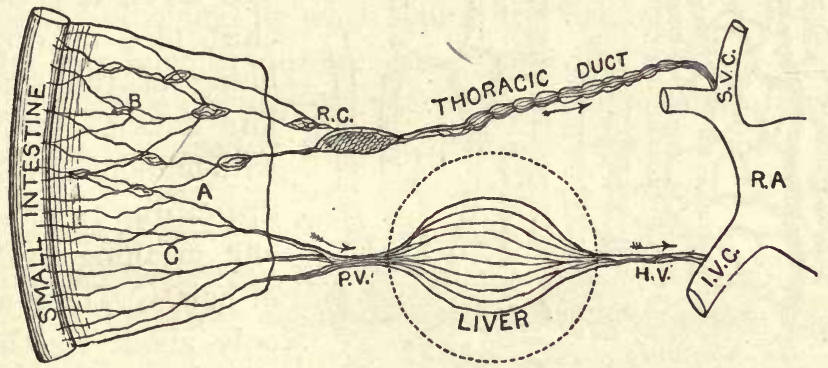

FIG. 59. Diagrammatic Scheme of Intestinal Absorption.

$A$, mesentery; $B$, lacteals and mesentery glands; $C$, veins of intestines; $R$. $C$., receptacle of the chyle (receptaculum chyli) ; $P . V$., portal vein ; $H$. $V$, hepatic veins; $S . V . C$., superior vena cava; $R$. A., right auricle of the heart; I. V.C., inferior vena cava.

only by a thin porous partition. Water, along with any substances in the food that have become dissolved, will pass through this partition and enter the blood current. A certain amount of starch that has been changed into sugar, of salts in solution, of proteids converted into peptones, is also taken up directly by the blood vessels of the stomach.

184. Absorption by the Intestines. The greatest part of absorption is accomplished by the small intestines. They 


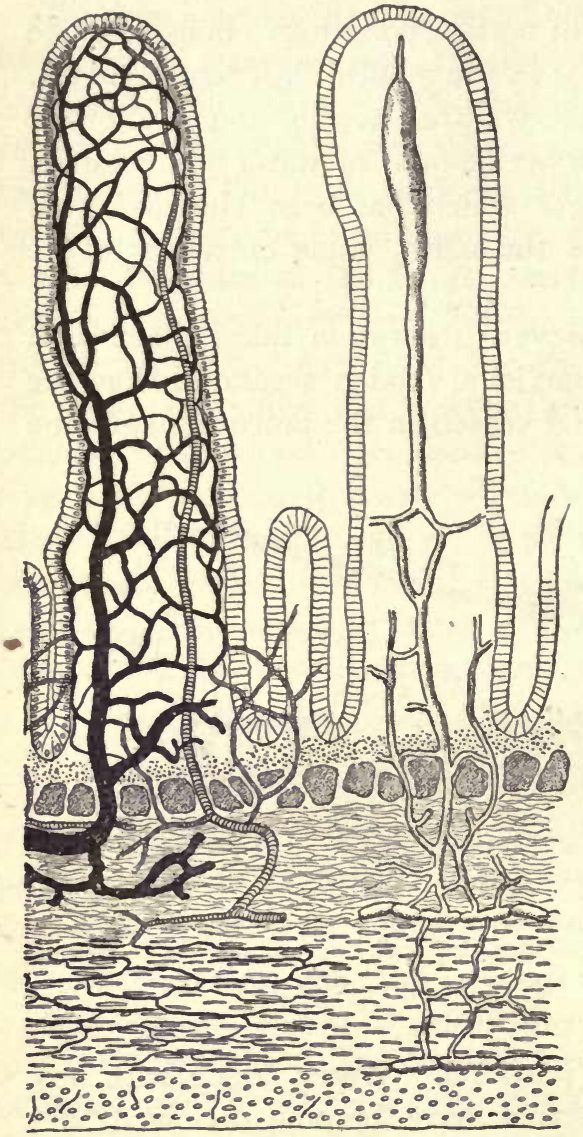

Fig. 60. Diagrammatic Scheme of a Transverse Section of the Small Intestine.

(In the figure on the left are seen the artery and vein of a villus. In the right figure are represented the central chyle vessel of villus, with plexus of lymph vessels at the base. The mucous, submucous, muscular, and serous coats are indicated at the base of the right-hand figure. The epithelium of each villus is well shown.) have not only a very large area of absorbing surface, but also structures especially adapted to do this work. It is a most active and complicated process.

$\times$ 185. The Work done by the Lacteals. We have learned that the mucous lining of the small intestines is crowded with millions of little appendages called villi, meaning "tufts of hair." These are only about one-thirtieth of an inch long, and a dime will cover more than five hundred of them. Each villus contains a loop of blood vessels, and a special kind of lymphatics, called the lacteals, so named from the Latin word lac, because of the milky appearance of the fluid they contain. 
The villi are adapted especially for the absorption of fat. They dip like the tiniest fingers into the chyle, and the minute particles of fat pass through their cellular covering and gain entrance to the lacteals. The milky material sucked up by the lacteals is not in a proper condition to be poured at once into the blood current. It is, as it were, in too crude a state, and needs some special preparation.

186. The Mesenteric Glands. The intestines are suspended from the posterior wall of the abdomen by a double fold of peritoneum, called the mesentery. That is, the intestines are wrapped in a fold of the peritoneum somewhat as one would lie when slung in a hammock.

In this membrane are some one hundred and fifty nodules about the size of an almond, called mesenteric glands. Now the lacteals join these glands and pour in their milky contents which they have just absorbed to undergo some important changes. It is not unlikely that the mesenteric glands may intercept, like a filter, material which, if allowed to enter the blood, would disturb the whole body.

Having been acted upon by the mesenteric glands, and passed through them, the chyle flows onward until it is poured into the sac-like expansion of the lower end of the thoracic duct, known as the receptaculum chyli. Into this receptacle are poured not only the contents of the lacteals, but also of the lymphatic vessels of the lower limbs.

4 187. The Thoracic Duct. This duct is a tube from fifteen to eighteen inches. long, which passes upwards in front of the spine to reach the base of the neck, where it opens at the junction of the great veins on the left side of the head with those of the left arm. Thus the thoracic duct carries the nutritive material obtained from the food and pours it into the blood current. It is to be remembered that the lacteals are lymphatics - lymphatics of the intestines. 
6 188. The Lymphatics. In nearly every tissue of the body there is a marvelous network of vessels, precisely like the lacteals, called the lymphatics. These are busily at work taking up and giving out waste or surplus materials derived from the blood and tissues generally. It is estimated that the quantity of fluid exuded from the blood and picked up by the lymphatics and restored daily to the circulation is equal to the bulk of the blood in the body.

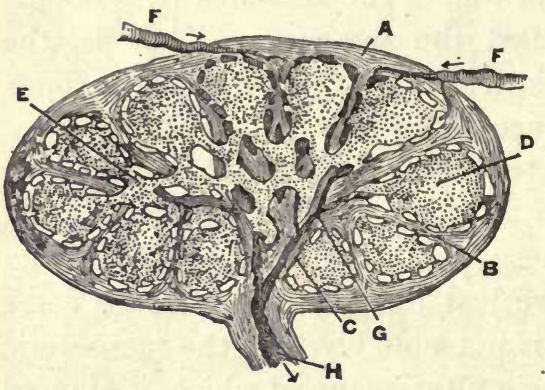

FIG. 6r. Section of a Lymphatic Gland. $A$, strong fibrous capsule sending partitions into the gland; $B$, partitions between the follicles or pouches of the cortical or outer portion; $C$, partitions of the medullary or central portion; $D, E$, masses of protoplasmic matter in the pouches of the gland; $F$, lymph vessels which bring lymph to the gland, passing into its center; $G$, confluence of those leading to the efferent vessel; $H$, vessel which carries the lymph away from the gland.

The minute branches of the lymphatics, or lymph capillaries, seem to start out from the part in which they are found like the rootlets of a plant in the soil. They carry a turbid, slightly yellowish fluid, called lymph, which seems to play the part of a "middleman" between the blood on the one hand and the tissues on the other.

X189. Work done by the Lymphatics. Now, just as the chyle was not fit to be immediately taken up by the blood, but was passed through the mesenteric glands to be properly worked over, so the lymph is carried to small rounded or bean-shaped bodies called lymphatic glands, where it undergoes certain changes to fit it for being poured into the blood. Nature, like a careful housekeeper, allows nothing to be wasted that can be of any service in the body (Figs. 63 and 64). 
The lymphatic vessels gradually unite to form larger vessels and at last join the thoracic duct, except the lymphatics on the right side of the head and neck, on the right arm and the right lung. These open by the right lymphatic duct into the venous system on the right side of the neck.

The whole lymphatic system may be regarded as a necessary appendage to the blood-vascular system (Chapter VII). It is convenient, however, to treat it under the general topic of absorption, in order to complete the history of food digestion.

190. The Spleen and Other Ductless Glands. With the lymphatics may be classified, for convenience, a number of organs called ductless glands, because they have no ducts or canals along which may be carried the result of their work.

The spleen is the largest of these glands. It lies beneath the diaphragm and upon the left side of the stomach. It is of a deep-red color and full of blood.

The functions of the spleen are as yet but little understood. It appears to take some part in the formation of blood corpuscles. In certain diseases, like malarial fever, it may become remarkably enlarged.

The spleen may be removed from man and from animals without any apparent effect.

The thyroid is a ductless gland situated beneath the muscles of the neck on the sides of "Adam's apple" and below it. It undergoes great enlargement in the disease called goitre.

The thymus is also a ductless gland. It is situated around the windpipe, behind the upper part of the breastbone. Until about the end of the second year it increases in size, and then it begins gradually to shrivel away. . Its use is not certainly known.

The suprarenal capsules are two little bodies, one perched on the upper edge of each kidney, in shape not unlike that of a conical hat. Their functions are important, but as yet nothing definite is known about them. 
Experiment 52. Simple apparatus for illustrating endosmotic action." "Remove carefully a circular portion, about an inch in diameter, of the shell from one end of an egg, which may be done without injuring the membranes, by cracking the shell in small pieces,

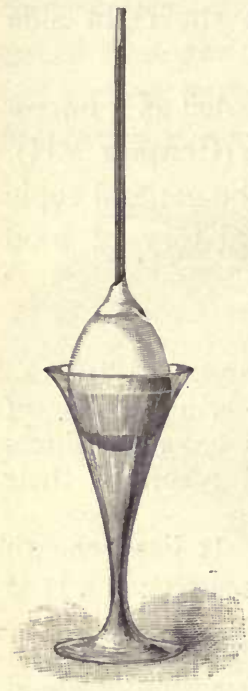

FIG. 62. which are picked off with forceps. A small glass tube is then introduced through an opening in the shell and membranes of the other end of the egg, and is secured in a vertical position by wax or plaster of Paris, the tube penetrating the yolk. The egg is then placed in a wine-glass partly filled with water, as in Fig. 62. In the course of a few minutes the water will have penetrated the exposed membrane, and the yolk will rise in the tube."-FLINT's Human Physiology.

Experiment 53. Stretch a piece of moist bladder across a glass tube, - a common lamp chimney will do. Into this put a strong sugar or saline solution. Now suspend the tube in a wide-mouthed vessel of water. After a short time it will be found that a part of the sugar or salt solution has passed through into the water, while a larger amount of water has passed into the tube and raised the height of the liquid within it.

\section{The Quantity of Food as affected by Circumstances.} The quantity of food required to keep the body in proper condition is modified to a great extent by circumstances.

1 The action produced by the tendency of fluids to mix, or become equally diffused in contact with each other, is known as osmosis, a form of molecular attraction allied to that of adhesion. The various physical processes by which the products of digestion are transferred from the digestive canal to the blood 'may be illustrated in a general way by these simple experiments.

The student must, however, understand that the necessarily crude experiments of the class-room may not conform in certain essentials to those great processes conducted in the living body, which they are intended to illustrate and explain. 
Age, occupation, place of residence, climate, and season, as well as individual conditions of health and disease, are always important factors in the problem.

192. The Quantity of Food as affected by Occupation. Occupation has an important influence upon the quantity of food demanded for the bodily support. Those who work long and hard at physical labor need a generous amount of nutritious food. A liberal diet of the cereals and lean meat, especially beef, gives that vigor to the muscles which enables one to undergo laborious and prolonged physical exertion. On the other hand, those who follow a sedentary occupation do not need so large a quantity of food. Brainworkers who would work well and live long should not indulge in too generous a diet. $\times$ 193. Some of the Ill Effects of a too Generous Diet. A generous diet, even of those who take active muscular exercise, should be indulged in only

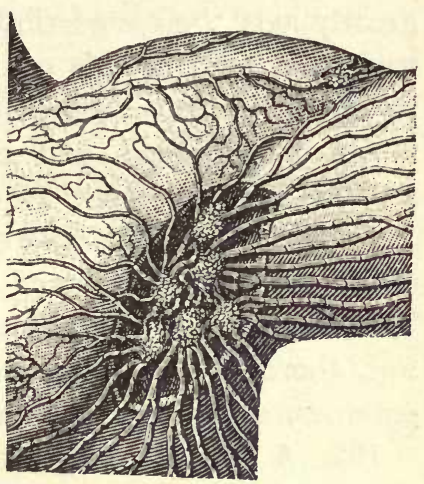

FIG. 63. Lymphatics and Lymphatic Glands of the Axilla.

with discretion. Frequent sick or nervous headaches, a sense of fullness, bilious attacks, and dyspepsia are some of the after-effects of eating more food than the body actually requires.

If too much and too rich food be persistently indulged in, the complexion is apt to become muddy, the skin, especially of the face, pale and sallow and more or less covered with blotches and pimples; the breath may have an unpleasant odor, and the general appearance of the body may be unhealthy. 
194. Need of a Variety of Food. Food should be both nutritious and digestible. Certain foods, as the vegetable albumins, are both nutritious and digestible. A hard-working man may grow strong and maintain vigorous health on most of them, even if deprived of animal food.

Animal food of some kind is, however, an economical and useful addition to the diet. The common custom of eating meat with bread and vegetables is a sound one.

The judicious admixture of different classes of foods greatly aids their digestibility. The great abundance and variety of food in this country permit this principle to be put into practice. A variety of foods, as milk, eggs, vegetables, fruit, bread, and meat, may be wisely used to a greater or less extent at every meal.

Oftentimes, where there is of necessity a sameness of diet, there arises a craving for special articles of food. Thus, on protracted voyages, and during long campaigns in war, there is an almost universal craving for onions, raw potatoes, and other vegetables.

195. A Few Suggestions about Meals. Every person in good health, who takes a moderate amount of daily exercise, should have a keen appetite for three meals a day.

The stomach, like other organs, does its work best at regular periods. We should make it a point not to omit a meal unless forced to do so. Children, and even adults, often have the habit of going to school or to work in a hurry, without eating any breakfast. There is almost sure to be a faint or "all-gone" feeling at the stomach before another mealtime.

Eating out of mealtimes should be strictly avoided, for it robs the stomach of its needed rest. Food eaten when the body and mind are wearied is not well digested. Rest, even for a few minutes, should be taken before eating a 


\section{The Digestion of Food}

full meal. It is well to lie down, or sit quietly and read, fifteen minutes before eating, and directly afterwards.

Severe exercise and hard study just after a full meal are very apt to delay or actually arrest digestion.

196. Practical Points about Eating. We should not eat for at least two or three hours before going to bed. In many cases of sleeplessness, however, a small quantity of some simple food, especially if the stomach seems to feel exhausted, often appears to promote sleep and rest.

The state of mind has much to do with digestion. We should laugh and talk at our meals, and thus aim to drive away anxious thoughts and avoid unpleasant topics.

The proper chewing of the food is an important element in digestion. Hence, eat slowly and do not "bolt" large fragments of food.

Do not drink too much with the meals, for the flow of the saliva is checked and digestion is hindered. If we drink freely of ice water during meals, it takes some time for the stomach to regain its natural heat.

It is a poor plan to stimulate a flagging appetite with an undue amount of pepper, mustard, horseradish, pickles, and highly seasoned meat sauces. They may stimulate digestion for the time, but they soon impair it.

Note:- The table on the next page shows the results of many experiments to illustrate the time taken for the gastric digestion of a number of the more common solid foods. There are a great many factors of which the table takes no account, such as the interval since the last meal, state of the appetite, amount of work and exercise, method of cooking, and especially the quantity of food.

197. Hints about the Care of the Teeth. If an ounce of prevention is ever worth a pound of cure, it is in keeping the teeth in good order. Bad teeth and toothless gums 


\section{TABLE SHOWING THE DIGESTIBILITY OF THE MORE COMMON SOLID FOODS}

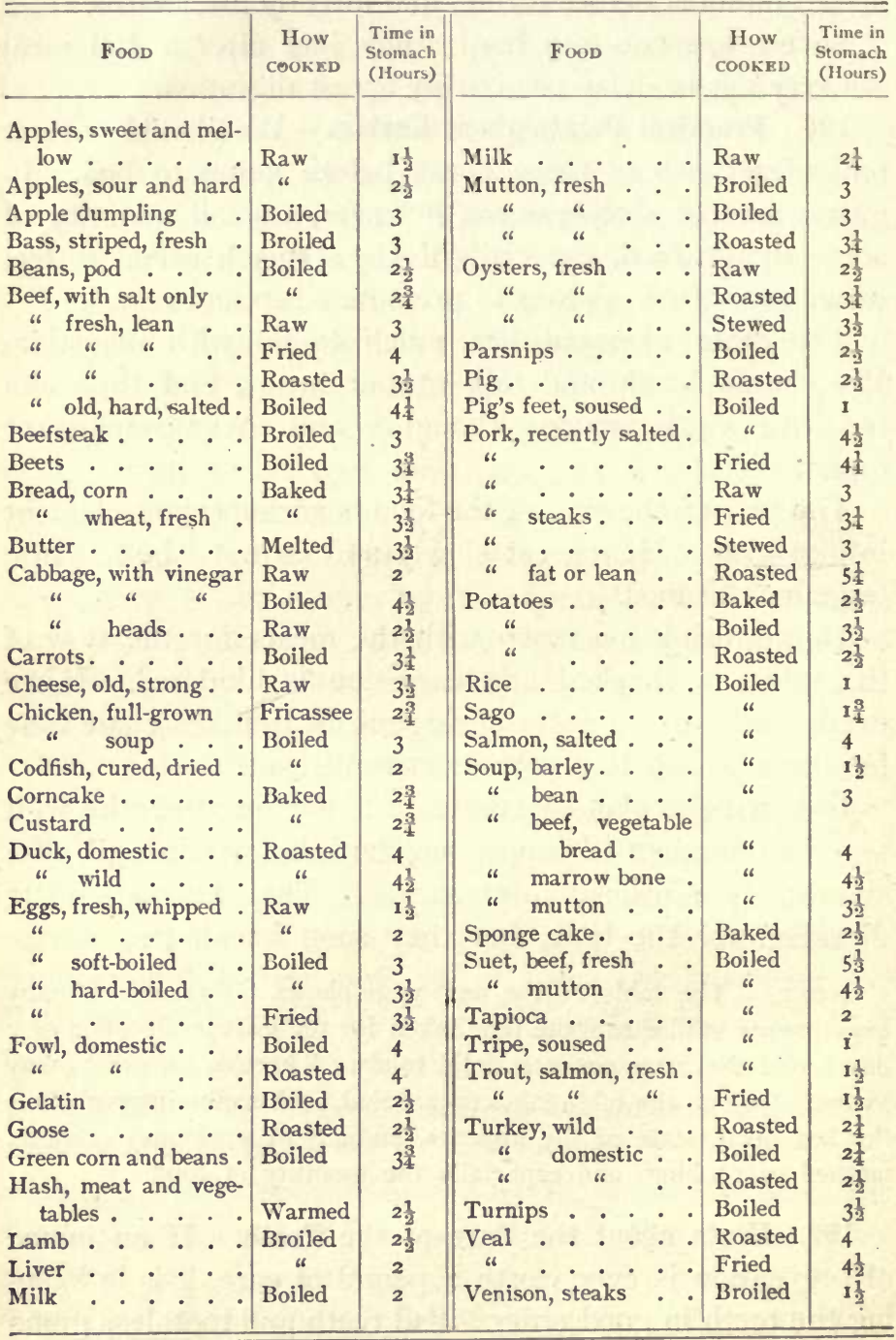


mean imperfect chewing of the food, and, hence, impaired digestion. Decayed teeth are often the cause of an offensive breath and a foul stomach.

The teeth should be thoroughly cleansed at bedtime and in the morning with a soft brush and warm water. Some prepared tooth powder without grit should be used, and the brush should be applied on both sides of the teeth.

When the enamel is once broken through it is never renewed. The tooth decays, slowly but surely; hence we must guard against certain habits which injure the enamel, as picking the teeth with pins and needles. We should never crack nuts, crush hard candy, or bite off stout thread with the teeth.

To remove fragments of food which have lodged between adjacent teeth, a quill or wooden toothpick should be used. Even better than these

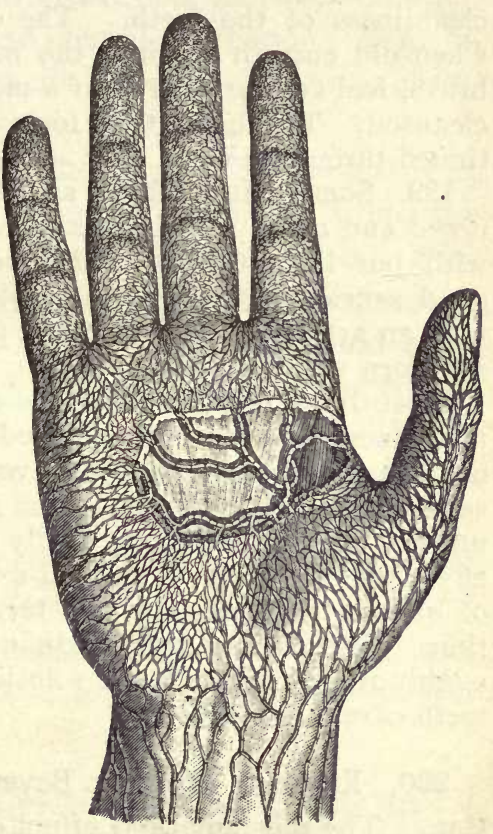

FIG. 64. Lymphatics on the Inside of the Right Hand. is the use of surgeon's floss or silk, which when drawn between the teeth effectually dislodges retained particles.

If the teeth are not regularly cleansed they become discolored, and a hard coating known as tartar accumulates on them and tends to loosen them. It is said that after 
the age of thirty more teeth are lost from this deposit than from all other causes combined.

198. The Care of Children's Teeth. The teeth of children should be often examined by the dentist, especially from the beginning of the second dentition, at about the sixth year, until growth is completed. In infancy the mother should make it a part of her daily care of the child to secure perfect cleanliness of the teeth. The child thus trained will not, when old enough to rinse the mouth properly or to use the brush, feel comfortable after a meal until the teeth have been cleansed. The habit thus formed is almost sure to be continued through life.

199. Some Hints about saving Teeth. People are often urged and consent to have a number of teeth extracted which, with but little trouble and expense, might be kept and do good service for years. The object is to replace the teeth with an artificial set. Very few plates, either partial or entire, are worn with real comfort.

Most drugs have no injurious effect upon the teeth. Some medicines, however, must be used with great care. The acids used in the tincture of iron have a great affinity for the lime salts of the teeth. As this form of iron is often used it is not unusual to see teeth very badly stained or decayed from the effects of this drug. The acid used in the liquid preparations of quinine may destroy the teeth in a comparatively short time. After taking such medicines the mouth should be thoroughly rinsed with a weak solution of common soda, and the teeth carefully cleansed.

\section{Effect of Alcoholic Beverages on the Gastric Diges-} tion. The most marked effect of alcohol upon the stomach is to irritate the gastric cells and cause an increased flow of gastric juice. This abnormal irritation of the gastric glands does not assist digestion, as might at first be supposed, but serves to weaken the functional power of the gastric juice.

After a time the stomach may gradually undergo lasting structural changes. Its blood vessels remain dilated 
and congested, its connective tissue becomes excessive, its power of secreting gastric juice diminishes, and its mucous secretion becomes abnormally abundant. ${ }^{1}$

As a result, the habitual user of alcoholic beverages usually suffers from the effects of a disordered and retarded digestion, viz., obstinate dyspepsia and its familiar symptoms, - loss of appetite, acid eructation, nausea, vomiting, headache, unnatural thirst, and mental depression. Remember that alcoholic drinks are not necessary or desirable to arouse the appetite and stimulate digestion.

201. Effect of Alcohol upon the Liver. The portal vein, as you should remember, brings the blood from the stomach and intestines to the liver to be acted upon. Now when alcohol, which is rapidly absorbed by the blood vessels of the stomach, is brought to the liver, we should naturally expect this great blood-purifying organ to suffer from a marked effect of the narcotic. And so it does. The tissues become at first irritated, then inflamed, and finally may be seriously diseased. The fine bands, or septa, which serve as partitions between the hepatic lobules seem to suffer from prolonged alcoholic ingestion. The liver is at first enlarged, but soon becomes contracted; the secreting cells are compressed, and are less able to perform their proper work.

1 Professor Chittenden has made careful experiments upon the effect of varying amounts of alcohol upon gastric digestion. He finds, in digestion experiments made with mixtures of digestive juice outside the body, that even small amounts of alcohol retard digestion. The same amounts cause a slight increase in the secretion of gastric juice when taken into the body. The retardation effects, however, somewhat more than neutralize the secretion effects, for the experimenter says: "The results obtained suggest a tendency towards prolongation of the period during which the meat remains in the stomach when alcoholic fluids are present." - American Journal of the Medical Sciences, vol. cxi; American Journal of Physiology, vol: i, pp. 202, 203 . 
202. Effect of Tobacco upon Digestion. Tobacco acts as an irritant poison to the organs of digestion. It contains a very poisonous substance known as nicotine.

The irritant properties of tobacco are shown in the abnormal stimulation of the salivary glands. The excess of saliva thus produced is expectorated or swallowed. The normal quantity of saliva necessary for the proper digestion of food is thus diminished.

203. Other Harmful Effects of Tobacco upon Digestion. This unnatural secretion and loss of saliva, which especially results from chewing tobacco, causes a dryness of the mouth and throat, often resulting in an unnatural thirst. This thirst may tend to provoke a craving for alcoholic liquors.

Tobacco users generally have a heavily coated tongue and a foul breath, which are symptoms of a disordered condition of the digestive organs.

In chewing tobacco, more or less of the nicotine is dissolved by the saliva and a part of it is swallowed. In smoking, the nicotine in the vapor and smoke is absorbed by the saliva and the mucous membranes. Thus, both in smoking and chewing, the harmful effects of the nicotine are seen in the irritation of all the tissues with which it comes in contact. There may result loss of appetite, sinking feeling, nausea, belching of gas, vomiting, distress after eating, and other forms of indigestion so common with those who habitually smoke or chew tobacco. ${ }^{1}$

${ }^{1}$ Tobacco lessens the natural appetite, more or less impairs digestion, and induces constipation, while it irritates the mouth and throat, rendering it habitually congested, and destroying the purity of the voice. It induces an habitual sense of uneasiness and nervousness, with epigastric sinking, palpitation, and neuralgia. - Alfred Strlle, Professor of Theory and Practice of Medicine in the University of Pennsylvania. 


\section{ADDITIONAL EXPERIMENTS}

Experiment 54. Test a portion of $C$ (Experiment 42) with solution of iodine; no blue color is obtained, as all the starch has disappeared, having been converted into sugar, or maltose.

Experiment 55. To show the action of gastric juice on milk. Mix two teaspoonfuls of fresh milk in a test tube with a few drops of neutral artificial gastric juice $;^{1}$ keep at about $100^{\circ} \mathrm{Fahr}$. In a short time the milk curdles, so that the tube can be inverted without the curd falling out. By and by whey is squeezed out of the clot. The curdling of milk by the rennet ferment present in the gastric juice is quite different from that produced by the "souring of milk," or by the precipitation of caseinogen by acids. Here the casein (carrying with it most of the fats) is precipitated in a neutral fluid.

Experiment 56. To the test tube in the preceding experiment add two teaspoonfuls of dilute hydrochloric acid, and keep at $100^{\circ} \mathrm{Fahr}$. for two hours. The pepsin in the presence of the acid digests the casein, gradually dissolving it, forming a straw-colored fluid containing peptones. The peptonized milk has a peculiar odor and bitter taste.

Experiment 57. To show the action of rennet on milk. Place milk in a test tube, add a drop or two of commercial rennet, and place the tube in a water bath at about $100^{\circ} \mathrm{Fahr}$. The milk becomes solid in a few minutes, forming a curd, and by and by the curd of casein contracts, and presses out a fluid, - the whey.

Experiment 58. Repeat the experiment, but previously boil the rennet. No such result is obtained as in the preceding experiment, because the rennet ferment is destroyed by heat.

1 An artificial gastric juice may be obtained for experimental purposes by dissolving about ten grains of pepsin powder (made by some reputable manufacturer and obtained of any druggist) in half a pint of water and adding perhaps fifteen to twenty drops of strong hydrochloric acid, or about two teaspoonfuls of the dilute acid. 


\section{CHAPTER VII}

\section{THE BLOOD AND ITS CIRCULATION}

2 204. Physical Properties of Blood. The blood is a red, warm, heavy, alkaline fluid, slightly salt in taste, and has a somewhat fetid odor. Its color varies from bright red in the arteries and when exposed to the air, to various tints, from dark purple to red, in the veins.

The temperature of the blood varies slightly in different parts of the circulation. Its average temperature near the

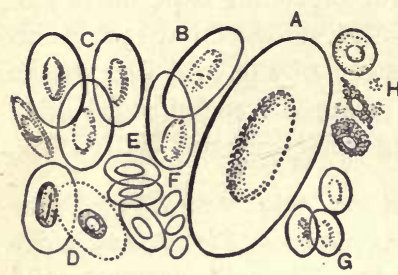

Fig. 65. Red Blood Corpuscles of Various Animals. (Magnified to the same scale.)

$A$, from proteus, a kind of newt; $B$, salamander; $C$, frog; $D$, frog after addition of acetic acid, showing the central nucleus; $E$, bird; $F$, camel; $G$, fish; $H$, crab or other invertebrate animal.

surface is in health about the same, viz., $98 \frac{1}{2}^{\circ} \mathrm{Fahr}$. The total amount of the blood in the body is about one-thirteenth of its total weight.

$\times 205$. Blood Corpuscles. If we put a drop of fresh blood upon a glass slide and place upon it a cover of thin glass, we can flatten it out until the color almost disappears. If we examine this thin film with a microscope, we see that the blood is not altogether fluid. We find that the liquid part, or plasma, is of a light straw color, and has floating in it a multitude of very minute bodies, called corpuscles.

There are two kinds of corpuscles, red and white.

+206 . The Red Corpuscles. The red corpuscles are circular disks about $\frac{1}{3200}$ of an inch in diameter, and doubly 
concave in shape. They tend to adhere in long rolls like piles of coins. They are soft, flexible, and elastic, readily squeezing through passages narrower than their own diameter, then at once resuming their own shape.

The principal constituent of these corpuscles, and that which gives them color, is hamoglobin, a compound containing iron and a colorless proteid substance. A very important office of the red corpuscles is to act as carriers of oxygen from the lungs to all of the tissues.

$\times 20 \%$. The White Corpuscles. The white corpuscles are larger than the red, their average diameter being about $\frac{1}{2500}$ of an inch. They are of very irregular shape and stick close to the glass slide on which they are placed.

The white corpuscles spontaneously undergo active and curious changes of form, resembling those of the amœba, a very minute organism found in stagnant water (Fig. 2).

The white corpuscles have been called the warrior-cells of the bodily tissues, forever battling against the invasion of bacteria. They have the power of moving about among the tissues and picking up foreign particles, thus acting as little scavengers.

$\times 208$. The Clotting or Coagulation of Blood. When blood is drawn directly from the blood vessels of an animal into a cup it is at first as fluid as water; but in a few minutes it
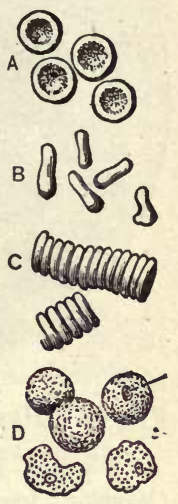

FIG. 66. Human Blood Corpuscles.

$A$, red corpuscles; $B$, the same seen edgeways; $C$, the same arranged in rows; $D$, white corpuscles with nuclei. becomes a jelly-like mass, called a clot. The cup containing it can be turned upside down, without a drop of blood being spilled. If carefully shaken out, the mass will form a complete mould of the vessel. 
At first the clot includes the whole mass of blood and is of a uniform color. But in a short time a pale yellowish

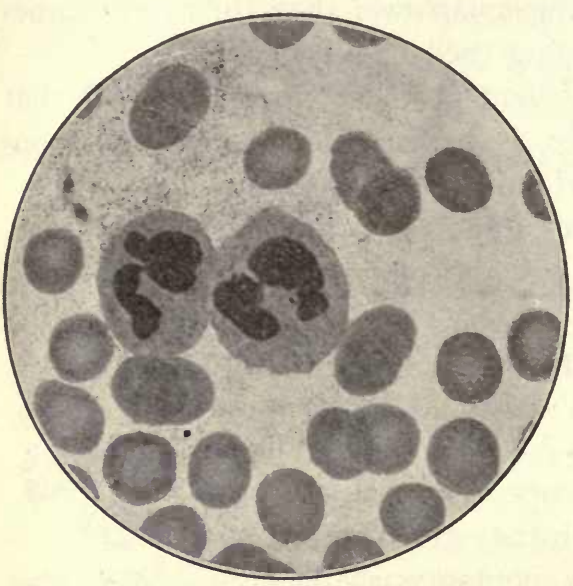

Fig. 67. Human Red and White Blood Corpuscles, as seen under the Microscope.

(Magnified 1000 diameters. Two white corpuscles are seen, with their nuclei stained to show black.)

fluid begins to ooze out and to collect on the surface. The clot gradually shrinks, until at the end of a few hours it is much firmer and floats in the yellowish fluid.

This remarkable process is known as coagulation, or the clotting of blood; and the liquid which separates from the clot is called serum.

The process of the clotting of blood is not yet fully understood, but is claimed to be due in part to the action of a ferment in the white corpuscles which produces a substance called fibrin.

Experiment 59. To show the blood corpuscles. A moderately powerful microscope is necessary to examine blood corpuscles. Let a small drop of blood (easily obtained by pricking the finger with a needle) be placed upon a clean slip of glass and covered with thin glass such as is ordinarily used for microscopic purposes.

The blood is thus spread out into a film and may be readily examined. At first the red corpuscles will be seen as pale, disk-like bodies floating in the clear fluid. Soon they will be observed to stick to each other by their flattened faces, so as to form rows. The white corpuscles are to be seen, but are much less numerous. 
×209. Why the Clotting of Blood is of Vital Importance. This clotting of the blood is of vital importance. But for this, a very small cut might cause bleeding sufficient to empty the blood vessels, and death would speedily follow. In slight cuts, Nature plugs up the wound with clots of blood, and thus prevents excessive bleeding.

Experiment 6o. Put two or three drops of fresh blood on a white individual butter plate inverted in a saucer in which is a little water. Cover it with an inverted goblet. Take off the cover in five minutes, and the drop has set into a jelly-like mass. Take it off in half an hour, and a little clot will be seen in the watery serum.

Experiment 6r. To show the blood clot. Carry to the slaughter house a clean six or

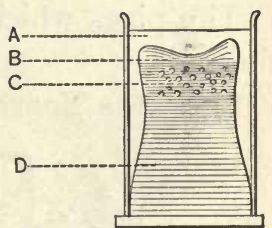

Fig. 68. Diagram of Clot with Buffy Coat. $A$, serum; $B$, cupped upper surface of clot; $C$, white corpuscles in upper layer of clot; $D$, lower portion of clot with red corpuscles. eight ounce wide-mouthed bottle. Fill it with fresh blood. Carry it home with great care, and let it stand over night. The next day the clot will be seen floating in the nearly colorless serum.

Experiment 62. Obtain a pint of fresh blood; put it irto a bowl and whip it briskly for five minutes with a bunch of dry twigs. Fine white threads of fibrin collect on the twigs, the blood remaining fluid. This is "whipped," or defibrinated blood, which has lost the power of coagulating spontaneously.

NotE. - Fresh blood may be prevented from clotting by adding to it one-fourth part of a saturated solution of Epsom salt and keeping it in a cool place. By adding ten times its amount of water, the "salted" blood may be made to clot.

\section{$\times$ 210. The Apparatus for the Circulation of the Blood.} The apparatus for the circulation of the blood consists of the heart, the arteries, the capillaries, and the veins.

The central pump is the heart. 
The pipes leading from it and gradually growing smaller and smaller are the arteries.

The very minute vessels into which they lead at last are capillaries.

The pipes which convey the blood back to the heart are the veins.

y 211. The Heart. The heart is a pear-shaped, muscular

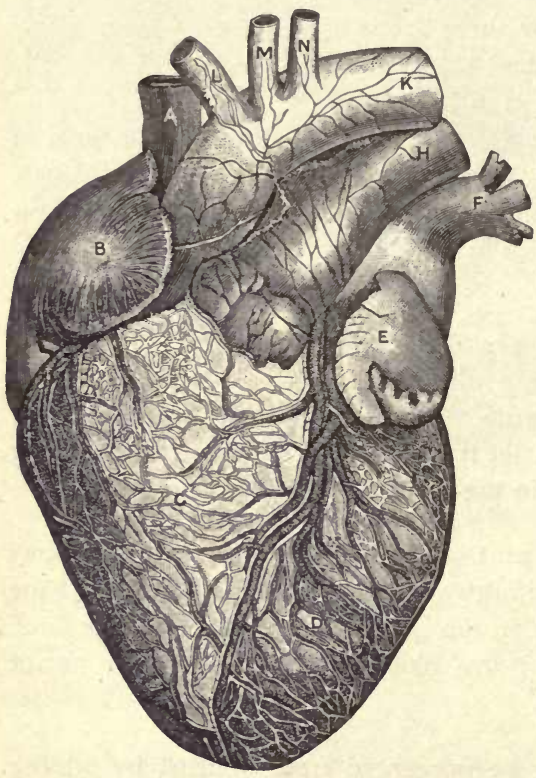

FIG. 69. Anterior View of the Heart.

$A$, superior vena cava; $B$, right auricle; $C$, right ventricle; $D$, left ventricle; $E$, left auricle; $F$, pulmonary vein; $H$, pulmonary artery; $K$, aorta ; $L$, right subclavian artery; $M$, right common carotid artery; $N$, left common $\approx$ rotid artery. organ, roughly estimated as about the size of the closed fist of the person to whom it belongs. It lies in the chest behind the breastbone and is lodged between the lobes of the lungs, which partly cover it.

In health the apex of the heart beats against the chest wall between the fifth and sixth ribs, about an inch and a half to the left of the middle line of the body. The beating of the heart can be readily felt, heard, and often seen moving the chest wall as it strikes against it.

$\times 212$. The Pericar-

dium. The heart is enclosed in a bell-shaped covering, called the pericardium. This is really double, with two 
layers, one over the other. The inner (or visceral) layer covers the external surface of the heart and is reflected back upon itself in order to form, like all membranes of this kind, a sac without an opening. The space between the two membranes is filled with fluid which permits the heart and the pericardium to glide one upon the other with the least friction. ${ }^{1}$

213. Serous Membranes. The serous membranes form shut sacs, one portion of each of which is applied to the walls of the cavity which it lines; the other is reflected over the surface of the organ or organs contained in the cavity. The sac is completely closed, so that no communication exists between the serous cavity and the parts in its neighborhood. These membranes secrete a fluid, commonly called serum, but which is really a form of lymph. The various serous membranes are the pleura, which envelops the lungs; the pericardium, which surrounds the heart; and the

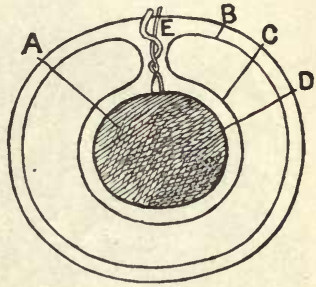

Fig. 70. Diagram illustrating the Structure of a Serous Membrane.

$A$, the viscus, or organ, enveloped by serous membrane; $B$, layer of membrane lining cavity; $C$, membrane reflected to envelop viscus; $D$, outer layer of viscus, with blood vessels at $E$ communicating with the general circulation.

peritoneum, which invests the viscera of the abdomen. In health the serous membranes secrete only sufficient fluid to lubricate and keep soft and smooth the opposing surfaces.

\section{× 214. The Auricles and Ventricles. The heart is a hollow} organ, divided into two great cavities or "chambers" by a fixed partition forming a left and a right side. These two cavities are each divided transversely by a movable partition into an upper and a lower chamber. These partitions,

${ }^{1}$ A correct idea may be formed of the arrangement of the pericardium around the heart by recalling how a boy puts on and wears his toboggan cap. The pericardium encloses the heart exactly as this cap covers the boy's head. 
however, include a set of valves which open like folding doors between the two rooms.

The heart thus has four cavities, two on each side. The two upper are called auricles, from the resemblance of one

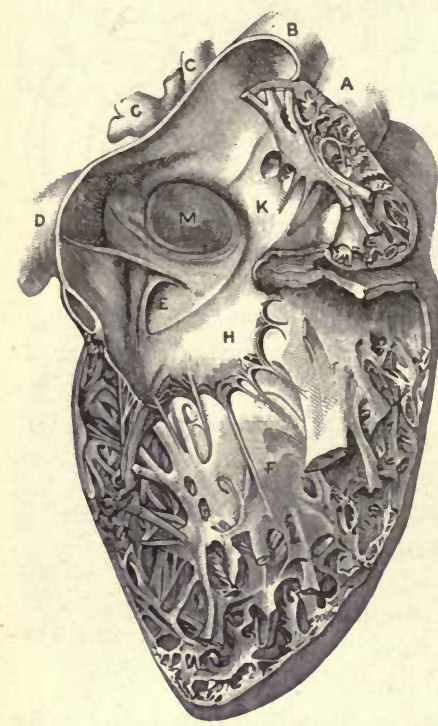

FIG. 71. Right Cavities of the Heart.

$A$, aorta ; $B$, superior vena cava ; $C, C$, right pulmonary veins; $D$, inferior vena cava; $E$, section of coronary vein; $F$, right ventricular cavity; $H$, posterior curtain of the tricuspid valve; $K$, right auricular cavity; $M$, fossa ovalis, oval depression, partition between the auricles formed after birth. fancied resemblance to a bishop's miter, consists of two
folds which close together as do those of the tricuspid
valve. fancied resemblance to a bishop's miter, consists of two
folds which close together as do those of the tricuspid
valve. fancied resemblance to a bishop's miter, consists of two
folds which close together as do those of the tricuspid
valve. dog. The two lower cavities are called ventricles.

\section{215. The Valves of the}

Heart. The valves of the heart consist of thin, but strong, triangular folds of connective tissue which hang down from the edges of the passages into the ventricles. They may be compared to swinging doors which, by opening only one way, allow the blood to flow from the auricles to the ventricles, but by instantly folding back prevent its return.

The valve on the right side is called the tricuspid, because it consists of three little folds which fall over the opening and close it. It is kept from falling too far by a number of slender threads called chordæ tendinex.

The valve on the left side, called the mitral, from its corner of each to the ear of a 
X216. The Semilunar Valves. From the right ventricle a large vessel, called the pulmonary artery, passes to the lungs, and from the left ventricle a large vessel, called the aorta, arches out to the general circulation of the body. The openings from the ventricles into these vessels are guarded by the semilunar valves. Each valve has three folds, each halfmoon shaped, hence the name "semilunar." These valves, when shut, prevent any backward flow of the blood from the pulmonary artery to the right ventricle, and from the aorta to the left ventricle.

$+21 \%$. The Great Blood Vessels connected with the Right Side of the Heart. There are a few large blood vessels connected with the heart, the relative position and the use of which must be understood.

The two largest veins in the body, the superior vena cava and the inferior vena cava, open into the right auricle. They bring venous blood from all parts of

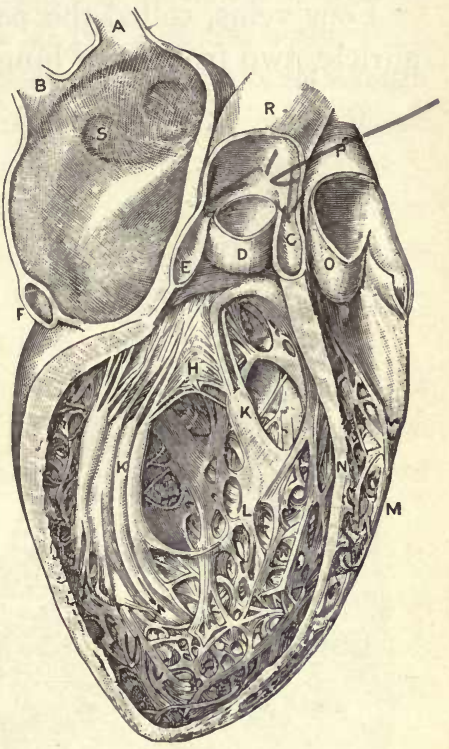

FIG. 72. Left Cavities of the Heart.

$A, B$, right pulmonary veins; with $S$, openings of the veins; $E, D, C$; aortic valves; $R$, aorta ; $P$, pulmonary artery; $O$, pulmonic valves; $H$, mitral valve; $K$, columnæ carnœæ; $M$, right ventricular cavity ; $N$, interventricular septum. the body and pour it into the right auricle.

From the right ventricle arises one large vessel, the pulmonary artery, which soon divides into two branches of nearly equal size, one for the right lung, the other for the left. 
× 218. The Great Blood Vessels connected with the Left Side of the Heart. Let us now turn to the left sicle of the heart and study the general plan of its great vessels.

Four veins, called the pulmonary veins, open into the left auricle, two from each lung. They start from very minute

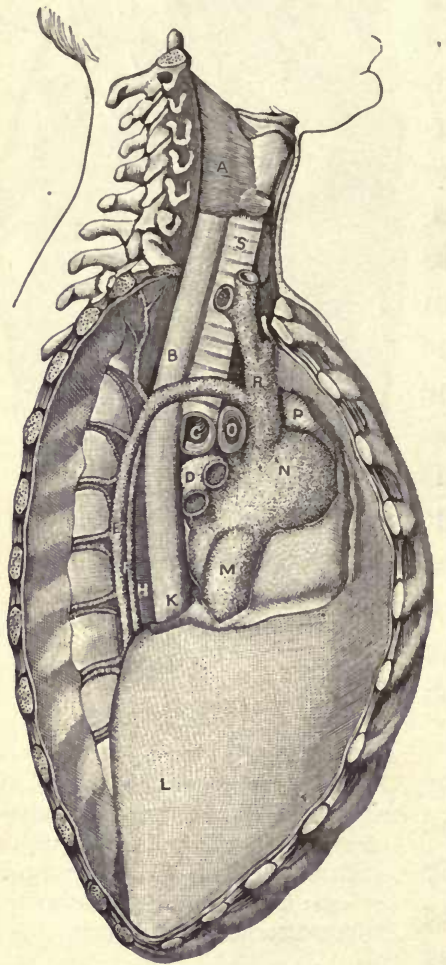

FIG. 73. Lateral Section of the Right Chest.

(Showing the relative position of the heart and its great vessels, and of the osophagus and trachea.)

$A$, inferior constrictor muscle (aids in conveying food down the œsophagus) ; $B$, œesophagus; $C$, section of the right bronchus; $D$, two right pulmonary veins; $E$, great azygos vein crossing œsophagus and right bronchus to empty into the superior vena cava; $F$, thoracic duct; $H$, thoracic aorta ; $K$, lower portion of œesophagus passing through the diaphragm; $L$, diaphragm as it appears in sectional view, enveloping the heart; $M$, inferior vena cava passing through diaphragm and emptying into auricle; $N$, right auricle; $O$, section of right branch of the pulmonary artery; $P$, aorta ; $R$, superior vena cava; $S$, trachea.

vessels and form larger and larger vessels until they become two large veins in each lung, and pour their contents into the left auricle.

Remember, then, that the pulmonary artery carries venous blood from the right ventricle to the lungs, and that the 
pulmonary veins carry arterial blood to the left auricle from the lungs.

From the left ventricle springs the largest arterial trunk in the body, called the aorta. From the aorta other arteries branch off to carry the blood to all parts of the body.

$x$ 219. The Arteries. The blood vessels are tubes through which the blood is carried to and from the tissues. There are three kinds, - the arteries, the veins, and the capillaries.

The arteries are the highly elastic and extensible tubes which carry the blood from the heart to all parts of the body. All the arteries except the pulmonary may be regarded as branches of the aorta.

$\times 220$. The Aorta and its Great Branches. After the aorta leaves the left ventricle it rises towards the neck, but soon turns downwards, making a curve known as the arch of the aorta.

From the arch are given off the arteries which supply the head and arms with blood. These are the two carotid arteries, which run up on each side of the neck to the head, and the two subclavian arteries, which pass beneath the collar bone to the arms.

The aorta now passes down in front of the spine to the pelvis, giving off arteries to the different organs. Of these branches the chief are the cœliac artery, which supplies the stomach, the liver, and the spleen; the renal arteries, one to each kidney; and the mesenteric arteries, which supply the intestines.

. The aorta at last divides into two main branches, the common iliac arteries, which, by their subdivisions, furnish the arterial vessels for the pelvis and the lower limbs.

221. The Veins. The veins are the blood vessels which carry the impure blood from the various tissues of the body to the heart. They begin in the minute capillaries and, 
passing onwards toward the heart, at length form the two great vessels which open into the right auricle.

These two great venous trunks are the inferior vena cava, which brings the blood from the trunk and the lower limbs, and the superior vena cava, which brings the blood from the head and the upper limbs.

The four pulmonary veins, as we have learned, carry the arterial blood from the lungs to the left auricle.

Many of the veins lie near the surface of the body. Some of them may be easily seen under the skin of the

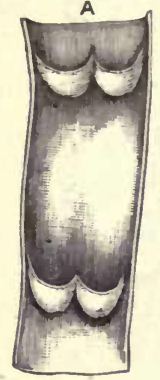

FIG. 74 .

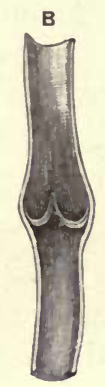

$A$, part of a vein laid open, with two pairs of valves; $B$, longitudinal section of a vein, showing the valves closed. hand and forearm, especially if the arm is allowed to hang down a few moments.

722. How the Blood flows in the Veins. The walls of the larger veins are thin, and when empty they collapse. The inner surfaces of many of the veins are supplied with pouchlike folds, or pockets, which act as valves to prevent the backward flow of the blood. These valves can be shown by letting the forearm hang down and sliding the finger upwards over the veins.

The onward flow of the blood in the veins is due to various causes, the chief being the pressure behind of the blood pumped into the capillaries. Then as the pocketlike valves prevent the backward flow of the blood, the pressure of the various muscles of the body urges along the blood and thus promotes the onward flow.

+ 223. The Capillaries. The capillaries are minute tubes, with very thin walls, which form the connection between the ending of the finest arteries and the beginning of the 
smallest veins. They are distributed through every tissue of the body, except the epidermis and its appendages, the epithelium, the cartilages, and the enamel of the teeth.

$\times$ 224. The Work done by the Capillaries. The capillaries are closed vessels, and the space between the walls of the capillaries and the cells of the tissues is filled with lymph. As the blood flows along the capillaries, certain parts of the plasma of the blood filter through their walls into the lymph, and certain parts of the lymph filter in the opposite direction through the walls of the capillaries and mingle with the blood current.

A similar exchange of material is constantly going on between the lymph and the tissues themselves, so that the lymph acts as a medium of exchange between the blood and the tissues.
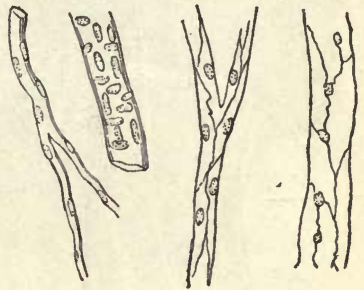

FIG. 75. The Structure of Capillaries.

(Capillaries of various sizes, showing cells with nuclei.)

In brief, the tissues, with the lymph as a kind of "middleman," may be said to live on the blood.

.Experiment 63. Grasp the left wrist tightly with the thumb and two fingers of the right hand. Note the little knots or swellings in the veins caused by checking the flow of the venous blood towards the heart. These swellings show the location of the valves of the veins.

225. The Pulmonary, or Lesser, Circulation. Let us now study the circulation as a whole, tracing the course of the blood from a certain point until it returns to the same point. We may conveniently begin with the portion of blood contained at any moment in the right auricle.

The superior and inferior venæ cavæ are busily filling the right auricle with dark, impure blood. When it is full it contracts. The passage leading to the right ventricle lies 
open and through it the blood pours till the ventricle is full. Instantly this begins, in its turn, to contract. The tricuspid valve at once closes and blocks the way backward. The blood is now forced through the open semilunar valves

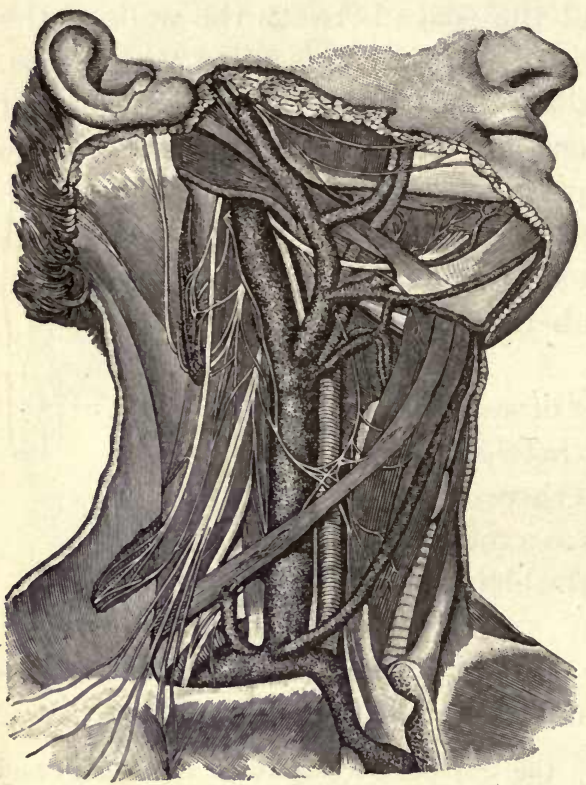

FIG. 76. Showing the Carotid Artery and Jugular Vein on the Right Side, with Some of their Main Branches.

(Some branches of the cervical plexus, and the hypoglossal nerve are also shown.) into the pulmonary artery.

The pulmonary artery, bringing venous blood, by its alternate expansion and recoil draws the. blood along until it reaches the pulmonary capillaries. These tiny tubes surround the air spaces of the lungs, and here an exchange takes place. The dark, venous blood here gives up its waste in the form of carbon dioxide and water, and in return takes up a large amount of oxygen and becomes bright red. Thus the blood brought to the lungs by the pulmonary arteries leaves the lungs entirely different in character and appearance.

This is often called the pulmonary, or lesser, circulation. +226. The Systemic, or Greater, Circulation. The four pulmonary veins bring back bright scarlet blood and pour it into the left auricle of the heart, whence it goes past the mitral 
valve into the left ventricle. As soon as the left ventricle is full, it contracts. The mitral valve instantly closes and blocks the passage backward into the auricle; the blood, having no other way open, is forced past the semilunar valves into the aorta. •

Now red in color from its fresh oxygen, and laden with nutritive materials, the blood is distributed by the arteries to the various tissues of the body. Here it gives up its oxygen and certain nutritive materials to build up the tissues, and receives certain products of waste, and, changed to a purple color, passes from the capillaries into the veins.

All the veins of the body, except the pulmonary veins and those from the lungs and the heart itself, unite into the two large veins, as already described, which pour their contents into the right auricle of the heart, and thus the grand round of circulation is continually maintained.

This is often called the systemic, or greater, circulation.

\section{$\times$ 227. The Portal Circulation.}

A certain part of the systemic,

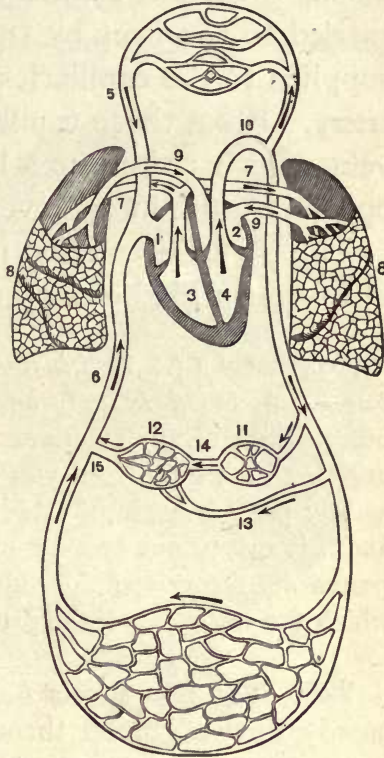

FIG. 77. Diagram illustrating the Circulation.

1, right auricle; 2 , left auricle; 3 , right ventricle; 4 , left ventricle; 5 , vena cava superior; 6 , vena cava inferior; 7 , pulmonary arteries; 8 , lungs; 9 , pulmonary veins ; 10, aorta ; 11, alimentary canal; 12, liver; 13, hepatic artery; 14 , portal vein; 15 , hepatic vein.

or greater, circulation is often called the portal circulation. By this is meant the flow of the blood from the abdominal viscera through the portal vein and liver to the hepatic vein. 
The blood brought to the capillaries of the stomach, intestines, spleen, and pancreas is gathered into veins which unite into a single trunk called the portal vein. The blood, thus laden with certain products of digestion, is carried to the liver by the portal vein, mingling with that supplied to the capillaries of the same organ by the hepatic artery. From these capillaries the blood is carried by small veins which unite into a large trunk, the hepatic vein, which opens into the inferior vena cava.

The portal circulation is thus not an independent system, but forms a kind of loop on the systemic circulation.

Experiment 64. To illustrate the action of the heart, and how it pumps the blood in only one direction. Take a household rubber bulb syringe of any standard make. Sink the suction end into water and press the bulb. As you let the bulb expand, it fills with water; as you press it again, a valve prevents the water from flowing back, and it is driven out in a jet along the other pipe. The suction pipe represents the veins; the bulb, the heart; and the tube end, out of which the water flows, the arteries.

228. The Rhythmic Action of the Heart. To maintain a steady flow of blood throughout the body the action of the heart must be regular and methodical. The heart does not contract as a whole. The two auricles contract at the same time, and this is followed at once by the contraction of the two ventricles. While the ventricles are contracting, the auricles begin to relax, and after the ventricles contract they also relax. Now comes a pause, or rest, after which the auricles and ventricles contract again in the same order as before, and their contractions are followed by the same pause as before. This cycle of changes is known as the rhythmic action of the heart.

+ 229. The Beat, or Impulse, of the Heart. If the hand be laid flat over the chest wall on the left, between the fifth and sixth ribs, the heart will be felt beating. This movement is known as the beat, or impulse, of the heart, and can be 
both seen and felt on the left side. The heart beat is unusually strong during active bodily exertion and under mental excitement. This is commonly known as palpitation.

$X$ The impulse of the heart is due to the striking of the lower, tense part of the ventricles - the apex of the heart - against the chest wall at the moment of their vigorous contraction.

$\times 230$. The Sounds of the Heart. If the ear be applied over the region of the heart, two distinct sounds will be heard. Their character may be tolerably imitated by pronouncing the syllables "lŭb," "dŭp." One sound is heard immediately after the other, then there is a pause, then come the two sounds again. The first is a dull, muffled sound, known as the "first sound," followed at once by a shorter and sharper sound, known as the "second sound" of the heart.

The precise cause of the first sound is not certainly

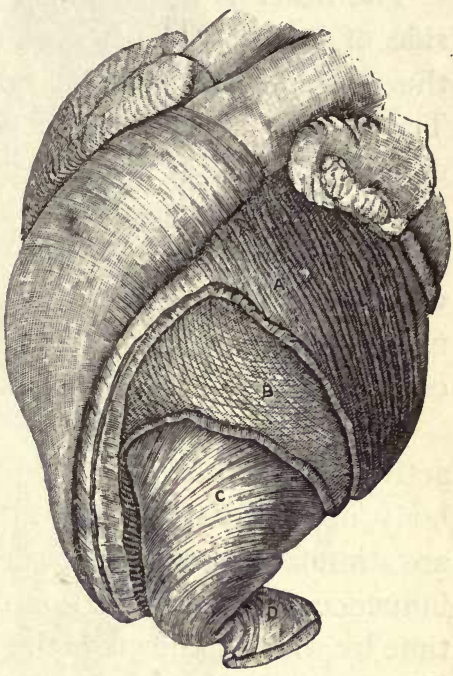

Fig. 78. Muscular Fibers of the Ventricles.

$A$, superficial fibers common to both ventricles; $B$, fibers of the left ventricle; $C$, deep fibers passing upwards towards the base of the heart; $D$, fibers penetrating the left ventricle.

known, but the second sound is, without doubt, caused by the sudden closure of the semilunar valves of the pulmonary artery and the aorta, at the moment when the contraction of the ventricles is completed.

231. The Nervous Control of the Heart. The regular, rhythmic movement of the heart is maintained by the action 
of certain nerves. Within the substance of the heart are masses of nerve matter called ganglia. From these ganglia there proceed, at regular intervals, discharges of nerve energy, some of which excite movement, while others seem to restrain it.

The heart is also subject to nerve influences from outside of itself. Two nerves are connected with the heart, the pneumogastric and the sympathetic (secs. 332 and 342). The former appears to be connected with the restraining ganglia, the latter with the exciting ganglia.

× 232. The Nervous Control of the Blood Vessels. The tone and caliber of the blood vessels are controlled by certain vaso-motor nerves, which are distributed among the muscular fibers of the walls. These nerves are governed from a center in the medulla oblongata (sec. 330).

Now the vaso-motor center may be excited to increased activity by influences reaching it from various parts of the body, or even from the brain itself. As a result, the nerves are stimulated, and the vessels contract. Again, the normal influence of the vaso-motor center may bo suspended for a time by what is known as the inhibitory, or restraining effect. The result is that the tone of the blood vessels becomes diminished, and their channels widen.

The effect of this action of the nervous system is to give it a certain control over the circulation in particular parts. Thus, though the force of the heart and the general average blood pressure remain the same, the state of the circulation may be very different in different parts of the body.

× 233. The Importance of this Nervous Control. This local control over the circulation is of the utmost importance. Thus, when an organ is at work it needs to be more richly supplied with blood than when at rest. For example, when the salivary glands need to secrete saliva, and the stomach 


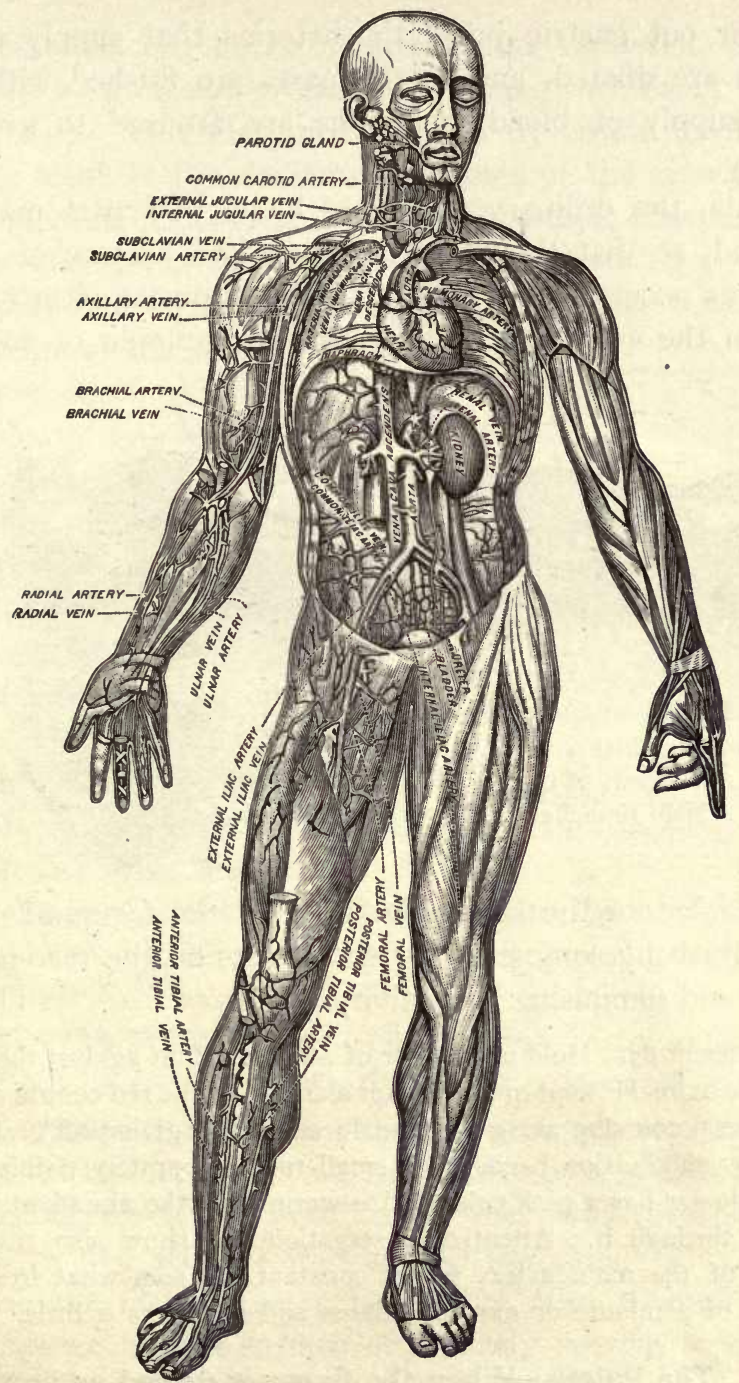

FIG. 79. Showing Principal Muscles on the Right, Certain Organs of the Chest and Abdomen, and the Larger Blood Vessels on the Left. 
to pour out gastric juice, the arteries that supply these organs are dilated, and so the parts are flushed with an extra supply of blood, and thus are aroused to greater activity.

Again, the ordinary supply of blood to a part may be lessened, so that the organ is reduced to a state of inactivity, as occurs in the case of the brain during sleep. We have in the act of blushing a familiar example of sudden

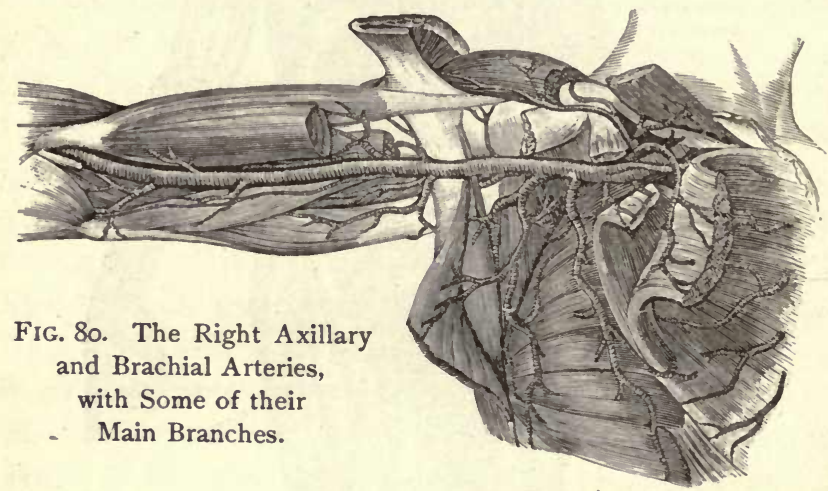

enlargement of the smaller arteries of the face and neck, called forth by some emotion which acts on the vaso-motor center and diminishes its activity.

Experiment 65. Hold up the ear of a white rabbit against the light while the animal is kept quiet and not alarmed. The red central artery can be seen coursing along the translucent organ, giving off branches which by subdivision become too small to be separately visible, and the whole ear has a pink color and is warm from the abundant blood flowing through it. Attentive observation will show also that the caliber of the main artery is not constant; at somewhat irregular periods of a minute or more it dilates and contracts a little.

234. The Pulse. When the finger is placed on any part . of the body where an artery is located near the surface, as, 
for example, on the radial artery near the wrist, there is felt an intermittent pressure, throbbing with every beat of the heart. This movement, frequently visible to the eye, is the result of the alternate expansion of the arterial walls by the wave of blood, and the recoil by their elasticity. In other words, it is the wave produced by throwing a mass of blood into the arteries already full. The blood wave strikes upon the elastic walls of the arteries, causing an increased distention, followed at once by contraction.

This intermittent rise and fall of the arterial wall felt just under the fingers, which corresponds to the successive heart beats, is known as the pulse.

This wave of distention, or the pulse, may be easily felt at the wrist, the temple,

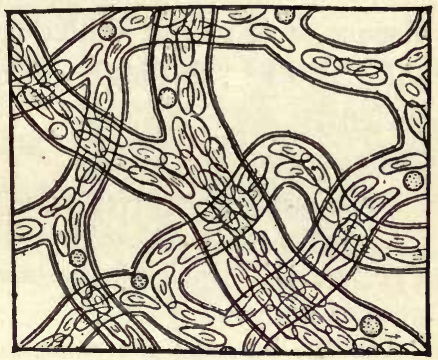

Fig. 81. Capillary Blood Vessels in the Web of a Frog's Foot, as seen with the Microscope. and the inner side of the ankle. The throb of the two carotid arteries may be plainly felt by pressing the thumb and finger backwards on each side of the larynx.

- 235. The Pulse Wave. The progress of the pulse wave must not be confused with the actual current of the blood itself. For instance, the pulse wave travels at the rate of about thirty feet a second, and takes about one-tenth of a second to reach the wrist, while the blood itself is from three to five seconds in reaching the same place. The pulse wave may be compared to the wave produced by a stiff breeze on the surface of a slowly moving stream.

236. How the Pulse Rate may be modified. The rate of the pulse is modified by age, fatigue, posture, exercise, 
disease, and many other circumstances. At birth the rate is about 140 times a minute; in early infancy, 120 or upwards ; in the healthy adult, between 65 and 75 , the more common number being 72 .

In the same individual the pulse is quicker when standing than when lying down, is quickened by excitement, is faster in the morning, and is slowest at midnight.

As the pulse varies much in its rate and character in disease, it is to the skilled touch of the physician an invaluable help in the diagnosis of the physical condition of his patient.

Experiment 66. Press three fingers over the radius to find the pulse in the wrist. Note by a watch the rate of the beat per minute. Take a friend's pulse in the same way and compare the characteristics of the two.

Observe how the character and frequency of the pulse are altered by posture, muscular exercise, a prolonged, sustained, deep inspiration, prolonged expiration, and other conditions.

237. Effect of Alcohol upon the Blood. Alcohol is rapidly absorbed, unchanged by the capillaries of the stomach, and is carried directly into the general circulation and distributed throughout the body.

The red blood corpuscles, as we have just learned, are the great oxygen carriers. Now alcohol has such a strong affinity for oxygen that good authorities believe it plays the part of a highwayman and robs the red corpuscles of a portion of their oxygen.

Again, it is claimed that the white blood corpuscles have a certain germicidal power, but that they are so acted upon by the presence of alcohol that they become less active in defending the system against the germs of disease. 
238. First Effect of Alcohol upon the Circulation. When alcohol is taken in moderate quantities by a person in health the pulse beats faster and usually less regularly, the circulation becomes more rapid, and the blood passing rapidly through the tissues yields to them less of its oxygen. From this it is evident that under these conditions the blood is not doing its full work.

This early stage in the action of alcohol lasts for only a short time, and is followed by a reaction in which the strength and rapidity of the heart beats fall even below the point at which they were working when the dose of alcohol was given. Thus the total amount of work done at the end of a given period is no greater than if the alcohol had not been given at all.

Owing to the increased demand made on the wall of the heart during the period of increased

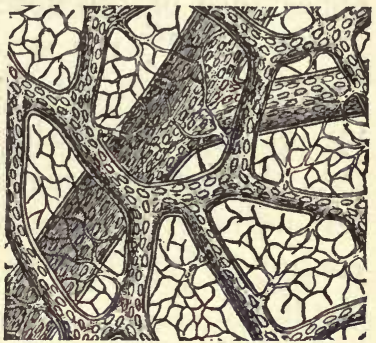

FIG. 82. Circulation in the Capillaries, as seen with the Microscope. activity, the heart itself is in a distinctly worse condition than it would have been if the increased strain had not been put upon it in consequence of the action of the alcohol.

239. Further Effect of Alcohol upon the Circulation. The inhibitory nerves, as we have seen, exercise a restraining control over the heart and the arteries, very much as the reins control a running horse. In health this inhibitory influence is protective and sustaining. When alcohol is taken, these inhibitory nerves are partially paralyzed, because the narcotic has had its effect upon that part of the vaso-motor center which governs them. 
The warm and flushed condition, or the "glow," of the face which follows the social glass of alcoholic liquor is a familiar illustration of this loss of inhibitory action. The alcohol has caused a partial paralysis of that part of the vaso-motor center which controls the arteries of the face. In other words, they are no longer under perfect control, and the blood is flushed into the blood vessels in greater quantities. The dilatation of the superficial blood vessels may become permanent, resulting in the red-streaked appearance of the nose and face, so cornmon with those who habitually use strong drink.

240. Effect of Alcohol upon the Heart. This "whipping up" of the heart, produced by the action of alcoholic liquors, cuts short its periods of rest and after a time may cause serious heart exhaustion. If the alcohol is repeated and continued, it may involve grave changes of the structure of the heart.

In still other cases the heart may suffer from what is called fatty degeneration; that is, minute particles of fat are deposited in large amounts in its tissues in place of the normal material.

241. Effect of Tobacco upon the Heart. The nicotine of tobacco has a deadening effect upon the nerves that control the heart's action. ${ }^{1}$ The heart beats often become irregular, feeble, and fluttering. Frequently there is dizziness, with short breath, palpitation on slight exertion, extreme pallor, and fainting.

In this erratic condition of the pulse the physician may

1 Tobacco depends for its activity upon the presence of an alkaloid, nicotine, a poison of such intensity that it has caused death in three minutes. Even one thirty-second of a grain will cause serious symptoms. Tobacco is a powerful depressant to the motor nerves. The sensory nerves are probably also depressed. Nicotine has a very distinct influence upon the circulation. - Wood's Therapeutics (Edition of 1901). 
read the existence of the "tobacco heart," an affection recognized by all medical men. It is claimed that one in every four of tobacco users is subject, in some degree, to this disturbance. Test examinations of a large number of young men who used cigarettes showed that only a very small percentage escaped cardiac trouble. ${ }^{1}$

\section{ADDITIONAL EXPERIMENTS}

Experiment 67. To show how blood holds a mineral substance in solution. Put an eggshell crushed fine into a glass of water made acid by a teaspoonful of muriatic acid. After an hour or so the eggshell will disappear, having been dissolved in the acid water. In like manner the blood holds various minerals in solution.

Experiment 68. To hear the sounds of the heart. Locate the heart exactly. Note its beat. Borrow a stethoscope from some physician. Listen to the heart beat of some friend. Note the sounds of your own heart in the same way.

Experiment 69. To show how the pulse may be studied. The movements of the artery in the human body as the pulse wave passes through it may be shown to consist in a sudden dilatation, followed by a slow contraction, interrupted by one or more secondary dilatations. This demonstration may be made by pressing a small piece of lookingglass about one centimeter square (two-fifths of an inch) upon the wrist over the radial artery, in such a way that with each pulse beat the mirror may be slightly tilted. If the wrist be now held in such a position that sunlight will fall upon the mirror, a spot of light will be reflected on the opposite side of the room, and its motion upon the wall will show that the expansion of the artery is a sudden movement, while the subsequent contraction is slow and interrupted.Bowditch's Hints for Teachers of Physiology.

1 Tobacco, and especially cigarettes, being a depressant upon the heart, should be positively forbidden. - DR. J. M. Keating on "Physical Development," in Cyclopedia of the Diseases of Children. 
Experiment 70. Place on a glass slide a thin layer of defibrinated blood (see Experiment 62); try to read printed matter through it. This cannot be done.

Experiment 7x. Wash away the coloring matter from the twigs (see Experiment 62) with a stream of water until the fibrin becomes quite white. It is fibrous and elastic. Stretch some of the fibers to show their extensibility; on freeing them, they regain their elasticity.

Experiment 72. Take some of the serum saved from Experiment 62 and note that it does not coagulate spontaneously. Boil a little in a test tube over a spirit lamp, and the albumen will coagulate.

Experiment 73. To illustrate some of the phenomena of circulation. Take a common rubber bulb syringe, of any standard make. Attach a piece of rubber tube about six or eight feet long to the delivery end of the syringe.

To represent in a very crude way the resistance made by the capillaries to the flow of blood, slip the large end of a common glass medicine dropper into the outer end of the rubber tube. This dropper has one end tapered to a fine point.

Place the syringe flat, without kinks or bends, on a desk or table. Press the bulb slowly and regularly. The water is thus pumped into the tube in an intermittent manner, and yet it is forced out of the tapering end of the glass tube in a steady flow.

Experiment 74. Take off the tapering glass tube, or, in the place of one long piece of rubber tube, substitute several pieces of glass tubing connected together by short pieces of rubber tubes. The obstacle to the flow has thus been greatly lessened, and the water flows out in intermittent jets to correspond to the compression of the bulb.

Experiment 75. By injecting with a syringe warm liquid gelatin (colored red) into the aorta of a dead animal, the whole vascular system can be filled. The gelatin sets solid when it becomes cold, and by cutting up the organs into thin slices and examining these under the microscope, the network of blood vessels can be most clearly observed. - Hill's Manual of Human Physiology. 


\section{CHAPTER VIII}

\section{RESPIRATION}

242. Nature and Object of Respiration. The blood, as we have learned, not only provides material for the growth and activity of all the tissues of the body, but also serves as a means of removing from them certain waste products.

We have now to consider a new source of nourishment to the blood, viz., that which it receives from the oxygen of the air. We are also to learn one of the methods by which the blood gets rid of poisonous waste matters.

We are to study the process of respiration, or the means by which oxygen is supplied to the various tissues, and by which the principal waste matters, or chief products of oxidation, are removed from the tissues.

+243. The Respiration of the Tissues. The tissues are continually taking in oxygen and are continually producing carbon dioxide and other waste products. In fact, the life of the tissues is dependent upon a continual succession of oxidations. When the blood leaves the tissues it is poorer in oxygen, and is richer in carbon dioxide. This exchange of gases between the blood and the tissues is sometimes spoken of as the respiration of the tissues, or internal respiration.

244. The Essential Step in Respiration. Now, as we have seen, the capillaries of the lungs are the only means of communication between the pulmonary arteries and the pulmonary veins. The blood in the pulmonary capillaries is separated from the air only by a delicate tissue formed 
of its own wall and the pulmonary membrane. Hence a gaseous interchange, the essential step in respiration, takes place between the blood and the air, by which the latter gains moisture and carbon dioxide, and loses its oxygen. These changes in the lungs also restore to the dark blood its bright red tint.

The only condition absolutely necessary to respiration is an organ having a delicate membrane, on one side of

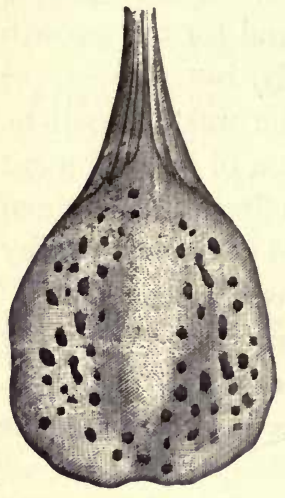

FIG. 83 .

The Epiglottis. which is a thin sheet of blood, while the other side is in such contact with the air that an exchange of gases can readily take place.

The demand for oxygen is, however, so incessant, and the accumulation of carbon dioxide is so rapid in every tissue of the body, that an All-Wise Creator has provided an extensive and complicated accessory system of machinery to effect this most remarkable and important change in the blood.

Let us now study the arrangement and working of this machinery, or, in other words, the organs of respiration.

245. Passages from the Mouth. If we look into the mouth of a friend, or into our own with the aid of a mirror, we see at the back part an arch which is the boundary line of the mouth proper. The funnel-shaped cavity beyond, into which both the mouth and the posterior nasal passages open, is called the pharynx. In its lower part are two openings: the trachea, or windpipe, in front, and the œsophagus behind (Figs. 5 I and 45).

246. The Larynx and the Epiglottis. The trachea, or windpipe, is surmounted by a box-like structure of cartilage, about 
four and one-half inches long, called the larynx. It contains the organ of voice and is more fully described in Chapter XII.

The upper end of the larynx opens into the pharynx, or throat, and is provided with a kind of lid, - the epiglottis, (sec. 156 and Fig. 45).

247. The Trachea, or Windpipe. The continuation of the larynx is the trachea, a tube about threefourths of an inch in diameter and about four inches long. It extends downwards along the middle line of the neck, where it may readily be felt in front, below the Adam's apple.

The walls of the windpipe are strengthened by a series of cartilaginous rings, each somewhat the shape of a horseshoe or like the letter $\mathrm{C}$, being incomplete behind, where they come in contact with the œsophagus. Thus the trachea, while always open for the passage of air, admits of the distention of the food passage.

$\times 248$. The Bronchial Tubes. The lower end of

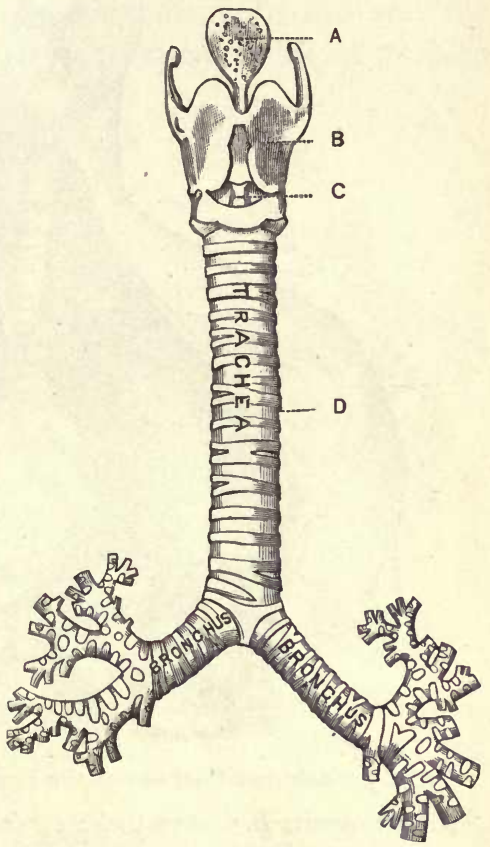

FIG. 84. Larynx, Trachea, and the Bronchi. (Front view.) the windpipe divides into two branches called bronchi. Each branch enters the lung of its own side and breaks up into a great number of smaller branches called bronchial tubes. 
These divide into smaller tubes, which continue subdividing till the whole lung is penetrated by their minute branches.

The walls of the larger bronchial tubes would readily collapse and close the passage for air, but for a wise

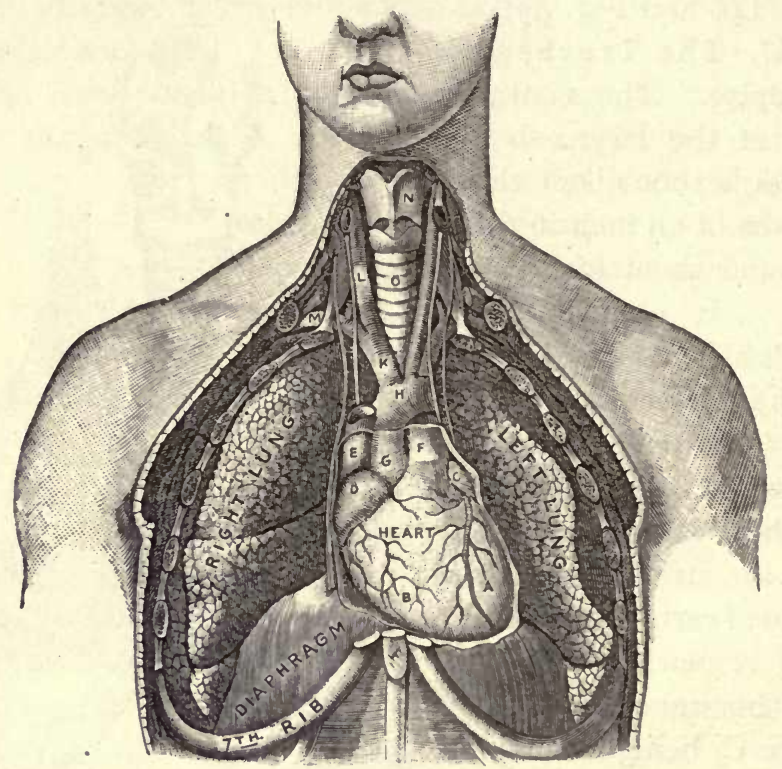

Fig. 85. Relative Position of the Lungs, Heart, and its Great Vessels.

$A$, left ventricle; $B$, right ventricle; $C$, left auricle; $D$, right auricle; $E$, superior vena cava; $F$, pulmonary artery ; $G$, aorta ; $H$, arch of the aorta ; $K$, innominate artery; $L$, right common carotid artery; $M$, right subclavian artery; $N$, thyroid cartilage forming upper portion of the larynx; $O$, trachea.

precaution. The horseshoe-shaped rings of cartilage in the trachea and plates of cartilage in the bronchial tubes keep these passages open.

+ 249. The Cilia of the Air Passages. The inner surfaces of the windpipe and bronchial tubes are lined with mucous membrane, which serves to keep the parts moist. 
Delicate filaments, called cilia, not unlike the threads which make up the pile on velvet, spring from the epithelial lining of the air tubes. Their constant wavy movement drives excessive secretion upwards towards the larynx, where it is finally expelled by coughing. In this way the lungs are also kept quite free from particles of foreign matter derived from the air. Thus these tiny cilia act as dusters which Nature uses to keep the air tubes free and clean (sec. 23).

-250. General Structure of the Lungs. The lungs, the chief organs of respiration, are two pinkish-gray structures of a light spongy appearance that fill the chest cavity, except the space taken up by the heart and large vessels. Between the lungs are situated the large bronchi, the œsophagus, the heart in its pericardium, and the great blood vessels.

The base of the lungs rests on the dome-like diaphragm, which separates the chest from the abdomen. This partly muscular and partly tendinous partition is a most important factor in breathing.

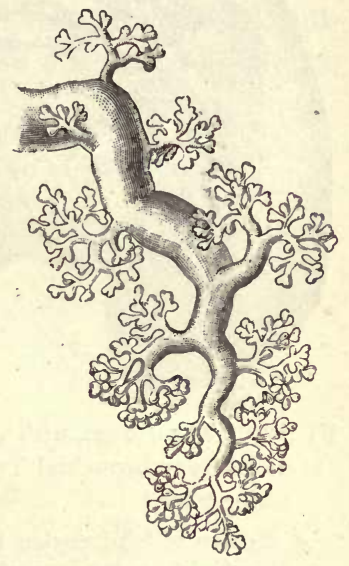

FIG. 86. Bronchial Tube, with its Divisions and Subdivisions.

(Showing groups of air sacs at the termination of minute bronchial tubes.)

251. The Pleura. Each lung is covered by an elastic serous membrane in a double layer, called the pleura. One layer closely envelops the lung, at the apex of which it is reflected to the wall of the chest cavity of its own side, which it lines. The two layers thus form between them a closed sac, a serous cavity (see Fig. 70, also sec. 213). 
In health the two pleural surfaces of the lungs are always in contact, and they secrete just enough serous fluid to allow

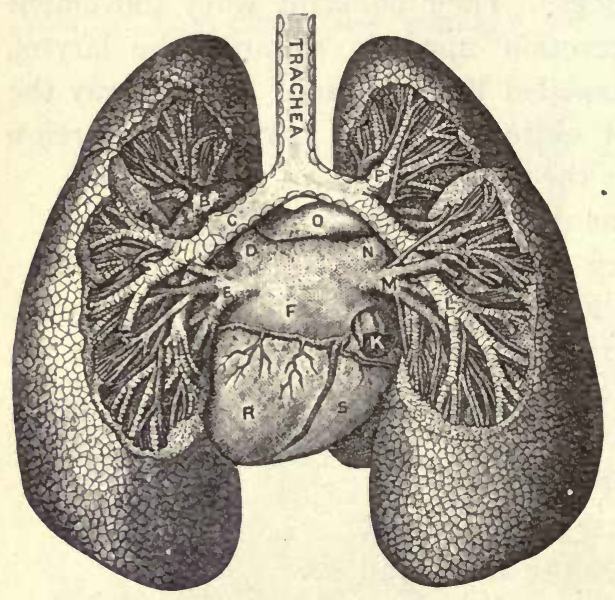

Fig. 87. The Lungs, with the Trachea, Bronchi, and larger Bronchial Tubes exposed. (Posterior view.)

$A$, division of left bronchus to upper lobe; $B$, left branch of the pulmonary artery; $C$, left bronchus; $D$, left superior pulmonary vein; $E$, left inferior pulmonary vein; $F$, left auricle; $K$, inferior vena cava; $L$, division of right bronchus to lower lobe; $M$, right inferior pulmonary vein; $N$, right superior pulmonary vein; $O$, right branch of the pulmonary artery; $P$, division of right bronchus to upper lobe; $R$, left ventricle; $S$, right ventricle. the surfaces to glide smoothly upon each other. + 252. M i n u $\mathrm{te}$ Structure of the Lungs. If one of the smallest bronchial tubes be traced in its treelike ramifications, it will be found to end in an irregular funnel-shaped passage, wider than itself. Around this passage is grouped a number of cavities with honeycomblike walls, the air cells, ${ }^{1}$ or air sacs, of the lungs. These communicate freely with the passage, and through it with the bronchial branches, but have no other openings. ' The whole arrangement of passages and air sacs springing from the end of a bronchial tube is called an ultimate lobule.

${ }^{1}$ The word "cell" is not used in this connection in its technical signification of a histological unit of the body (sec. 16), but merely in its primary sense of a small cavity. It is better, however, to call these cavities "air sacs." 
Countless numbers of these lobules, bound together by connective tissue, are grouped after the same fashion to form by their aggregation the lobes of the lung. The right lung has three such lobes, and the left, two.

The walls of the air sacs are of extreme thinness, consisting of delicate elastic and connective tissue, and lined inside by a single layer of thin epithelial cells. In the connective tissue run capillary vessels belonging to the pulmonary artery and veins. Now these delicate vessels are

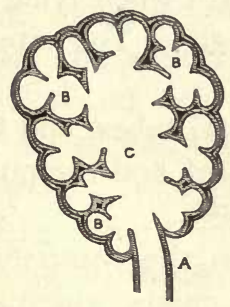

A

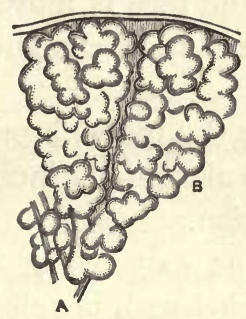

B

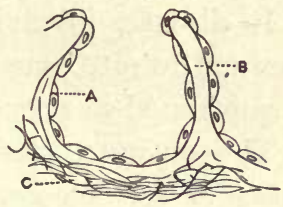

C

FIG. 88.

$A$, diagrammatic representation of the ending of a bronchial tube in air sacs, or alveoli ;

$B$, termination of two bronchial tubes in enlargement beset with air sacs (Huxley);

$C$, diagrammatic view of an air sac. A lies within sac and points to epithelium

lining wall; B, partition between two adjacent sacs, in which run capillaries;

c, elastic connective tissue (Huxley).

surrounded on all sides by air sacs. It is evident, then, that the blood flowing through these capillaries is separated from the air within the sacs only by the thin walls of the vessels and the delicate tissues of the air sacs (Fig. 90).

This arrangement is perfectly adapted for an interchange between the blood in the capillaries and the air in the air sacs. This will be more fully explained in sec. 260.

253. Inspiration and Expiration. The act of breathing consists of a series of rhythmical movements, succeeding one another in regular order. In the first movement the 
chest expands, and there is an inrush of fresh air. This is known as inspiration.

This is at once followed by the falling of the chest walls and the expulsion of air. This is known as expiration.

A pause now occurs, and the same breathing movements are repeated.

254. The Number of Respirations. In a healthy adult the number of respirations should be from 16 to 18 per minute. Exercise increases the number, while rest diminishes it. In standing the rate is more than when lying at rest. Mental excitement quickens the rate. The rate is lowest during sleep.

In diseases involving the lungs, bronchial tubes, and the pleura, the rate may be alarmingly increased, and the pulse is quickened in proportion.

The entrance and the exit of air into the respiratory passages are accompanied with peculiar sounds, which are readily heard on placing the ear at the chest wall.

+255. The Chest as an Air-Tight Chamber. The chest is an air-tight chamber with movable walls and floor. It has bony walls, with ribs connecting in front with the breastbone and behind with the spine. The spaces between the ribs are occupied by the intercostal muscles, while large muscles clothe the entire chest. The diaphragm serves as a movable floor to the chest.

In this air chamber are suspended the lungs, the air cells of which communicate with the outside through the bronchial passages, but have no connection with the chest cavity. The thin space between the lungs and the walls of the chest, called the pleural cavity, is in health a vacuum.

256. The Mechanism of Normal Respiration. Let us now, study the chief points about the mechanism of breathing, or respiration. 
When the diaphragm contracts it descends and thus increases the depth of the chest cavity. Being elastic, the lungs expand, filling up the inereased space, and a quantity of air is drawn into them. As soon as the diaphragm relaxes, returning to its arched position and reducing the size of the chest cavity, the lungs diminish in size and the air is driven out. After a short pause the diaphragm again contracts, and the same round of operations is repeated.

By the contractions of the intercostals and other muscles the ribs are raised and the breastbone pushed forward. The chest cavity is thus enlarged from side to side and from behind forwards. Thus, by the simultaneous descent of the diaphragm and the elevation of the ribs, the cavity of the chest is enlarged in three directions, - downwards, sideways, and from behind forwards.

$x$ It is thus evident that inspiration is due to a series of muscular contractions.

When the contractions cease the walls of the chest resume their former position and the diaphragm ascends. As a result of these movements, the original size of the chest cavity is

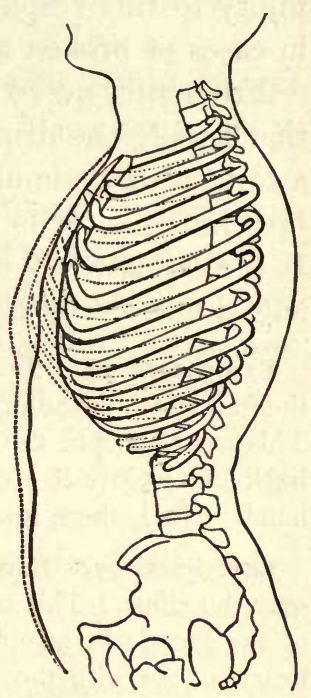

FIG. 89. Diagrammatic Section of the Trunk.

(Showing the expansion of the chest and the movement of the ribs. The dotted lines indicate the position during inspiration.) restored, and the inhaled air is driven from the lungs. Expiration may then be regarded as the result of an elastic recoil, and not of active muscular contractions. 7 25\%. The Nervous Control of Respiration. The movements of breathing go on without our attention. In sleep 
the regularity of respiration is even greater than when we are awake. There is a particular part of the nervous systern that presides over the breathing function. It is situated in that part of the brain called the medulla oblongata and is fancifully called the "vital knot" (sec. 330). It is injury to this respiratory center which usually proves fatal in cases of broken neck.

From this nerve center there is sent out to the nerves that supply the diaphragm and other muscles of breathing a force which stimulates them to regular contraction. This breathing center is modified by the condition of the blood. It is stimulated by an excess of carbon dioxide in the blood and is quieted by the presence of oxygen.

Experiment 76. To locate the lungs. Mark out the boundaries of the lungs by "sounding" them; that is, by percussion, as it is called. This means to put the forefinger of the left hand across the chest or back and to give it a quick, sharp rap with two fingers of the right hand. Note where it sounds hollow or resonant.

Experiment 77. Borrow a stethoscope and listen to the respiration over the chest. This is known as auscultation. Note the difference of the sounds in inspiration and in expiration. Do not confuse the heart sounds with those of respiration. The respiratory sounds are better heard on the right side. They may be heard fairly well by applying the ear flat to the chest, with only one garment interposed.

Experiment 78. Get a sheep's lungs, with the windpipe attached. Ask for the heart and lungs all in one mass. Take pains to examine the specimen first and accept only a good one. Parts are apt to be hastily snipped or mangled. Examine the windpipe. Note the horseshoe-shaped rings of cartilage in front, which serve to keep it open.

Experiment 79. Examine one bronchus, carefully dissecting away the lung tissue with curved scissors. Follow along until small branches of the bronchial tubes are reached. Take time for the dissection and save the specimen in dilute alcohol. Put pieces of the lung tissue in a basin of water and note that they float. 
258. The Gases of the Blood. The blood contains three gases, partly dissolved in it and partly in chemical union with certain of its constituents. These are oxygen, carbon dioxide, and nitrogen. The nitrogen need not be taken into account.

The oxygen is the material which the tissues require to carry on their work.

The carbon dioxide is a waste substance which the tissues produce by their activity, and which the blood carries away from them.

+259 . Effects of Respiration upon the Blood. As we have learned in a previous chapter, the arterial blood loses part of its oxygen in the tissues, and carbon dioxide takes its place. Now if the blood is to maintain its efficiency in this respect, it must always be receiving new supplies of oxygen, and also have some mode of throwing off its excess of carbon dioxide. This, then, is the double function of respiration.

Again, the blood sent out from the left side of the heart is of a bright scarlet color. After the blood has passed through the tissues and returns to the right side of the heart, it is of a more purple or claret color. This change in color takes place in the systemic capillaries and is due to the fact that there the blood gives up most of its oxygen to the tissues and receives from them a great deal of carbon dioxide.

In brief, while passing through the capillaries of the lungs the blood is changed from the venous to the arterial condition. That is to say, the blood in its progress through the lungs rids itself of its excess of carbon dioxide and obtains a fresh supply of oxygen. ${ }^{1}$

1 The student must guard himself against the idea that arterial blood contains no carbonic acid, and venous blood no oxygen. In passing through the lungs venous blood loses only a part of its carbonic acid; and arterial 
260. Effects of Respiration upon the Air in the Lungs. It is well known that if two different liquids be placed in a vessel in contact with each other and left undisturbed, they do not remain separate, but gradually mix, and in time will be perfectly combined. This is called diffusion of liquids.

Diffusion occurs with gases also, though the process is not usually visible. Two liquids will mingle even when separated from each other by a membrane. In a similar manner two gases, especially if of different densities, may mingle even when separated from each other by a membrane.

In a general way this explains the respiratory changes that occur in the blood in the lungs. Blood containing oxygen and carbon dioxide is flowing in countless tiny capillaries through the walls of the air sacs of the lungs. The air sacs themselves contain a mixture of the same two gases. A thin, moist membrane, well adapted to allow gaseous diffusion, separates the blood from the air. This membrane is the delicate wall of the capillaries and the epithelium of the air sacs.

By experiment it has been found that the pressure of oxygen in the blood is less than that in the air sacs, and that the pressure of carbon dioxide gas in the blood is greater than that in the air sacs. A diffusion of gases ensues.

The results of respiration upon the air in the lungs are thus twofold :

The blood gains oxygen and loses carbon dioxide.

The air sacs lose oxygen and gain carbon dioxide.

blood, in passing through the tissues, loses only a part of its oxygen. In blood, however venous, there is in health always some oxygen; and in even the brightest arterial blood there is actually more carbonic acid than oxygen. - T. H. HuXLEY. 
261. The Changes of Air in Breathing. The air which we exhale during respiration differs in several important particulars from the air we inhale. Expired air contains about 5 per cent less oxygen and 5 per cent more carbon dioxide than inspired air.

The temperature of expired air is usually higher than that of inspired air; it is also loaded with aqueous vapor, imparted to it in the upper air passages. The average daily quantity of water exhaled as vapor is about one-half pint.

The quantity of oxygen removed from the air by the breathing of an adult person at rest amounts daily to about eighteen cubic feet. About the same amount of carbon dioxide is expelled.

Expired air contains, besides carbon dioxide, a small amount of poisonous organic matter, which, from the presence of microorganisms, introduced in the inspired air, is apt to putrefy rapidly.

Various animal substances give rise, by decomposition, to distinct poisonous products known as ptomaines.

It is possible that some of the constituents of the expired air are of an allied nature. At all events, these substances have an injuri-

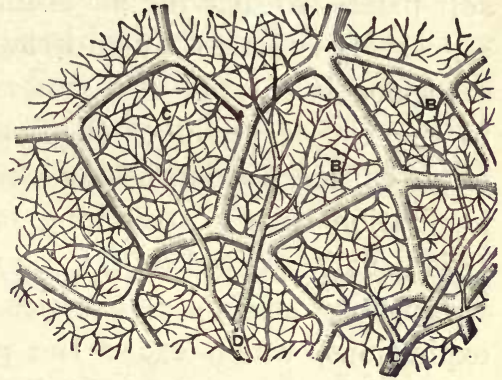

Fig. 90. Capillary Network of the Air Sacs and Origin of the Pulmonary Veins.

$A$, small branch of pulmonary artery ; $B$, twigs of pulmonary artery anastomosing to form peripheral network of the primitive air cells ; $C$, capillary network around the walls of the air sacs; $D$, branches of network converging to form the veinlets of the pulmonary veins. ous action, for an atmosphere containing simply I per cent of pure carbon dioxide has very little harmful effect on the animal economy, but an atmosphere in which the carbon dioxide has been raised even half of I per cent by breathing is highly injurious.

NOTE. - The nature, propagation, and action of bacteria are described in more detail under the topic of "Bacteria," in Chapter XIII of this book. 
262. Modified Respiratory Movements. Certain modified respiratory movements need explanation.

Coughing is usually produced by irritation in the upper part of the windpipe and larynx. A deep breath is drawn, the opening of the windpipe is closed and immediately is burst open with a violent effort, which sends a blast of air through the upper air passages. The object is to expel any mucus or foreign matter that is irritating the air passages.

Sneezing is like coughing; the tongue is raised against the soft palate, so that the air is forced through the nasal passages. It is caused by an irritation of the nostrils or eyes.

Sighing is a rapid and generally audible expiration, due to the elastic recoil of the lungs and chest walls. It is often caused by depressing emotions. Yawning is a deep inspiration with a stretching of the muscles of the face. It is usually excited by fatigue or drowsiness.

Laughing consists of a series of short, rapid, spasmodic expirations, which cause the peculiar sounds, with characteristic movements of the facial muscles. Crying, caused by emotional states, consists of sudden jerky expirations, with long inspirations, and facial movements indicative of distress. In sobbing, which often follows long-continued crying, there is a rapid series of convulsive inspirations, with sudden involuntary contractions of the diaphragm.

Hiccough is a sudden jerking inspiration due to the spasmodic contraction of the diaphragm and of the vocal cords, causing the air to rush suddenly through the larynx and produce this peculiar sound.

263. How the Atmosphere is made Impure. The air around us is constantly being made impure in a great variety of ways. The combustion of fuel, the respiration of men and animals, the exhalations from their bodies, the noxious gases and effluvia of the various industries, together 
with the changes of fermentation and decomposition to which all organized matter is liable, - all tend to pollute the atmosphere.

The breathing of dust and smoke in the air of towns, which is to a greater or less extent laden with the germs of disease, is an ever-present and most potent menace to public and personal health. It is one of the main causes of the excess of mortality in towns and cities over that of country districts.

. This is best shown in the overcrowded streets and houses of great cities, which are deprived of the purifying influence of sun and air. The fatal effect of living in vitiated air is especially marked in the mortality among infants and children living in the squalid and overcrowded sections of our great cities.

Experiment 80. Simple apparatus to illustrate the movements of the lungs in the chest. $T$ is a bottle from which the bottom has been removed; $D$, a flexible and elastic membrane tied on the bottle and capable of being pulled out by the string $S$, so as to increase the capacity of the bottle. $L$ is a thin elastic bag representing the lungs. It communicates with the external air by a glass tube fitted air-tight through a cork in the neck of the bottle. When $D$ is drawn down the pressure of the external air causes $L$ to expand. When the string is let go $L$ contracts again by virtue of its elasticity.
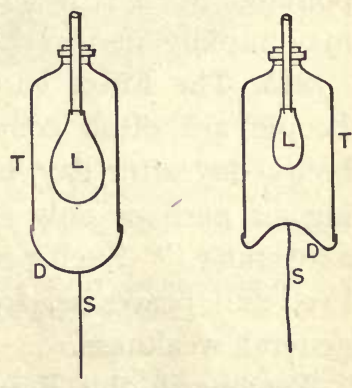

Fig. 9r.

\section{The Necessity for a Proper Supply of Pure Air; the} Need of the Removal of Impure Air. As we have learned, the expired air contains, besides carbon dioxide, not only a certain amount of organic matter in the form of vapor, but minute dust particles including many micro-organisms. 
The air thus already vitiated putrefies very rapidly after it leaves the mouth. It is at once absorbed by clothing, curtains, carpets, porous walls, and by many other objects. It is difficult to dislodge these enemies of health even by free ventilation. The close and disagreeable odor of a filthy or overcrowded room is due to these organic exhalations from the lungs and the skin, as well as from the unclean clothing of the occupants.

The necessity of having a proper supply of fresh air in enclosed places, and the need of removal of impure air are thus evident. If a man were shut up in a tightly sealed room containing 425 cubic feet of air, he would be found dead, or nearly so, at the end of twenty-four hours. Long before this time he would have suffered from nausea, headache, dizziness, and other proofs of poisoning. These symptoms are often felt by those who are confined for an hour or more in a room where the atmosphere has been polluted by a crowd of people. The unpleasant effects may rapidly disappear on breathing fresh air.

265. The Effect on the Health of breathing Foul Air. People are often compelled to remain indoors for many hours, day after day, in shops, factories, or offices, breathing air perhaps only slightly vitiated, but still recognized as "stuffy." Such persons often suffer from loss of appetite, dull headache, fretfulness, persistent weariness, and general weakness.

Persons in this lowered state of health are much more prone to suffer from colds, catarrhs, bronchitis, and pneumonia than if they were living in the open air, or breathing only pure air. Thus, in military service, the soldiers who live in tents in the coldest weather are far more free from colds and lung troubles than those who live in tight and ill-ventilated huts. 
266. The Danger from Pulmonary Infection. The germ of pulmonary consumption, known as the bacillus tuberculosis, is contained in the breath and the sputa from the lungs of its victims. It is not difficult to understand how these bacilli may be conveyed through the air from the lungs of the sick to those of apparently healthy people. Such persons may, however, be predisposed, either constitutionally or by defective hygienic surroundings, to fall victims to this dread disease. Overcrowding, poor ventilation, and dampness all tend to increase the risk of pulmonary infection.

These bacilli are not necessarily transmitted directly through the air from the lungs of the sick to be implanted in the lungs of the healthy. They may

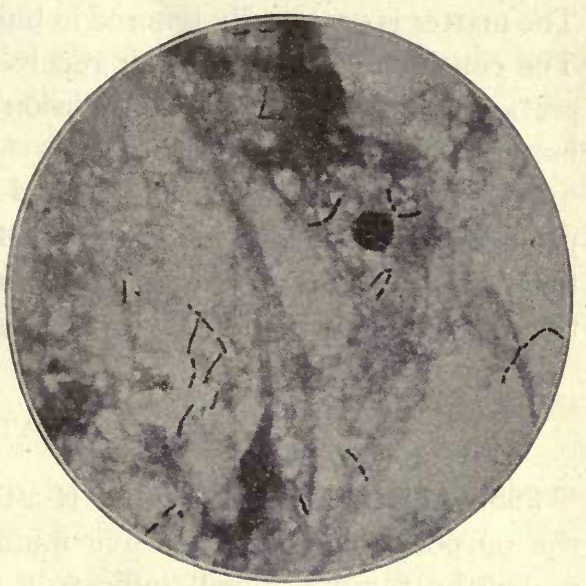

FIG. 92. Bacillus Tuberculosis.

(A minute portion of sputum from a case of phthisis, or "consumption" of the lungs, magnified by Ioo0 diameters. These bacilli are rod-shaped bacteria, stained to show black. The black spots in the figure are merely the débris in the sputum, also stained to show black.)

remain for a time in the dust of damp, filthy, and overcrowded houses. The dust contains the germs, and thus they may enter the body with the air breathed. In a congenial soil the bacilli retain their vitality for a long time, and possibly may take on more virulent infective properties than they possessed when expelled from the diseased lungs. 
f 267. The Object of Ventilation. The question of a practicable and economical system of ventilation for our homes, schoolrooms, workshops, and public places presents many difficult and perplexing problems. It is perhaps due to the complex nature of the subject that ventilation, as an ordinary condition of daily health, has been so much neglected. The matter is practically ignored in building ordinary houses. The continuous renewal of air receives little, if any, consideration, compared with the provision made to furnish our homes with heat, light, and water.

The object of ventilation should be twofold: first, to provide for the removal of the impure air; second, to provide for a supply of pure air without cold draughts. This is one of the most difficult of sanitary problems.

\section{ANIMAL HEAT}

268. Animal or Vital Heat. If a thermometer, made for the purpose, be placed for five minutes in the armpit.or under the tongue, it will indicate a temperature of about $98 \frac{1}{2}^{\circ}$ Fahr., whether the surrounding atmosphere be warm or cold. This is the normal temperature of a person in health, and it rarely varies more than a degree or two. Now, as the body is constantly losing heat by radiation and conduction, it is evident that if the normal temperature be maintained, a certain amount of heat must be generated within the body to make up for this loss.

The heat thus produced is known as animal or vital heat.

269. Sources of Bodily Heat. The heat of the body is generated by the chemical changes which are constantly going on in the tissues. These chemical changes are of various kinds, but the great source of heat is the katabolic process known as oxidation. 
Wherever there is life, this process of oxidation is going on, but more energetically in some tissues and organs than in others. In other words, every tissue in the body is a source of heat in proportion to the activity of its chemical changes. The more active the changes, the greater is the heat produced, and the greater the amount of urea, carbon dioxide, and water eliminated.

The waste caused by this oxidation must be made good by a due supply of food to be built up into protoplasmic material. For the production of heat, therefore, food is necessary. The oxidation process is not so simple and direct as the statement of it might seem to indicate; but the ultimate result is as simple as in ordinary combustion outside of the body, and the products are the same.

The continual chemical changes, then, chiefly by oxidation of combustible materials in the tissues, produce an amount of heat which is sufficient to maintain the temperature of the living body at about $98 \frac{1}{2}^{\circ}$ Fahr. This process of oxidation provides not only for the heat, but also for the mechanical energy, required to carry on the work of the body.

+270. Regulation of the Bodily Temperature. While bodily heat is being continually produced, it is also as continually being lost by the lungs, by the skin, and to some extent by certain excretions. The blood, in its swiftly flowing current, carries warmth from the tissues where heat is being rapidly generated, to the tissues or organs in which it is being lost by radiation, conduction, or evaporation. Were there no arrangement by which heat could be distributed and regulated, the temperature of the body would be very unequal in different parts and would vary at different times. 
The normal temperature is maintained with slight variations throughout life. Indeed, a change of more than a degree above or below the average indicates some disease in the organism or some unusual influence. It is evident, then, that the mechanisms which regulate the temperature of the body must be exceedingly sensitive.

The two chief means of regulating the temperature of the body are the lungs and the skin.

Experiment 8x. To show the natural temperature of the body. Borrow a physician's clinical thermometer, and take your own temperature, and that of several friends, by placing the instrument under the tongue, closing the mouth, and holding it there for five minutes. Read it while in position, or the instant the instrument is removed. The natural temperature is about $98 \frac{1}{2}^{\circ} \mathrm{Fahr}$. The thermometer should be thoroughly cleansed after each use.

If a doctor's thermometer is not to be obtained, unfasten and use one of the little thermometers often found on calendars and advertising circulars. The bodily temperature will not be indicated accurately in this crude way.

Note. - A substitute for a clinical thermometer may be readily contrived by taking an ordinary house thermometer from its tin case and cutting off the lower part of the scale so that the bulb may project freely. With this instrument the pupils may take their own and each other's temperatures, and it will be found that, whatever the season of the year or the temperature of the room, the thermometer in the mouth will record about $99^{\circ} \mathrm{Fahr}$. Care must, of course, be taken to keep the thermometer in the mouth till it ceases to rise, and to read while it is still in position. - Professor H. P. Bowditch.

\section{The Skin as a Heat Regulator. The great regulator of the bodily temperature is the skin. \\ First, the skin regulates the loss of heat by means of the vaso-motor mechanism. The greater the quantity of blood which passes through the skin, the greater will be the loss of heat by conduction, radiation, and evaporation.}


Hence any action of the vaso-motor mechanism which causes dilatation of the cutaneous capillaries leads to a larger flow of blood through the skin and will tend to cool the body. On the other hand, when by the same mechanism the cutaneous vessels are constricted there will be a smaller flow of blood through the skin, which will serve to check the loss of heat from the body.

Again, the special nerves of perspiration act directly as regulators of temperature. They increase the loss of heat when they promote the secretion of the skin, and diminish the loss when they cease to promote it.

272. How the Bodily Temperature is adjusted during Exercise. The practical working of this heat-regulating mechanism is well shown when we take exercise. The bodily temperature rarely rises as much as a degree during vigorous exercise. The respiration is increased, the cutaneous capillaries become dilated from the quickened circulation, and a larger amount of blood circulates through the skin. The presence in the skin of so much blood stimulates the sweat glands to increased activity, resulting in a free perspiration. A large amount of heat is thus lost to the body, sufficient to offset the addition caused by the muscular contractions.

This topic is again treated in the description of the skin as a regulator of the bodily temperature (sec. 29I).

273. Effect of Alcohol upon the Respiration. Alcohol tends to diminish the breathing capacity of the lungs. This effect follows from its partial paralyzing influence upon the sympathetic nervous system.

The enfeebled respiration explains (though it is only one of the reasons) why habitual users of alcoholic liquors cannot endure a normal amount of vigorous and prolonged exertion. The hurried circulation produced by intoxicants 
involves in turn quickened respiration, which means more rapid exhaustion of the life forces.

The prolonged use of alcohol also involves a repeated dilatation of the capillaries, which steadily diminishes their distensive power, thereby rendering the person more sus-. ceptible to the attack of pulmonary diseases.

274. Effect of Alcohol upon Pulmonary Diseases. The habitual use of alcoholic liquors, it is believed, makes a person unusually susceptible to pneumonia.

It has also been found that pulmonary tuberculosis is more frequent in drinkers than in ordinary people. A noted physician of Paris (M. Legendre) says : "Alcohol is a frequent cause of consumption by its power of weakening the lungs." 1

The persistent user of alcohol also suffers, more severely than abstainers, from other and less dangerous pulmonary diseases, as simple colds, chronic bronchitis, and influenza.

275. Effect of Tobacco upon the Respiratory Passages. The effects of tobacco upon the throat and lungs are frequently marked and persistent. The smoke irritates the mucous membrane of the mouth and throat, producing an unnatural thirst. The inflammation may extend up the Eustachian tube, and impair the sense of hearing.

The inhalation of tobacco smoke often produces unhealthful effects upon the delicate mucous membrane of the bronchial tubes and of the lungs. This results frequently in an irritating cough, with short breath. ${ }^{2}$

${ }^{1}$ Alcohol, instead of preventing consumption, reduces the vitality so much as to render the system unusually susceptible to that fatal disease. DR. R. S. TrACY, Sanitary Inspector, New York Health Department.

2 The action of the heart and lungs is impaired by the influence of the narcotic on the nervous system, but a morbid state of the larynx, trachea, and lungs results from the direct action of the smoke.-DR. LAYCock, Professor of Medicine in the University of Edinburgh. 


\section{ADDITIONAL EXPERIMENTS}

Experiment 82. To show how the lungs may be filled with air. Take one of the lungs saved from Experiment 78. Tie a glass tube six inches long in to the larynx. Attach a piece of rubber to one end of the glass tube. Now inflate the lungs several times and let them collapse.

Experiment 83. To show that the expired air contains carbon dioxide. Put a glass tube into a bottle of lime water and blow through the tube. The liquid will soon become cloudy, because the carbon dioxide of the expired air unites with the lime held in solution and forms the white, solid carbonate of lime.

Experiment 84. To illustrate the manner in which the movements of inspiration cause the air to enter the lungs. Fit up an apparatus, as represented in Fig. 93, in which a stout glass tube is provided with a sound cork, $B$, and also an airtight piston, $D$, resembling that of an ordinary syringe. A short tube, $A$, passing through the cork, has a small India-rubber bag, $C$, tied to it. Fit the cork in the tube while the piston is near the top. Now, by lowering the piston, we increase the capacity of the cavity containing the bag. The pressure outside the bag is thus lowered, and air rushes into it through the tube, $A$, till a balance is restored. The bag is thus stretched. As soon as we push up the piston, the elasticity of the bag, being free to act, drives out the air just taken in, and the piston returns to its former place.

In this experiment the elastic bag and its tube

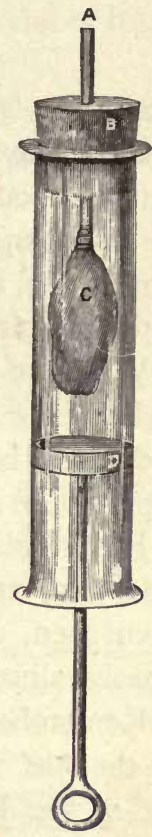

FIG. 93. Apparatus for illustrating the Movements of Respiration. represent the lungs and trachea, and the glass vessel enclosing it represents the thorax. It must be remembered, however, that the space between the wall of the thorax and the outside of the lung is a vacuum. 


\section{CHAPTER IX}

\section{THE SKIN AND THE KIDNEYS}

+ 276. The Formation of Waste Products. We have learned that the food materials, prepared by the digestive processes, are taken up by the branches of the portal vein, or by the lymphatics, and carried to the tissues to provide them with nourishment.

We have learned also that oxygen, introduced into the body by the lungs, is being continually carried to the tissues, and that the blood is constantly being purified by being deprived in the lungs of its excess of carbon dioxide.

From this tissue activity, which is mainly a process of oxidation, are formed certain waste products which, as we have seen, are carbon dioxide, water, and urea, or some closely allied body.

Remember, then, that carbon dioxide, urea, salts, and water are the chief waste products of the body, and that they are cast out of the body by three main channels, - the lungs, the skin, and the kidneys.

+277. How the Waste Products are eliminated. The elimination of these waste products is brought about by a special apparatus called the organs of excretion. The worn-out substances themselves are called excretions, as opposed to secretions, which are elaborated for use in the body (see note, p. 99).

As already shown, the lungs are the main channels for the elimination of carbon dioxide. They also excrete a considerable quantity of water as vapor. 
By the skin the body gets rid of a small quantity of salts, a little carbon dioxide, and a large amount of water in the form of perspiration.

From the kidneys are eliminated nearly all the urea and allied bodies, most of the salts, and a large amount of water. Practically all the nitrogenous waste products leave the body by the kidneys.

\section{The Skin as an Important and Complex Organ.} The skin is a blood-purifying organ as truly as are the lungs and the kidneys, while it performs other and complex duties. It also serves as a protective covering for the surface of the body.

The skin, being richly supplied with nerves, is an important organ of sensibility and touch (sec. 370).

The skin ranks as an important organ of excretion, its product being the sweat.

The skin also plays an important part in regulating the bodily temperature (sec. $27 \mathrm{I}$ ).

279. General Structure of the Skin. The skin is divided into two distinct layers, which may

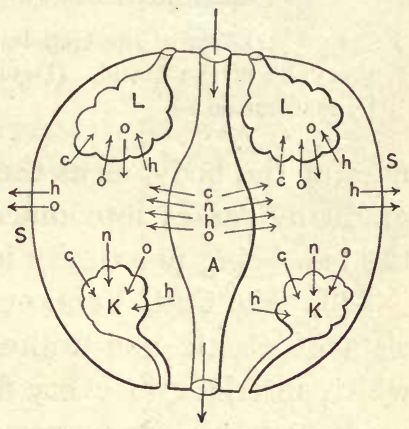

FIG. 94. Diagrammatic Scheme to illustrate in a very General Way Absorption and Excretion.

$A$, represents the alimentary canal; $L$, the pulmonary surface; $K$, the surface of the renal epithelium; $S$, the skin ; $o$, oxygen ; $h$, hydrogen; $n$, nitrogen. be readily separated: the deeper layer, - the true skin, dermis, or corium ; and the superficial layer, or outer skin, the epidermis, cuticle, or scarf skin. In some parts of the body the skin is closely attached to the structures beneath, while in others it is less firmly adherent and rests upon a variable amount of fatty tissue. It thus assists in relieving 
the abrupt projections and depressions of the general surface, and in giving roundness and symmetry to the entire body. The thickness of the skin varies in different parts of the body. Where exposed to pressure and friction, as on the

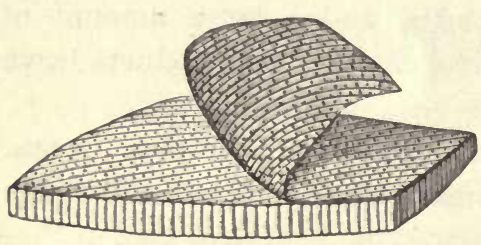

FIG. 95. A Layer of the Cuticle from the Palm of the Hand. (Detached by maceration.) soles of the feet and in the palms of the hands, it is much thickened.

The true skin is $\frac{1}{12}$ to $\frac{1}{8}$ of an inch in thickness, but in certain parts, as in the lips and ear passages, it is often not more than $\frac{1}{1} \frac{1}{0}$ of an inch thick. At the orifices of the body, as at the mouth, ears, and nose, the skin gradually passes into mucous membrane, the structure of the two being practically identical.

280. The Cutis Vera, or True Skin. The true skin consists of elastic and white fibrous tissue, the bundles of which interlace in every direction. Throughout this feltwork structure are numerous muscular fibers, as about the hair follicles and the oil glands. When these tiny muscles contract from cold or emotion, the little hairs project upon the surface, producing what is called "goose flesh."

The true skin is richly supplied with blood vessels and nerves, as shown by the fact that it bleeds freely when cut and that it is very sensitive. The surface of the true skin is thrown into a series of minute elevations, called the papillæ, upon which the outer skin is moulded. These abound in blood vessels, lymphatics, and peculiar nerve endings, which will be described in connection with the organ of touch (sec. $37 \mathrm{I}$ and Fig. IO4).

The papillæe are large and numerous in sensitive places, as the palms of the hands, the soles of the feet, and the 
fingers. They are arranged in parallel curved lines, and form the elevated ridges seen on the surface of the outer skin (Figs. 97 and 98).

281. The Epidermis, or Cuticle. Above the true skin is the epidermis, which as seen under the microscope resembles the scales of a fish. It is this layer that is raised by a blister.

As the epidermis has neither blood vessels nor lymphatics, it may be cut without bleeding. It contains no nerves except in the deepest layers, therefore the surface is not sensitive to pain. The cuticle is made up of several layers of cells, which next to the true skin are soft and active, but gradually become harder towards the surface, where they are flattened and scale-like.

The upper scales are continually being rubbed off and are replaced by deeper cells from beneath. These new cells continually push upward the cells already existing, then gradually become dry and are cast off as fine white dust.

Rubbing with a coarse towel after a hot bath removes countless numbers of these dead cells. During and after an attack of scarlet fever the patient "peels," that is, sheds an unusual amount of the scaly cells of the cuticle.

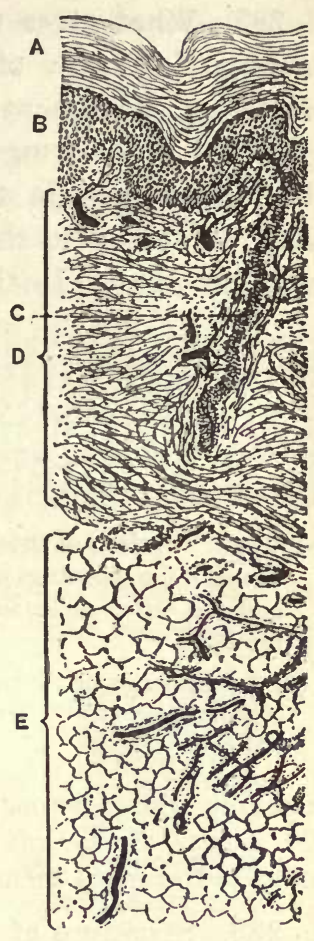

Fig. 96. Cross-Section of Skin, with Blood Vessels injected.

(Magnified 30 diameters.)

$A$, horny layer of cuticle; $B$, deeper layer of cuticle, rete mucosum; $C$, duct of sweat gland; $D$, corium, or true skin; $E$, subcutis, or sub-layer of corium, with columnar epidermic cells in immedia te contact with dermis. (The blood vessels are injected and in this figure show black.) 
282. What gives the Skin its Color. The deeper and more active layer of the epidermis, the rete mucosum, is made up of pigment cells, some of which contain minute granules of coloring matter that give color to the skin. The differences in the tint, as brunette, fair, and blond, are due mainly to the amount of coloring matter in these pigment cells. In the European this amount is generally

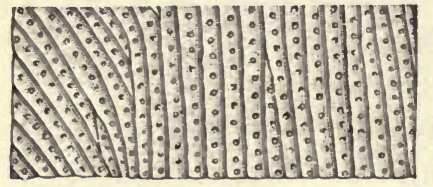

Fig. 97. Surface of the Palm of the Hand, showing the Openings of the Sweat Glands and the Grooves between the Papillæ of the Skin.

(In the smaller figure the same epidermal surface is shown as seen with the naked eye. Magnified 4 diameters.)

carefully with a strong magnifying glass. Study the papillæ on the palms. Scrape off with a blunt knife a few bits of the scarf skin, and examine them with the microscope.

283. Structure of the Hair. The hair and the nails are modified forms of the epidermis.

A hair is formed in a depression, or furrow, the inner walls of which consist of the infolded outer skin. This - depression takes the form of a sac and is called the hair follicle, in which the roots of the hair are embedded.

Opening into each hair follicle are usually one or more sebaceous, or oil glands, producing an oily secretion which serves to oil the hair and keep the skin moist and pliant (Fig. 100).

At the bottom of the follicle there is an upward projection of the true skin, a papilla, which contains blood vessels 
and nerves. It is covered with epidermic cells which multiply rapidly, thus causing the rapid growth of the hair.

Surmounting each papilla is a bulbous expansion, the hair bulb, from which the hair begins to grow.

284. How the Hair grows. The cells on the papillæ form the hairs. As these cells are pushed upwards by new ones formed beneath, they are compressed, and the shape of the follicle determines the cylindrical form of the shaft of the hair. So closely are these cells welded to form the cylinder that even under a microscope the hair presents only a fibrous appearance, except in the center, where the cells are larger, forming the medulla, or pith (Fig. I07).

285. What gives the Color to the Hair. The medulla of the hair contains the pigment granules, or coloring matter, which may be of any shade between a light yellow and an intense black. It is this that gives the great variety in color. Generally with old people the pigment is absent, the cells being occupied by air ; hence the hair becomes gray or white.

$\sqrt{ }$ 286. The Nails. A nail is simply a thick layer of epidermic cells or horny scales built from the outer part of the scarf skin. It lies upon very fine and closely set papillæ, forming its matrix, or bed. It is covered at its base with a fold of the true skin, called its root, from beneath which it seems to grow (Figs. IOI, I02, and 108).

$\checkmark$ 28\%. Structure of the Sweat Glands. Deep in the substance of the true

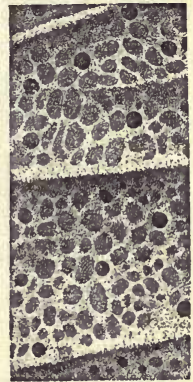

FIG. 98. Epidermis of the Foot.

(It will be noticed that there are only a few orifices of the sweat glands in this region. Magnified 8 diameters.) skin, or in the fatty tissue beneath it, are the sweat glands. Each gland consists of a single tube with a blind end, coiled 
in a sort of ball about one-sixtieth of an inch in diameter. From this coil the tube passes upward through the dermis in a wavy course until it reaches the cuticle, which it penetrates with a number of spiral turns, at last opening on the surface.

The tubes have delicate walls lined with epithelial cells. The coil of the gland is enveloped by minute blood vessels.

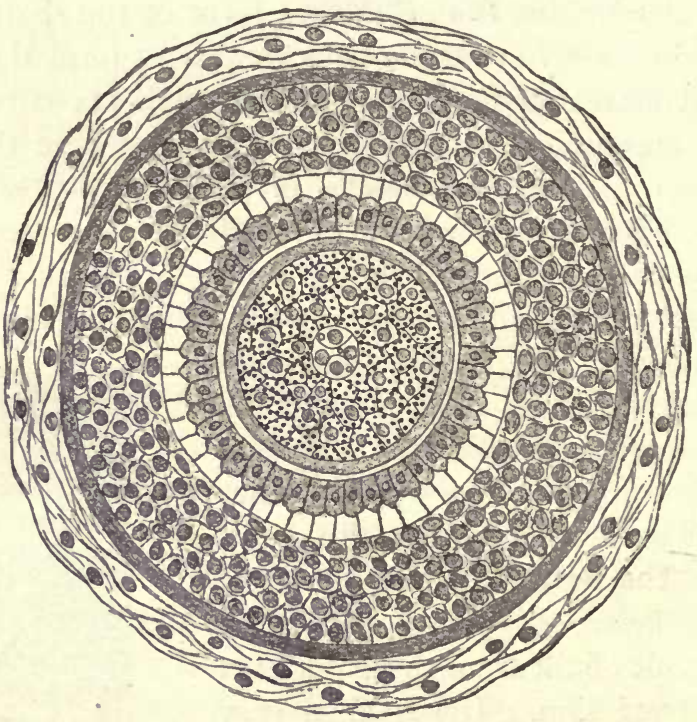

Fig. 99. Cross-Section of a Human Hair with its Follicle. (Magnified about 300 diameters.)

The cells of the glands are separated from the blood only by a fine partition and draw from it whatever supplies they need for their special work.

$>$ 288. Number of Sweat Glands. With few exceptions every portion of the skin is provided with sweat glands, but they are not equally distributed over the body. They 
are fewest in the back and neck, where it is estimated they average 400 to the square inch. They are thickest in the palms of the hands, where they amount to nearly 3000 to each square inch. These minute openings occur in the ridges of the skin and may be easily seen with a hand lens. The length. of a tube when straightened is about one-fourth of an inch. The total number in the body is roughly estimated at about 2,500,000, thus making about ten miles of sweat tubes.

\section{\lrcorner 289. The Composition and Quantity of} Sweat. The sweat is a turbid, saltish fluid with a feeble but characteristic odor due to certain volatile fatty acids. Of the inorganic constituents of sweat, common salt is the largest and most important. Some carbon dioxide passes out through the skin, but not more than one-fiftieth as much as escapes by the lungs.

The sweat ordinarily evaporates from the pores into the air as fast as it is formed. This is called insensible perspiration. About a pint of sweat is thus lost in the course of a day.

If there is no perspiration visible we must not infer that the skin is inactive, since sweat is continually passing from the surface.

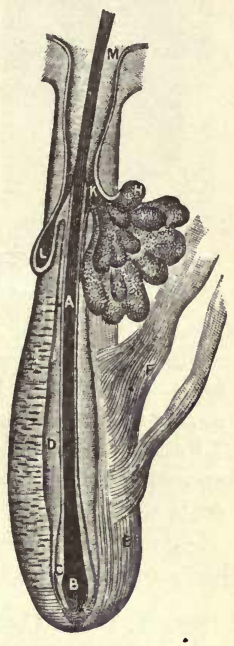

FIG. 100. Hair and Hair Follicle.

$A$, root of hair; $B$, bulb of the hair; $C$, internal root sheath ; $D$, external root sheath ; $E$, external membrane of follicle; $F$, muscular fibers attached to the follicle ; $H$, compound sebaceous gland with its duct, $K ; L$, simple sebaceous gland; $M$, opening of the hair follicle.

290. The Visible Sweat. The visible sweat, frequently spoken of as sensible perspiration, becomes abundant during active exercise, after copious drinking of cold water, on taking certain drugs, and when the body is exposed to 
excessive warmth. Forming more rapidly than it evaporates, it collects in drops on the surface.

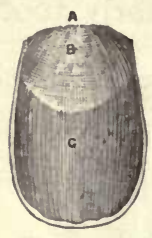

FIG. 101. Concave or Adherent Surface of the Nail.

$A$, border of the root; $B$, whitish portion of semilunar shape (the lunula); $C$, body of nail. The continuous line around border represents the free edge.

A man's weight may be considerably reduced within a few hours by means of the perspiration alone. This may explain to some extent the weakening effect of profuse perspiration, as from " night sweats" of consumption, and during convalescence in typhoid fever.

Experiment 86. Study the openings of the sweat glands with the aid of a strong magnifying glass. They are conveniently examined on the palms.

ง 291. The Skin as a Regulator of the Temperature of the Body. By means of the sweat the skin performs a third, and a most important, function, viz., that of regulating the temperature of the body.

The blood vessels of the skin, like those of other parts of the body, are under the control of the nervous system, which regulates their diameter. If the nervous control be relaxed, the blood vessels dilate, more blood flows through them, and more material is brought to the glands of the skin to be acted upon.

External warmth relaxes the skin and its blood vessels. There results an increased flow of blood to the skin, with

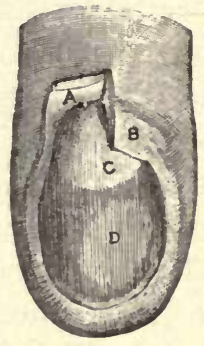

FIG. 102. Nail in Position.

$A$, section of cutaneous fold $(B)$ turned back to show the root of the nail ; $B$, cutaneous fold covering the root of the nail; $C$, semilunar whitish portion (lunula); $D$, body of nail. increased perspiration. External cold has the opposite effect. 
Now, it is a law of physics that the change from liquid to vapor involves a loss of heat. For instance, a few drops of ether or of any volatile liquid placed on the skin produce a marked sense of coldness, because the heat necessary to change the liquid into vapor has been drawn rapidly from the skin. This principle holds good for every drop of sweat that reaches the mouth of a sweat gland. As the sweat evaporates, it absorbs a certain amount of heat and cools the body to that extent.

292. How the Action of the Skin may be modified. After profuse sweating we feel chilly from the evaporation of a large amount of moisture, which rapidly cools the surface. When the weather is very warm the evaporation tends to prevent the bodily temperature from rising. On the other hand, if the weather be cold, much less sweat is produced, the loss of heat from the body is greatly lessened, and its temperature prevented from falling. Thus it is plain why certain drugs and hot baths are often given and other efforts are made to sweat the fever patient. The increased activity of the skin helps to reduce the bodily heat.

2 293. The Secretion of Sweat and its Nervous Control. The sweat glands are under the control of certain nerve fibers originating in the spinal cord and

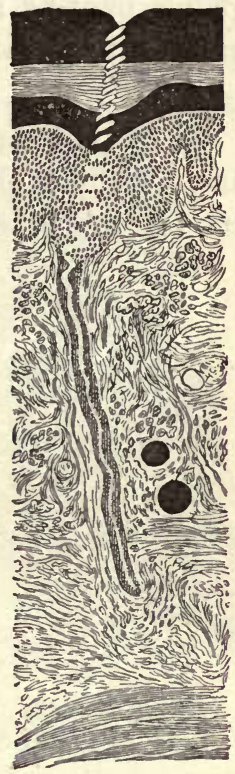

FIG. 103. Transverse Section through the Human Skin.

(Treated with osmic acid; showing three outer layers of the cuticle, two in black and a middle light layer. Below the inner dark layer, the active layer, or rete mucosum, is well shown. All below is the true skin. The tortuous course of a sweat gland is well marked. The two round black spots are fat cells. Magnified 30 diameters.) 
are not necessarily excited to action by an increased flow of blood through the skin. In other words, the sweat glands may be stimulated to increased action, both by an increased flow of blood, and also by special nerve impulses sent to them.

These two agencies, while usually working in harmony, may produce phenomena which are essentially independent of each other. Thus a strong emotion, like fear, may

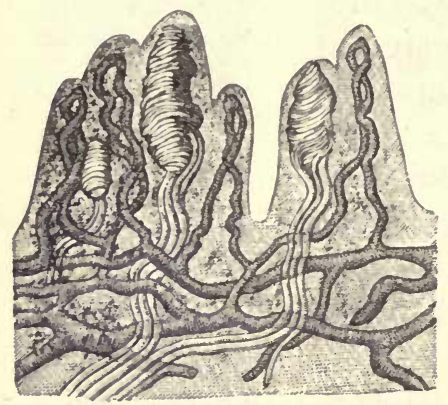

FIG. 104. Papillæ of the Skin of the Palm of the Hand.

(In each papilla are seen vascular loops (dark lines) running up from the vascular network below; the tactile corpuscles with their nerve branches (white lines) which supply the papillæ.)

cause a profuse sweat to break out, with cold, pallid skin. In this case the two sets of nerves act in the opposite way. The sweat glands secrete, but the blood vessels are constricted.

7294. Absorbent Powers of the Skin. The skin serves to some extent as an organ for absorption. It is capable of absorbing certain substances to which it is freely exposed. Ointments rubbed in are absorbed by the lymphatics in those parts where the skin is thin, as in the bend of the elbow or knee, and in the armpits. Physicians use medicated ointments in this way. House painters are often poisoned by the absorption of lead into the body through the skin.

A slight amount of water is absorbed in bathing. Sailors deprived of fresh water have been able to allay partially their intense thirst by soaking their clothing in salt water.

If the outer skin be removed from parts of the body, the exposed surface absorbs certain substances rapidly. When 
the physician wishes remedies to act through the skin, he sometimes raises a small blister, and dusts over the surface some drug in the form of a fine powder.

$\checkmark 295$. Necessity for Personal Cleanliness. The surface of the skin is continually casting off perspiration, oily material, and dead scales. By friction and regular bathing we are able to get rid of a great deal of this waste material. If this is not frequently and thoroughly done, the oily secretion retains the particles of waste substances on the surface of the body, while dust and dirt collect and form a layer upon the skin.

As this unwholesome layer is a fertile soil in which bacteria may develop, many skin diseases may result from neglect of personal cleanliness. It is also highly probable that germs of disease thus adherent to the skin may be absorbed into the system. Parasitic diseases are greatly favored by the presence of dirt on the skin.

$\lambda 296$. Why we need to bathe. In bathing we have two distinct objects in view, - to keep the skin clean and to invigorate the body as a whole. These are closely related,

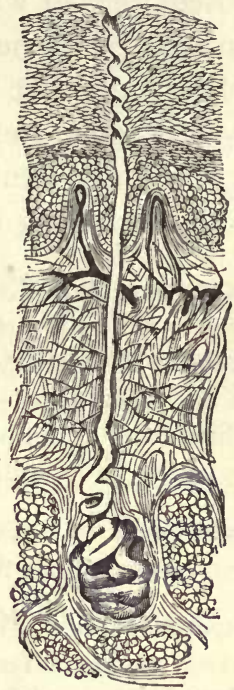

FIg. I05. Magnified View of a Sweat Gland with its Duct.

(The convoluted gland is seen surrounded with big fat cells and may be traced through the dermis to its outlet in the horny layers of the epidermis.)

for the removal of worn-out material from the skin in bathing serves indirectly to give vigor to other organs. Thus a cold bath is useful locally to cleanse the skin, and also acts through the nervous system to call out, in response 
to the temporary loss of heat at the surface, a freer play of the general vital powers.

297. Hot Baths. Hot baths should be taken at night before going to bed, as in the morning there is usually more risk of taking cold. The body is readily chilled if exposed to cold when the blood vessels of the skin have been relaxed by heat. Besides their use for the purposes of cleanliness, hot baths have a sedative influence upon the nervous system, tending to allay restlessness and weariness. They are excellent after severe physical or mental work and give a feeling of restful comfort like that of sleep.

Experiment 87. To illustrate the sense of temperature. Ask the person to close his eyes. Use two test tubes, one filled with cold and the other with hot water, or two spoons, one hot and one cold. Apply each to different parts of the surface and ask the person whether the touching body is hot or cold. Test roughly the sensibility of different parts of the body with cold and warm metallic-pointed rods.

Experiment 88. Touch fur, wood, and metal. The metal feels coldest, although all the objects are at the same temperature. Why?

Experiment 89. Plunge the hand into water at about $97^{\circ} \mathrm{Fahr}$; one experiences a feeling of heat. Then plunge it into water at about $86^{\circ} \mathrm{Fahr}$; ; t first it feels cold, because heat is abstracted from the hand. Plunge the other hand directly into water at $86^{\circ} \mathrm{Fahr}$. without previously placing it in water at $97^{\circ} \mathrm{Fahr}$; it will feel pleasantly warm.

Experiment 9o. To illustrate warm and cold spots. With a blunt metallic point, touch different parts of the skin. Certain parts feel a sensation of warmth, others of cold, although the temperatures of the skin and of the instrument remain constant.

298. Cold Baths. Cold baths serve as an excellent tonic and stimulant to the bodily functions. The best time for a robust person to take a cold bath is in the morning, immediately after rising. 
A cold bath which is not followed by reaction is likely to do more harm than good. The lack of this reaction may be due to the water being too cold, the bath too prolonged, or to the bather being in a low condition of health. The ruddy glow which follows a cold bath is the main indication of its favorable influence. After taking a bath the skin should be vigorously rubbed dry with a rough towel, and the clothing at once put on.

$\downarrow$ 299. Precautions in taking a Cold Bath. A daily cold bath, when the body is comfortably warm, is a safe tonic for almost all persons during the summer months. It should not be indulged in after severe exercise or great fatigue. Serious results

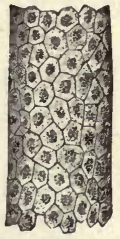

FIG. 106. Epithelial Cells from the Sweat Glands.

(The cells are very distinct, with nuclei enclosing pigmentary granulations.' Magnified 350 times.) have ensued from cold baths taken when the body was in a state of exhaustion or of profuse perspiration. Cold baths, taken regularly, render persons who are susceptible to colds much less liable to them, and less likely to be disturbed by sudden changes of temperature.

$\checkmark$ 300. Additional Hints on Bathing. Outdoor bathing should not be indulged in for at least an hour after a full meal. Except for the robust, it is not prudent to bathe with the stomach empty.

Hot baths, if taken at bedtime, are often serviceable in preventing a threatened cold or in cutting it short, especially if the patient goes immediately to bed, with extra clothing and hot drinks. The free perspiration induced helps to break up the cold.

The golden rule of all bathing is that it must never be followed by a chill. If chilliness occur after bathing, it must immediately be broken up by some appropriate 
methods, as lively exercise, brisk friction, hot drinks, and the application of heat.

301. Salt-Water Bathing. Salt water acts more as a stimulant to the skin. than fresh water. Salt-water bathing

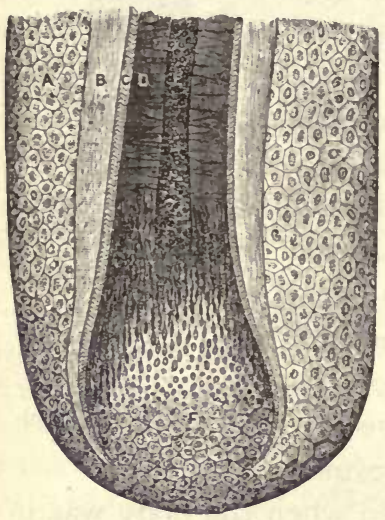

FIG. 107. Magnified Section of the Lower Portion of a Hair and Hair Follicle.

$A$, membrane of the hair follicle, cells with nuclei and pigmentary granules; $B$, external lining of the root sheath; $C$, internal lining of the root sheath; $D$, cortical or fibrous portion of the hair shaft; $E$, medullary portion (pith) of shaft; $F$, hair bulb, showing its development from cells from $A$. is refreshing and invigorating for those who are healthy, but the bather should come out of the water the moment there is the slightest feeling of chilliness. The practice of bathing in salt water more than once a day is unhealthful, and even dangerous. Only the strongest can sustain so severe a tax on their power of endurance. Sea bathing is beneficial in many ways for children, if their skin reacts well after it. In all cases, brisk rubbing with a rough towel should follow.

302. Care of the Hair and Nails. The hairbrush should not be too stiff, as this increases the tendency toward scurfiness of the head. Moreover, if the hair is brushed too long or too hard, the scalp is greatly stimulated and an increased production of scurf may result. If the head be washed too often with soap, its natural secretion is checked, and the scalp becomes dry and scaly. The various hair pomades are as a rule undesirable and unnecessary.

The nails should be kept in proper condition, else they are not only unsightly, but may serve as carriers of germs of disease. The nails are often injured by too much trimming. The upper surfaces should on no account be scraped. The nailbrush is sufficient to cleanse them without impairing their smooth and polished surfaces. 
303. Use of Clothing. The chief use of clothing, from a hygienic point of view, is to assist in keeping the body at a uniform temperature. It also serves for protection against injury and for personal adornment. The heat of the body, as we have learned, is normally about $98 \frac{1}{2}^{\circ} \mathrm{Fahr}$. This varies but slightly in health. A rise of temperature of more than one degree is a symptom of disturbance. The normal temperature does not vary with the season. In summer it is kept down by the rapid evaporation of the perspiration. In winter it is maintained by more active oxidation, by extra clothing, and by artificial heat.

$\mathcal{R}$ 304. Suggestions for the Use of Clothing. Prudence and good sense should guide us in the spring in changing winter clothing for fabrics of lighter weight. A change from heavy to lighter clothing should be made first in the outer garments, the underclothing being changed very cautiously.

The two essentials of healthful clothing are cleanliness and dryness. To wear garments that are daily being soiled by perspiration is a most uncleanly and unhealthful practice. Clothing, especially woolen underclothing, should be frequently changed.

1 Infectious and contagious diseases may be conveyed by the clothing. Hence special care must

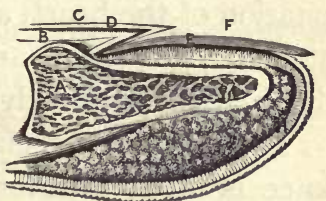

FIG. 108. Longitudinal Section of a Finger Nail.

$A$, last phalanx of the fingers; $B$, true skin on the dorsal surface of the finger; $C$, epidermis; $D$, true skin; $E$, bed of the nail; $F$, superficial layer of the nail; $H$, true skin of the pulp of the finger.

be taken that all clothing in contact with sick people is burned or properly disinfected.

305. Precautions in the Use of Clothing. We should never sleep in a damp bed or between damp sheets. The practice of sitting with wet feet and damp clothing is 
highly injurious to health. The surface of the body thus chilled may be small, yet there is a grave risk of serious, if not of fatal, disease. No harm may be done, even with clothing wet with water or damp with perspiration, so long as exercise is maintained, but the failure to change into dry garments as soon as the body is at rest is fraught with danger.

Woolen comforters, scarfs, and fur mufflers, so commonly worn around the neck, are more likely to produce throat troubles than to have any useful effect.

R 306. Bad Effects of wearing tightly fitting Clothing. The injury to health caused by tight lacing is due to the compression and displacement of various organs by the pressure exerted on them. Thus the lungs and the heart may be compressed, causing short breath on exertion, palpitation of the heart, and other distressing symptoms. The stomach, the liver, and other abdominal organs are often displaced, causing dyspepsia and all its attendant evils.

The use of tight elastic bands on the arms or below the knee is often injurious. They obstruct the local venous circulation and are a fruitful source of cold hands or feet and of enlarged or varicose veins.

The compression of the scalp by a tight-fitting hat often interferes with the local circulation and may cause headache, neuralgia, or baldnesss. The compression of the abdomen by a tight belt may interfere with the descent of the diaphragm.

Tightly fitting boots and shoes often cause corns, bunions, and ingrowing nails. Boots too narrow in front crowd the toes together, make them overlap, and render walking difficult and painful. High-heeled boots throw the weight of the body forwards, so that the body rests too much on the toes instead of on the heels. 


\section{THE KIDNEYS}

307. General Structure of the Kidneys. The kidneys are of a reddish-brown color and lie between the upper lumbar vertebræ and the crest of the hip bone, close against the rear wall of the abdomen, with the intestines in front of them. The human kidneys, though somewhat larger, are of the same shape, color, and general appearance as those of the sheep, so commonly seen in the markets.

The hollow or concave side of the kidneys is turned inwards, and the deep fissure of this side, known as the hilus, widens out to form the pelvis of the kidney. Through the hilus the renal artery passes into each kidney, and from each hilus passes outwards the renal vein, a branch of the inferior vena cava.

A tube, called the ureter, passes out from the concave border of each kidney, turns downwards, and enters the bladder in the basin of the pelvis. This tube conveys the secretion of the kidneys to the bladder.

Experiment 9r. Obtain a sheep's kidney in good order. Observe that its shape is something like that of a bean, and note that the concave part (hilus), when in its normal position, is turned towards the backbone. Notice that all the vessels leave and enter the kidneys at the hilus. Observe a small, thick-walled vessel with open mouth, from which may be pressed a few drops of blood. This is the renal artery. Pass a bristle down it. With the forceps, or even with a penknife, lift from the kidney the fine membrane enclosing it. This is the kidney capsule.

Divide the kidney in halves by a section from its outer to near its inner border. Do not cut directly through the hilus. Note on the cut surfaces, on the outer side, the darker cortical portion, and on the inner side the smooth, pale, medullary portion. Note also the pyramids of Malpighi. 
308. Minute Structure of the Kidneys. The pelvis of the kidney is surrounded by reddish cones, about twelve in number, projecting into it, called the pyramids of Malpighi.

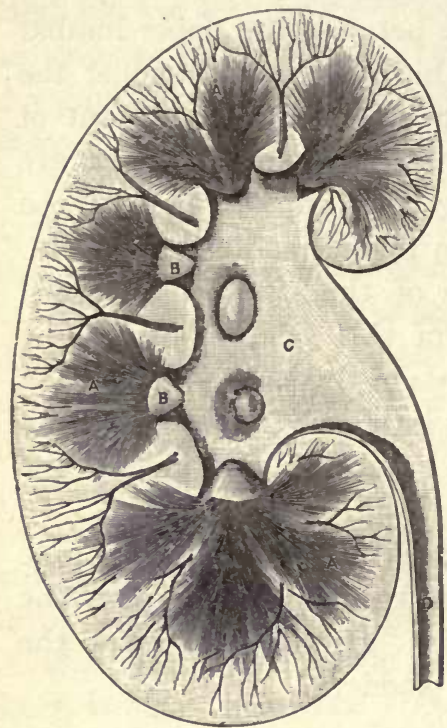

FIG. I09. Vertical Section of the Kidney.

$A$, pyramids of Malpighi ; $B$, apices, or papillæ, of the pyramids, surrounded by subdivisions of the pelvis known as cups, or calices; $C$, pelvis of the kidney; $D$, upper end of ureter. The apices of these cones, known as the papilla, are crowded with minute openings, the mouths of the uriniferous tubules, which form the substance of the kidney, and which end at last in dilated closed sacs called Malpighian capsules.

$\checkmark$ 309. Function of the Kidneys. The Malpighian capsules are really the beginning of the tubules, for here the work of excretion begins. The thin wall of the capillaries within each capsule separates the blood from the cavity of the tubule. The blood pressure on the delicate capillary walls causes the exudation of the -watery portions of the blood through the cell walls into the capsule. The epithelial cell membrane allows the water of the blood with certain salts in solution to pass, but rejects the albumin.

From the capsules the excretion passes through the tubules into the pelvis of the kidneys, and on through the ureters to the bladder. But the delicate epithelial walls of the tubules through which it passes permit the inflow 
of urea and other waste products from the surrounding capillaries.

Thus by a peculiar and delicate kind of filtering process - the fluid portions of the renal secretion with soluble salts, and the urea with other waste material are separated from the blood.

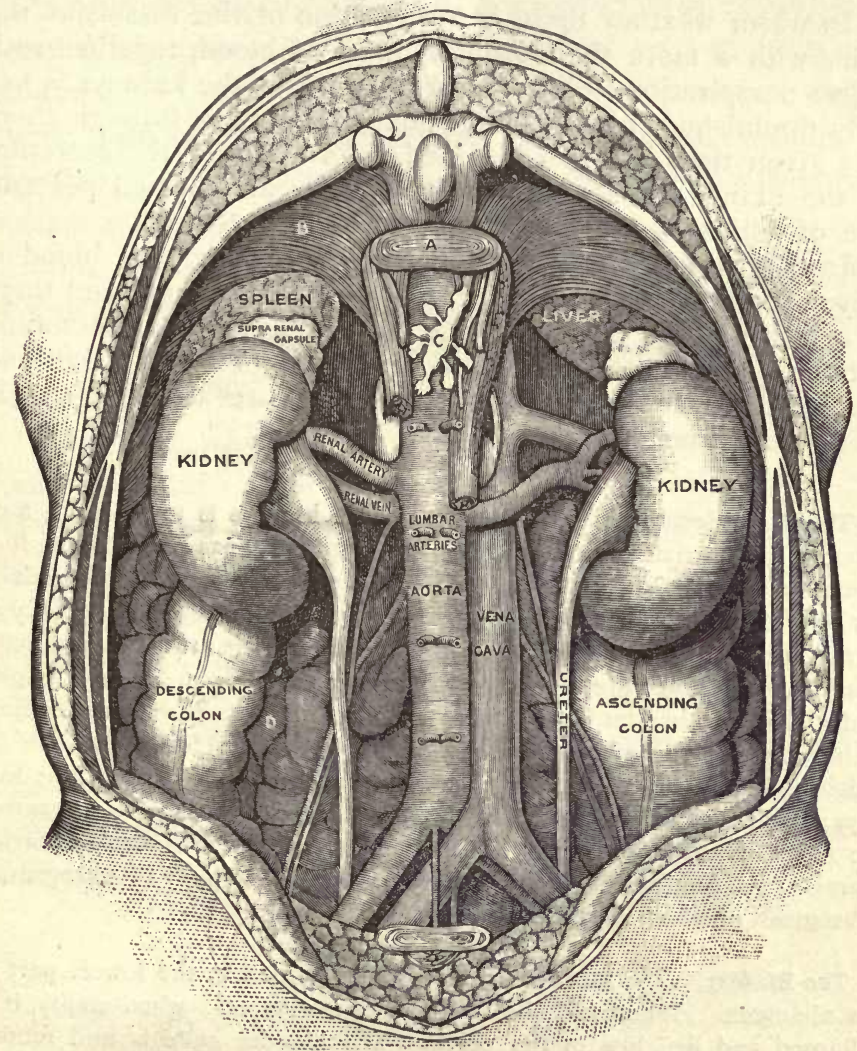

FIG. I Io. Vertical Section of the Back.

(Showing kidneys in situ and the relative position of adjacent organs and vessels. Posterior view.) $A$, I2th dorsal vertebra; $B$, diaphragm; $C$, receptaculum chyli; $D$, small intestines. 
310. How the Action of the Kidneys may be modified. In the kidneys, as elsewhere, the vaso-motor nerves are distributed to the walls of the blood vessels and modify the quantity and the pressure of blood in these organs. Thus some strong emotion, like fear or undue anxiety, increases the blood pressure, drives more blood to the kidneys, and causes a larger flow of watery secretion.

In warm weather there is a relaxation of the vessels of the skin, with a more than ordinary flow of blood, together with active perspiration. The blood pressure in the kidneys is not only diminished, but the total quantity passing through them in a given time is much lessened. As a result, the secretion of the kidneys is scanty, but it contains an unusual percentage of solids.

In cold weather the cutaneous vessels contract, the blood is driven to the deeper organs with increased pressure, and there is a less amount of sweat, but an increased renal secretion, containing a smaller proportion of solids. Thus the skin and the kidneys work in harmony in their efforts to rid the body of its superfluous water.

The Renal Secretion. The function of the kidneys is to secrete a fluid commonly known as the urine. The average quantity passed in twenty-four hours by an adult is about three pints. Normal urine consists of about 96 per cent of water and four per cent of solids. The latter consist chiefly of certain nitrogenous substances known as urea and uric acid, a considerable quantity of mineral salts, and some coloring matter. Urea, the most important and most abundant constituent of urine, contains the four elements, carbon, hydrogen, oxygen, and nitrogen, but nitrogen forms one-half its weight. While, therefore, the lungs expel carbon dioxide chiefly, the kidneys expel urea and other nitrogenous wastes. All these substances express the result of oxidations going on in the body. The urea and uric acids represent the final result of the breaking down in the body of nitrogenous substances, of which albumin is the type.

The Bladder. The bladder is an oval bag situated in the lowest part of the abdomen. When full, the bladder is pear-shaped; when empty, it is collapsed and lies low in the pelvis. The bladder collects and retains the urine, which has reached it drop by drop from the kidneys through the ureters, until a certain quantity accumulates. Owing to the distention of the bladder, a feeling of uneasiness arises which compels the expulsion of its contents. 
311. Effects of Alcohol upon the Kidneys. The duty of the kidneys in ridding the blood of waste products, and of any foreign or poisonous material introduced, must be carried on continually, or the whole body suffers from the bad effects of the retained waste matters.

These two important organs, with their large blood vessels conveying enormous amounts of blood to and from their tissues, feel very quickly the presence of alcohol. Alcoholic liquors may irritate the delicate renal tissues and speedily disturb their normal action in excreting the proper waste materials from the blood.

The continued congestion of the kidneys, together with repeated irritation of their structural cells, resulting from strong drink, tends to cut off their needed nutrition and usually results in a series of renal disturbances.

The urea, which is a poison and which must be removed, may be retained in the system, while the albumin, which is essential to healthy blood, may be filtered away through the diseased kidneys. The presence of albumin in the renal excretion is often an important symptom to the physician in making a diagnosis of the insidious and fatal disease known as albuminuria, or "Bright's disease."

Repeated indulgence in alcoholic liquors often results in the infiltration of fat cells into the cortical substance of the kidneys. This is known as "fatty degeneration of the kidneys." 


\section{CHAPTER $\mathrm{X}$}

\section{THE NERVOUS SYSTEM}

y 312. The Nervous System, the Master Organs. We are now prepared to study a higher, a more wonderful and complex agency, - the nervous system, the master organs, which control, regulate, and direct every other organ of the human body.

The nervous system is the medium through which all impressions are received. It connects all the parts of the body into an organism in which each acts in harmony with every other part for the good of the whole. It animates and governs all movements, voluntary or involuntary, secretion, excretion, nutrition; in fact, all the processes of organic life are subject to its regulating power.

× 313. The Nervous System brings us into Relation with the World around us. In men and other highly organized animals nerves are found in every organ of the body. They come into contact with the most minute muscular fibers; they are closely connected with the cells of the glands and are found in the coats of even the smallest blood vessels. They are among the chief constituents of the sense organs, including the skin. When we hear, our nerves of hearing are bringing us into relation with the outer world. So sight opens up to us another gateway of knowledge.

In brief, the nervous system is the system of organs through which we are brought into relation with the world around us. 
$X$ 314. Nerve Cells. However complicated the structure of the nerve tissue in man seems to be, it is found to consist of only two different elements, nerve cells and nerve fibers. These are associated and combined in many ways. They are arranged in distinct masses called nerve centers, or in the form of cords known as nerves.

Nerve cells consist of masses of protoplasm, with a large nucleus and nucleolus. A number of processes branch off from them, some cells giving off one or two, others many.

Certain forms of cells are found only in particular parts of the nervous system. Thus, we have in the spinal cord the large, irregular cells with many processes, and in the brain proper the three-sided cells with a process jutting out from each corner (Fig. 3).

315. Structure of Nerve Fibers. The nerve fibers, the essential elements of the nerves, somewhat resemble tubes filled with a clear, jelly-like substance. They consist of a rod,

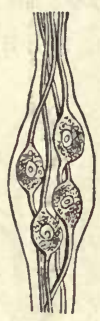

FIG. III.

Nerve Cells from the Spinal Cord. or central core, continuous throughout the whole length of the nerve, called the axis cylinder. This core is surrounded by the white substance of Schwann, or medullary sheath, which gives the nerve its characteristic ivory-white appearance. The whole is enclosed in a thin, delicate sheath known as neurilemma.

The axis cylinder generally passes without any break from the nerve centers to the end of the fibers: The outer sheath (neurilemma) is also continuous throughout the length of the fibers.

The medullary sheath, on the other hand, is broken at intervals of about one twenty-fifth of an inch, and at the same intervals nuclei are found along the fiber, around 
each of which is a minute protoplasmic mass. Between each pair of nuclei the sheath is interrupted. This point is known as the node of Ranvier (Figs. II 3 and I I4).

Experiment 92. Obtain a small piece of nerve from the market. Place the least bit of it on a glass slide. Tease it out lengthwise with needles. Note the delicate thread-like fibers. Examine with the high power of the microscope.

316. White and Gray Nerve Fibers. Some nerve fibers have no inner sheath (medullary), the outer alone protect-

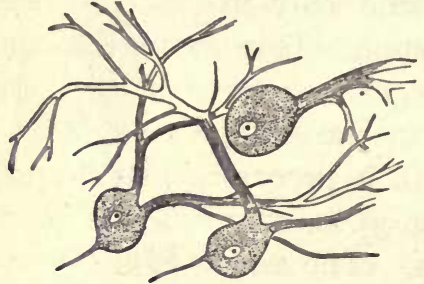

FIG. I I2. Nerve Cells from the Gray Matter of the Brain. ing the axis cylinder. These are known as the non-medullated fibers. They are gray, while the ordinary medullated fibers are white in appearance.

The white nerve fibers form most of the white part of the brain and of the spinal cord, and the greater part of the cerebro-spinal nerves.

The gray fibers occur chiefly in branches from the sympathetic ganglia, though found to some extent in the nerves of the cerebro-spinal system.

$x$ 317. General Structure of Nerves. The separate microscopic threads or fibers, bound together in cords of various sizes, form the nerves. Each strand or cord is surrounded and protected by its own sheath of connective tissue. According to its size a nerve may have one or many of these strands.

The whole nerve, not unlike a minute tendon in appearance, is covered by a dense sheath of fibrous tissue, in which the blood vessels and lymphatics are distributed to the nerve fibers. 


\section{X318. The Functions of the Nerve Cells and Nerve Fibers.} The nerve cells are a highly active mass of living material. They find their nourishment in the blood, which is supplied to them in abundance. We may think of the nerve cells as a sort of a miniature manufactory, deriving their material from the blood, and developing from it nervous energy.

The nerve fibers, on the other hand, are conductors of nervous energy. They furnish a pathway along which the nerve energy generated by the cells may travel. The fibers can also generate energy, yet it is their special function to conduct impulses to and from the cells.
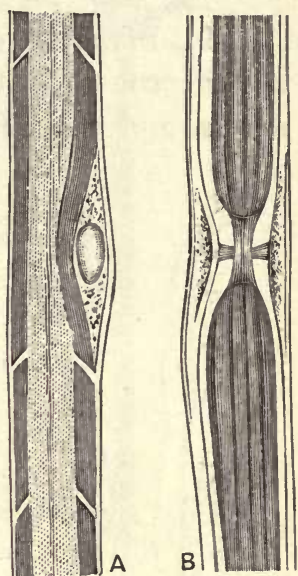

Fig. II3. Medullated Nerve Fibers.

319. The Nervous System compared $A$ to a Telegraphic System. It will help us the better to understand the complicated functions of the nervous system if we compare it to a telegraph system. The brain and the spinal cord are the main offices, and the multitudes of nerve fibers branching off to all parts of the body are the wires. By means of these, nerve messages are constantly being sent to the cerebro-spinal center to inform it of what is going on in various parts of the body, and asking what is to be done in each case. The cerebro-spinal center, on receiving the intelligence, at once sends back the required instructions. Countless messages are sent to and fro with unerring accuracy and marvelous rapidity. Thus, when we accidentally pick up something hot, it is instantly dropped. A nerve impulse passes from the nerves of a medullated nerve fiber,
showing the subdivision of the medullary sheath into cylindrical sections imbricated with their ends; a nerve corpuscle with an oval nucleus is seen between the neurilemma and the medullary sheath. $B$, a medullated nerve fiber at a node or constriction of Ranvier; the axis cylinder passes uninterruptedly from one segment into the other, but the medullary sheath is interrupted. 
touch in the fingers to the cerebro-spinal center, which at once hurries off its order along another set of nerves for the hand to drop the hot object.

₹ 320. Divisions of the Nervous System. The nervous system consists of two great divisions: the cerebro-spinal system and the sympathetic system.

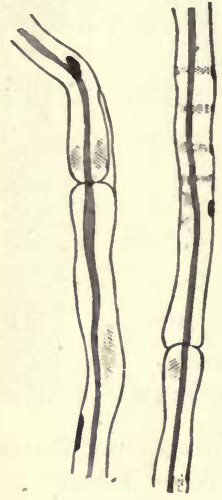

Fig. II4. NonMedullated Fibers.

(Two nerve fibers, showing the nodes or constrictions of Ranvier and the axis cylinder. The medullary sheath has been dissolved away. The deeply stained oblong nuclei indicate the nerve corpuscles within the neurilemma.)

The first is the great nerve center of the body, the cerebro-spinal system, which rules the organs of animal life, and includes the brain, the spinal cord, and the cerebro-spinal nerves.

Nerves are given off from the brain and the cord, and form the mediums of communication between them and the external parts of the body.

The second division is the sympathetic system. This consists of numerous small nerve centers arranged in oval masses varying greatly in size, called ganglia, or knots. These are either scattered irregularly through the body or arranged in a double chain of knots lying in the front of the spine, within the chest and abdomen. From this chain large numbers of nerves are given off, which end chiefly in the organs of digestion, circulation, and respiration (Fig. I 23).

* 321. The Brain as a Whole. The brain is the seat of the intellect, the will, the affections, the emotions, the memory, and sensation. It has also many other and complex functions. In it are established many reflex, automatic, and coördinating centers, which are as independent of consciousness as are those of the spinal cord. 
322. Weight of the Brain. The average weight of the adult human brain is about fifty ounces for men and forty-five ounces for women. Other things being equal, the size and weight of the brain bear a general relation to the mental power of the individual. As a rule, a large, healthy brain stands for a vigorous and superior intellect.

The brains of many eminent men have been found to be eight to twelve ounces above the average weight, but there are notable exceptions. The brains of idiots are usually small and badly developed. The brain and head of a child are very large in proportion to the rest of the body.

x 323. The Cerebrum. The three principal masses which make up the brain when viewed as a whole are:

I. The cerebrum, or brain proper.

2. The cerebellum, or lesser brain.

3. The medulla oblongata.

The cerebrum comprises nearly seven-eighths of the entire mass and fills the upper part of the skull. It consists of two halves, the right and left cerebral hemispheres. These are almost separated from each other by a deep median fissure. Each of the hemispheres is subdivided into three

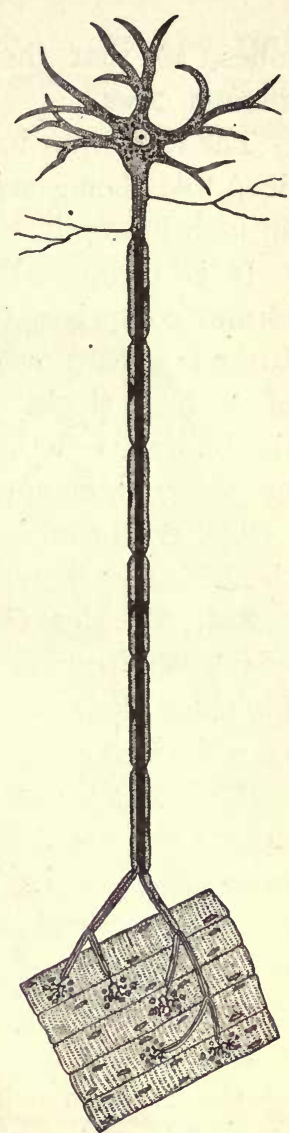

FIG. I I 5. Diagram of a Motor Nerve Cell.

(Showing its long, unbranched process (with two little lateral offshoots), with motor endings in striated, voluntary muscle tissue. By comparison with Figs. II 3 and I 14 the several unmarked parts in this diagram may be readily understood.) 
lobes, so that the entire cerebrum is made up of six distinct lobes.

The cerebrum has a peculiar convoluted appearance, its deep folds being separated by fissures, some of them nearly an inch in depth.

It is composed of both white and gray matter. The former comprises the greater part of the mass, while the latter is spread over the surface in a layer about one-eighth of an inch thick. The gray matter is the portion having the highest functions, and its quantity is largely increased by its arrangement in convolutions.

The cerebrum is the seat of the sensations, the intellect, the will, and the emotions.

324. The Convolutions of the Cerebrum. The convolutions of the cerebrum are without doubt associated with all those higher actions which distinguish man's life; but all the convolutions are not of equal importance.

The convolutions in the human brain are more prominent than are those in the brain of the higher animals most nearly allied to man, although some species of animals, not especially intelligent, have marked cerebral convolutions. The higher races of men have more marked convolutions than have those that are less civilized.

325. Under Surface of the Brain. The under surface of the brain, which rests on the floor of the skull, shows the origin of important nerves called the cranial nerves; the cerebellum; the structure connecting the optic nerves (optic commissure); the bridge of nervous matter (pons Varolii) connecting the two hemispheres of the cerebellum; and lastly, numerous and well-marked convolutions.

千 326. The Cerebellum. The cerebellum, or lesser brain, lies in the back of the cranium and is covered over by the posterior lobe of the cerebrum. It is, as it were, 
astride of the back of the cerebro-spinal axis and consists of two hemispheres joined by a central mass. On its under surface is a depression which receives the medulla oblongata (Figs. I I 9 and I 2 I).

The cerebellum is connected with other parts of the nervous system by strands of white matter on each side, radiating from the center and divided into numerous branches. Around these branches the gray matter is arranged in a beautiful manner, suggesting the leaves of a tree: hence its fanciful name, arbor vita, or the tree of life. $x_{327 .}$ The Functions of the Cerebellum. The functions of the cerebellum are not certainly known. It appears to aid (Showing its division into two hemispheres, and also the in the control of

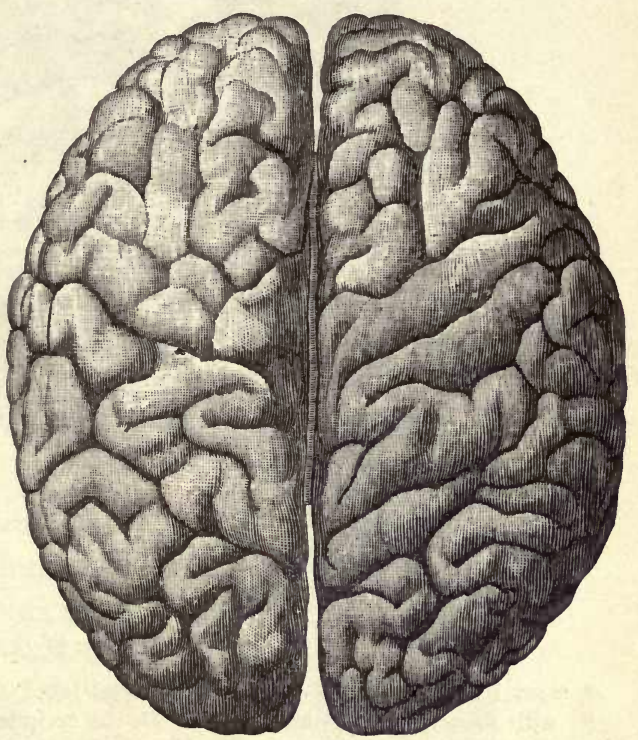

FIg. I16. The Upper Surface of the Cerebrum. convolutions.)

the muscles of the pody ; that is, it serves to bring the various muscular movements into harmonious action. The mechanism by which it does this has not yet been clearly explained. In an animal from which the cerebellum has been removed the functions of life are not destroyed, but the power of either walking or flying straight is temporarily lost. 
Disease or injury of the cerebellum usually produces blindness, dizziness, a staggering gait like that of a drunken man, and a feeling of insecurity in maintaining right positions during the execution of movements. There is no loss of consciousness or other disturbance of the mental functions.

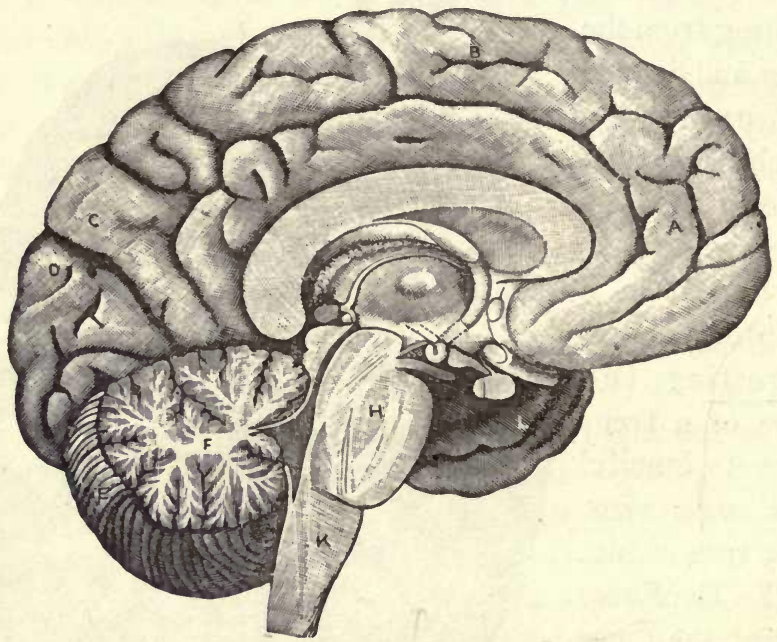

FIG. I 17. A Vertical Section of the Brain.

$A$, trontal lobe of the cerebrum; $B$, parietal lobe; $C$, parieto-occipital lobe with fissure between this lobe and $D$, the occipital lobe; $E$, cerebellum; $F$, arbor vitæ; $H$, pons Varolii ; $K$, medulla oblongata; $L$, portion of lobe on the opposite side of brain. The white curved band above $H$ represents the corpus callosum.

Experiment 93. Examine the least bit of the white matter of the brain under a microscope of high power. The fibers are the ordinary white fibers. Now examine the gray matter and note the elongated cells with their long, fine branches.

328. The Membranes of the Brain. The brain and spinal cord are protected by three important membranes, known as the meninges, - the dura mater, the arachnoid, and the pia mäter. 
The outer membrane, the dura mater, is much thicker and stronger than the others, and closely lines the inner surface of the skull and forms a protecting covering for the brain.

The arachnoid is a thin membrane which secretes a serous fluid that keeps the inner surfaces moist.

The pia mater is a very delicate vascular membrane which covers the convolutions, dips into all the fissures, and even penetrates into the interior of the brain.

329. The Medulla Oblongata. The medulla oblongata is the enlarged upper part of the spinal cord lying within the cavity of the skull. It is immediately under the cerebellum and forms the connecting link between the brain and the spinal cord. It is about an inch and a quarter long, and from one-half to threefourths of an inch wide at its upper part (Fig. I I9).

The gray matter of the medulla is broken up into

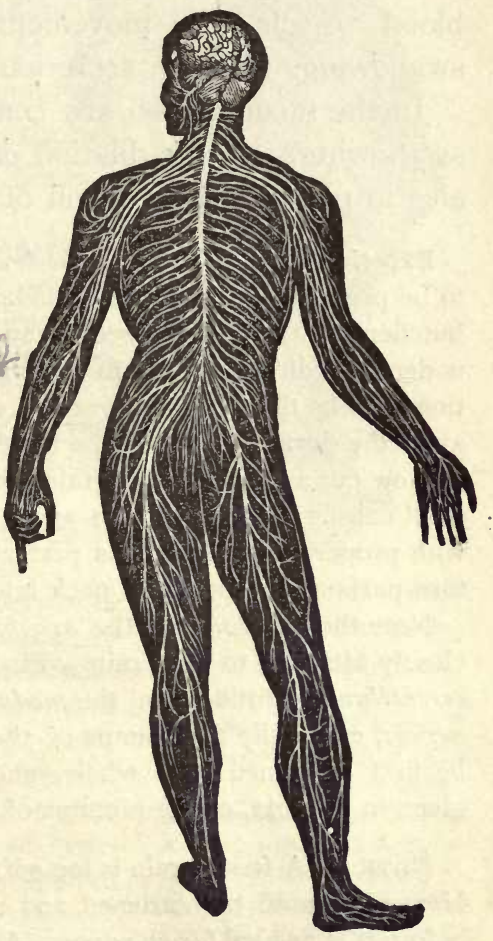

FIg. 118. Illustrating the General Arrangement of the Nervous System. (Posterior view.) masses which serve as centers of origin for various nerves. X 330. The Functions of the Medulla Oblongata. The functions of the medulla oblongata are closely connected with the vital processes. It is a great nerve tract for 
transmitting sensory and motor impressions from the cord to the brain and return.

The medulla is also the seat of a number of reflex centers connected with the influence of the nervous system on the blood vessels, the movements of the heart, respiration, swallowing, and the secretion of saliva.

In the medulla also are centers for coughing, vomiting, swallowing, and the dilation of the pupil of the eye. It is also in part the deep origin of important cranial nerves.

Experiment 94. To show the brain. A sheep's or calf's brain is to be preferred, on account of its larger size. Get one fresh from the butcher. Pay him to dissect away the skin and muscles of the skull, under your direction, and to saw open the cranium in a circular direction. Take time, and remove the sawed top with great care, tearing away the dura mater from the bones.

Now cut away enough of this membrane so that the sides of the skull can be sawed and torn away, to allow us to lift out the brain, with proper dissection, in as perfect a state as need be. Put all the torn parts and membranes back into place.

Note the dura mater, the arachnoid lining it, and the pia mater closely attached to the brain. Find the cerebrum, or big brain, the cerebellum, or little brain, the medulla, and the stumps of the cranial nerves, especially the stumps of the optic nerves. The brain should be first examined as a whole, and compared with the description given in the text, or the pictures of the human brain. ${ }^{1}$

NOTE. - A fresh brain is too soft for handling or for careful study. Hence it should be hardened and made ready for use several weeks before it is needed for class use. A mixture of $\frac{1}{4}$ ounce of bichromate of potash and I ounce of a 40 per cent solution of formalin to about I quart of water makes a useful hardening and preserving fluid. A mixture of two-thirds strong alcohol and one-third 2 per cent solution of formalin is also recommended.

${ }^{1}$ Space does not allow us to give in necessary detail the directions for the experimental study of the brain. Such directions are admirably given in Brown's Physiology for the Laboratory, a book already referred to on page 20. 
331. The Cranial Nerves. The cranial or cerebral nerves consist of twelve pairs of nerves which pass from the brain through different openings in the base of the skull. They are distributed over the head and face, and also to some parts of the trunk and to certain internal organs. These nerves proceed in pairs from the corresponding parts on each side of the brain.

\section{Distribution and Functions} of the Cranial Nerves. The cranial nerves are thus arranged in pairs:

The first pair are the olfactory nerves, the special nerves of smell.

The second pair are the optic nerves, which pass to each eyeball, and are devoted to sight.

The third, fourth, and sixth pairs control the muscles of the eyes.

Each of the fifth pair of nerves is in three branches and proceeds mainly to the face. They are called tri-facial nerves, and are partly sensory and partly motor.

The seventh pair, the facial nerves, control the facial muscles. The eighth pair are the auditory, or nerves of hearing, and are distributed to the special organs of hearing.

The ninth pair, the glossopharyngeal nerves, are partly sensory and partly motor. Each nerve contains two roots: one a nerve of taste, which spreads

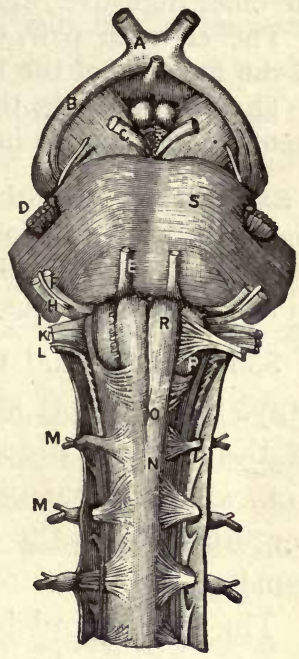

FIG. II9. Anterior View of the Medulla Oblongata.

$A$, chiasm of the optic nerves; $B$, optic tracts ; $C$, motor oculi communis ; $D$, fifth nerve $E$, motor oculi externus; $F$, facial nerve; $H$, auditory nerve; $I$, glossopharyngeal nerve; $K$, pneumogastric ; $L$, spinal accessory; $M$, cervical nerves; $N$, upper extremity of spinal cord; $O$, decussation of the anterior pyramids; $P$, hypoglossal nerve; $R$, anterior pyramids ; $S$, pons Varolii. over the back part of the tongue; the other a motor nerve, which controls the muscles engaged in swallowing (Fig. 123).

The tenth pair, the pneumogastric nerves, also known as the vagi, or wandering nerves, are the longest and most important of all the cranial nerves. They are both motor and sensory. 
Passing from the medulla, they descend near the œsophagus, sending off, on their way, branches to the windpipe, the larynx, the chief digestive organs, the lungs, and the heart (Fig. r 25).

The eleventh pair, the spinal accessory nerves, supply some of the muscles of the neck and the back.

The twelfth pair, the hypoglossal nerves, control the movements of the tongue in speech and in swallowing.

Experiment 95. If the brain has been carefully removed, most of the twelve pairs of cranial nerves may be identified by careful study. Such as are found may be compared with the cranial nerves indicated on a diagram of the human brain.

333. The Spinal Cord. The spinal cord is a column of grayish-white, soft substance, which extends from the base of the skull to the lower border of the first lumbar vertebra, where it narrows off into a slender filament. It is continuous with the medulla oblongata and is lodged in the canal of the spinal column.

The spinal cord is from sixteen to eighteen inches long and has about the thickness of one's little finger, weighing about one and one-half ounces. Like the brain, it is enclosed in three membranes, which protect the delicate cord and convey vessels for its nourishment. The space between the two inner membranes contains a small quantity of fluid, supporting the cord, as it were, in a water bed. It is thus guarded against shocks.

334. Structure of the Spinal Cord. The arrangement of the parts of the spinal cord is best understood by a transverse section. Two fissures, one behind, the other in front, penetrate deeply into the cord, very nearly dividing it into lateral halves. In the middle of the isthmus which joins the two halves is a very minute opening, the central canal, which extends the entire length of the cord.

The spinal cord, like the brain, consists of gray and white matter, but the arrangement is different. In the brain the 
white matter is within, and the gray matter is on the surface. In the cord the gray matter is arranged in two half-moon-shaped masses, the backs of which are connected at the central part. The white matter, consisting mainly of fibers, running for the most part in the direction of the length of the cord, is outside of and surrounds the gray crescents.

Thus each half or side of the cord has its own gray crescent, the horns of which point one forwards and the other backwards, called respectively the anterior and posterior cornua, or horns.

It will also be seen that the white substance itself, in each half of the cord, is divided by the horns of the gray matter and by fibers passing from them into three parts, which are known as the anterior, posterior, and lateral columns (Fig. I 20).

Experiment 96. Procure at the market an uninjured piece of the spinal cord from the loin of mutton or the sirloin or the rib of beef. After noting its general character while fresh, preserve it in one of the fluids just mentioned (note, p. 216), until it is sufficiently hard to be cut in sections.

335. The Spinal Nerves. From the gray matter on each side of the spinal cord thirty-one spinal nerves are given off and distributed chiefly to the muscles and the skin. They pass out at regular intervals on each side of the canal, by small openings between the vertebræ.

Each spinal nerve has two roots, one from the anterior, the other from the posterior, portion of the cord. These unite and run side by side, forming as they pass between the vertebræ one silvery thread, or nerve trunk. Although bound up in one bundle, the nerve fibers of the two roots remain quite distinct and perform two entirely different functions. 
336. Motor and Sensory Nerves. After leaving the spinal cord each nerve divides into minute branches which are

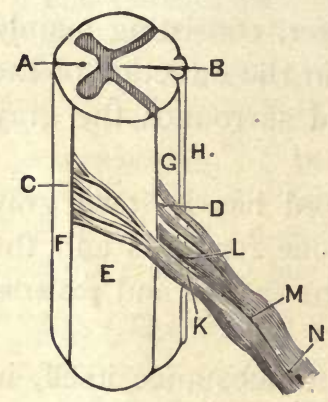

FIG. I 20. Side View of the Spinal Cord. (Showing the fissures and columns.)

$A$, anterior median fissure; $B$, posterior median fissure; $C$, anterior lateral fissure; $D$, posterior lateral fissure; $E$, lateral column; $F$, anterior column; $G$, posterior column ; $H$, posterior median column; $K$, anterior root; $L$, posterior root; $M$, ganglion of $N$, a spinal nerve. distributed through the muscles and terminate on the surface of the body.

The anterior roots become motor nerves, their branches being distributed to certain muscles of the body to control their movements.

The posterior roots develop into sensory nerves, their branches being distributed through the skin and over the surface of the body to become nerves of touch.

In brief, the spinal nerves divide and subdivide to reach with their twigs all parts of the body and connect every organ with the brain.

The spinal nerves themselves are merely conductors to carry messages to and fro. They neither issue commands nor feel a sensation.

337. Functions of the Spinal Cord. The spinal cord is the principal channel through which all impulses from the trunk and extremities pass to the brain, and all impulses to the trunk and extremities pass from the brain. That is, the spinal cord receives from various parts of the body by means of its sensory nerves certain impressions and conveys them to the brain, where they are interpreted.

The cord also transmits by means of its motor nerves the commands of the brain to the voluntary muscles and so causes movement. Thus, when the cord is divided at any point, compressed, as by a tumor or broken bone, or 
disorganized by disease, the result may be a complete loss of sensation and voluntary movement below the point of injury.

If by accident the spinal cord is injured at some point, all sensation and power of motion may be lost below that spot. The impulse to movement started in the brain by the will does not reach the muscles, because traveling down the spinal cord, it cannot pass the seat of injury.

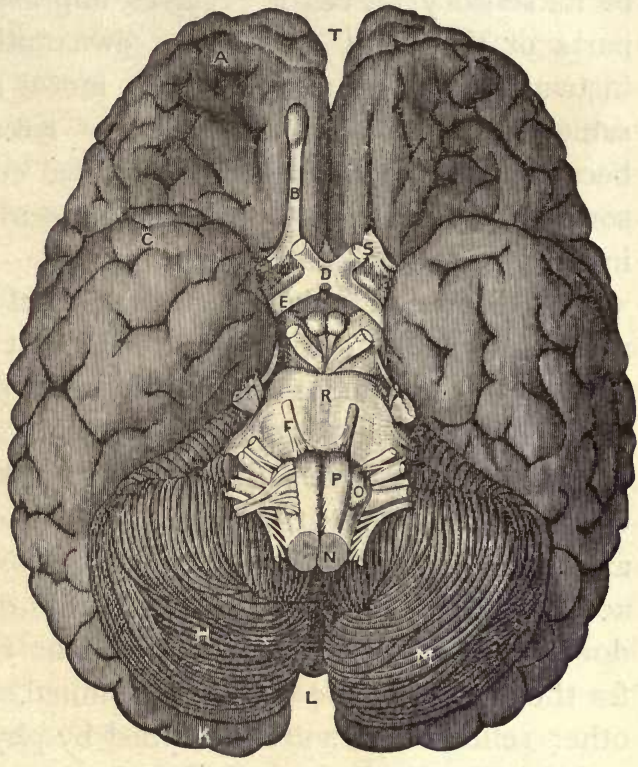

FIg. I2I. The Base of the Brain.

So the impres- $A$, anterior lobe of the cerebrum; $B$, olfactory nerve; sion produced by pricking the leg with a pin, which, before pain can be felt, must travel $u p$ the spinal cord $C$, sphenoid portion of the posterior lobe; $D$, optic chiasm ; $E$, optic tract; $F$, abducens ; $H, M$, hemispheres of the cerebellum; $K$, occipital portion of the occipital lobe; $L$, fissure separating the hemispheres; $N$, medulla oblongata; $O$, olivary body; $P$, anterior pyramids; $R$, pons Valorii; $S$, section of olfactory nerve, with the trunk removed to show sulcus in which it is lodged; $T$, anterior extremity of median fissure.

to the brain, cannot reach the brain because the injury obstructs the path. The telegraph wire has been cut, and the message can no longer be sent.

* 338. The Spinal Cord as a Reflex Center. Besides serving as a great nerve conductor to carry sensations to the 
brain and bring back its orders, the spinal cord is also an independent center for what is called reflex action. By means of its sensory nerves it receives impressions from certain parts of the body, and on its own authority sends back instructions to the muscles by its motor nerves, without consulting the brain. This constitutes reflex action, so called because the impulse sent to the spinal cord by certain sensory nerves is at once reflected or sent back as a motor impulse to the muscles (Fig. I 22).

$\times$ 339. Reflex Action through the Spinal Cord. This reflex action through the spinal cord is a most important matter. This power is possessed only by the gray matter of the cord, the white substance being simply a conductor.

As already mentioned, certain groups of nerve cells in the medulla oblongata preside over specific functions of animal life. Thus, there are centers for maintaining the action of the heart and the movements of breathing. Low down in the cord also, in the lumbar region, are centers for the control of the various abdominal organs. Numerous other reflex centers are described by physiologists.

$\Varangle$ 340. The Brain as a Reflex Center. The brain, as we have just stated, is the seat of consciousness and intelligence. It is also the seat of many reflex, automatic, and coördinating centers. These give rise to certain reflex actions which are as entirely independent of consciousness as are those of the spinal cord.

These acts take place independently of the will, and often without the consciousness of the individual. Thus, a sudden flash of light causes the eyes to blink, as the result of reflex action. The sudden start of the whole body at some loud noise, the instinctive dodging a threatened blow, and the springing back from sudden danger, are also the results of this reflex action. 
341. Importance of Reflex Action. Reflex action is a marvelous provision of nature for our comfort, health, and safety. Its vast influence is not realized, as its numberless acts are continually going on without our knowledge. In fact, the greater part of nerve power is expended to produce reflex action. The conscious centers are thus relieved of a vast amount of work. It would be impossible for the brain by serving as a "thinking center" to control every act of our life.

The fact that the gray cells of the spinal cord can originate a countless number of reflex and automatic actions is not only of great importance in protecting the body from injury, but increases vastly the range of our activities.

Even walking, riding the bicycle, writing one's signature, "playing at sight" a difficult piece of music, and numberless other such acts may become reflex movements. To learn how, requires, of course, the action of the brain, but by frequent repetition the muscles become so accustomed to certain successive movements that they are continued by the cord without the action of the brain.

We may thus acquire a sort of artificial reflex action, often called "unconscious cerebration," which in time becomes in a way a part of our organization and is carried on without will power or even consciousness. ${ }^{1}$

Thus, while the hands are busily doing one thing, the brain can be intently thinking of another: In fact, any attempt to control reflex action is more apt to hinder than to help. In coming rapidly down stairs, for instance, the

1 There is a story, which is creditable enough, though it may not be true, of a practical joker, who, seeing a discharged veteran carrying home his dinner, suddenly called out "Attention!" whereupon the man instantly brought his hands down, and lost his mutton and potatoes in the gutter. The drill had been thorough, and its effects had been embodied in the man's nervous structure. - HUXLEY's Lessons in Elementary Physiology. 
descent will be made with ease and safety if the spinal cord is allowed entire charge of the act, but the chances of stumbling or of tripping are very much increased if each

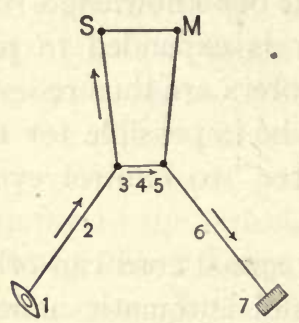

Frg. I 22. Dr. Waller's Diagrammatic Illustration of the Reflex Process.

From the sentient surface ( 1 ) an afferent impulse passes along (2) to the posterior root of the spinal cord, the nerve fibers of the posterior root ending in minute filaments among the small cells of this part of the cord (3). In some unknown way this impulse passes across the gray part of the cord to the large cells of the anterior root (5), the cells of this part being connected by their axis cylinder with the efferent fibers (6). These convey the stimulus to the fibers of the muscle (7), which accordingly contract. Where the brain is concerned in the action the circuit is longer through $S$ and $M$. step be taken as the result of the will power.

Experiment 97. To illustrate reflex action by what is called knee-jerk. Sit on a chair and cross the right leg over the left one. With the tips of the fingers or the back of a book strike the right ligamentum patellæ. The right leg will be raised and thrown forward with a jerk, owing to the contraction of the quadriceps muscles. An appreciable time elapses between the striking of the tendon and the jerk. The presence or absence of the knee-jerk may be a most significant symptom to the physician.

\section{$\times$ 342. The Sympathetic System.} Running along each side of the spine, from the base of the skull to the coccyx, is a chain of nerve knots, or ganglia. These ganglia, twenty-four on each side, and their branches form the sympathetic system, as distinguished from the cerebro-spinal system. The sympathetic ganglia are connected with each other and with the sensory roots of the spinal nerves by a network of gray nerve fibers. At the upper end the chain of each side passes up into the cranium and is closely connected with the cranial nerves. In the neck, branches pass to the lungs and the heart. From the ganglia in the chest these nerves form 


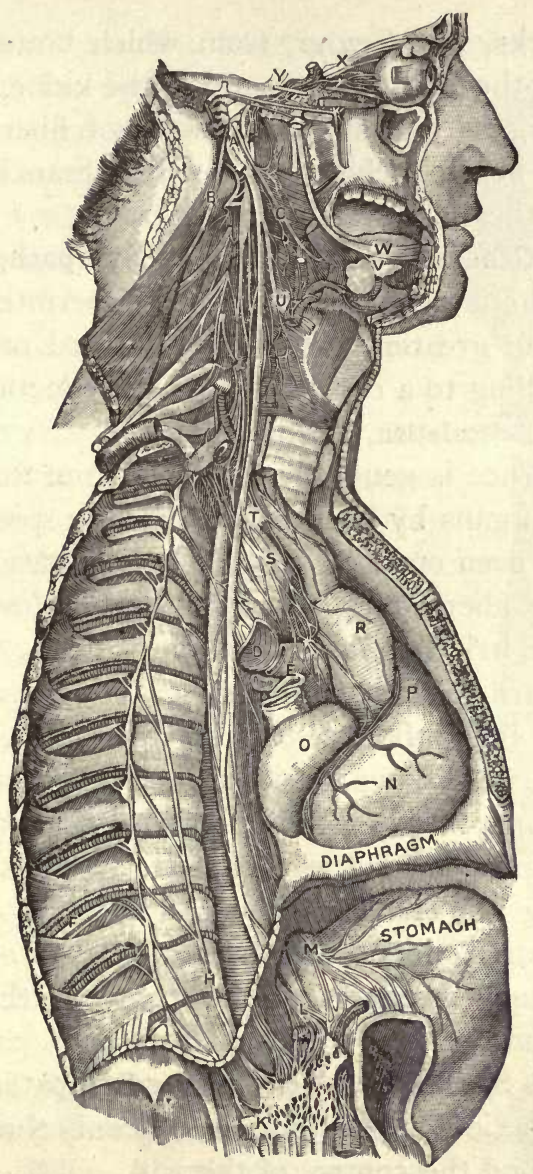

FIG. 123. The Cervical and Thoracic Portion of the Sympathetic Nerve and its Main Branches.

$A$, right pneumogastric; $B$, spinal accessory; $C$, glossopharyngeal; $D$, right bronchus; $E$, right branch of pulmonary artery; $F$, one of the intercostal nerves; $H$, great splanchnic nerve; $K$, solar plexus; $L$, left pneumogastric; $M$, stomach branches of right pneumogastric; $N$, right ventricle; $O$, right auricle; $P$, trunk of pulmonary artery; $R$, aorta ; $S$, cardiac nerves; $T$, recurrent laryngeal nerve; $U$, superior laryngeal nerve; $V$, submaxillary ganglion; $W$, lingual branch of the fifth nerve; $X$, ophthalmic ganglion; $Y$, motor oculi externus. 
great networks, or plexuses, from which branches pass to the stomach, the liver, the intestines, the kidneys, and other abdominal organs. A similar network of fibers is situated lower down in the pelvis, from which branches are distributed to the pelvic organs.

$x$ 343. The General Functions of the Sympathetic System. The sympathetic system exercises a superintending influence over the greater part of the internal organs of the body, controlling to a certain extent the functions of digestion, nutrition, circulation, and respiration.

This influence is generally different from that conveyed to the same organs by fibers running in the spinal or cranial nerves, or is even opposed to it. Thus, irritation of certain cranial nerve fibers, as those of the vagus, slows the heart beat, but the irritation of certain sympathetic fibers which go to the heart quickens its beat.

The controlling influence of the sympathetic system does not originate in the system itself, but is derived from the spinal cord or from the brain. We may, for convenience, think of this system, not as a separate nervous system, but as an outlying part of the cerebro-spinal system, - a series of ganglia through which the fibers of a part of the trunk of each spinal nerve pass on their way to the important internal organs of the body.

344. Some Special Functions of the Sympathetic System. The sympathetic nerves affect directly only those processes that are beyond the control of the will.

If it were not for this action of the sympathetic nerves, the heart would stop beating during sleep, digestion would cease, and breathing would be suspended. Gentle irritation of these nerves, induced by contact of food in the stomach, causes that organ to begin the churning motion needed for digestion. 
Various emotions also have a reflex action upon the sympathetic system. Thus terror dilates the pupils of the eyes, fear acts upon the nerves of the small blood vessels of the face to produce pallor, and the sight of an accident, or even the emotions produced by hearing of one, may excite nausea and vomiting.

The maintenance of the tone of the arteries all over the body, as we have learned, is one of the special functions of the sympathetic system (sec. 232).

$\times$ 345. Need of Rest. The tissues of the body, as has been emphasized in the preceding chapters, are subject to constant waste, which goes on every moment, from the first breath of infancy to the last moment of old age. We should speedily exhaust our vitality from this continual loss, but for its constant renewal. This exhaustion of life is increased by exertion, and the process of repair is vastly promoted by rest. Thus, while exercise is a duty, rest is equally imperative.

The eye, when exactingly used in fine work, should have frequent intervals of rest in a few moments of darkness, by closing the lids. The brain should have occasional seasons of rest and refreshment by a dash of cold water upon the forehead, and a brief

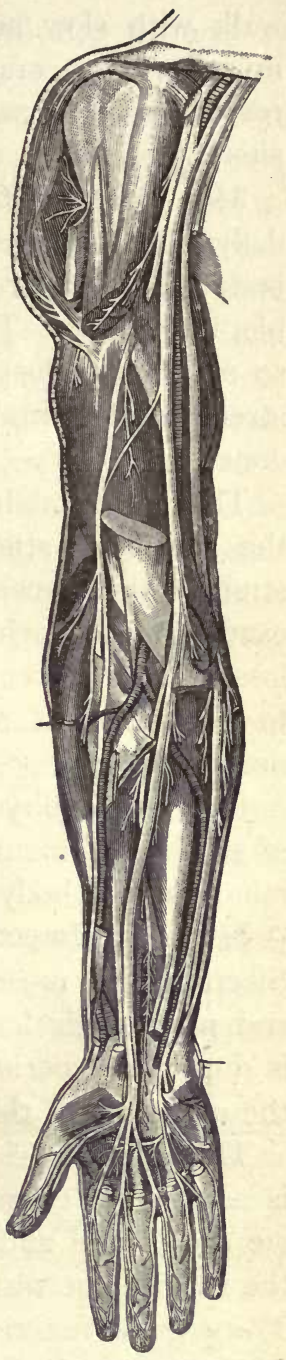

FIG. I24. Nerve Trunks of the Right Arm. 
walk with slow and deep inspirations of fresh air. The muscles, long cramped in a painful attitude, should be rested as often as may be by change of posture or by a short, brisk walk.

346. Benefits of Rest. There is too little repose in our daily life. A sense of fatigue is the mute appeal of the body for a brief respite from labor, which should, if possible, be heeded. The feeling that even a ten-minute rest is so much time lost is a mistake. It is a gain of physical strength, of mental vigor, and of the total amount of work done.

The merchant burdened with the cares of business life, the ambitious student overanxious to win success in his studies, the housewife weảied with her many hours of exacting toil, each would get through the task with less loss of vital force by devoting a few minutes every day to absolute rest of the strained muscles and overtaxed nerves.

It is sound physiology to cease from the usual routine of six days of mental or physical work and to rest both the mind and the body on the seventh.

347. The Importance of Sleep as a Periodical Rest. Sleep is the most marked manifestation of the periodic and physiological rest by which Nature refreshes us. It is during the periods of sleep that the energy expended in the activities of the waking hours is mainly renewed.

The need of sleep is self-evident, and the loss of it is a common cause of the impairment of health. While we are awake and active the waste of the body exceeds the repair; but when we are asleep the waste is diminished. The organic functions, such as are under the direct control of the sympathetic nervous system, - circulation, respiration, and digestion, - are diminished in activity during 
sleep. The pulsations of the heart and the respiratory movements are less frequent. ${ }^{1}$

348. The Amount of Sleep required. No precise rule can be laid down concerning the amount of sleep required. It varies with age, occupation, temperament, and climate to a certain extent. An infant spends the greater part of its time in sound sleep. Adults of average age who work hard with their hands or brain usually require at least eight hours of sleep.

Personal peculiarities, and perhaps habit to a great extent, exert a marked influence. Throughout his long and active life Frederick the Great never slept more than five or six hours in the twenty-four. Napoleon slept but four hours a day. On the other hand, some of the busiest brain workers require at least eight or nine hours of sound sleep every night.

+ 349. Practical Rules about Sleep. Children should not be allowed to play boisterously just before bedtime, nor should their minds be excited with weird goblin stories, or a long time may pass before the wide-open eyes and agitated nerves become composed to slumber.

At all ages the last hour before sleep should, if possible, be spent quietly, to smooth the way towards sound and refreshing rest. Medicines should not be taken to induce sleep except on the advice of a physician.

${ }^{1}$ Remarkable instances are cited to illustrate the imperative demand for sleep. Cavalrymen and frontiersmen have slept soundly in the saddle during the exhausting campaigns against the Indians. A case is reported of a captain of a British frigate who fell asleep and remained so for two hours beside one of the largest guns of his vessel, the gun being served vigorously all the time. Whole companies of men have been known to sleep while on the march during an arduous campaign. Gunner boys have been known to fall asleep during the height of a naval battle, owing to the fatigue occasioned by the arduous labor in carrying ammunition for the gunner. 
It is better, as a rule, not to engage in severe study just before bedtime. One hour of morning or day study is worth a much longer time late at night. It is, therefore, an economy both of time and of nerve force to use the day hours and the early evening for study.

The so-called "cat naps" should never be made to serve as a substitute for a full night's sleep. Late hours are usually associated with exposure, excitement, and various other drains upon the nerve force, and hence are injurious.

350. General Effect of Alcohol upon the Nervous System. We have learned in the preceding chapters that alcohol tends to a serious disturbance of the tissues of the body. The direct influence of this narcotic upon the nervous system is marked even when taken in small quantities.

In the early stages, alcohol acts upon the nervous tissues as does ether, to excite both the cerebral and the spinal centers. This is rapidly followed by a marked depressant action upon both the sensory and motor nerves.

351. Effect of Varying Amounts of Alcohol upon the Brain. Scientific investigation has ascertained numerous facts concerning the influence of alcohol, when used in varying amounts, on the structure and function of the brain. A single small dose - half a pint of beer - has been shown to weaken the mental power required to carry on the processes of adding, committing to memory, association of ideas ; also the power of perception and of attention to simple sense impressions. Larger quantities cause a more rapid decrease of power, and the evil effects continue longer, sometimes until the evening of the next day. ${ }^{1}$

1 Dr. A. Forel, formerly professor of psychiatry in the University of Zurich, says concerning the effect ${ }^{\circ}$ of beer drinking upon the students of Germany: "One only needs to study in Germany the beer jokes, beer conversation, and beer literature. They have stifled in Germany the idealism, 
352. No Precise Boundary in the Different Stages of Alcoholic Intoxication. Large doses of alcohol cause the condition known as drunkenness, or intoxication, a term which comes from the word "toxic," meaning "poison." The effect of wine seen at a social dinner where those who have taken moderate amounts begin to grow talkative, excitable, and hilarious, represents a pathological state of the nervous system; that is, a disturbance of the natural conditions of the body. Such a person is poisoned, even though he is only in the first

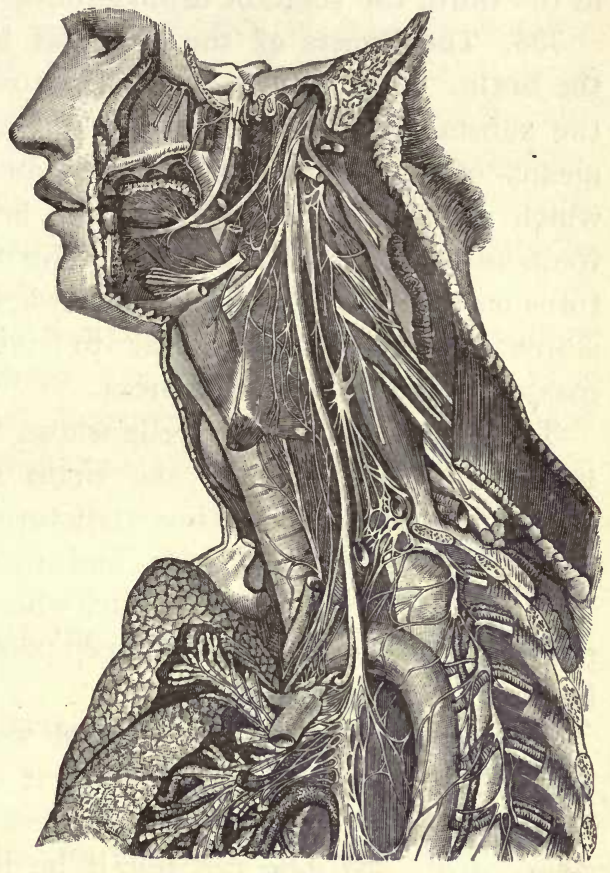

FIG. I25. Trunk of the Left Pneumogastric.

(Showing its distribution by its branches and ganglia to the larynx, pharynx, heart, lungs, and other parts.) stage of intoxication, which is that of mental excitement. There is no precise boundary between the quantity which produces the first and that which produces the second, the taste for the classics, and the finer mental pleasures throughout broad parts of the nation, and in both sexes, to an extent that makes one cry for help. Among the academic youth of Germany the drinking of beer has truly killed the ideals and the ethics and has produced an incredible vulgarity." 
that is, the stage of unsteadiness of muscle; nor between that which causes the second and that which eventuates in the third, the stage of drunkenness.

353. The Effects of the Habitual Use of Alcohol upon the Brain. The effects of the habitual use of alcohol on the substance of the brain itself have been studied by means of high-power microscopes and staining methods, which show actual changes in the brain cells caused by frequent contact with alcohol. The fine granular structures on the outer branches and twigs of the nerve cells soften and swell and appear to run together in small masses, causing local coarseness.

These changes in the cells whose function is the evolution of thought make the brain slower in receiving impressions, because the fine structures thus changed are concerned in the formation and association of images. This is also verified in real life, where changes in mental power and in moral character keep pace with the increasing indulgence of the drinker.

354. The Power of Self-Control weakened by Alcohol. The effect of even a small amount of alcohol upon the brain is shown by its action in weakening the power of self-control. No one can tell, if he begins to drink, how many indulgences in even a moderate amount of alcohol may make him the victim of an overmastering alcoholic appetite. A single glass, in the case of a person who has at any previous time been overcome by such an appetite, may at once, for the time being, take away his self-control. It is the general testimony of such men that if they take but one glass of any alcoholic liquor, their power of further resistance is destroyed. It is not that such men had in the beginning less power of self-control, but that alcohol weakens the will by its effect upon the nervous system. 
355. Evil Results of Alcoholism inherited. Children may inherit from drinking parents a disordered nervous system which makes them more liable to acquire a craving for strong drink. Careful statistics of a large number of families descended from drunkards show that a large proportion of them give undoubted proof of well-marked hereditary neuroses, i.e., diseases of the nervous system. This heredity is proved by the unusual prevalence in such families of infant mortality, convulsions, epilepsy, hysteria, obscure brain diseases, and imbecility. ${ }^{1}$

356. Opium and its Common Forms. Opium is a gumlike substance, the dried juice of the unripe capsule of a variety of poppy which is grown chiefly in Asia Minor and India. It is usually seen as a powder of a yellowish-brown color.

Morphine, a white powder, is a very condensed form of opium. Laudanum is an alcoholic solution of opium. Paregoric is a diluted and flavored form of an alcoholic tincture of opium.

357. Poisonous Effects of Opium. Opium is often used solely for its narcotic and intoxicating influence. The drug thus used lays its benumbing hand upon the brain. The mind is befogged; thought and reasoning are dulled.

The moral sense after a time may become benumbed; persons once honest resort to fraud and theft, if need be, to obtain the drug, till at last health, character, and life itself all become a pitiful wreck.

${ }^{1}$ After careful examination of the whole question, physiologists - and among physiologists I include those who maintain alcohol may be useful, as well as those who hold that it is harmful - have come to the conclusion that the principal action of alcohol is to blunt sensation, and to remove what we may call the power of inhibition by blunting the higher centers of the brain. - DR. G. Sims Woodhead, Professor of Pathology in Cambridge University, England. 
358. The Victim of the Opium Habit. Occasionally persons convalescing from serious sickness in which anodynes were taken unwisely cling to them long after recovery. Other persons, jaded with business or with worry, and unable to sleep, unwisely resort to some narcotic mixture to procure rest. In these and other similar cases the use of opiates is always most pernicious. The amount must be steadily increased to obtain the desired repose.

Even if the desired sleep is procured, it is hardly the coveted rest, but a troubled and dreamy slumber, leaving the body in the morning quite unrefreshed, the head aching, the mouth dry, and the stomach devoid of appetite. But far worse than even this condition may be the opium habit, which soon becomes a bondage in which life is shorn of its wholesome pleasures, and existence becomes a burden.

359. Chloral. Chloral is a powerful drug that has been much resorted to by unthinking persons to produce sleep. Others, yielding to a morbid reluctance to face the problems of life, have sought shelter in artificial forgetfulness. The chloral habit is a source of great danger and is difficult to cure.

360. Ether and Chloroform. Ether and chloroform, those priceless blessings to the human race if properly bestowed, may become instruments of death when carelessly trifled with. Persons who have been accustomed to inhale the vapor in slight whiffs for neuralgia or similar troubles do so at great peril, especially if lying down. They are liable to become slowly unconscious, and so to continue the inhalation till life is ended.

361. Other Powerful Drugs. There is still another class of drugs, often carelessly used, whose effect, while less directly serious than those mentioned, is yet far from harmless. They have sprung into popular use since the 
disease la grippe began its dreaded career, and include phenacetin, antipyrine, antifebrine, and many other similar preparations.

The popular use of the narcotic drug known as cocaine is beset with danger. The cocaine habit is easily formed, but difficult to relieve.

These drugs, taken freely and carelessly for all sorts and conditions of mental and physical ailments, are powerful depressants. They lower the action of the heart and the tone of the nervous centers.

362. Effect of Tobacco on the Nervous System. The profound effect of tobacco upon the nervous system is shown by the distressing prostration and pallor, the dizziness and faintness, with nausea and vomiting, which follow its use by the beginner.

The morbid effect of tobacco upon the nervous system of those who habitually use it is often shown in the irregular and enfeebled action of the heart, with dizziness and muscular tremor. The character of the pulse may show plainly the unsteady heart action caused by the partial paralysis of the nerves controlling this organ.

The nervous breakdown of many men in mature life is often due to the continued use of this depressing agent. This is shown more especially in men of sedentary habits.

363. Effects of Tobacco on the Mental Abilities of Young Men. The mind of the habitual user of tobacco may lose its capacity for study or successful effort. This is especially true of the young. The growth and development of the brain having been once retarded, the youthful user of tobacco has established a permanent drawback which may hamper him all his life. The keenness of his mental perception may be dulled and his ability to seize and hold an abstract thought may be impaired. 
The honors of the great schools, academies, and colleges are very largely taken by the abstainers from tobacco. This is proved by the result of repeated and extensive comparisons of the advanced classes in a great number of institutions in this country and in Europe. Our military and naval academies and very many seminaries and colleges very properly prohibit the use of tobacco by their students. The laws of many states rigidly forbid the sale of tobacco, especially of cigarettes, to minors.

\section{ADDITIONAL EXPERIMENTS}

Experiment 98. To illustrate the coöperation of certain parts of the body. Tickle the inside of the nose with a feather. This does not interfere with the muscles of breathing, but by reflex action they come to the help of the irritated part and provoke sneezing to clear and protect the nose.

Experiment 99. Pretend to aim a blow at a person's eye. Even if he is warned beforehand, the lids will close in spite of his effort to prevent them.

Experiment 100. To illustrate how sensations are referred to the ends of the nerves. Strike the elbow end of the ulna, where the ulnar nerve is exposed, against anything hard (commonly called " hitting the crazy bone"), and the little fingcr and the ring finger will tingle and become numb.

Experiment ror. To show that every nerve is independent of any other. Press two fingers closely together. Let the point of the finest needle be carried ever so lightly across from one finger to another, and we can easily tell just when the needle leaves one finger and touches the other.

Experiment 102. To paralyze a nerve temporarily. Throw one arm over the sharp edge of a chair back, bringing the inner edge of the biceps directly over the edge of the chair. Press deep and hard for a few minutes. The deep pressure on the nerve of the arm will put the arm "asleep," causing numbness and tingling. The leg and foot often fall "asleep" by deep pressure on the nerves of the thigh. 


\section{CHAPTER XI}

\section{THE SPECIAL SENSES}

364. The Special Senses. The senses are the avenues by which we obtain information concerning our bodily condition and the world around us.

In a general way, our senses may be compared to a certain number of disciplined picket-guards, along the outposts of the mind, whose business it is to take note of events and to report to headquarters any information which may be within the range of their duty.

In other words, we are provided with special senses, or "five gateways of knowledge," as they are often called, by means of which information is given us regarding outward forces and objects.

These special senses are touch, taste, smell, sight, and hearing, to which may be added the muscular sense and a sense of temperature.

365. General Sensations. The body, as we have learned, is made up of a great number of complicated organs, each doing its own part of the general work required for the welfare of the bodily structure. Through the agency of the nervous system each of these organs is designated to work in harmony with the others for the good of the whole. Now we must have some means of knowing whether this harmony is maintained, and of receiving timely warning if any organ fails to do its particular duty. 
Such information is supplied by the general sensations. Thus we have a feeling of hunger or thirst, indicating the need of food, and a feeling of discomfort when imperfectly clad, warning us of the need of more clothing. To these may be added the sensations of pain, tickling, and itching.

The great majority of sensations result from some outward stimulus or agency; and yet some sensations, such as those of faintness, restlessness, and fatigue, seem to spring up within us in some mysterious way, without any obvious cause.

$\checkmark$ 366. Essentials of a Sense Organ. Certain conditions are necessary for a sensation. First, there is a special structure adapted to a particular kind of influence. Thus the ear is formed specially for being stimulated by the waves of sound, while the eye is not influenced by sound, but responds to the action of light. These special structures are called terminal organs.

Again, a nerve proceeds from the special structure, and provides direct communication with nerve cells in the brain in the region of consciousness. This last point is important to remember, for if for any reason the impression is arrested in the connecting nerve, no sensation will result. Thus a man whose spine has been injured may not feel a severe pinch on either leg. The impression may be sufficient to produce as marked a reflex act as in a person with a healthy cord, but the man thus hurt does not feel the pinch, because the injury has prevented the impression from being carried up the cord to the higher centers in the brain.

367. The Condition of Sensation. It is thus evident that while an impression may be made upon a terminal organ, it cannot strictly be called a sensation until the person becomes conscious of it. The consciousness of an impression is, therefore, the essential element of a sensation. 
It follows that sensation may be prevented in various ways. In the sense of sight, for example, one person may be blind because the terminal organ, or eye, is defective or diseased. Another may have perfect eyes and yet have no sight, because a tumor presses on the nerve between the eye and the brain. In this case the impression fails because of the break in the communication. Once more, the eye may be perfect and the nerve connection unbroken, and yet the person cannot see, because the center in the brain itself is injured from disease or accident and cannot receive the impression.

$\checkmark$ 368. The Functions of the Brain Center in the Perception of an Impression. Sensation is really the result of a change which occurs in a nerve center in the brain, and yet we refer sensations to the various terminal organs. Thus, when the skin is pinched, the sensation is referred to the skin, although the perception is in the brain. We may think it is the eyes that see objects ; in reality, it is only the brain that takes note of them.

This is largely the result of education and habit. Thus, from the effects of a blow on the head one often sees flashes of light (familiarly known as "stars") as vividly as if torches actually danced before the eyes. Impressions have reached the seeing center in the brain from irritation of the optic nerve, or the center itself may have been irritated, producing the same effect as real lights would cause. In this case, however, knowing the cause of the flashes, the injured person is able to correct the erroneous conclusion.

369. Organs of Special Sense. The organs of special sense, the means by which we are brought into relation with surrounding objects, are usually classed as five in number (sometimes fancifully called "the five gateways of knowledge"): the skin, the chief organ of touch; the tongue, 
the chief organ of taste; the nose, of smell; the eye, of sight; and the ear, of hearing.

$\checkmark$ 370. The Organ of Touch. The organ of touch, or tactile sensibility, is the most widely extended of all the special senses, and perhaps the simplest. It is this sense to which we instinctively appeal to escape from the illusions into which the other senses may lead us. It has its seat in the skin all over the body, and in the mucous membrane

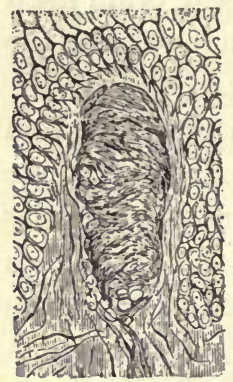

Fig. 126. Magnified View of a Papilla of the Skin, with a Touch Corpuscle.

at the entrance to various passages. All parts of the body, however, have not this sense in an equal degree.

We learned in Chapter IX that the superficial layer of the skin covers and dips in between the papillæ, which are richly provided with blood vessels and sensory nerve fibers. Now many of these nerve fibers terminate in oval-shaped bodies about one three-hundredth of an inch long, around which the nerve fibers wind, and which they finally enter. These are called touch or tactile corpuscles, and are found in great numbers on the fingers and toes, and more scantily in other places, as on the edges of the eyelids (Figs. 104 and 126).

Again, many of the nerve fibers terminate in corpuscles, the largest about one-twentieth of an inch long, called Pacinian corpuscles. These are most numerous in the palm of the hand and the sole of the foot.

$\checkmark 371$. The Sense of Touch. Touch includes the sense of contact and the sense of pressure. The sense of heat and cold may be regarded as a distinct sense.

The sense of contact is the most important element in touch. By it we judge of the form, size, and texture of the 
surface of the body touched. As we all know, the sense of touch varies in different parts of the skin. It is most acute where the outer skin is thinnest. The tips of the fingers, the edges of the lips, the forehead, and the tip of the tongue are especially sensitive.

372. How the Sense of Touch may be educated. The sense of touch is capable of education and may be developed to an extraordinary degree in persons who are deprived of some other special sense, as sight or hearing. We read of a famous blind sculptor who was said to model excellent likenesses, guided entirely by the sense of touch. An eminent authority on botany was a blind man, able to distinguish rare plants by the fingers and by the tip of the tongue. The blind learn to read with facility by passing their fingers over raised letters.

It is impossible to contemplate, even for a moment, the prominence assigned to the sense of touch in the physical organism, without being impressed with the manifestations of design, - the work of an all-wise Creator.

\section{Experiment ro3. To illustrate how the sense of touch is a matter} of habit or education. Shut both eyes and let a friend run the tips of your fingers, first lightly, over a hard plane surface; then press hard, then lightly again, and the surface will seem to be concave.

× Experiment ro4. Cross the middle finger over the index finger, roll a small marble between the fingers; one has a distinct impression of two marbles. Cross the fingers in the same way and rub the crossed ends against the point of the nose. A similar illusion is experienced.

Experiment ro5. To test the sense of locality. Ask a person to shut his eyes, touch some part of his body lightly with the point of a pin, then remove it, and ask him to indicate the part touched.

$\checkmark$ 373. Muscular Sense. When a heavy object is laid upon certain parts of the body it produces a sensation of pressure. 
By it we are enabled to estimate differences of weight. If an attempt be made to raise this object, it offers resistance, which the muscles must overcome. The feeling of effort accompanying an action is known as the muscular sense. It depends on sensory nerves in the muscles, which carry impressions from them to the nerve centers.'

$\checkmark 374$. Sense of Temperature. The skin also judges, to a certain extent, of heat and cold. These sensations can be felt only by the skin and the mucous membrane at the entrance to various passages. Direct irritation of a nerve does not give rise to them. Thus, the exposed pulp of a diseased tooth, when irritated by cold fluids, gives rise, not to a sensation of heat or cold, but simply to pain. Various portions of the body have different degrees of sensibility. The hand will bear a degree of heat which would cause pain to some other parts of the body.

J 375. Sense of Pain. The sense of pain is due to an excessive stimulation of the sensory nerves, and in it all finer sensations are lost. Thus, when a piece of hot iron burns the hand, the sensation is the same as when the iron is very cold. Extreme cold feels like intense heat.

$\checkmark$ 376. The Tongue as an Organ of Taste. The sense of taste is located chiefly in the tongue but may also be referred even to the region of the fauces. Taste, like touch, has its seat in special nerve endings.

The tongue is a muscular organ, covered with mucous membrane, and is richly supplied with blood vessels and nerves. It is an important factor in chewing, in swallowing, and in articulation.

The surface of the tongue is nearly covered with irregular projections called filiform papillæ, — fine, thread-like processes, about one-twelfth of an inch high. Interspersed with these are the fungiform papillæ. These are shaped 
something like a puffball fungus and may often be detected by their bright red points when the rest of the tongue is coated.

Towards the root of the tongue is another kind of papillæ, the circumvallate, eight to fifteen in number, arranged in the form of the letter $\mathrm{V}$, with the apex directed backwards.

In many of the papillæ are peculiar structures called taste buds or taste goblets. These exist in great numbers and are believed to be connected with nerve fibers. These taste buds are readily excited by savory substances and transmit the impression along the nerves of taste.

The tongue is supplied with sen-

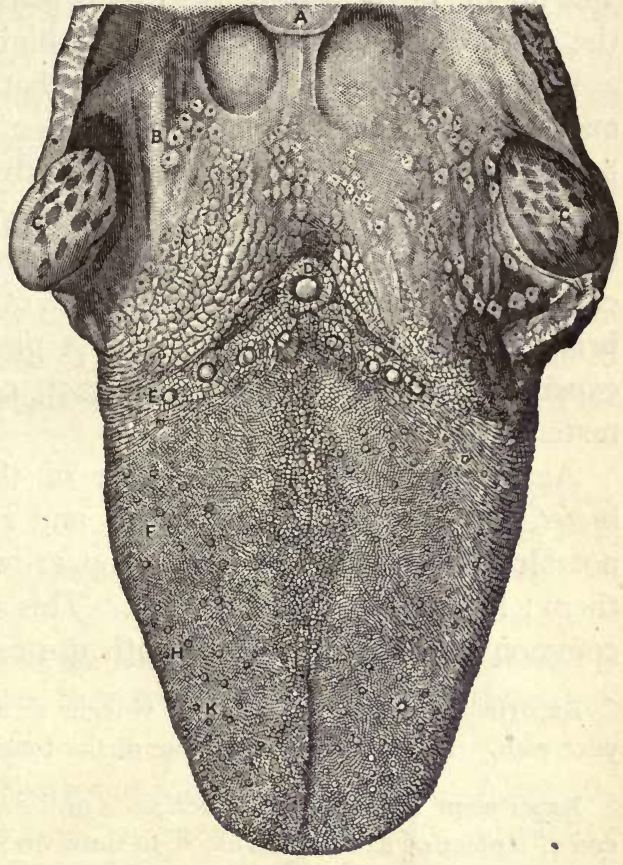

Fig. 127. The Tongue.

$A$, epiglottis ; $B$, glands at the base of tongue ; $C$, tonsil; $D$, median. circumvallate papilla; $E$, circumvallate papillæ; $F$, filiform papillæ; $H$, furrows on border of the tongue; $K$, fungiform papillæ.

sory nerve fibers which confer taste on the front and on the back part. Nerve branches also pass to the soft palate and neighboring parts and confer taste on them to a limited extent. 
377. The Sense of Taste. The sense of taste is excited by stimulation of the mucous membrane of the tongue and of the palate, affecting the ends of the nerve fibers. Taste is most acute in or near the circumvallate papilla. The middle of the tongue is scarcely sensitive to taste, while the edges and the tip are, as a rule, highly sensitive.

Certain conditions are necessary that the sense of taste may be excited. First, the substance to be tasted must be in solution, or be soluble in the fluids of the mouth. Insoluble substances are tasteless. If we touch our tongue to a piece of rock crystal, there is a sensation of contact or cold, but no sense of taste. On the other hand, when we bring the tongue in contact with a piece of rock salt we experience the sensations of contact, coolness, and saline taste.

Again, the mucous membrane of the mouth must be moist. When the mouth is dry and receives substances not already in solution there is no saliva ready to dissolve them ; hence they are tasteless. This absence of taste is common with the parched mouth during a fever.

Experiment ro6. Put a drop of vinegar on a friend's tongue, or on your own. Notice how the papillæ of the tongue start up.

Experiment 107. Rub different parts of the tongue with the pointed end of a piece of salt or gum aloes, to show that the back of the tongue is most sensitive to salt and bitter substances.

Experiment ro8. Repeat the same w'th some sweet or sour substance, to show that the edges of the tongue are the most sensitive to these substances.

Experiment rog. We often fail to distinguish between the sense of taste and that of smell. Chew some pure, roasted coffee, and it seems to have a distinct taste. Pinch the nose hard while chewing it, and there is little taste. Coffee has a powerful odor, but only a feeble taste. The same is true of garlic, onions, and various spices. 
378. Modifications of the Sense of Taste. Taste is modified to a great extent by habit, education, and many other circumstances. Articles of food that are unpleasant in early life often become agreeable in later years. The most savory dishes may excite disgust, while the simplest articles may have a delicious flavor to one long deprived of them. The taste for certain articles is certainly acquired. This is often true of raw tomatoes and olives.

The organs of taste and smell may be regarded as necessary accessories of the general apparatus of nutrition and are, therefore, more or less essential to the maintenance of animal life. While taste and smell are generally maintained until the close of life, sight and hearing are often impaired by time and may be altogether destroyed in extreme old age.

Experiment r1o. Light helps the sense of taste. Shut the eyes, and palatable foods taste insipid. Pinch the nose; close the eyes, and see how palatable one-half of a teaspoonful of cod-liver oil becomes.

- Experiment irr. Close the nostrils, shut the eyes, and attempt to distinguish by taste alone between a slice of an apple and one of a potato.

379. Effect of Tobacco and Alcohol upon Taste. Alcoholic liquors and tobacco tend to impair the delicate sensibility of the tender papillæ of the tongue. The keen appreciation of fine flavors is destroyed. The once clear and enjoyable taste for plainly cooked foods is diminished. Highly spiced and seasoned articles of diet are craved, indulgence in which usually results in various forms of indigestion.

380. Smell. The sense of smell is lodged in the delicate membrane which lines the nasal cavities. Man, in common with all air-breathing animals, has two nasal cavities. They communicate with the outer air by two nostrils opening in 
front, while two other passages open into the pharynx behind.

To increase the area of the air passages the two light, spongy turbinated bones, one on each side, form narrow, winding channels. The mucous membrane, with the branches of the olfactory nerve, lines the dividing wall and the inner surfaces of these winding passages.

381. The Sense of Smell. The sense of smell is excited by the contact of odorous particles contained in the air with the fibers of the olfactory nerves, which are distributed over the delicate surface of the upper parts of the nasal cavities.

In ordinary quiet breathing, the air simply flows along the lower nasal passages into the pharynx, scarcely entering the olfactory chamber at all. This is the reason why, when we wish to perceive a faint odor, we sniff up the air sharply.

The delicacy of the sense of smell varies greatly in different individuals and in different animals. It is generally more acute in savage races. Many animals are more highly endowed with this sense than is man. The dog appears to depend on the sense of smell almost as much as on sight. Deer, wild horses, and antelopes probably surpass all other animals in vividness of the sense of smell.

382. Association of Smell and Taste. Smell has been defined as "taste at a distance," and it is obvious that these two senses not only form a natural group, but are clearly associated in their physical action, especially in connection with the perception of the flavor of food. The sense of odor gives us information as to the quality of food and drink, and more especially as to the quality of the air we breathe.

Taste is at the gateway of the alimentary canal, while smell acts as the sentinel of the respiratory tract. Just as 
taste and flavor influence nutrition by affecting the digestive process, so the various odors about us have an important bearing upon respiration.

+383. The Marvelous Sense of Sight. Sight is well regarded as the highest and the most perfect of all our senses. It plays so common a part in our daily lives that we scarcely appreciate the marvelous gift. Sight is essential not only to the simplest matters of daily comfort and necessity, but is also of prime importance in the culture of the mind and in the higher forms of pleasure. It opens to us the widest and the most varied range of observation and enjoyment.

Unlike the senses of taste and smell, the sense of vision seems to make us aware of the existence of objects which are entirely

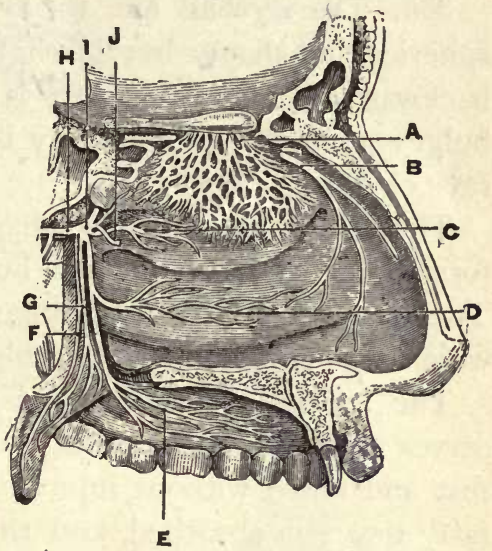

FIG. 128. Distribution of Nerves over the Interior of the Nostrils. (Outer wall.)

$A$, branches of the nerves of smell,-olfactory nerve, or ganglion; $B$, nerves of common sensation to the nostrils; $E, F, G$, nerves to the palate springing from a ganglion at $C ; H$, vidian nerve, from which branches $D, I$, and $J$ spring to be distributed to the nostrils.

apart from us and have no direct or material link connecting them with our bodies.

+ 384. The Eye. Apart from its uses, the eye itself is an interesting and instructive object of study. It presents beyond comparison the most beautiful example of design and artistic workmanship to be found in the bodily structure. It is the watchful sentinel and investigator of the external world. 
All the parts of this most wonderful and ingenious machine are arranged with such a delicate adjustment to one another, and such an exquisite adaptation of every part to the great object of the whole, that the eye is properly regarded as one of the wonders of nature.

t 385. The Eyeball and the Orbit. The eyeball is nearly spherical in shape, but is slightly elongated from before backwards. The front part is clear and transparent and bulges somewhat prominently to allow the entrance of the rays of light.

The eye rests in a bowl-shaped socket called the orbit, formed by parts of various bones of the head and face. The margins of this cavity are formed of strong bone which can withstand heavy blows.

The socket is padded with loose, fatty tissue, which serves as a soft and yielding bed in which the eyeball can rest and move without injury. In a severe sickness this fatty tissue is absorbed, and this fact explains the sunken appearance of the eyes. The eye is bathed with a watery fluid and protected by the eyelids and the eyebrows; it is moved in various directions by muscles, all of which will be described later.

+ 386. The Optic Nerve. The orbit is pierced through its posterior surface by an opening through which the nerve of sight, the optic, passes to the eyeball. We may think of the optic nerve holding the eyeball much as the stem holds the apple. It is the function of this most important nerve to transmit impressions of light to the seat of consciousness in the brain, where they are interpreted.

+ 387. The Coats of the Eyeball. The eyeball proper is composed of three coats, or layers, each of which performs important functions. These coats are the sclerotic, the choroid, and the retina. 
388. The Sclerotic Coat. The sclerotic coat is the outside layer and enclosing membrane of the eyeball. It is a tough . fibrous coat for the protection and maintenance of the shape of the eye. It is white and glistening in appearance; the part of it which is visible is known as "the white

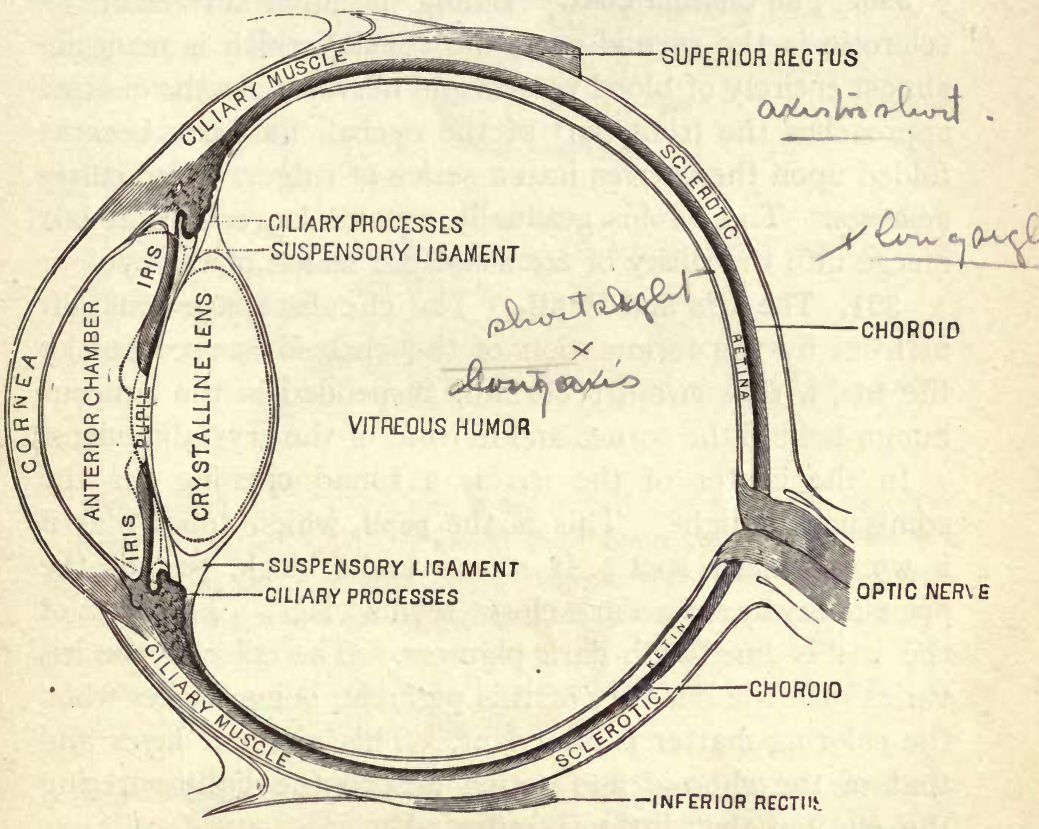

FIG. 129. Section of the Human Eye.

of tne eye." To this coat, which serves as a kind of framework for the eye, are attached the muscles which move the eyeball.

389. The Cornea. In front of the globe the sclerotic passes into a transparent circular portion forming a kind of window, through which one can see into the interior. This is the cornea, a clear, transparent, circular disk, which fits 
into the sclerotic, somewhat as the crystal fits into the - metallic case of a watch, forming a covering for its dial. It projects from the general surface of the eyeball, not unlike a rounded bay window, and is often spoken of as the "window of the eye."

390. The Choroid Coat. Lining the inner surface of the sclerotic is the second coat, the choroid, which is made up almost entirely of blood vessels and nerves. As the choroid approaches the front part of the eyeball its parts become folded upon themselves into a series of ridges, called ciliary processes. These folds gradually become larger and at last merge into the ciliary or accommodation muscle of the eye.

391. The Iris and Pupil. The circular space thus left in front by the termination of the choroid is occupied by the iris, a thin circular curtain, suspended in the aqueous humor behind the cornea and in front of the crystalline lens.

In the center of the iris is a round opening for the admission of light. This is the pupil, which appears as if it were a black spot. It seems to be black, just as the open doorway to a dark closet seems black. The back of the iris is lined with dark pigment. The color of the iris varies with the quantity of this pigment, being darker when the coloring matter is abundant. This pigment layer and that of the choroid and retina absorb the light entering the eye, so that little is reflected.

+ 392. The Retina. The third and innermost coat of the eyeball is the retina, upon which the images of external objects are received. It lines all but the extreme front of the inner surface of the posterior chamber.

The retina is a very thin, delicate membrane which forms the terminal organ of vision. It is really an expansion of the ultimate fibers of the optic nerve, by means of which impressions are sent to the brain. 
393. Inner Structure of the Eye. Let us imagine an eyeball divided through the middle from above downwards. Let us now start in front and observe its parts. We come first to the cornea, which has just been described (Fig. 129). The iris forms a sort of partition, dividing the cavity of

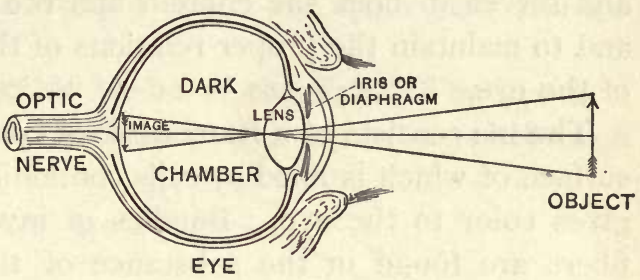
the eyeball into FIG. I30. Diagram illustrating the Manner in which two chambers.

The anterior the Image of an Object is brought to a Focus on the Retina.

chamber occupies the space between the cornea and the iris. It is filled with a thin, watery fluid called the aqueous humor.

Experiment I12. The retina is not sensitive where the optic nerve enters the eyeball. This is called the "blind spot." Put two ink bottles, about two feet apart, on a table covered with white paper. Close the left eye and fix the right steadily on the left-hand inkstand, gradually varying the distance from the eye to the ink bottle. At a certain distance the right-hand bottle will disappear, but nearer or farther than that, it will be plainly seen.

Experiment Ir3. Close one eye and look steadily at the small a in the figure below. The other letters will also be visible at the same time. If now the page be brought slowly nearer to the eye, while the eye is kept steadily looking at the small a, the large $A$ will disappear at a certain point, reappearing when the book is brought still nearer.

\section{a}

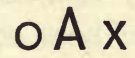

On the reappearance of the $A$ it will be noted that it comes into view from the inner side, the $x$ being seen before it. If now we move the book back towards its original place, the $A$ will again disappear, coming again into view from the outer side when the o is seen before it. 
The portion behind the iris forms the posterior chamber and contains the crystalline lens and the vitreous humor.

The vitreous humor fills about four-fifths of the eyeball, and serves to hold the choroid and the retina in position and to maintain the proper relations of the inner structures of the eye.

The iris consists of a framework of connective tissue, the surface of which is lined by cells containing pigment, which gives color to the eye. Bundles of involuntary muscular fibers are found in the substance of the iris, which are arranged to allow the pupil to contract or dilate more or less widely.

394. The Crystalline Lens. Just behind the pupil and close to the iris is a semisolid, doubly convex body, called the crystalline lens. It is shaped like a magnifying glass, convex on each side, but with the posterior surface more convex than the anterior. In health it is perfectly clear and transparent, and highly elastic. When the lens becomes opaque, from change in old age, or from ulcers or wounds, we have the disease known as cataract.

The crystalline lens is not placed loosely in the eyeball, but is enclosed in a transparent and elastic capsule suspended throughout its circumference by a ligament called the suspensory ligament. This ligament not only retains the lens in place, but is capable of altering its shape.

395. The Ciliary Muscle. All around the edge, where the cornea, sclerotic, and choroid meet, is a ring of involuntary muscular fibers, forming the ciliary muscle. When these fibers contract, they draw forwards the attachment of the suspensory ligament of the lens, the pressure of which on the lens is consequently diminished. The elasticity of the lens causes it at once to bulge forwards, and it becomes more convex. 
The ciliary muscle is thus known as the muscle of accommodation, because it has the power to accommodate the eye to near and distant objects. In this respect it corresponds in its use to the adjusting screw in the opera glass and the microscope.

396. The Refractive Media of the Eye. The eye is a closed chamber, into which no light can pass except through
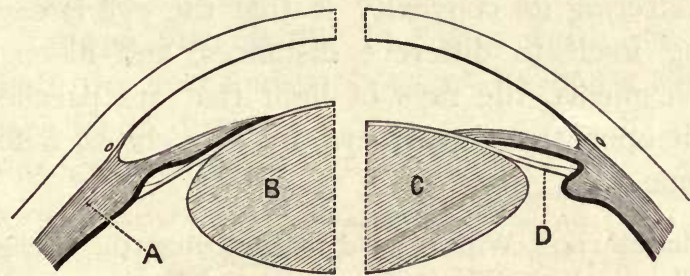

FIG. I3I. Diagram showing the Change in the Lens during Accommodation.

(On the right the lens is arranged for distant vision, the ciliary muscle is relaxed, and the ligament $D$ is tense, so flattening by its compression the front of the lens $C$; on the left the muscle $A$ is acting, and this relaxes the ligament and allows the lens $B$ to become more convex, and so fitted for the vision of near objects.)

the cornea. All the rays that enter the eye must also pass through the crystalline lens, which brings them to a focus as would an ordinary lens.

Now, if the media through which the light from an object passes to reach the retina were all of the same density as the air, and were also plane surfaces, an impression would be produced, but the image would not be distinct.

The action of the crystalline lens is aided by several refractive media in the eye. These media are the cornea, the aqueous humor, and the vitreous humor. By reason of their shape and density these media refract the rays of light, and bring them to a focus upon the retina, thus 
aiding in producing a sharp and distinct image of the object. Each point of the image, being the focus or meeting place of a vast number of rays coming from the corresponding point of the object, is sufficiently bright to stimulate the retina to action.

Thus, the moment rays of light enter the eye they are bent out of their course. By the action of the crystalline lens in altering its convexity so that the eye is capable of adjusting itself to different distances, and aided by the refractive media, the rays of light that are parallel when they fall upon the normal eye are brought to a focus on the retina.

Experiment 114. With a hand mirror reflect the sunlight on a white wall. Look steadily at the spot for a full minute, and then let the mirror suddenly be removed. The "complementary" color - a dark spot - will appear.

Experiment 115. To show that impressions made upon the retina do not disappear at once. Look steadily at a bright light for a moment or two, and then turn away suddenly, or shut the eyes. A gleam of light will be seen for a second or two.

Look steadily at a well-lighted window for a few seconds, and then turn the eyes suddenly to a darkened wall. The window frame may be plainly seen for a moment.

Experiment 116. Take a round piece of white cardboard the size of a saucer, and paint it in alternate rings of red and yellow, - two primary colors. Thrust a pin through the center and rotate it rapidly. The eye perceives neither color, but orange, - the secondary color.

397. Old Sight. "Old sight," known as presbyopia, is a common defect of vision in advancing years. This is a partial loss of the power to accommodate the eye to different distances. This defect is caused by an increase in the density of the crystalline lens, and an accompanying diminution in the ability to change its form. The far point of 
vision is not changed, but the near point is removed so far from the eye that near objects are no longer visible.

Hence, when a person about forty-five years of age complains of dim light, poor print, and tired eyes, the time has come to seek the advice of an oculist. A convex lens may be needed to aid the failing power to increase the convexity of the lens, and to assist it in bringing the divergent rays of light to a focus.

+ 398. Long or Far Sight. In "long sight," or hypermetropia, both the near and far point of vision are concerned, and there is no distinct vision at any distance without a strain. It is a defect in the focus, dependent upon the form of the eyes, and often exists in childhood. The axis of the eyeball is too short, and the focus falls beyond the retina, which is too near the cornea.

In childhood this strain

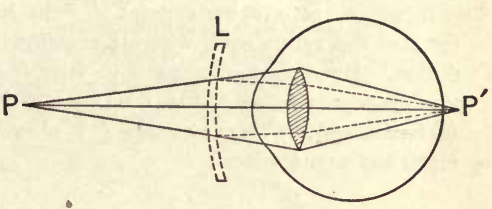

FIG. I32. Diagram illustrating the Hypermetropic (Farsighted) Eye.

The image $P^{\prime}$ of a point $P$ falls behind the retina in the unaccommodated eye. By means of a convex lens $(L)$ it may be focused on the retina without accommodation (dotted lines). (To save space $P$ is placed much too near the eye.) may pass unnoticed, but sooner or later it manifests itself by a sense of fatigue, dizziness, and a blurred and indistinct vision. The remedy is in the use of convex glasses to converge parallel rays of light before they enter the eye. The muscles of accommodation are thus relieved of their extra work.

399. Short or Near Sight. "Short sight," known as myopia, is one of the commonest defects of vision. In this defect the axis of the eye, or the distance between the cornea and the retina, is too long and the rays of light are brought to a focus in front of the retina. The tendency, 
to shortsightedness exists in many cases at birth, and is largely hereditary. It is alarmingly common with those

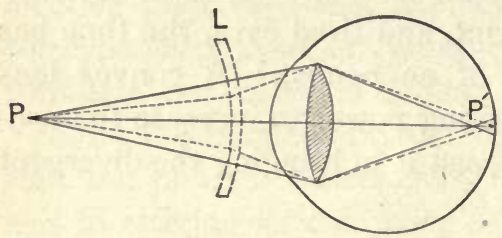

FIG. I33. Diagram illustrating the Myopic (Nearsighted) Eye.

The image $P^{\prime}$ of a distant point $P$ falls in front of the retina even without accommodation. By means of a concave lens $(L)$ the image may be made to fall on the retina (dotted lines). (To save space $P$ is placed much too near the eye.) who make a severe demand upon the eyes.

During childhood there is a marked increase of nearsightedness. The results of imprudence and abuse, in matters of eyesight, are so disastrous, especially during school life, that the question of short sight becomes one of much importance.

Nearsightedness often demands skillful advice and careful treatment. Concave glasses, properly adjusted to meet the conditions of the eyes, may be needed.

Experiment 117. To note the shadows cast upon the retina by opaque matters in the vitreous humor (popularly known as floating specks, or gossamer threads), look through a small pinhole in a card at a bright light covered by a ground-glass shade.

fExperiment 118 . To illustrate accommodation. Standing near a source of light, close one eye, hold up both forefingers not quite in a line, keeping one finger about six or seven inches from the other eye, and the other forefinger about sixteen to eighteen inches from the eye. Look at the near finger; a distinct image is obtained of it, while the far one is blurred or indistinct. Look at the far image; it becomes distinct, while the near one becomes blurred. Observe that in accommodating for the near object, one is conscious of a distinct effort.

400. Astigmatism. There is an optical condition of the eye known as astigmatism, in which the cornea is usually at fault. In this defect of vision the curvature of the cornea 
is greater in one meridian than in another. As a result, the rays from an object are not all brought to the same focus. Objects appear distorted or are seen with unequal clearness.

Glasses of a peculiar shape are required to counteract this defect.

+ 401. The Movements of the Eyes. The mechanical arrangement by which the eyeballs are moved in different

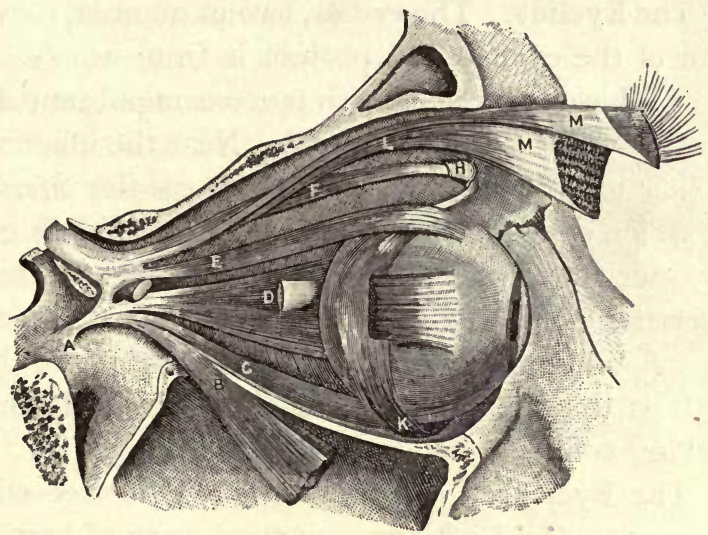

FIG. I34. Muscles of the Eyeball.

$A$, attachment of tendon connected with the four recti muscles; $B$, external rectus, divided and turned downward, to expose the internal rectus; $C$, inferior rectus; $D$, internal rectus; $E$, superior rectus; $F$, superior oblique; $H$, pulley and reflected portion of the superior oblique; $K$, inferior oblique; $L$, levator palpebri superioris; $M$, middle portion of the same muscle $(L)$.

directions is quite simple. It is done by six little muscles, arranged in three pairs. Four of these muscles run a straight course and are called the recti. The remaining two muscles bend in their course and are called oblique. The coördination of these tiny muscles is marvelous in its delicacy, accuracy, and rapidity of action. 
Thus the beauty of the internal mechanism of the eye has its fitting complement in the precision, delicacy, and range of movement conferred upon it by its muscles.

402. Strabismus. When, for any cause, the coördination is faulty, "cross-eye," technically called strabismus, is produced. Thus, if the internal rectus is shortened, the eye turns in; if the external rectus, the eye turns out, producing what is known as "wall-eye."

t 403. The Eyelids. The eyelids, two in number, move over the front of the eyeball and protect it from injury. They consist of folds of skin lined with mucous membrane, kept in shape by a layer of fibrous material. Near the inner surface of the lids is a row of glands, known as the Meibomian glands, which open on the free edges of each lid (Fig. I 37).

The inner lining membrane of the eyelids is known as the conjunctiva ; it is richly supplied with blood vessels and nerves. After lining the lids it is reflected on to the eyeballs. It is this membrane which is occasionally inflamed from taking cold.

$\downarrow$ 404. The Eyelashes and Eyebrows. The free edges of the lids are bordered with two or more rows of hairs called the eyelashes, which serve to protect the eyes from dust, and to a certain extent to shade them. Their loss gives a peculiar, unsightly look to the face.

The upper border of the orbit is provided with a fringe of short, stiff hairs, the eyebrows. They help to shade the eyes from excessive light, and to protect the eyelids from perspiration, which would otherwise cause discomfort.

$\times$ 405. The Lachrymal Apparatus. Nature provides a special secretion, the tears, to moisten and protect the eye. The apparatus producing this secretion consists of the lachrymal or tear gland and lachrymal canals or tear passages (Figs. I 35 and 137). 
Outside of the eyeball, in the loose, fatty tissue of the orbit, in the upper and outer corner, is the lachrymal or tear gland. It is about the size of a small almond, and from it lead several little canals which open on the inner surface of the upper lid.

The fluid from the gland flows out by these openings over the eyeball, and is collected at the inner or nasal corner. Here in each lid is a little reddish elevation, or lachrymal caruncle, in which is an opening, communicating with a small canal in the lid which joins the lachrymal sac, lodged between the orbit and the bridge of the nose (Fig. I 37).

406. The Nasal Duct. From the lachrymal sac there passes a channel, the nasal duct, about one-half of an inch long, leading into the lower portion of the nostril. The fluid which has flowed over the eye is drained off by these canals into the nose.

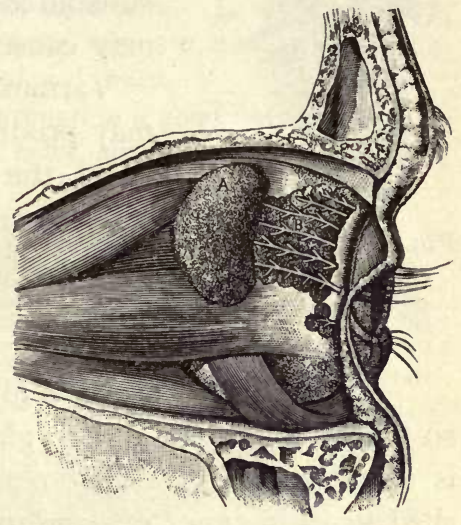

FIG. 135. Lachrymal Gland and Ducts.

$A$, lachrymal gland, the size of a small almond, lodged in a shallow depression in the bones of the orbit; $B$, lachrymal ducts, which form a row of openings into the conjunctival fold.

During sleep this secretion is much diminished. When the eyes are open the quantity is sufficient to moisten the eyeball, the excess being carried into the nose so gradually that the attention is not attracted to it.

The flow of the tears into the nose may be blocked by inflammation of the nasal duct. The fluid collects in the corners of the eyelids and overflows down the cheeks, producing much discomfort. 
407. The Tears. If the eyelids are irritated the sensory nerves are stimulated and the impression is carried to the

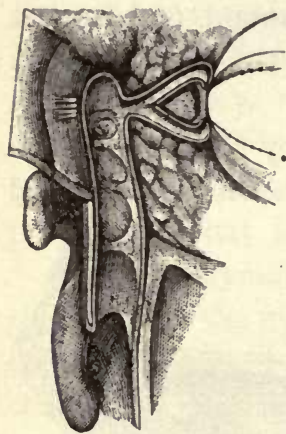

Fig. 136. Lachrymal

Canals, Lachrymal Sac, and Nasal Duct, opened by their Anterior Portion. brain. Thence the nerve impulses travel to the lachrymal glands, leading to an increased flow of their secretion. Thus the irritation of the sensory nerves in the nasal passages by smelling such substances as onions, or pungent salts, may cause a copious flow of tears.

Various emotions, as joy and grief, may produce similar results. In these cases the glands secrete the fluid in such quantities that it cannot escape by the lachrymal canals, and the excess rolls over the cheeks as tears. Excessive grief sometimes acts on the nerve centers in exactly the opposite manner, so that the activity of the glands is arrested and less fluid is secreted. This is the reason why some people do not shed tears in times of deep grief.

Experiment I19. Gently turn the inner part of your lower eyelid down. Look in a mirror, and the small lachrymal point, or opening into the nasal duct, may be observed.

408. Color-Blindness. The power of discriminating between different colors is impaired in color-blindness. Experiment shows that ninety-six out of every one hundred men agree as to the identity or the difference of color. The remaining four show a defective perception of color and are said to be color-blind.

In its true sense, color-blindness is always congenital, often hereditary. This condition of abnormal vision is totally incurable. A person may be color-blind and not know it until 
the defect is accidentally revealed. The common form of defective color vision is the inability to distinguish between red and green. This abnormal defect of vision may be a matter of great practical importance to those employed on steam and electric railways, on shipboard, and elsewhere.

Experiment 120. To test color-blindness. On no account is the person being tested to be asked to name a color. In a large class of students one is pretty sure to find some who are more or less colorblind. The common defects are red and green.

Place worsteds on a white background in a good light. Select, as a test color, a skein of light green color, such as would be obtained by mixing a pure green with white. Ask the examinee to select and pick out from the heap all those skeins which appear to him to be of the same color, whether of lighter or darker shades. A colorblind person will select amongst others some of the confusion colors, e.g., pink, yellow. A colored plate showing these should be hung up in the room. Any one who selects all the greens and no confusion colors has normal color vision. If, however, one or more confusion colors be selected, proceed as follows: select as a test color a skein of pale rose. If the person be red

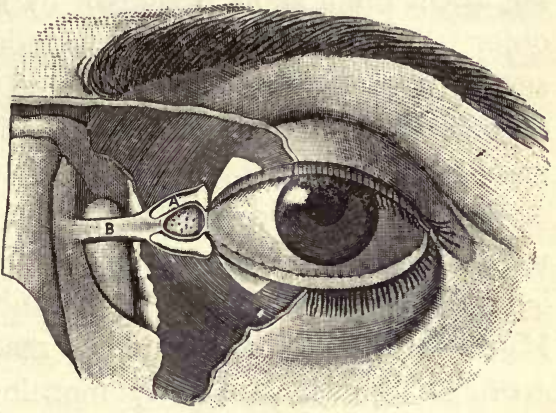

Frg. 137. Showing thc Relative Position of the Lachrymal Apparatus, the Eyeball, and the Eyelids.

$A$, lachrymal canals, with the minute orifices represented as two black dots (puncta lacrymalia) to the right ; $B$, tendon of the orbicularis palpebrarum muscle; apparently under $B$ is seen the lachrymal sac. The minute openings of the Meibomian glands are seen on the free margins of the eyelids. Below $A$ is seen a small conical elevation, with black dots (the lachrymal papilla or caruncle).

blind, he will choose blue and violet; if green blind, gray and green.

Select a bright red skein. The red blind will select green and brown; the green blind will choose red or lighter brown. 
409. How the Eyes may be abused in Reading. The battered type and poor presswork, now so commonly used in the cheap editions of books and periodicals, are often injurious to the eyesight. The habit of reading, in the cars or elsewhere, the daily paper and poorly printed books, with their blurred and indistinct type, is a severe strain on the eyes. It is a dangerous practice to read in bed at night, or while lying down in a darkened or shaded room. This is especially true during recovery from illness.

410. Hints on giving the Eyes Rest. After reading steadily for some time, the eyes should be rested by closing them for a short period or by looking at some distant object, even if only for a few moments. The book, the sewing, and work generally, should be held as far from the eyes as is compatible with good vision. The natural tendency is to reverse this rule.

We should never read, write, sew, stitch, or otherwise use the eyes when they smart or tingle, or when the sight is dim or blurred. The eyes are then tired and need a rest. Much injury may be done by reading in twilight, or by artificial light in the early morning, and by reading and working in badly lighted and ill-ventilated rooms.

411. Additional Hints on the Care of the Eyes. Good artificial light is much to be preferred to insufficient sunlight. The artificial light should be sufficiently bright and steady; a flickering light is always bad. Riding against a strong wind, especially on a bicycle, may prove hurtful, at least for eyes that are inclined to any kind of inflammation. The light reflected from snow is a common source of injury to the eyes.

The eyes should never be rubbed when they are irritated by any foreign substance. The sooner the offending substance is removed the better. The Germans have a quaint 
proverb that one should never rub his eyes except with his elbows.

The eyes of young infants should not be exposed to electric lights or to the direct rays of the sun. Special care should be taken with children's eyes during and after an attack of measles and scarlet fever.

Glasses should be worn when they are needed A failure to do this usually causes much unnecessary suffering. It is far from wise to postpone as long as possible the first use of glasses.

\section{Effect of Alcohol} and Tobacco upon Vision. A wide comparison of cases by careful observers proves that a large fraction of those who indulge in
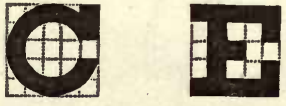

Fig. I 38. The Actual Size of the TestType, which should be seen by the Normal Eye at a Distance of Twenty Feet.

strong drink suffer from some disease of the eye. The earlier and slighter forms of injury done to the eye by the use of intoxicants are quite familiar, - the watery condition of the eye and of the lids, and its red and bleared aspect. The nerves controlling the circulation of the eye are partially paralyzed, and thus the relaxed vessels become distended.

Long use of intoxicants may produce diseases of the retina, involving, in many cases, marked diminution of acuteness as well as quickness of vision.

What is known to oculists as "tobacco blindness," and a temporary form of color-blindness, may result from an excessive use of tobacco.

The ill effects of tobacco, and especially of cigarettes, upon the eyes of the young are generally recognized.

413. The Sense of Hearing. The structure of the human ear is much more complicated than is generally supposed. 
As a whole, it may be considered a peculiar form of nerve ending.

The external ear forms only a part of a most elaborate apparatus whereby sound waves may be transmitted inward to the real organ of hearing. The really sensitive part of the ear, in which the auditory nerve ends, is buried for protection so deep in the bones of the head that sounds

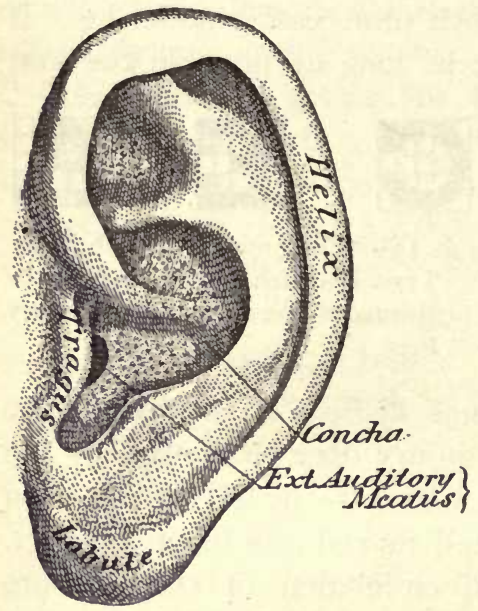

FIG. 139. The Pinna, or Auricle. cannot directly affect it. Some arrangement, therefore, is required for conducting the sounds inward to this organ.

In studying the structure of the ear we may divide it, for convenience, into three parts: the external ear, the middle ear, and the deeply placed portion, the inner ear.

$\checkmark$ 414. The External Ear. The external ear consists of an expanded portion known as the pinna, or auricle, and of a passage, the auditory canal, or meatus, leading inward from it. The surface of the auricle is convoluted to collect and transmit the vibrations of air by which sound is produced. Many animals move the auricle in the direction of the sound. Thus the horse pricks up its ears when it hears a noise, the better to judge of the direction of sounds. ${ }^{1}$

1 The student who will take a little trouble in noticing the ears of the persons whom he meets from day to day will be greatly interested and surprised to see how much the auricle varies. 
415. The Auditory Canal. The auditory canal, the passage to the middle ear, conducts the vibrations of sound to the tympanic membrane. It is about an inch and a quarter long. Near its outer portion are a number of fine hairs slanting outwards. These prevent the entrance of insects. Embedded in the deeper parts of the canal are

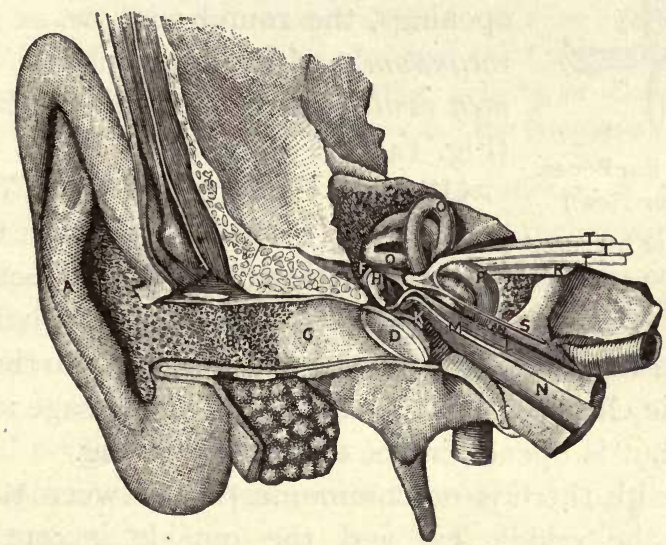

Fig. I 40. General View of the Organ of Hearing.

$A$, pinna ; $B$, cavity of the concha, showing the orifices of a great number of sebaceous glands; $C$, external auditory meatus; $D$, membrana tympani; $F$, incus; $H$, malleus; $K$, handle of malleus applied to the internal surface of the membrana tympani ; $L$, tensor tympani muscle; between $M$ and $K$ is the tympanic cavity; $N$, Eustachian tube ; $O, P$, semicircular canals; $R$, internal auditory canal; $S$, large nerve given off from the facial ganglion; $T$, facial and auditory nerves.

glands which secrete the cerumen, or earwax, which keeps the canal moist and helps to protect it against foreign bodies and insects.

416. The Middle Ear. At the inner end of the outer ear passage is the middle ear or tympanum, or "the drum of the ear." Stretched at an angle across the deep end of the passage is a thin oval membrane which completely closes it. 
This membrane, the tympanic membrane, or drum membrane, thus forms a partition between the passage of the outer ear and the cavity of the middle ear. The latter is

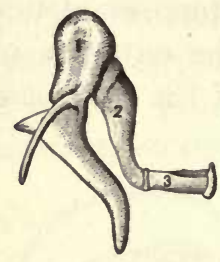

Fig. 14I. Ear Bones.

(Anterior view.)

I, malleus, or hammer;

2, incus, or anvil; 3 , stapes, or stirrup.

a small air chamber in the petrous portion of the temporal bone. On the bony inner wall of this tympanum are two openings, the round window, or foramen rotundum, and the oval window, or foramen ovale, which lead into the labyrinth (Fig. 145).

417. The Eustachian Tube. The tympanic cavity communicates with the back part of the throat by the Eustachian tube. This tube is about one and one-half inches long and lined with mucous membrane similar to that of the tympanic chamber and the throat. This passage is usually closed, but is opened in the act of swallowing.

In health there is no communication between the chamber of the middle ear and the outside, except by the Eustachian tube. Thus a throat cold, with swelling of the mucous membrane, is often accompanied with some degree of deafness, because the swelling may block the lumen of the tube and thus prevent the free passage of the air to and fro.

>418. The Bones of the Ear. A most curious feature of the ear is the chain of tiny movable bones which stretch across the cavity of the middle ear. They connect the tympanic membrane with the labyrinth and serve to convey the vibrations communicated to the membrane across the cavity of the tympanum to the internal ear.

These bones are three in number and from their shape are called the malleus, or hammer; incus, or anvil; and stapes, or stirrup. 
These little bones are connected with each other and the tympanum by ligaments and moved by three tiny muscles. Two are attached to the hammer and tighten and relax the drum; the other is attached to the stirrup and prevents it from being pushed too deeply into the oval window.

Experiment 121. To vibrate the tympanic membrane and the little ear bones. Shut the mouth and pinch the nose tightly. Try to force air through the nose. The air dilates the Eustachian tube and is forced into the ear drum. The distinct crackle, or clicking sound, is due to the movement of the ear bones and the tympanic membrane.

419. The Internal Ear. The internal ear, one of the most delicate and complex pieces of mechanism in the whole body, receives the impression of sound and carries it directly to the seat of consciousness in the brain.

The internal ear, or labyrinth, consists of three distinct parts, or variously shaped chambers, hollowed out in the temporal bone, - the vestibule, the semicircular canals, and the cochlea, or snail's shell (Figs. I44 and I45).

420. The Vestibule. The vestibule is an oval-shaped chamber, about one-fifth of an inch in diameter, occupying the middle part of the internal ear. It is on the inner side of the oval window, which is closed, as we have seen, by the stirrup bone. From one side of this vestibule, or cen-

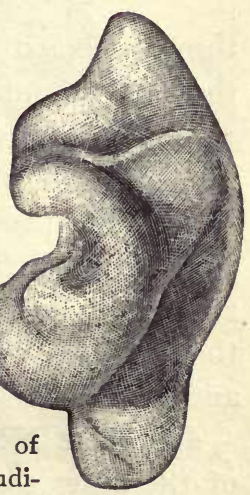

FIG. 142. A Cast of the External Auditory Canal. (Posterior view.) tral hall, the three semicircular canals pass off, and from the other side the cochlea.

421. The Semicircular Canals. The three semicircular canals, so called from their shape, are simply bony tubes 
about one-twentieth of an inch in width, making a curve of about one-quarter of an inch in diameter. They pass out from the vestibule, and, after bending around somewhat like a hoop, return again to the vestibule. Each bony

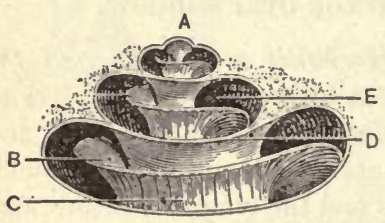

FIG. 143. Section of Cochlea.

(From $A$ straight downwards is the direction of the central column, to which $E$ points. $B$ points to the projecting ridge, almost dividing the canal of the tube into an upper compartment, $D$, and a lower, C.) canal has a swelling at the end where it opens into the vestibule. This is called the ampulla.

1422. The Cochlea. The cochlea, or snail's shell, is another chamber hollowed out in the solid bone. It is coiled on itself somewhat like a snail's shell. There is a central pillar, around which winds a long spiral canal. One passage from the cochlea opens directly into the vestibule; the other leads to the chamber of the middle ear and is separated from it by the little round window already described.

The cochlea contains thousands of the most minute cords, known as the fibers or organ of Corti. Under the microscope they present the appearance of the keyboard of a piano. These fibers appear to vibrate in sympathy with the countless shades of sounds which penetrate the ear. From the hair-like processes on these tightly stretched fibers, auditory impulses appear to be transmitted to the brain.

423. The Membranous Sac. The tubes and chambers of the inner ear enclose and protect a delicate membranous sac of exactly the same shape as themselves. Between the bony walls of the passages and the membranous bag inside is a thin, clear fluid, the perilymph. The membranous sac itself contains a similar fluid, the endolymph. In this fluid are found some minute crystals of lime, like tiny particles 
of sand, called otoliths, or ear stones. Every movement of the fluid itself throws these grains from side to side.

$\rightarrow$ 424. The Auditory Nerve. The auditory nerve, or nerve of hearing, passes to the inner ear through a passage in the solid bone of the skull. Its minute filaments spread at last over the inner walls of the membranous labyrinth in two branches. One goes to the vestibule and the ampullæ at the ends of the semicircular canals; the other leads to the cochlea.

1 425. Mechanism of Hearing. Waves of sound reach the ear and are directed by the concha to the external passage, at the end of which they reach the tympanic membrane. When the sound waves beat upon this thin membrane it is thrown into vibration, reproducing in its movements the character of the air vibrations that have fallen upon it.

The vibrations of the tympanic membrane are now passed along the chain of bones attached to its inner surface and reach the stirrup bone. The stirrup now performs a toand-fro movement at the oval window, passing the auditory impulse inwards to the internal ear.

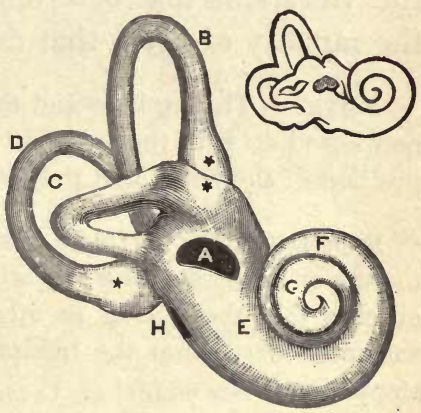

Fig. 144. Bony Internal Ear of the Right Side. (Magnified; the upper figure of the natural size.)

$A$, oval window (foramen ovale); $B, C$, $D$, semicircular canals; * represents the bulging part (ampulla) of each canal; $E, F, G$, cochlea ; $H$, round window (foramen rotundum).

Every time the stirrup bone is pushed in and drawn out of the oval window the watery fluid (the perilymph) in the inner ear is set in motion more or less violently, according to the intensity of the sound. The membranous 
labyrinth occupies the central portion of the vestibule and the passages leading from it. When, therefore, the perilymph is shaken it communicates the impulse to the fluid (endolymph) contained in the inner membranous sac.

The endolymph is now driven against the sides of the membranous sac and so strikes the ends of the nerves of hearing, which transmit the auditory impulses to the seat of sensation in the brain.

It is in the seat of sensation in the brain that the various auditory impulses received from different parts of the inner ear are interpreted as sounds. It is the extent of the vibrations that determines the loudness of the sound; the rapidity of them that determines the pitch.

NOTE. - The otoliths and the semicircular canals probably have nothing to do with the sense of hearing. They enable us to feel the position of the head, and thus help us to preserve our equilibrium.

$f$ Experiment 122. Hold a ticking watch between the teeth, or touch the upper incisors with a vibrating tuning fork; close both ears and observe that the ticking or vibration is heard louder. Unstop one ear and observe that the ticking or vibration is heard loudest in the stopped ear.

Experiment 123. Hold a vibrating tuning fork on the incisor teeth until it can no longer be heard. Close one or both ears, and it will be heard again.

Experiment 124. Listen to a ticking watch or a tuning fork kept vibrating electrically. Close the mouth and nostrils and take either a deep inspiration or deep expiration, so as to alter the tension of the air in the tympanun; in both cases the sound is diminished.

- Experiment 125. With a blindfolded person test his sense of the direction of sound, e.g., by clicking two coins together. It is very imperfect. Let a person press both auricles against the side of the head and hold both hands vertically in front of each meatus. If a person makes a sound in front, the observed person will refer it to a position behind him. 
426. Practical Hints on the Care of the Ear. The ears are often neglected when skilled treatment is urgently needed, and they are often ignorantly and carelessly tampered with when they should be left alone.

Never insert into the ear canal the corners of towels, ear spoons, the ends of toothpicks, hairpins, or any other pointed instruments. It is a needless and dangerous practice, usually causing, in time, some form of inflammation.

Again, there is always risk that the elbow may be jogged and the instrument pushed through the drumhead. There is, of course, a natural impulse to relieve itching of the ear when it occurs. This should be done with the tips of the fingers or not at all.

Very cold water

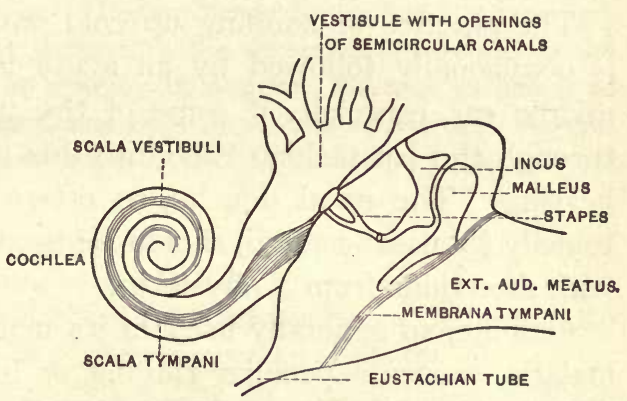
should never be used to bathe the

FIG. 145. Diagram of the Middle and Internal Ear. ears and nostrils. Bathe moderately and gently in lukewarm water, using a wash rag in preference to a sponge; dry. gently and thoroughly. Do not go to sleep with the head on a window sill or in any position in which the ears are exposed to draughts of cold or damp air.

Never shout suddenly in a person's ear. The ear is not prepared for the shock, and deafness has occasionally resulted. Insects may gain entrance to the ears and occasion annoyance, pain, and fright, perhaps leading to vomiting, even to convulsions, with nervous children. A lighted lamp held at the entrance of the ear will often 
induce the offending insect to crawl out towards the light. A few drops of warm water, sweet oil, or molasses dropped into the ear will help remove the intruder.

427. Additional Suggestions on the Health of the Ears. No effort should be made to remove the earwax unless it unduly accumulates. The skin of the canal grows outward, and the extra wax and dust will be naturally carried out if let alone. Never employ any of the many articles or "drops" advertised to cure deafness. Neuralgic pain in the auditory canal, usually classed as earache, may be due to decayed or improperly filled teeth.

The practice of snuffing up cold water into the nostrils is occasionally followed by an acute inflammation of the middle ear, especially if some of the water finds its way through the Eustachian tube into this part of the organ of hearing. The nasal douche, so often advised as a home remedy for nasal catarrh, should be used only in accordance with directions from a physician.

Quinine, so generally used in its many preparations for malaria, causes a peculiar ringing or buzzing in the ears. This is a warning that it should be taken in smaller doses, or perhaps stopped for a time. In some cases quinine may produce temporary deafness.

428. Effect of Alcohol and Tobacco upon the Hearing. Alcoholic beverages tend to inflame the mucous membrane of the throat, then the lining of the Eustachian tube, and finally may injure the delicate apparatus of the internal ear.

The sense of hearing may be injured by the immoderate use of tobacco. The irritating smoke, filling all the inner cavity of the mouth and throat, readily finds its way up the Eustachian tube and irritates the delicate middle ear. Thus alcohol and tobacco may produce a partial loss of hearing, accompanied with ringing in the ears. 


\section{ADDITIONAL EXPERIMENTS}

Experiment 126. Use a small pair of wooden compasses, or an ordinary pair of dividers with their points guarded by a small piece of cork. Apply the points of the compasses lightly and simultaneously to different parts of the body and ascertain at what distance apart the points are felt as two. The following is the order of sensibility : tip of tongue, tip of the middle finger, palm, forehead, and back of hand.

Experiment 127. By means of a spray producer spray the back of the hand with ether and observe how the sensibility is deadened.

Experiment 128. Generally speaking, the sensation of touch is referred to the cutaneous surfaces. In certain cases, however, it is referred even beyond this. Holding firmly in one hand a cane or a pencil, touch an object therewith; the sensation is referred to the extremity of the cane or pencil. If, however, the cane or pencil be held loosely in one's hand, one experiences two sensations : one corresponding to the object touched, and the other due to the contact of the rod with the skin.

Experiment 129. Wipe the tongue dry and lay on its tip a crystal of sugar. It is not tasted until it is dissolved.

Apply a crystal of sugar to the tip, and another to the back of the tongue. The sweet taste is more pronounced at the tip.

Experiment 130. Prepare a strong solution of sulphate of quinine with the aid of a little sulphuric acid to dissolve it (bitter), a 5 per-cent solution of sugar (sweet), a Io per-cent solution of common salt (saline), and a I per-cent solution of acetic acid (acid). Repeat the process in Experiment 129 with sulphate of quinine in solution. It is scarcely tasted at the tip, but is tasted immediately on the back part of the tongue.

Test in the same way the places in which the salines and acids are tasted most acutely.

t Experiment 131. To illustrate the muscular sense. Take two equal iron or lead weights; heat one and leave the other cold. The cold weight will feel the heavier.

Experiment 132. Place a thin disk of cold lead, the size of a silver dollar, on the forehead of a person whose eyes are closed; remove the disk, and on the same spot place two warm disks of equal size. The 
person will judge the two warm disks to be about the same weight, or lighter, than the single cold disk.

Experiment 133. To illustrate the influence of excitation of one sense organ upon the other sense organs. On listening to the ticking of a watch, the ticking sounds feebler or louder on looking at a light through glasses of different colors.

If the finger be placed in cold or warm water the temperature appears to rise when a red glass is held in front of the eyes.

Experiment 134. To show the movements of the iris. Look through a pin hole in a card at a uniform white surface, as the white shade of an ordinary reading lamp. With the right eye look through the pin hole, the left eye being closed. Note the size of the (slightly dull) circular visual field. Open the left eye, the field becomes brighter and smaller (contraction of pupil); close the left eye, after an appreciable time, the field (now slightly dull) is seen gradually to expand. One can thus see and observe the rate of movements of his own iris.

f Experiment 135. To show the blind spot. The left eye being shut, let the right eye be fixed on the cross as in Fig. 146. When

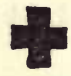

FIG. 146.

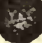

the book is held at arm's length both cross and round spot will be visible; but if the book be brought to about eight inches from the eye, the gaze being kept steadily upon the cross, the round spot will at first disappear, but as the book is brought still nearer both cross and round spot will again be seen.

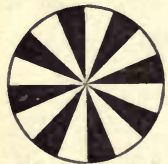

A

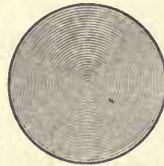

B

FIg. 147. Optic Disks. (The $\operatorname{disk} A$, when rotated rapidly, gives an even gray tint as in $B$.)

Experiment 136. To illustrate the duration of retinal impressions. On a circular white disk, about halfway between the center and circumference, fix a small, black, oblong disk, and rapidly rotate it by means of a rotating wheel. There appears a ring of gray on the black, showing that the impres. sion on the retina lasts a certain time. 
Experiment 137. Mark off a round piece of cardboard into black and white sectors modeled after the disk in $A$ (Fig. 147). Attach it so as to rotate it rapidly, as on a sewing machine. An even gray tint will be produced as in $B$.

Experiment 138. To illustrate imperfect visual judgments. Make three round black dots, $A, B, C$, of the same size, in the same

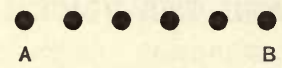

c

line, and let $A$ and $C$ be equidistant from $B$. Between $A$ and $B$ make several more dots of the same size. $A$ and $B$ will then appear to be farther apart than $B$ and $C$.

Experiment 139. Make on a white card two squares of equal size. Across the one draw horizontal lines at equal distances, and in the other make similar vertical lines. Hold them at some distance. The one with horizontal lines appears higher than it really is, while the one with vertical lines appears broader, i.e., both appear oblong.

Experiment 140. Look at the row of letters (S) and figures (8).

$$
\text { S S S S S S S } \quad 88888888
$$

To some the upper halves of the letters and figures may appear to be of the same size as the lower halves, to others the lower halves may appear larger. Hold the figure upside down and observe that there is a considerable difference between the two, the lower halves being considerably larger.

Experiment 14I. The length of a line appears to vary according to the angle and direction of certain other lines in relation to it (Fig. I48). The length of the two vertical lines is the same, yet $B$ appears much longer than $A$.
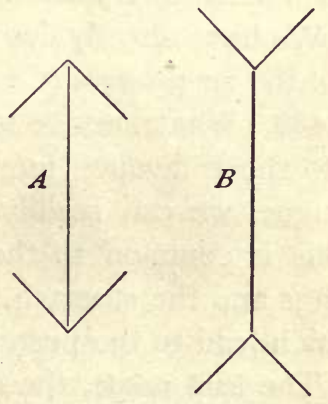

FIG. 148. To show False Estimate of Size. 


\section{CHAPTER XII}

\section{THE THROAT AND THE VOICE}

× 429. The Throat. The throat is a double highway, as it were, through which the air we breathe passes to the larynx on its way to the lungs, and through which the food we swallow reaches the œsophagus on its passage to the stomach. It is, therefore, a very important region of the body, being concerned in the great acts of respiration and digestion.

The throat is enclosed and protected by various muscles and bony structures, along which run the great blood vessels that supply the head and the great nerve trunks that pass from the brain to the parts below. The throat is lined with mucous membrane covered with ciliated epithelium, which secretes a lubricating fluid (mucus) which keeps the parts moist and pliable.

-We have already described the food passages (Chapter VI) and the air passages (Chapter VIII).

430. What may be seen in the Open Mouth. If we look into the wide-open mouth of some friend and depress the tongue, we can readily see the back wall of the pharynx. This is common to the two main avenues leading to the lungs and the stomach. Above, we notice the air passages which lead to the posterior cavities of the nose.

The hard palate, the soft palate, the uvula, and the tonsils have already been described (Figs. 45 and $5 \mathrm{I}$ ).

On looking directly beyond these organs we see the beginning of the downward passage, - the pharynx. If 
now the tongue be forcibly drawn forward, a curved ridge may be seen behind it. This is the epiglottis, which, as we have already learned, shuts down, like the lid of a box, on the top of the larynx (secs. 156 and 246).

431. The Larynx. The larynx, the essential organ of voice, forms the box-like top of the windpipe. It is built of variously shaped cartilages, connected by ligaments. It is clothed on the outside with muscles; on the inside it is lined with mucous membrane, continuous with that of the other air passages.

432. The Thyroid Cartilage. The larynx has for a framework two cartilages, the thyroid and the cricoid, one above the other.

The larger of these, called the thyroid, from a supposed resemblance to a shield, consists of two extended wings which join in front but are separated by a wide interval behind. The united edges in front project and form the "Adam's apple," plainly seen and easily felt on most people, especially on very lean men.

Above and from the sides rise

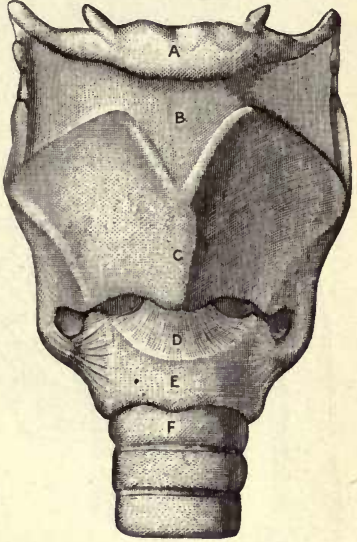

FIG. I49. View of the Cartilages and Ligaments of the Larynx. (Anterior view.)

$A$, hyoid bone; $B$, thyro-hyoid membrane; $C$, thyroid cartilage; $D$, crico-thyroid membrane; $E$, cricoid cartilage, lateral ligaments seen on each side; $F$, upper ring of the trachea. ("Adam's apple" is in the $\mathrm{V}$-shaped groove on a line with $B$ and $C$.) two horns which are connected by bands to the hyoid bone, from which the larynx is suspended (sec. 42 and Fig. 45).

From the underside of the thyroid two horns project downwards to become jointed to the cricoid. The thyroid thus rests upon, and is movable on, the cricoid cartilage. 
433. The Cricoid Cartilage. The cricoid cartilage, so called from its fancied resemblance to a signet ring, is smaller but thicker and stronger than the thyroid and forms the lower and back part of the cavity of the larynx. This cartilage is quite sensitive to pressure from the fingers

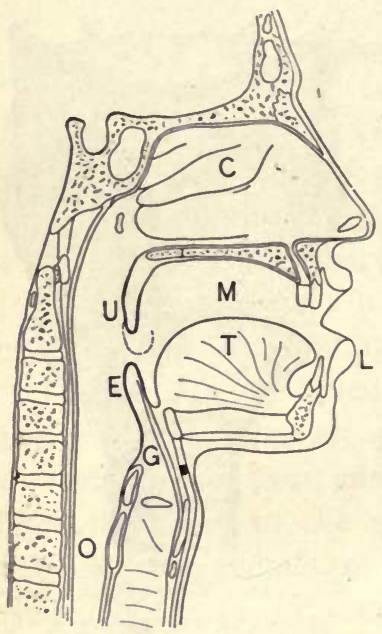

Fig. I 50. Diagram of a Sectional View of Nasal and Throat Passages.

$C$, nasal cavities; $T$, tongue; $L$, lower jaw; $M$, mouth; $U$, uvula; $E$, epiglottis; $G$, larynx; $O$, œsophagus. and is the cause of the sharp pain felt when we try to swallow a large and hard piece of food not properly chewed.

434. The Arytenoid Cartilages. On the upper edge of the cricoid cartilage are perched a pair of very singular cartilages, pyramidal in shape, called the arytenoid, which are of great importance in the production of the voice.

These cartilages are capped with little horn-like projections and give attachment at their anterior angles to the true vocal cords, and at their posterior angles to the muscles which open and close the glottis, or upper opening of the windpipe. When in their natural position the arytenoid cartilages resemble somewhat the mouth of a pitcher, hence their name.

435. The Vocal Cords. The mucous membrane which lines the various cartilages of the larynx is thrown into several folds. Thus, one fold, the free edge of which is formed of a band of elastic fibers, passes horizontally outwards from each side towards the middle line, at the level of the base of the arytenoid cartilages. 
These folds are the true vocal cords, by the movement of which the voice is produced.

Above them are other folds of mucous membrane called the false vocal cords, which take no part in the production of the voice.

The arrangement of the true vocal cords, projecting as they do towards the middle line, reduces to a mere chink the space between the part "of the larynx above them and the part below them. This constriction of the larynx is called the glottis.

$\times 436$. The Mechanism of the Voice. The mechanism of the voice may be more easily understood by a study of Fig. I5I. We have here the larynx, viewed from behind, with all the soft parts in connection with it. On looking down, the folds forming the true vocal cords are seen enclosing a $\mathrm{V}$-shaped aperture (the glottis), the narrow part being in front.

The form of this aperture may be changed by the delicately

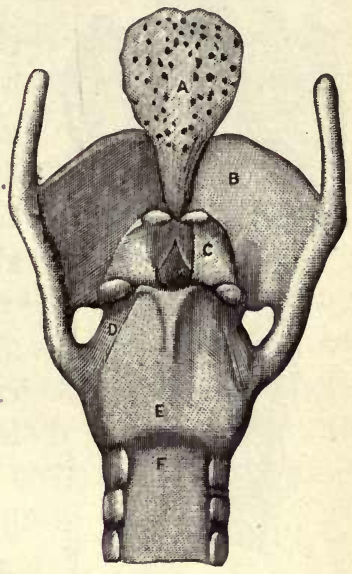

FIG. I 51. View of the Cartilages and Ligaments of the Larynx. (Posterior view.)

$A$, epiglottis ; $B$, thyroid cartilage; $C$, arytenoid cartilage; $D$, ligament connecting lower cornu of the thyroid with the back of the cricoid cartilage; $E$, cricoid cartilage; $F$, upper ring of the trachea.

coördinate action of the muscles of the larynx. For instance, the vocal cords may be brought so closely together that the space becomes a mere slit. Air forced through the slit will throw the edges of the folds into vibration, and a sound will be produced (Figs. I 53 and I 54).

The variations in the form of the opening will determine the variations in the sound. If the various muscles of the 
larynx be relaxed, the opening of the glottis is wider. Thus the air enters and leaves the larynx during breathing, with-

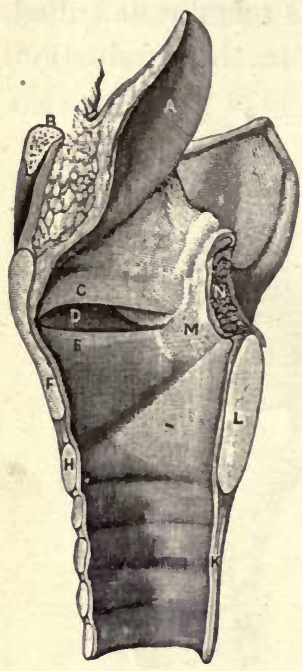

FIG. 152. Longitudinal Section of the Larynx. (Showing the vocal cords.)

$A$, epiglottis ; $B$, section of hyoid bone; $C$, superior vocal cord; $D$, ventricle of the larynx; $E$, inferior vocal cord; $F$, section of the thyroid cartilage; $H$, section of anterior portion of the cricoid cartilage; $K$, trachea; $L$, section of the posterior portion of the cricoid cartilage; $M$, arytenoid cartilage; $N$, section of the arytenoid muscle. out throwing the cords into vibration enough to produce any sound:

In a general way, we may say that the production of the voice is effected by an arrangement like that of some musical instruments, the sounds produced by the vibrations of the vocal cords being modified by the tubes above and below.

All musical sounds are due to movements or vibrations occurring with a certain regularity, and they differ in loudness, pitch, and quality.

Loudness of the sound depends upon the extent of the vibrations, and pitch on the rapidity of the vibrations. The quality depends upon the admixture of tones produced by vibrations of varying rates of rapidity, related to one another.

$X_{437}$. Factors in the Production of the Voice. We have just learned that the pitch of sound depends on the rapidity of the vibrations. This depends upon the length of the cords and their tightness, for the shorter and tighter a string is, the higher is the note which its vibration produces. The vocal cords of women are about one-third shorter than those of men, hence the higher pitch of the notes they produce. 
In children the vocal cords are shorter than those of adults. The voices of boys " break," or " change," because of the sudden growth or enlargement of the larynx and consequent increase in length of the vocal cords, at from fourteen to sixteen years of age. Those qualities of the voice which we speak of as sweet, harsh, and sympathetic depend to a great extent upon the peculiar structure of the vocal cords of the individual.

The general shape and structure of the trachea, the larynx, the throat and mouth, also influence the quality of voice. Thus the air passages, both below and above the vibrating cords, act as resonators, or resounding chambers, and intensify and modify the sounds produced by the cords. It is this fact that prompts skillful teachers of music and elocution to urge upon their pupils the necessity of the mouth being properly opened during speech, and especially during singing.

Experiment 142. To show the anatomy of the throat. Study the general construction of the throat by the help of a hand mirror. Repeat the same on the throat of some friend.

Experiment 143. To show the construction of the vocal organs. Get a butcher to furnish the windpipes of two sheep or calves. The vocal organs of these animals differ somewhat from those of the human body, but the different parts which have been described can be readily recognized.

One specimen should be cut open lengthwise in the middle line in front, and the other cut in the same way from behind.

438. Speech. Speech is to be distinguished from voice. It may exist without voice, as in a whisper.

Speech consists of articulated sounds, that is, interrupted sounds, the interruptions being produced by the action of various parts of the mouth, throat, and nose. 
Voice is common to most animals, but speech is the peculiar privilege of man.

The organ of speech is perhaps the most delicate and perfect motor apparatus in the whole body. It has been

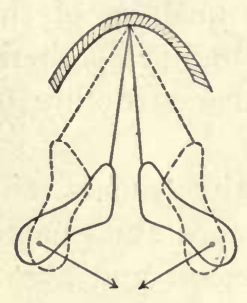

FIG. I53. Diagrammatic Horizontal Section of Larynx. (Shows the direction of pull of the posterior crico-arytenoid muscles, which abduct the vocal cords. Dotted lines show position in abduction.) calculated that upwards of nine hundred movements per minute can be made by the movable organs of speech during reading, speaking, and singing. It is said that a hundred different muscles of the body are called into action in talking. Each part of this delicate apparatus is so admirably adjusted to every other that all parts of it act in perfect harmony.

$y$ 439. Production of Articulate Sounds. To secure an easy and proper production of articulate sounds, the mouth, teeth, lips, tongue, and palate should be in perfect order. The modifications in articu. lation which are occasioned by a defect in the palate or in the uvula, and by the loss of teeth, are sufficiently familiar.

Many animals have the power of making articulated sounds; a few have risen, like man, to the dignity of sentences, but accomplish this only by imitation of the human voice. Both vowels and consonants can be distinguished in the notes of birds.

Persons idiotic from birth are often incapable of producing any other vocal sounds than inarticulate cries, although supplied with all the internal means of articulation. Persons born totally deaf are in the same situation, though from a different cause; the one being incapable of imitating, and the other being deprived of the power of hearing the sounds to be imitated. 
$\Varangle$ 440. Whispering and Stammering. In whispering, the larynx takes scarcely any part in the production of the sounds; the vocal cords remain apart and comparatively slack, and the expiratory blast rushes through without setting them in vibration.

In stammering, spasmodic contraction of the diaphragm interrupts the effort of expiration. The stammerer has full control of the mechanism of articulation, but not of the expiratory blast. His larynx and his lips are at his command, but not his diaphragm. To conquer this defect he must train his muscles of respiration to steady action during speech.

The stutterer, on the other hand, has full control of the muscles of expiration. His diaphragm is well drilled, but his lips and tongue are insubordinate.

441. Hints on the Care of the Throat. The throat, exposed as it is to unwholesome and overheated air, irritating dust of the street, factories, and workshops, is often inflamed, resulting in that common ailment, sore throat. The parts are red, swollen, and painful on swallowing, but rarely require any special treatment.

The action of cold air upon the heated

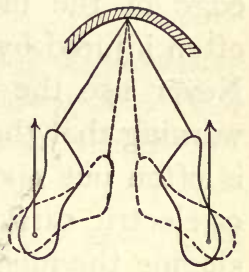

FIG. 154. Direction of Pull of the Lateral CricoArytenoids, which adduct the Vocal Cords.

(Dotted lines show position in adduction.) body, especially during active perspiration, is a very common cause of throat trouble. For this reason a cold bath should not be taken while a person is perspiring freely.

The muscles of the throat are frequently overstrained by loud talking, screaming, shouting, or by reading aloud too much. People who strain or misuse the voice often suffer from what is called "clergyman's sore throat." 
Persons subject to throat disease should take special care to wear suitable underclothing, adapted to the changes of the seasons. Frequent baths are excellent tonics to the skin and serve indirectly to protect one liable to throat ailments from changes in the weather. It is not prudent to muffle the neck in scarfs, furs, and wraps, unless perhaps during an unusual exposure to cold. Such a dress for the neck only makes the parts tender and increases the liability to sore throat.

4442. Hints for the Care of the Voice. Every teacher of elocution or of vocal music should have a practical knowledge of the mechanism of the voice. Good voices are often injured by an injudicious and incompetent instructor. Never use the voice when its weakness or failure gives warning that the general health is impaired. Undue strain is often put upon the voice even by conversation in steam or electric cars, and other noisy places. Cease speaking or singing the moment there is any hoarseness or sore throat. Always stop before fatigue is felt. Avoid sudden changes from hot to cold air, even when the voice has not been used.

The voice should not be exercised just after a full meal, for a full stomach interferes with the free play of the diaphragm. A sip of water taken at convenient intervals, and held in the mouth for a moment or two, will relieve the dryness of the throat during the use of the voice.

443. Effect of Alcohol and Tobacco upon the Throat and, Voice. Alcoholic beverages often injure the throat, and consequently the voice, by irritating the membrane of the larynx and the vocal cords. The vocal cords may be thickened, roughened, and enfeebled, and their delicate vibration may be impaired. The clearness and purity of the vocal tones may be diminished. Hence vocalists, whose 
fortune is the purity and compass of their tones, are careful not to impair these fine qualities by the habitual use of strong drink.

Tobacco often produces a disease well known to physicians as "the smoker's sore throat." It may also cause inflammation of the larynx and thus may entail disorders of the vocal cords, involving rough voice and harsh tones. For this reason vocalists should not attempt to use the voice in a room full of tobacco smoke.

\section{ADDITIONAL EXPERIMENTS}

Experiment 144. To illustrate the importance of the resonating cavity of the nose in articulation. Pinch the nostrils and try to pronounce slowly the words "Lincoln," "something," or any other words which require the sound of $m, l n$, or $n g$.

Experiment 145. To illustrate the passage of air through the glottis. Take two strips of India rubber and stretch them over the open end of a boy's "bean blower," or any kind of a tube. Tie them tightly with thread, so that a chink will be left between them, as shown in Fig. 155.

Force the air through such a tube by blowing hard, and if the strips are not too far apart, a sound will be produced. The sound will vary in character, just as the bands are made tight or loose.

Note. - The limitations of a text-book on physiology for schools do not permit so full a description of the voice as the subject deserves. For additional details, the student is referred to Cohen's The Throat and the Voice, a

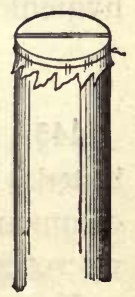

FIG. 155 . volume in the American Health Primer Series, and Browne and Behnke's Voice, Song and Speech. 


\section{CHAPTER XIII}

\section{THE PRESERVATION OF HEALTH}

444. The Teachings of Modern Hygiene. Modern hygiene not only formulates rules for the preservation of health, but it goes much farther and treats of the prevention of disease. It warns us of the unseen and invisible foes which assail our health at every moment and teaches us the best methods to check the prevalence of disease. Even if we obey every law of hygiene, we cannot, of course, wholly avoid these invisible enemies, but it is none the less true that there is a power in every healthy human body that may successfully battle the germs of disease. This power is best conserved and developed by living up to the best hygienic standards.

\section{BACTERIA}

445. Nature and Propagation of Bacteria. The words bacteria, bacilli, germs, micro-organisms, and microbes are terms commonly applied to certain low forms of plant life of microscopic size.

If some finely chopped hay be covered with water and set in a warm place for a few days, and a few drops of the liquid are examined under a high power of the microscope, the water is found to be swarming with various forms of living organisms, chiefly bacteria.

These microscopic plants belong to the great fungus division. They consist of many varieties, which may 
be roughly divided into groups, according as they are spherical, rod-like, or spiral in shape. The term bacillus is usually restricted to rod-shaped bacteria.

Bacteria are propagated in a very simple manner. Usually the parent cell divides into two; these two into two others, and so on. Under certain conditions, however, bacteria reproduce themselves by spores which are formed in the interior of cells and then passed out. These spores are much more tenacious of life and therefore are much harder to destroy than the fully developed cells. The
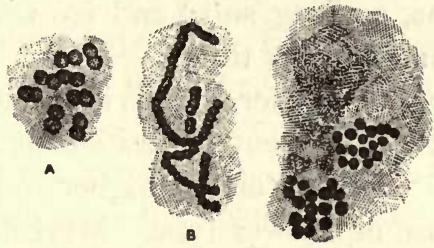

c

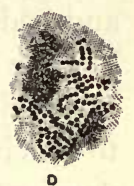

FIG. 156. Various Forms of Bacteria. (Drawn from photographs.)

$A$, spheroidal bacteria (called cocci) in pairs; $B$, same kind of bacteria in chains; $C$, bacteria found in pus (grouped in masses like a bunch of grapes). (Bacteria in $A, B$, and $C$ magnified about 1000 diameters.) $D$, bacteria found in pus (tendency to grow in the form of chains). (Magnified about 500 diameters.)

rapidity with which bacteria multiply under favorable conditions makes them, in some cases, dangerous enemies to plant and animal life.

446. General Action of Bacteria. Bacteria have the power of bringing about decomposition of various kinds. Thus, as we have learned in a previous chapter, a highly organized fungus, like the yeast plant, growing in the presence of sugar, has the power of breaking down this complex body into simpler ones, viz., alcohol and carbon dioxide (see Experiment 29).

In the same way various forms of bacteria have the power of breaking down complex bodies, the products depending upon the substance, the kind of bacteria, and the conditions under which they act. Thus, the bacteria 
lactis act upon the milk sugar present in milk and convert it into lactic acid, thus bringing about the souring of milk.

447. The Place of Bacteria in the Economy of Nature. The myriads of bacteria, with their marvelous rapidity of propagation, would devastate the earth were it not for the winds, rains, melting snow and ice which scatter them far and wide and destroy them.

Like countless other species of living organisms, bacteria are subject to the relentless law which allows only the fittest to survive. The bacteria of higher and more complex types devour those of a lower type. Myriads perish in the digestive tract of man and other animals. The excreta of some species of bacteria act as poison to destroy other species.

448. Disease-Producing Bacteria. Now, while many species of bacteria are harmless, some may be the cause of sickness and death when they gain admittance to the body
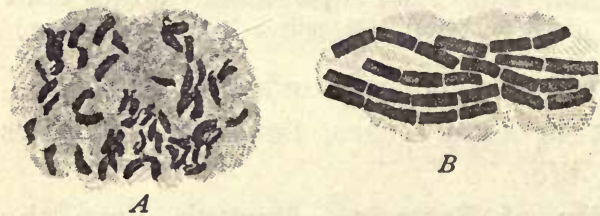

FIG. 157. Two Forms of Pathogenic Bacteria. (Drawn from photographs.)

$A$, spiral form of bacteria found in cholera. (Magnified about 1000 diameters.) B, rod-shaped bacteria (called bacilli) from a culture obtained in anthrax; or malignant pustule, of the face. Diseased hides carry this micro-organism and thus may occasion disease among those who handle hides and wool. (Magnified about 1000 diameters.) under certain conditions. Thes e disease-producing, or pathogenic, bacteria, when established in the tissues of the body, may produce a particular disease. It has been proved beyond all doubt that certain diseases are produced through the agency of bacteria. In yellow fever, diphtheria, typhoid fever, and consumption the causal relation of a particular kind of bacteria to each disease has been definitely established. 
449. Disease-Producing Bacteria in the Soil. Surface soils, especially those rich in organic matter, abound in many kinds of bacteria. There seems to be an intimate relation between the soil and important bacterial diseases.

The terrible disease called tetanus, or " lockjaw," is known to be due to a micro-organism common in the soil of certain localities.

Typhoid bacilli were kept alive for 456 days by one experimenter in soil which had been polluted with organic matter. Farm soils have been contaminated with the bacilli of anthrax, or malignant pustule (Fig. I 57 ), and have retained the infectious virus for several months.

In brief, the disease-producing bacteria found in the surface soils can and do retain their vitality, and sometimes even their virulence, for long periods of time.

450. Disease - Producing Bacteria in Foods. Good food as well as bad frequently contains large numbers of bacteria. It is fortunate, however, that harmful microorganisms are usually killed by cooking. Not all the persons eating infected food suffer equally, and oftentimes some escape altogether.

Bacteria have a

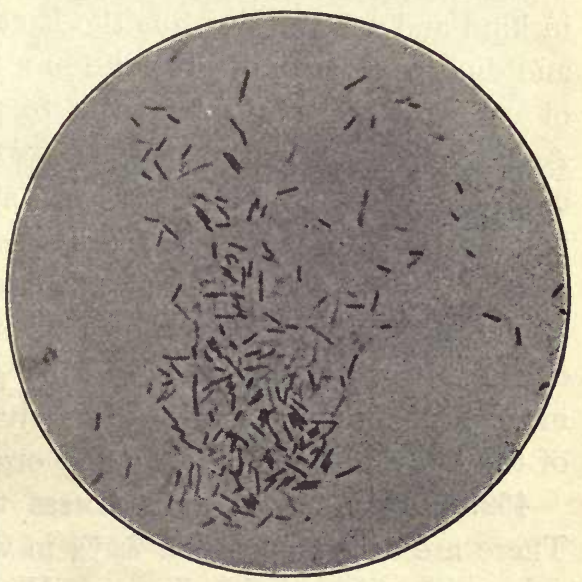

FIG. I 58. Bacilli of Typhoid Fever.

(Magnified rooo diameters.) special fondness for milk. In a hundred different ways, milk runs the risk of being polluted, - as from the animal, the 
milker, unclean methods of milking, the addition of typhoidinfected water, the use of unclean utensils and milk cans.

Typhoid fever and other infectious diseases have been traced to eating raw oysters that were fattened in salt water contaminated with the sewage. Disease-producing bacteria, as the typhoid bacillus, have been found in ice, and even in ice cream. Milk and meat from tuberculous animals have not unfrequently produced disease. Persons are occasionally poisoned from eating canned meats which have been contaminated with bacteria or their products.

Other foods and beverages are often contaminated with injurious bacteria, generally due to uncleanly manufacture or unprotected storage.

451. Some Common Diseases caused by Bacteria. The malign results brought about by certain bacteria vary greatly in kind and severity. Thus the bacteria of Asiatic cholera and diphtheria may destroy life in a few hours, while those of consumption may take years to produce a fatal result. Again, bacteria may attack some particular organ, or group of organs, and produce mostly local symptoms. Thus, in a boil there is painful swelling due to the local effect of bacteria, usually accompanied with slight general disturbance.

The epidemic disease known as influenza, or la grippe, or the "grip," is due to a specific germ. It attacks the mucous membranes more commonly than any other parts of the body, although hardly any organ has escaped.

452. How Bacteria gain Access to the Bodily Tissues. There are several possible ways in which germs of disease may gain access to the tissues. First, by contact between diseased and healthy persons; in brief, by contagion. Thus, ringworm, often called barber's itch, is a familiar example of bacteria "caught" from the germs on a razor or a soiled towel. 
As stated before, bacteria may enter the body with the food and water. We have already shown how the air may become infected with the germs of disease from the dust of dried sputa (page I 77).

Finally, bacteria may gain access to the body by inoculation, or by inserting the virus through a broken surface of the skin. This may result from using soiled instruments, from gunshot injuries, broken glass, rusty nails, and from many other causes.

453. How the Body defends itself against Bacteria. Germs of disease constantly assail the bodily tissues. There is a continual warfare between bacteria and the living cells. The plasma of the blood acts in some unknown manner to help kill the diseaseproducing germs.

The white blood corpuscles wage an unceasing warfare against bacteria and the toxins. While this warfare is going on and disease shows itself, a poison of

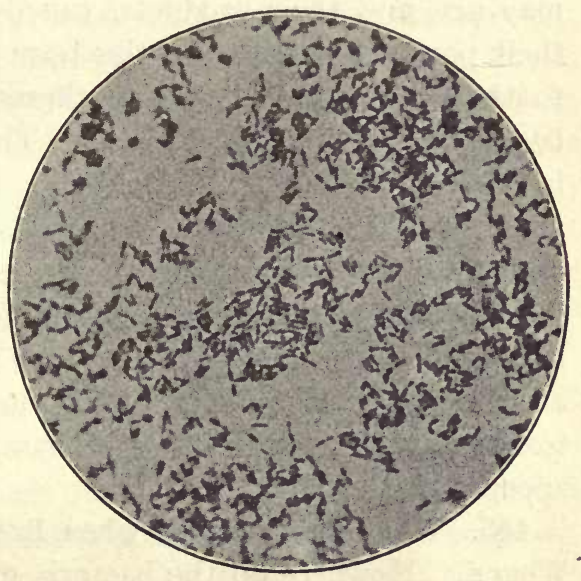

FIG. I 59. Bacilli of Diphtheria.

(Magnified rooo diameters.) another type, called for convenience antitoxin, is formed in the serum of the blood, which may antagonize the toxins and destroy their poisonous action.

454. Antitoxin Treatment of Disease. Within the past few years remarkable progress has been made by tireless scientific workers in their efforts to modify the action of 
disease-producing bacteria. For instance, the toxins of diphtheria germs are injected into the blood of a horse. In due time the antitoxin of the disease is removed from the serum of the infected blood, and after proper preparation is injected into the blood of a person exposed to or suffering from diphtheria. The effect is to modify decidedly the action of the poisonous germs of this dread disease.

455. How the Bacteria may behave within the Body. After gaining access to the body the bacteria may begin a twofold sort of action. Thus, the bacteria themselves may act, and their products, called toxins, may also play their part. For example, the term "infection" is applied to those conditions in which there is a multiplication of bacteria after entering the body. The word "intoxication" is often used to indicate a condition of poisoning brought about by their products, or toxins. Until these toxins begin to act there may be no symptoms of disease. Thus, one may drink typhoid-polluted water. The bacilli multiply for two weeks (the period of incubation) without any sign, but at the end of about foarteen days the typhoid toxins assert themselves, and symptoms of the disease appear.

456. What may happen when Bacteria gain Access to a Wound. Nowhere do the bacteria make their power more distinctly felt than in the changes which they may produce when they gain access to a wound. They now find just the conditions upon which they thrive, as heat, moisture, and an abundance of food in the form of broken-down organic matter. Now comes the tug of war between the germs of disease and the cells of the body, especially the white blood corpuscles. Sometimes the cells of the body conquer, and sometimes they are destroyed. More blood 
is sent to the affected part, resulting in redness and heat about the wound. The bodily cells multiply rapidly and form a barrier to retard the action of the bacteria. Usually, these cells appear upon the surface of the wound and carry along bacteria with them. The discharge, consisting of these cells of the body, lymph, and bacteria, is known as matter, or pus.

In this relentless warfare between the bacteria and living cells, if the former win, a certain portion of the tissues about the wound dies; if the cells are victorious, the tissues heal.

457. Septic Poisoning. Bacteria, after gaining access to a wound, may produce toxic substances, which may enter the blood current and prove an additional source of poison. This is known as septic infection, or commonly septicamia. The slight fever resulting from a boil or abscess may be due to this cause.

Sometimes these bacteria may get fastened into a clot of blood which softens, and portions of it may be carried to distant parts of the body by the blood current and there produce abscesses. This poisoning is known as pycemia.

458. Alcoholic Fermentation and Bacteria. Men of all ages and lands have known that when the sugary juice of any fruit is left to itself for a time, at a moderately high temperature, a change takes place under certain conditions, and that the result is a liquid which, when drank, produces a pronounced effect upon the body.

The real cause of this remarkable change in fruit juice was not known until revealed in recent years by the aid of the microscope. We know now that this change is due to alcoholic fermentation, brought about by the action of microscopic fungi (sec. I4I).

In other words, alcoholic or vinous fermentation is the result of the growth and activity of low forms of vegetable 
life known as organized ferments. These ferments, whether they are the commonly used brewer's yeast or any other species of alcoholic ferments, have the power to decompose or break down a large part of the sugar present in the liquid into alcohol, which remains as a poison, and carbon dioxide, which escapes more or less completely.

Thus man has now forced into his service the latest discoveries in science, more especially in bacteriology, that he may manufacture more scientifically and more economically alcoholic beverages of all sorts and kinds.

It matters little how, when, or where this process of alcoholic fermentation is brought about; the outcome and the intent are one and the same. The essential thing is to produce an alcoholic beverage which will have a marked physiological effect. This effect is poisonous, and is due solely to the alcoholic constituent, without which man would have little or no desire for an otherwise harmless liquid.

Experiment 146. The microscopic study of yeast. Draw off by means of a pipette a drop from the sediment of the "working" mixture in Experiment 29 and place it on a glass slide. Cover with a thin cover-glass and examine under the high power of the microscope (300 to 400 diameters). Note the yeast cells and the new cells budding from the parent cells.

Experiment 147. The examination of pathogenic bacteria by means of the microscope. Examine with the microscope prepared slides of culture of the bacteria that produce diphtheria (Fig. 159), typhoid fever (Fig. 158), consumption (Fig. 92), and such other slides of pathogenic bacteria as can be readily obtained from dealers in microscopical supplies. 


\section{THE PREVENTION AND RESTRICTION OF DISEASE}

459. Means to avert Danger of Disease. From the preceding pages we have learned many of the simplest principles which underlie the maintenance of good health. Wholesome food, pure air, proper clothing, cleanliness, and physical exercise all play their part in maintaining good health and in preventing disease.

We have now to consider other means used to avert danger of disease. The whole question strictly concerns public sanitation, which does not come within the scope of this book. It is well, however, for every intelligent person to understand a few of the simplest facts of so important a subject and one which affects the welfare of every community.

460. Vaccination, Isolation, and Disinfection. One of the most familiar means to prevent disease is the use of vaccination for smallpox. That is, persons who are vaccinated are immune, as it is called, from smallpox, or have it in a milder form.

The diphtheria antitoxin is now quite generally used to secure immunity from this dangerous disease.

One very common safeguard against the spread of contagious diseases is isolation. The patients, and often the family, are isolated from other people; a rigid system of nursing is instituted, a placard is placed upon the house, the premises are watched, and other familiar means of isolation are employed.

Disinfection is universally recognized as a most efficient and practical means to prevent the spread of disease.

461. A Few Words explained. Some substances kill bacteria and are known as germicides; other substances prevent the development of bacteria and resulting septic 
action, and these are called antiseptics. The word "disinfectant " is used with more or less confusion to cover both these words.

Disinfection is strictly the destruction of the germs of disease by means of heat, chemical agents, fumigation, or fresh air. An antiseptic, when used in a very strong dose or for a long time may act as a germicide, while a germicide in too weak solution to act as such may serve only as an antiseptic.

A deodorant is a substance that removes or conceals offensive odors. Deodorizers are not necessarily disinfectants.

462. Air and Water as Disinfectants. Nature has provided for our protection two most efficient means of disinfection, - pure air and pure water. The air of crowded rooms contains large quantities of bacteria, whereas in pure air there are comparatively few, especially after rain, which carries them to the earth.

In water tainted with organic matter putrefactive bacteria will flourish, whereas pure water is fatal to their existence. Surface water, because it comes from that part of the soil where bacteria are most active, and where there is most organic matter, generally contains great quantities of these organisms.

463. The more Common Disinfectants. Disinfection must be secured by other means than fresh air and cleanliness. The destruction of infected material by fire is, of course, a sure but costly means of disinfection. Heat in various forms, as dry heat, steam, and boiling water, is a valuable disinfectant and does not injure most fabrics. These agents are generally used in combination with various chemical disinfectants.

Certain chemical agents that are capable of destroying micro-organisms have come, of late years, into general use. 
A compound of mercury, called corrosive sublimate, is a most efficacious and powerful germicide, but is exceedingly poisonous and can be bought only under restrictions.

Carbolic acid, chloride of lime, permanganate of potash, sulphur, formaldehyde (formalin), and various preparations made from zinc, iron, and petroleum are the disinfectants which are most widely used at the present time.

There are also numerous varieties of commercial disinfectants now in popular use which the manufacturers claim to be efficient germicides.

The Prevention and Restriction of Dangerous Communicable Diseases. The following directions for the prevention and restriction of dangerous communicable diseases are issued by the Michigan Board of Health for the use of teachers of that state in giving instructions to the children in the schools.

Consumption is now known to be a communicable disease. It is spread by the dust of dried sputa, and also by milk and meat of tuberculous animals. The most important measure for the restriction of consumption is the disinfection or destruction of all sputa of every consumptive person.

It is best that all persons who have a cough should carry small pieces of cloth (each just large enough properly to receive one sputum) and paraffined paper envelopes or wrappers in which the cloth, as soon as once used, may be put and securely enclosed, and, with its envelope, burned on the first opportunity. These pieces of cloth must not be carried loose in the pocket and allowed to dry after being used.

Pneumonia is spread by a germ which is in the sputum of those who have the disease. Care should always be taken to destroy or disinfect all sputa of those who have pneumonia.

Influenza, la grippe, or plain "grip," is now believed to be spread by a germ which finds its way from infected handkerchiefs and other articles and places into the nose, throat, and air passages of persons susceptible to this disease. 
Diphtheria is spread by the sputa, saliva, and whatever comes from the throat and mouth of the patient, and by the dust which results from the drying of such substances. The germs of diphtheria sometimes remain in the throat weeks after apparently complete recovery. For its restriction and prevention, isolation and disinfection are the important measures - isolation of every infected person and thing, and complete disinfection.

Typhoid ferer is not so often contracted directly from the sick person, but usually from the discharges from the bowels and bladder of the patient. These discharges should always be disinfected. Undisinfected discharges, if dried and formed into dust, may spread the disease through the air. The chief source of danger, however, is believed to be drinking water contaminated by sewage or leachings from outbuildings. The germs permeate the entire body of an infected person, and sometimes are found some time after apparent recovery. The germs of typhoid fever are not always killed by freezing, but are killed by boiling. All suspected water should be boiled.

Scarlet fever has not yet been identified by its special germ, but that there is a germ seems to be proved by the well-known communicability of the disease from person to person. It is spread by the discharges from the nose, mouth, and throat, and probably also by the minute scales which are thrown off from the surfaces of the body. Isolation and disinfection are the measures by which this disease is restricted.

\section{THE CARE OF THE SICK ROOM}

464. Ventilation of the Sick Room. Proper ventilation is very essential to the sick room. One of the windows may be let down an inch or more at the top, a screen being arranged to avoid any draught on the patient. Remove all odors by ventilation and not by spraying perfumery, or burning pastils, which merely conceal offensive odors without purifying the air.

Avoid ventilation by means of doors, for the stale'air of the house, kitchen smells, and noises made by the occupants 
of the house are apt to reach the sick room. The entire air of the room should be changed at least two or three times a day, and in addition a constant supply of fresh air should be introduced in small quantities. During cold weather and in certain diseases, the patient may be covered entirely with blankets and the windows opened wide for a few minutes.

465. Location and Arrangement of the Sick Room. The sick room, if possible, should be on the quiet and sunny side of the house. Pure fresh air, sunshine, and freedom from noise and offensive odors are almost indispensable. A fireplace, as a means of ventilation, is invaluable. The bed should be so placed that the air may get to it on all sides and the nurse move easily around it. Screens should be used to exclude superfluous light and draughts.

Remove all useless ornaments and articles likely to collect dust, as unnecessary pieces of furniture and heavy draperies. A clean floor, with a few rugs to deaden the sounds of footsteps, is much better than a woolen carpet. Rocking-chairs should be banished from the sick room, as they are almost sure to disturb the sick.

A daily supply of fresh flowers tends to brighten the room. The medicines may be close at hand, but all poisonous drugs should be kept carefully by themselves and ordinarily under lock and key. A small table should be placed at the bedside, and on it the bell, food tray, flowers, and other small things which promote the comfort of the patient.

466. Hints for the Sick Room. Do not worry the sick with unnecessary questions, idle talk, or silly gossip. It is cruel to whisper in the sick room, for patients are always annoyed by it. They are usually suspicious that something is wrong and generally imagine that their condition has changed for the worse. Always strive to look cheerful and pleasant before the patient. Whatever may happen, 
do not appear to be annoyed, discouraged, or despondent. Do your best to keep up the courage of sick persons under all circumstances. In all things keep in constant mind the comfort and ease of the patient.

Symptoms of the disease should never be discussed before the patient, especially if he is thought to be asleep. He may be only dozing, and any such talk would then be gross cruelty. Loud talking must, of course, be avoided. The directions of the physician must be rigidly carried out in regard to visitors in the sick room. This is always a matter of importance, for an hour or even a night of needed sleep and rest may be lost from the untimely call of some thoughtless visitor.

467. Additional Hints in taking Care of the Sick. Keep, so far as possible, the various bottles of medicine, spoons, glasses, and so on, in an adjoining room, rather than make a formidable array of them on a bureau or table near the sick bed. A few simple things, as an orange, a tiny bouquet, one or two playthings, or even a pretty book, may well take their place.

Sick people take great comfort in fresh linen and fresh pillows. Two sets should be used, letting one be aired while the other is in use. In making changes the fresh linen should be thoroughly aired and warmed and everything in readiness before the patient is disturbed.

Feather beds are always objectionable in the sick room for many and obvious reasons. The proper making of a sick bed, with the forethought and skill demanded in certain diseases, is of great importance and an art learned only after long experience. The same principle obtains in all that concerns the lifting and the moving of the sick.

468. Helps for the Sick Room. Do not deceive sick people. Tell what is proper or safe to be told, promptly 
and plainly. If a physician is employed, carry out his orders to the very letter as long as he visits you. Make on a slip of paper a note of his directions. Make a brief record of exactly what to do, the precise time of giving medicines, etc. This should always be done in serious cases, and by night watchers; then there is no guesswork. You have the record before you for easy reference. All such things are valuable helps to the doctor.

Noises that are liable to disturb the patient, in other parts of the house than the sick room, should be avoided. Sounds of a startling character, especially those not easily explained, as the rattling or slamming of distant blinds and doors, are always irritating to the sick.

469. Hints on nursing Infectious and Contagious Diseases. Strip the room of superfluous rugs, carpets, furniture, etc. Isolate two rooms, if possible, and have these, if convenient, at the top of the house. Tack sheets, wet in some proper disinfectant, to the outer frame of the sick-room door. Boil these sheets every third day. In case of diseases to which the young are very susceptible, send the children who have not yet been attacked, if possible, to houses where there are no children.

The most scrupulous care should be taken in regard to cleanliness. Old pieces of linen, cheese cloth, and paper napkins should be used wherever convenient or necessary and then at once burned. All soiled clothing that cannot well be burned should be put to soak at once in disinfectants and afterward boiled apart from the family wash. Dishes and all utensils should be kept scrupulously clean by frequent boiling. For the bed and person old and worn articles of clothing that can be destroyed should be used so far as possible. 


\section{CHAPTER XIV}

\section{FIRST AID TO THE INJURED}

470. Prompt Aid in Common Accidents and Emergencies. What we have studied in the preceding chapters will become tenfold more interesting, instructive, and valuable to us, if we are able to supplement such study with its practical application to the treatment of the more common and less serious accidents and emergencies.

While no book can teach one to have presence of mind, a cool head, or to restrain a more or less excitable temperament in the midst of sudden danger, yet assuredly with proper knowledge for a foundation a certain self-confidence may be acquired which will do much to prevent hasty action and to maintain a certain amount of self-control.

471. Hints as to what to do first. Retain so far as possible your presence of mind; or, in other words, keep cool. Act promptly and quietly, but not with haste. Whatever you do in the presence of danger, do in earnest; and never act in a half-hearted manner. Be sure and send for a doctor at once if the emergency calls for skilled service. All that is expected of you is to tide over matters until the doctor comes.

Make the sufferer comfortable by giving him an abundance of fresh air and placing him in a restful position. Loosen all tight articles of clothing, as belts, collars, corsets, and elastics.

472. Contusion and Bruises. An injury to the soft tissues, caused by a blow from some blunt instrument or by a 
fall, is a contusion, or bruise. A black eye, a knee injured by a fall from a bicycle, and a finger hurt by a baseball are familiar examples of injuries which ordinarily require very simple treatment.

Wring out old towels or pieces of flannel in hot water and apply to the parts, changing as they become cool. For cold applications, use cloths wet with water diluted with vinegar, or witch-hazel.

When wounds are made with ragged edges, such as those made by broken glass and splinters, more skill is called for. Remove every bit of foreign substance. If the skin about the wound seems to need washing it should be done with one of the many antiseptic solutions; bring the torn edges together, and hold . them in place with strips of plaster.

Wounds made by toy pistols, percussion caps, and rusty nails and tools, if neglected, often lead to serious results from blood

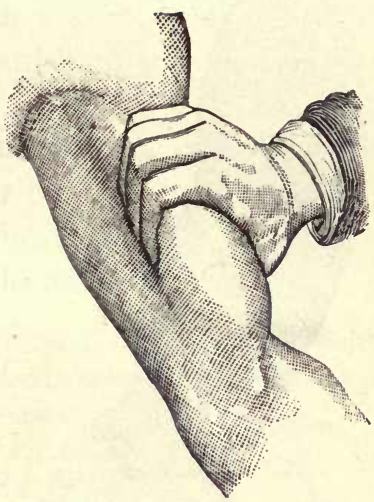
poisoning. Keep such wounds FIG. I60. Showing how Digital clean by washing or syringing them twice a day with anti-

Compression should be ap. plied to the Brachial Artery. septics, which kill the bacteria or prevent their growth.

473. Injuries to the Blood Vessels. It is very important to know the difference between the bleeding from an artery and that from a vein.

If an artery bleeds, the blood leaps in spurts and is of a bright scarlet color.

If a vein bleeds, the blood oozes in a steady stream and is of a somewhat darker color. 
Bleeding from an artery is a dangerous matter in proportion to the size of the vessel, and may speedily cause the loss of life itself. When an artery is bleeding always remember to make deep pressure between the wound and the heart. In all such cases send for the doctor.

Do not be afraid to act at once. A resolute grip in the right place with firm fingers will do well enough, until a twisted handkerchief, stout cord, shoestring, suspender, or

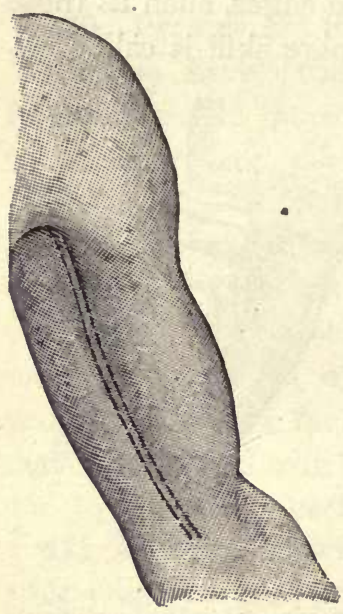

FIG. 16r. Dotted Line showing the Course of the Brachial Artery. an improvised tourniquet ${ }^{1}$ is ready to take its place. If the flow of blood does not stop, change the pressure until the right spot is found.

474. Where and how to apply Pressure. The principal places in which to apply pressure when arteries are injured and bleeding should always be kept in mind.

If in the finger, grasp it with the thumb and forefinger and pinch it

${ }^{1}$ A tourniquet is a bandage, handkerchief, or strap of webbing into the middle of which a stone, a potato, a small block of wood, or any hard, smooth body is tied. The band is tied loosely about the limb, the hard body is held over the artery to be constricted, and a stick is inserted beneath the band on the opposite side of the limb and used to twist the band in such a way that the limb is tightly constricted thereby, and the hard body thus made to compress the artery.

The entire circumference of the limb may be constricted by any sort of elastic band or rubber tube, or any other strong elastic material passed around the limb several times on a stretch, drawn tight and tied in a knot. In this way bleeding may be stopped at once from the largest arteries. The longer and softer the tube the better. It requires no skill and but little knowledge of anatomy to apply it efficiently. - ALEXANDER B. Johnson, Surgeon to Roosevelt Hospital, New York City. 
firmly on each side; if in the hand, press on the bleeding spot, or press with the thumb just above and in front of the wrist.

For injuries below the elbow, grasp the upper part of the arm with the hands and squeeze hard. The main artery runs in the middle line of the bend of the elbow. Tie the knotted cord here and bend the forearm so as to press hard against the knot.

For the upper arm, press with the fingers against the bone on the inner side and just on the edge of the bulging part of the biceps muscle. Take a stout stick of wood, about a foot long, and twist the cord hard with it, bringing the knot firmly over the artery.

For the foot or leg, pressure as before, in the hollow behind the knee, just above the calf of the leg. Bend the thigh towards the abdomen and bring the leg up against the thigh, with the knot in the bend of the knee.

Experiment 148: How to tie a square knot. If the student would render efficient help in accidents and emergencies, to say nothing of service on many other occasions, he must learn how to tie a' square or "reef" knot. This knot is secure and does not slip as does the "granny" knot. The square knot is the one used by surgeons in ligating vessels and securing bandages. Unless one knew the difference, the insecure "granny" knot might be substituted.

A square knot is tied by holding an end of a bandage or cord in each hand, and then passing the end in the right hand over the

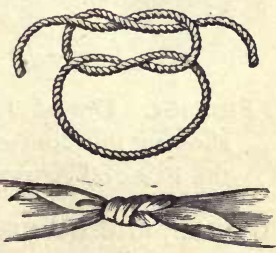

FIG. 162. Showing how a Square Knot may be tied with a Cord and a Handkerchief. one in the left and tying; the end now in the left hand is passed over the one in the right and again tied.

With a handkerchief, shoestring, and cords of various sizes, practice the square knot until it can be done accurately and rapidly. 
475. Bleeding from the Nose. Let the patient sit upright; leaning forward with the head low only increases the hemorrhage. Raise the arm on the bleeding side; do not blow the nose. Wring two towels in cold water; wrap one around the neck and the other properly folded over the forehead and upper part of the nose. Plug the nostril with a

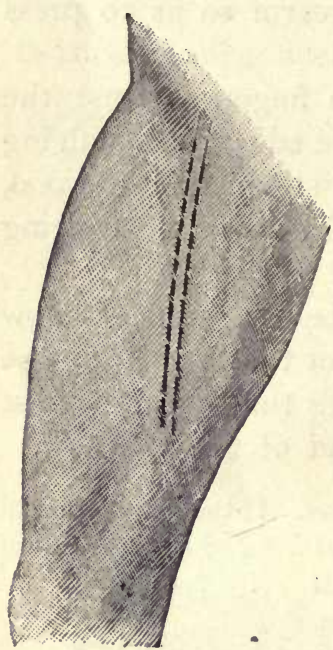

FIG. 163. Dotted Line showing the Course of the Femoral Artery. piece of absorbent cotton which has been wet with strong borax or alum water. When the nostril has been plugged, especially if the patient is a young child, it is important to make sure that blood is not trickling down into the throat from the posterior nares.

476. Burns or Scalds. Burns or scalds are dangerous in proportion to their extent and depth. A deep or extensive burn or scald should always have prompt medical attendance.

In burns by acids, bathe the parts with an alkaline fluid, as diluted ammonia or strong soda in solution, and afterwards dress the burn.

In burns caused by lime, caustic potash, and other alkalies, apply lemon juice, vinegar diluted with water, or any other diluted acid.

Remove the clothing with the greatest care. Do not pull off the clothes from the burned places, but gently loosen them or cut them away. Save the skin unbroken if possible, taking care not to break the blisters. The secret of treatment is to prevent friction and to keep out the air.

If the burn is slight, put on strips of soft linen soaked in a strong solution of baking soda and water, one heaping 
tablespoonful to a cupful of water. This is especially good for scalds.

Carron oil is one of the best applications. It is simply half linseed oil and half limewater shaken together until they form a cream. Soak strips of old linen or absorbent cotton in this time-honored remedy, and gently apply.

If carbolized or even plain vaseline is at hand, spread it freely on strips of old linen and cover well the burnt parts, keeping out the air with other strips carefully laid on.

477. Frost Bites. No warm air, warm water, or fire should be allowed near the frozen or frost-bitten parts until the natural temperature is nearly restored. Rub the frozen part vigorously with snow or snow water in a cold room. Continue this until a

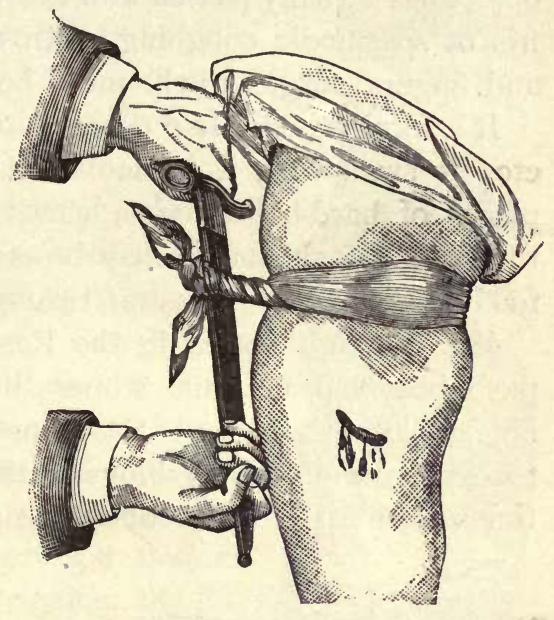

FIG. 164. Showing how Hemorrhage from the Femoral Artery may be arrested by the Use of an Improvised Tourniquet. burning, tingling pain is felt, when all active treatment should cease. Pain shows that warmth and circulation are beginning to return.

478. Setting the Clothing on Fire. When the clothing catches fire throw the person down on the ground or floor, as the flames will tend less to rise toward the mouth and nostrils. Then, without a moment's delay, roll the person in a carpet or rug, so as to stifle the flames, leaving only 
the head out for breathing. If no carpet or rug can be had, then take off your coat, shawl, or cloak, and use it instead.

479. Foreign Bodies in the Throat. Bits of food or other small objects sometimes lodge in the throat, and are easily extracted by the forefinger, or they may be driven out by sharp slaps on the back, or expelled by vomiting. If the object has actually passed into the windpipe, causing sudden fits of spasmodic coughing, with a dusky hue of the face and fingers, surgical help must be called without delay.

If a foreign body, like coins, pencils, keys, nails, buttons, etc., is swallowed, it is not wise to give a physic. Give plenty of hard-boiled eggs, cheese, and crackers, so that the intruding substance may be enfolded in a mass of solid food and allowed to pass off through the bowels.

480. Foreign Bodies in the Nose. Children are apt to push beans, peas, fruit stones, buttons, and other small objects into the nose. Sometimes we can get the child to expel the object by blowing the nose hard. At other times a sharp blow between the shoulders will cause the

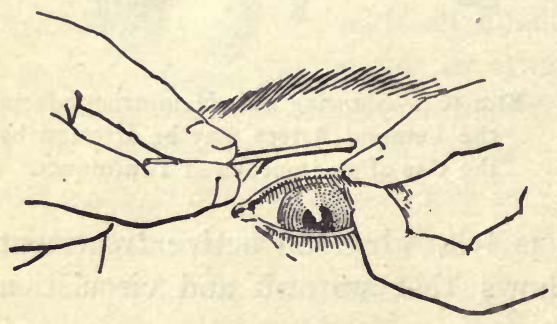

FIG. 165. Showing how the Upper Eyelid may be everted with a Pencil or Penholder. substance. If live insects get into the ear, drop in a little sweet oil, melted vaseline, salt and water, or even warm molasses.

substance to fall out.

481. Foreign Bodies in the Ear. It is a much more difficult matter to get foreign bodies out of the ear than from the nose. Syringe in a little warm water, which will often wash out the 
If the tip of the ear is pulled up gently, the liquid will flow in more readily. If a light is held close to the outside of the ear, the insect may be coaxed to crawl out, having been attracted by the bright flame.

482. Foreign Bodies in the Eye. Cinders, particles of dust, and other small bodies often get into the eye and cause much pain. It will only make bad matters worse to rub the eye. Often the copious flow of tears will wash the substance away. It is sometimes removed simply by the twisted corner of a handkerchief. Oftentimes the upper lid must be turned back (Fig. 165).

This is done usually as follows: Seize the lashes between the thumb and forefinger and draw the edge of the lid away from the eyeball. Now, telling the patient to look down, press a slender lead pencil or penholder against the lid, parallel to and above the edge, and then pull the edge up and turn it over the pencil by means of the lashes.

The eye is now readily examined, and usually the foreign body may be seen and easily removed with the corner of a pocket handkerchief. After the substance has been removed bathe the eye with hot water until all pain stops.

483. Broken Bones. Broken limbs

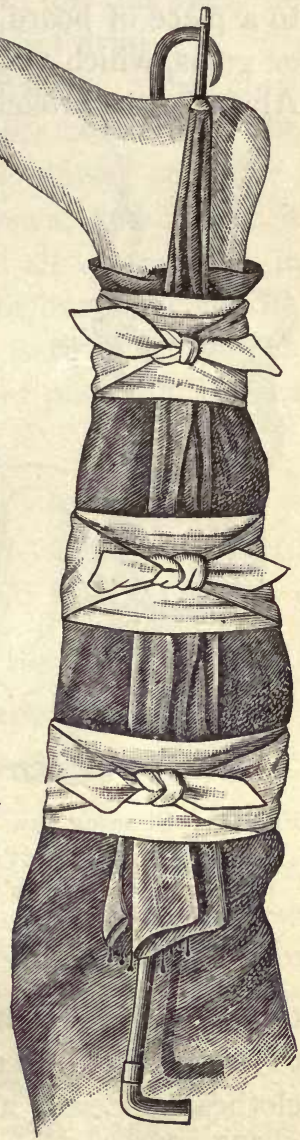

FIG. 166. Showing how an Umbrella may be used as a Temporary Splint on a Broken Leg. should always be handled with great care and tenderness. 
If the accident happens in the woods, the limb should be bound with handkerchiefs, suspenders, or strips of clothing, to a piece of board, pasteboard, or bark, padded with moss or grass, which will do well enough for a temporary splint. Always put a broken arm into a sling after the splints are on.

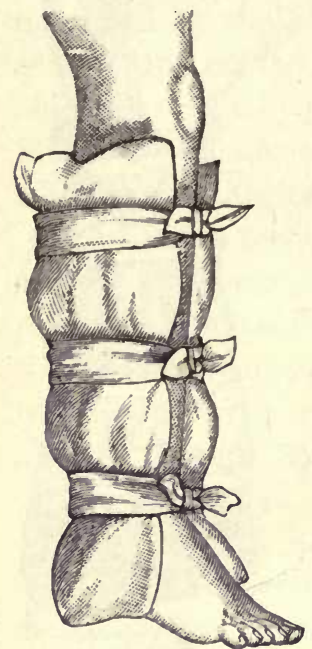

Fig. 167. Showing how a Pillow or a Blanket may be used as a Temporary Splint on a Broken Leg.

Never move the injured person until the limb is made safe from further injuries by putting on temporary splints. If you do not need to move the person, keep the limb in a natural, easy position until the doctor comes.

A surgeon is needed at once to set the broken bone.

484. Fainting. A fainting person should be laid flat at once. Give plenty of fresh air, and dash cold water, if necessary, on the head and neck. Loosen all tight clothing. Smelling salts may be held to the nose, to excite the nerves of sensation and thus stimulate respiration.

485. Epileptic and Hysterical Fits. See that the person does not injure himself; crowd a pad made from a folded handkerchief or towel between the teeth, to prevent biting of the lips or tongue. Do not try to make the sufferer swallow any drink. Unfasten the clothes, especially about the neck and chest.

486. Sunstroke or Heat Stroke. The main thing is to lower the temperature. Strip off the clothing; apply chopped ice, wrapped in flannel, to the head. Rub ice over the chest and place pieces under the armpits and at the sides. If there is no ice, use sheets or cloths wet with cold water. 
If the skin is cold, moist, or clammy, the trouble is due to heat exhaustion. Give plenty of fresh air, but apply no cold to the body. Apply heat and give hot drinks.

487. Asphyxia, or Suspended Animation. The chief dangers from poisoning by noxious gases come from the fumes of burning coal in the furnace, stove, or range; from "blowing out" gas, turning it down, and having it blown out by a draught; from the foul air often found in old wells or mines; and from the fumes of burning charcoal.

The first and essential thing to do is to give fresh air. Remove the person to the open air and place him on his

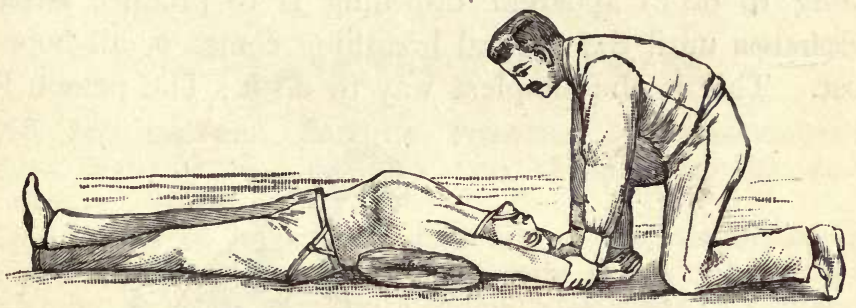

FIG. 168. Production of Artificial Respiration. (First movement - inspiration.)

back. Remove tight clothing about the throat and waist, dash on cold water, give a few drops of ammonia in hot water or hot ginger tea. Friction applied to the limbs should be kept up. If necessary, use artificial respiration as described in section 489 .

488. What to do in Apparent Drowning. Remove all tight clothing from the neck, chest, and waist. Sweep the forefinger, covered with a handkerchief or towel, round the mouth, to free it from froth and mucus. Turn the body on the face, raising it a little, with the hands under the hips, to allow any water to run out from the air passages. Take only a moment for this. 
Lay the person flat upon the back, with a folded coat, or pad of any kind, to keep the shoulders raised a little. Remove the wet, clinging clothing as far as possible. If in a room or sheltered place, strip the body and wrap it in blankets, overcoats, etc. If at hand, use bottles of hot water, hot flatirons, or bags of hot sand round the limbs and feet. Watch the tongue; it generally tends to slip back and to shut off the air from the glottis. Wrap a coarse towel round the tip of the tongue and keep it well pulled forward.

489. How to produce Artificial Respiration. The main thing to do in apparent drowning is to produce artificial respiration until the natural breathing comes or all hope is lost. This is the simplest way to do it: The person lies

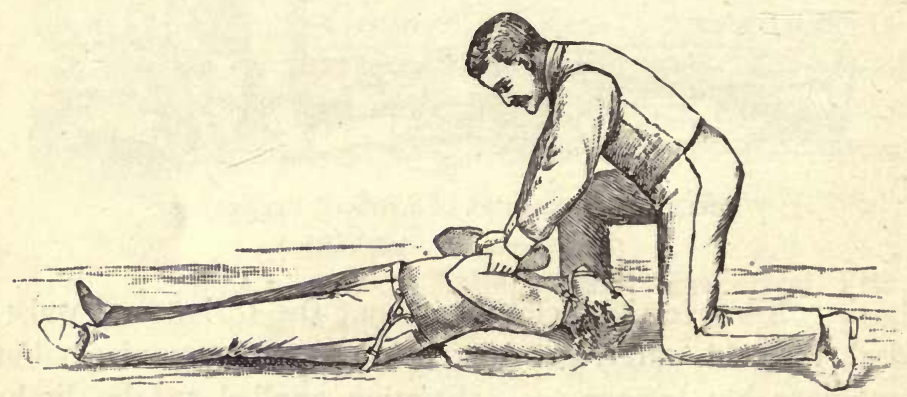

FIG. I69. Production of Artificial Respiration.

(Second movement-expiration.)

on the back; let some one kneel behind the head. Grasp both arms near the elbows and sweep them upward above the head until they nearly touch. Make a firm pull for a moment. This tends to fill the lungs with air by drawing the ribs up and making the chest cavity larger. Now return the arms to the sides of the body until they press hard against the ribs. This tends to force out the air. 
This makes artificially a complete act of respiration. Repeat this act about fifteen times every minute.

All this may be kept up for several hours. The first sign of recovery is often seen in the slight pinkish tinge of the lips or finger nails. That the pulse cannot be felt at the wrist is of little value in itself as a sign of death. Life may be present when only the most experienced ear can detect the faintest heart beat.

When a person can breathe, even a little, he can swallow. Hold smelling salts or hartshorn to the nose. Meanwhile do not fail to keep up artificial warmth in the most vigorous manner.

\section{POISONS AND THEIR ANTIDOTES}

490. Irritant and Narcotic Poisons. For convenience poisons may be divided into two classes, irritants and narcotics.

The effects of irritant poisons are evident immediately after being taken. They burn, or corrode, the skin or mucous membrane or other parts with which they come in contact. They produce burning pains in the mouth, throat, stomach, and intestines, with nausea and vomiting.

With narcotic poisoning the symptoms come on more slowly. After a time there is drowsiness, which gradually increases until there is a profound sleep or stupor, from which the patient can be aroused only with great difficulty. There are some substances which possess both the irritant and narcotic properties and in which the symptoms are of a mixed character.

491. Treatment of Poisoning. In the treatment of poisoning the first thing to do, if you know the special poison, is to give its antidote at once. An antidote is a substance which will either combine with a poison to render it harmless or which will have a directly opposite effect upon the body, thus neutralizing the effect of the poison.

If the poison is unknown, or there is any delay in obtaining the antidote, the first thing to do is to cause vomiting as 
quickly as possible. This may be done by stirring a tablespoonful of mustard or of common salt in a glass of lukewarm water and making the patient swallow the whole. Repeat as often as is necessary. Vomiting may be hastened by thrusting the forefinger down the throat.

For some poisons, as acids and alkalies, no emetic should be given. Again, for poisons like carbolic acid, which cause local irritation, but which also affect the system at large, no emetic should be given. An emetic, however, should be given in the case of arsenic.

492. Practical Points about Poisons. Poisons should never be kept in the same place with medicines or other preparations used in the household. They should always be put in some secure place under lock and key. Never use internally or externally any part of the contents of any package or bottle unless its exact nature is known. If there is the least doubt about the substance, do not assume the least risk, but destroy it at once. Many times the unknown contents of some bottle or package have been carelessly taken and found to be poison.

Careless and stupid people often take by mistake, with serious, and often fatal, results, poisonous doses of carbolic acid, insect poison, horse liniment, oxalic acid, and other poisons. A safe rule is to keep all bottles and boxes containing poisonous substances securely bottled or packed, and carefully labeled, with the word POISON plainly written in large letters across the label. Fasten the cork of a bottle containing poison to the bottle itself with copper wire twisted into a knot at the top. This is a simple but effective means of preventing any mistakes which are likely to be made by children or in darkness.

This subject of poisons assumes nowadays great importance, as it is a common custom to keep about stables, workshops, bath rooms, and living rooms generally a more or less formidable array of disinfectants, horse liniments, insect destroyers, and other preparations of a similar character. For the most part, they contain poisonous ingredients. 


\section{A TABLE OF THE MORE COMMON POISONS}

With their prominent symptoms, antidotes, and treatment

$\quad$ Poison
Strong Acids:
Muriatic
Nitric
Sulphuric (vitriol)
Oxalic

Alkalies:

Caustic potash and soda

Ammonia

Lye

Pearlash

\section{Arsenic:}

Paris green

Rough on rats

White arsenic

Fowler's solution

Scheele's green

\section{Other Metallic}

\section{Poisons :}

Blue vitriol

Copperas

Green vitriol

Sugar of lead

Corrosive sublimate

Insect poison

\section{Prominent Symptoms}

Burning sensation in mouth, throat, and stomach ; blisters about mouth ; vomiting; great weakness

Burning sensation in the parts ; severe pain in stomach; vomiting; difficulty in swallowing; cold skin; weak pulse

Intense pains in stomach and bowels; thirst; vomiting, perhaps with blood; cold and clammy skin

Symptoms in general, same as in arsenical poisoning. With lead and mercury there may be a metallic taste in the mouth

\section{Phosphorus from}

Matches, rat poisons, etc.

Pain in the stomach; vomiting; purging; general collapse

\section{Antidotes and} Treatment

No emetic. Saleratus; chalk; soap; plaster from the wall; lime; magnesia ; baking soda ( 3 or 4 tea. spoonfuls in a glass of water)

No emetic. Olive oil freely ; lemon juice ; vinegar; melted butter and vaseline; thick cream

Vomit patient repeatedly; give hydrated oxide of iron with magnesia, usually kept by druggists for emergencies; follow with strong solution of common salt and water

Emetic with lead; none with copper and iron; white of eggs in abundance with copper; with iron and lead give Epsom salts freely; afterwards, oils, flour, and water

No emetic with mercury; raw eggs; milk, or flour and water

Cause vomiting. Strong soapsuds; magnesia in water. Never give oils 


\section{Poison}

Opium :

Morphine

Laudanum

Paregoric

Dover's powder

Soothing syrups, etc.

\section{Carbolic Acid:}

Creosote

\section{Prominent Symptoms}

Sleepiness ; dullness; stupor; "pinhole" pupils; slow breathing; profuse sweat

Severe pain in abdomen; odor of carbolic acid, mucous membrane in and around mouth white and benumbed; cold, clammy skin

Aconite:

Wolfsbane

Monkshood

\section{Belladonna :}

Deadly nightshade Atropia

\section{Various Vegetable}

Poisons:

Wild parsley

Indian tobacco

Tobacco plant

Hemlock, etc.
Numbness everywhere; great weakness; cold sweat

Eyes bright, with pupil enlarged; dry mouth and throat

Stupor, nausea, great weakness and other symptoms according to the poison

\section{Antidotes and}

Treatment

Cause vomiting. Keep patient awake by any means, especially by vigorous walking; give strong coffee freely; dash cold water on face and chest

No emetic. Milk, or flour and water; white of eggs

Vomit patient freely. Give strong coffee freely.

Vomit patient freely
Cause brisk vomiting. Give strong coffee freely.

Note. - The teacher or student who is disposed to study the subject of "First Aid to the Injured" more thoroughly and in more detail than is possible in a class text-book will find all the material that is needed in several excellent books. These books are readily obtained by purchase, or may be found in the public libraries of larger towns. 


\section{CHAPTER XV}

\section{THE CAUSE AND PREVENTION OF TUBERCULOSIS OR CONSUMPTION}

493. Consumption a Widespread and Deadly Disease. Of all diseases known to mankind, consumption, often called the "great white plague," is without doubt the most widespread and the most deadly. For short periods other diseases, like "black death" and cholera, have caused more dread and even wider destruction, but consumption has been the most constant and the most deadly of all.

Consumption is more common in certain climates and among certain races, but it spares no nation, no age, no occupation, and no class of people. It is said that of all people who die every year, about one seventh die from this disease. It is estimated that over 150,000 people die of consumption every year in the United States, and that I,000,000 lives are annually lost by this disease in Europe.

494. Consumption a very 01d Disease. Consumption is a very old disease. Evidences of tuberculosis have been discovered even in the old Egyptian mummies. Famous writers of ancient times, whose writings may still be read, give us graphic pen pictures of this disease. It was then known, as it is now, as the "great white plague."

During what is known as the Dark Ages this dread disease swept through Europe and destroyed people by thousands. Consumptives were shunned and avoided as if they had smallpox. They were confined in rooms with the doors and 
windows closed. Fresh air and sunlight, things which we now know are so important in curing the disease, were shut out.

495. What is Tuberculosis or Consumption? "Tuberculosis " and "consumption" are two names for one disease. It is caused by a germ or microbe spoken of as the tubercle bacillus or consumption germ. This germ is a very tiny plant. It is so small that it would take 3000 put end to end to measure

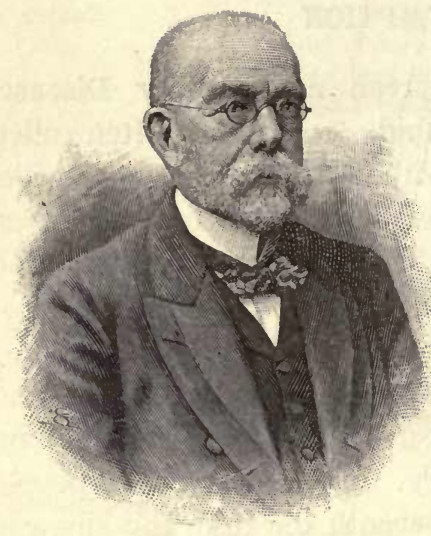

Fig. 170. Dr. Robert Koch,

Discoverer of the Tuberculosis Germ.

one inch. This germ does not readily grow outside of living bodies; but when it gains entrance into the body, it may grow and multiply. At last it destroys the tissues and thus causes the disease usually spoken of as tuberculosis.

The germ which causes tuberculosis was discovered by Dr. Robert Koch (Köke), a famous German physician, in the year I 882. He showed that a special germ (tubercle bacillus) was always present in every case of tuberculosis. Up to this time nobody knew what was the real cause of consumption. This great discovery has made possible the present widespread crusade against this infectious disease.

496. What Parts of the Body may be attacked by Tuberculosis? Any tissue or organ of our bodies may be infected by the consumption germ. The name given to this disease depends upon the tissue or organ attacked. Thus, "hip disease" is tuberculosis of the hip; "white swelling" of the knee, tuberculosis of the knee; and "lupus," a skin disease, tuberculosis of the skin. The most common form of 
tuberculosis, however, is that of the lungs, known generally as "consumption." Thus when we speak of tuberculosis, we usually mean consumption.

497. How the Germs of Consumption do their Work. The presence of the tubercle bacillus in the body does not always cause consumption. When the germs of this disease get into the body, a contest seems to take place between these germs and the cells of which the body is composed. If the germs gain the victory, little tumorlike knots, not unlike the tiniest grains of sand, called tubercles, are formed. After a time these tubercles in the lungs soften and break down. The matter of which they are composed

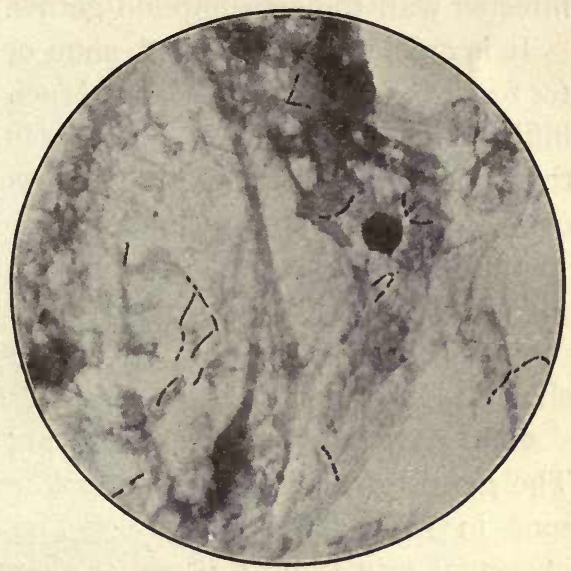

Fig. 171. Germs of Tuberculosis.

(A minute portion of sputum from a case of phthisis, or consumption, magnified rooo diameters. These germs are rod-shaped bacteria, stained to show black. The black spots in the figure are merely the débris in the sputum, also stained to look black.) is coughed up into the mouth and is known as sputum.

This matter thus coughed up often contains millions of tubercle baccilli and is therefore dangerous to the health of other people. It has been estimated that in the sputum of one consumptive there may be more than twenty-four millions of these germs in the course of twenty-four hours.

498. How Consumption is regarded as a Contagious Disease. We must remember that consumption is not contagious in the sense in which we speak of scarlet fever, smallpox, 
measles, and so on, as being "contagious." We do not get consumption from being in contact with a person suffering from it or from his breath, but only by breathing in for a longer or shorter time the germs from the matter coughed up (sputum), or by means of food or drink which has been infected with the consumption germs.

It is cruel and senseless to shun or neglect a consumptive for fear of catching the disease. Much needless pain has been inflicted upon the sick and suffering in so doing. A consumptive should be safe and harmless to work or live with, if he is cleanly in his habits, is careful in properly disposing of his sputum, and uses cloths or paper napkins before his mouth when coughing. There is no reason why a consumptive who carefully observes the precautions as set forth in this chapter should be shunned or neglected as dangerous.

499. How Consumption Germs are scattered by Persons. The germs of tuberculosis are scattered by consumptive persons in many different ways. The commonest and most important way is by the matter that leaves the mouth and nose. The germs are present in the matter that is coughed up by persons who have consumption of the lungs, and also in the tiny drops of fluid sprayed from the mouth and nose of such persons during coughing, sneezing, and talking.

The germ-laden substance from the mouths of consumptives may cling to glasses, cups, towels, napkins, handkerchiefs, spoons, sheets, pillowcases, slates, slate pencils, toys, and numerous other articles.

Tubercle bacilli are also scattered in the dust of dried sputum.

Drinking from glasses or cups without thoroughly cleaning them after they have been used by others is a practice through which not only consumption but also diphtheria, scarlet fever, and some other diseases may be communicated. 
500. The Chief Mode of communicating Consumption. The chief mode of communicating consumption is by the dried sputum of consumptives. The germs of this disease exist by the million in the sputum which may be hawked or coughed up and cast upon the sidewalk, the floors of public halls, schoolrooms, workshops, and public buildings, or upon

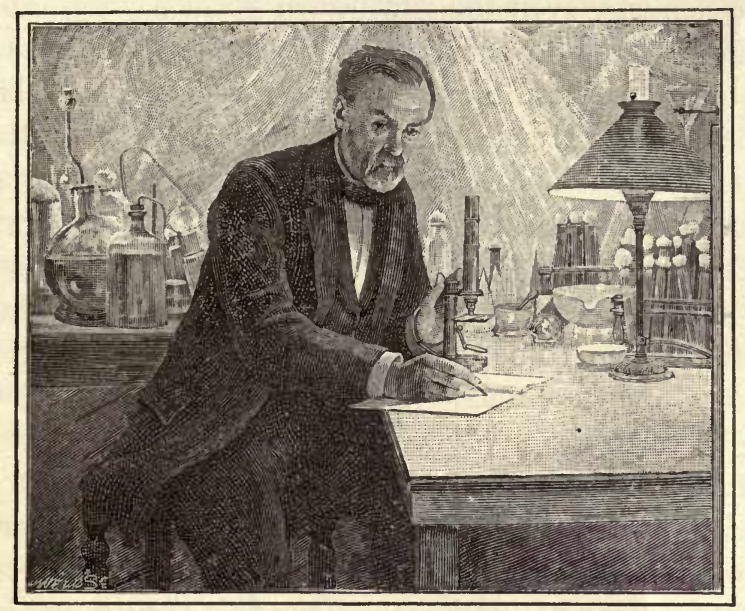

FIG. 172. Louis Pasteur (1822-1895).

(This picture represents Pasteur, the great master of modern science, busily at work in his laboratory recording the results of his study of bacteria.)

the floors or carpets in dwelling houses. In fact, any place where the consumptive may choose to spit may become infected.

When the sputum becomes dried, the germs which it contains in countless numbers mingle with the air and dust. It may thus infect susceptible persons and spread the disease to many. The danger of infection is increased by the great vitality of the germs, which exist for a long time after drying and mixing with the dust. 
The germs of consumption may often be found in the dust and dirt of overcrowded tenement houses and other dwelling places. In such places the germs may retain their vitality for many weeks. Darkness, dampness, cast-off clothing, dirt, and dust all serve as abiding places for consumption germs.

According to Pasteur and the more recent experiments of other scientists, even the earthworm plays a very important part in bringing to the surface disease-producing bacteria. The studies of these men refer especially to Koch's bacillus of tuberculosis. Hence cremation, in all cases of death from infectious diseases, has often been advocated by sanitarians. In recent years the experiments of scientists have shown that tuberculosis should be included among such diseases. In brief, it has been demonstrated conclusively that the consumption germ (tubercle bacillus) can resist putrefaction for years and be brought to the surface by the seemingly innocent earthworm.

501. Some of the Early Symptoms of Consumption. Consumption is usually a slow, insidious disease, the germs of which may be in the body a long time before they cause a noticeable change from health. Later on they cause general weakening, loss of appetite, a more or less severe cough, bleeding from the lungs, loss of flesh and strength, and other symptoms by which it is easily recognized. Cough is not always one of the early symptoms of consumption.

It is important that consumption should be recognized in its early stage, because the longer the disease is neglected the more difficult it is to cure.

502. Consumption is not inherited. Consumption is not inherited. It is the tendency which is inherited, but not the disease itself. In other words, consumptive parents may have children who are naturally of a poor constitution, with weak lungs, flat chests, and little or no power to resist infection. 
Children in such families should be brought up with the utmost care, and should be given the greatest amount of fresh air and sunlight.

503. Tuberculosis in Animals. Tuberculosis is not only the most widely spread of all diseases affecting human beings, producing a greater mortality than any other, but there is probably no disease which affects domestic animals so widely. The disease is most common in cattle; it is quite common in pigs, but rare in sheep.

Tuberculosis in fowls is a common and very infectious disease. Frequently nearly all the birds in a poultry yard are affected. It is now held to be an established fact by many scientific men that tuberculosis is transmissible from cattle to human beings, and that the milk of tuberculous cows is a common vehicle of transmission.

504. The Crusade against Consumption. The battle against consumption is now being fought at a lively pace throughout the civilized world. No disease is receiving such general attention at the present time as is the "great white plague." Nations, states, cities, and towns are all actively lending a hand in the crusade. The campaign is directed not only against the germ of consumption but quite as much against the numberless conditions which produce the favorable soil in the individual.

- In the crusade against consumption numerous agencies, both public and private, are now at work in the effort to control and prevent the disease. There is not a state nor territory in the United States which has not considered or taken action on the subject of tuberculosis.

In the year 1908, of 43 legislatures in session, 36 debated on matters pertaining to tuberculosis. A total of more than $\$ 4,000,000$ has been appropriated for the conduct of state campaigns against this disease, and millions more have been 
granted by cities for the same purpose, to say nothing of the vast sums given by private subscription for the suppression of the white plague.

505. Various Agencies at Work in this Crusade. The campaign against consumption in the various states is along two lines: First, that which is done by sanatoriums and

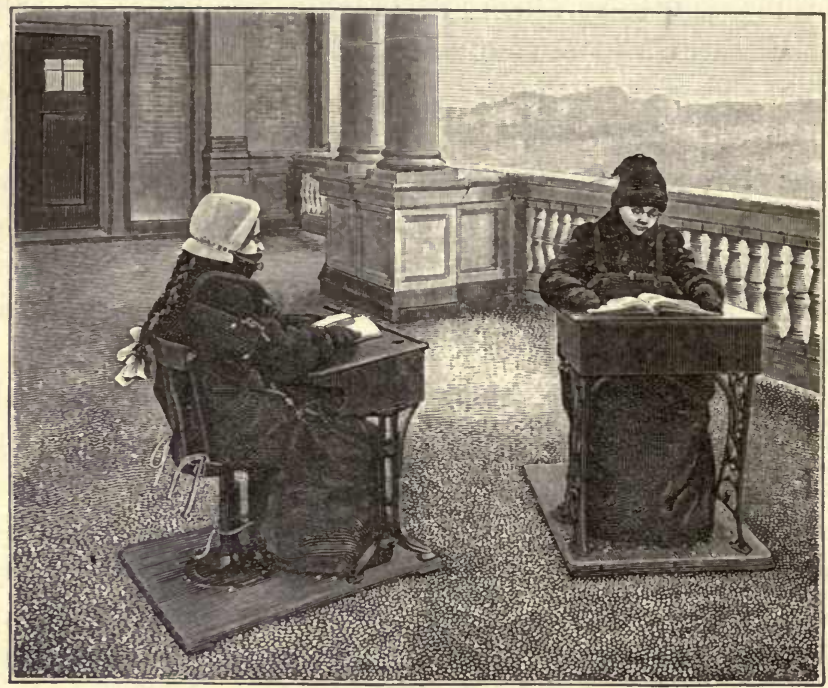

FIG. 173. Outdoor School for Consumptive Children, Franklin Park, Boston.

(Chair bags of weatherproof canvas lined with blanketing, and special ulster coats, wool mittens, and stockings and overshoes keep the children warm in all weathers.)

hospitals ; second, that which is being done outside of these institutions by medical men, boards of health, anti-tuberculosis associations, and so on, in teaching people how to live in their own homes.

Almost every country has one or more public sanatoriums for the relief of early, curable cases. In this country 


\section{The Cause and Prevention of Tuberculosis 325}

sanatoriums in the various states are rapidly increasing. In all of the large cities, and in many of the smaller cities and towns in some states, various anti-tuberculosis associations have been formed.

Dispensaries for the free examination and treatment of the poor who are sick with consumption have been established and are maintained at the public expense in almost all large cities.

Hospitals for the isolation and care of advanced cases of consumption are being rapidly established. Nothing is more important in the prevention of tuberculosis than the isolation in hospitals for consumptives of advanced cases which cannot be safely treated at home.

506. Day Camps, Open-Air Schools, and Seaside Sanatoriums. The "day camp" is now a popular and very valuable method of treating consumptive patients who cannot go away from home. They come to the camp every morning, spend the day out of doors, receiving good food and medical supervision, and return to their homes at night. The "night camp" is also being introduced, where patients who are obliged to work by day can spend the night under open-air conditions.

Open-air schools, called "forest schools" in Germany, are like the day camp with the addition of daily lessons. These schools are held in the summer out of doors, in winter in buildings with wide-open windows. The children are dressed warmly and are provided with proper food during the day.

It has been proved that sea air and sea bathing are very beneficial for children sick with consumption. Many sanatoriums for such cases have been established on the seacoast in Europe. In this country the "Sea-breeze Hospital" at Coney Island has become well known for its good work in behalf of consumptive children. 
507. The Outdoor Life. The outdoor life is one of the great essentials in the treatment of consumption. It is in striking contrast to the common indoor existence of most city people. The patient is out of doors from seven to ten hours every day, at rest a part or the whole of the time. He also sleeps out of doors, or with the windows of his sleeping room wide open, whatever the weather or temperature.

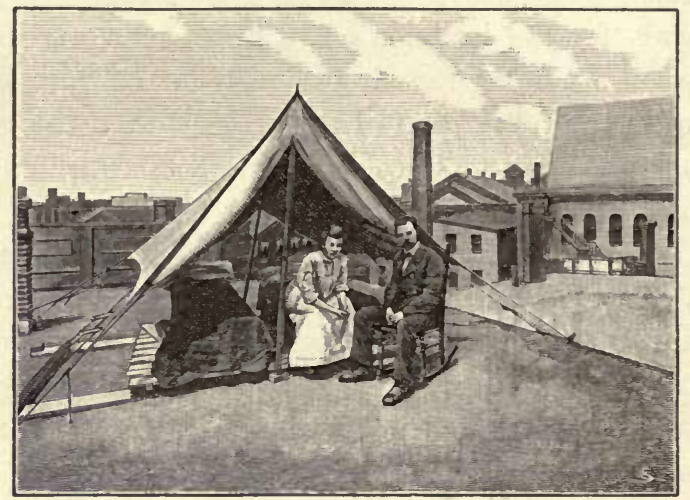

FIG. 174. The Open-Air Treatment of Tuberculosis. Service of Dr. J. H. Pratt, Boston.

(This consumptive patient is taking the treatment in a canvas tent, in a vacant lot in the rear of his home. The tent is converted into a canopy by fastening up the sides and ends.)

Outdoor sleeping is advised, and is now frequently practiced by those in good health as well as by the consumptive. For this purpose either a piazza, a so-called "shack" (which is a small open building), or a sleeping porch (which can be added to almost any house at a small expense), may be made use of.

Outdoor conditions of sleeping may also be obtained by means of the "window tent," which can be applied to any window, and by this device the body remains indoors while 
the head is practically out of doors. With proper protection one can be comfortable even in winter weather.

508. The Education of the General Public. It is by these agencies that we have just spoken of, and many others which space does not allow us to refer to, that the prevention and control of tuberculosis is being accomplished.

By means of tuberculosis clinics and district nurses the innumerable cases of consumption in homes, in overcrowded tenement houses, and in factories and workshops are being found out. The early cases are urged to go to the various state sanatoriums.

Proper hospital accommodation is obtained for the advanced cases, or they are taught how to live in their own homes. The masses of the people are educated by means of lectures, exhibits, cards and signs, etc. Boards of health are stimulated to take proper measures as regards disinfection.

Physicians are urged to report their cases of consumption as they do their cases of scarlet fever and diphtheria. Best of all, the general.public is aroused to realize the importance of the subject.

\section{Suggestions on protecting your Health against} Consumption. I. All nose and throat troubles, a cough which has lasted for some time, or a sudden loss of flesh and strength, should lead you to seek medical aid.

2. Insist upon having plenty of fresh air in your sleeping room, both day and night, in summer and winter.

3. Open the windows in all the living rooms often. Let in the sunlight.

4. Stay out of doors whenever you can. A balcony may be fitted up for both sitting and sleeping purposes. Children should live as much as possible in the open air. Every form of sport should be encouraged which tends to keep them there. 
5. A person who is ill with tuberculosis should be kept in the open air for at least several hours each day, in spite of fever or cough, although it is important that he should be kept warm. Sudden, unnecessary exposure to extreme changes in the weather should be avoided.

6. Wear light underwear of moderate weight, and put on outside wraps according to changes in the weather.

7. Bathe the neck and chest, front and back, with cold water every morning. After bathing rub the skin well with a coarse towel.

8. Spend your money for good food rather than for medicines. Patent medicines, or proprietary preparations, or drugs of any kind should not be taken internally without the advice or consent of a physician in good standing.

9. Avoid fatigue. If you are working, lie down when you have a few moments to spare.

I0. Remember that many persons who have suffered with tuberculosis are now well, and that the disease is no longer regarded as incurable.

I I. Do not spit on the sidewalk, the crosswalk, or on the floor of any building, street car, or other public conveyance where the sputum may become dry and permit the spread of the germs which it may contain. Join the anti-spit crusade. Favor the enactment and enforcement of laws prohibiting spitting on sidewalks, on floors, in street cars or other conveyances.

510. How may School Children help in the Crusade against Consumption. Every child and grown-up person can help in the crusade against consumption. School children can be helpful by heeding the following suggestions :

Do not spit except in a spittoon, a piece of cloth, or a handkerchief used for that purpose alone. On your return home have the cloth burned, or the handkerchief put in water until ready for the wash. 
Never spit on a slate, floor, playground, or sidewalk.

Do not wet the fingers in the mouth for the purpose of turning the leaves of books, especially library or school books, as book leaves are sometimes the lurking places of germs of disease.

Do not put pencils in your mouth or wet them with your lips.

Do not hold money in your mouth. This is extremely important, because money is liable to come in contact with all sorts of people and to become contaminated with many kinds of diseaseproducing bacteria.

Do not put into the mouth anything that another person has had in his mouth. This

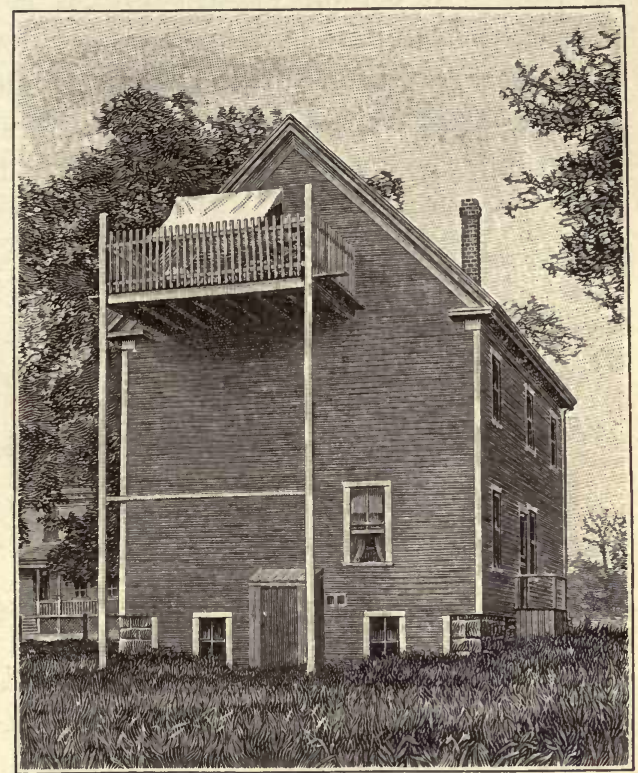

FIG. 175. The Open-Air Treatment of Tuberculosis. Service of Dr. J. H. Pratt, Boston.

(The porch in this cut was built at small cost for a consumptive patient who wished to sleep out of doors but did not wish to use the yard or a porch off the first floor. On a similar balcony a patient who had advanced tuberculosis spent most of the day and slept every night for a year. He gained sixty pounds in weight while taking the open-air treatment.) refers to gum, apple cores, candy, whistles, bean blowers, drinking cups, and many other things.

Never sneeze or cough in a person's face. Turn your face to one side or hold a handkerchief before your mouth. 
Learn to love fresh air and learn to breathe deeply and do it often.

Even a knife or a spoon coming from the sick room should be placed in boiling water before it is used by any other person. Water that is simply hot is not sufficient for this purpose. The water must be boiling, and it is better if the articles are placed in the water and the water boiled for five or ten minutes before they are taken out to be used. 


\section{NOTES}

For additional material on tuberculosis, either for reading or for reference, the student and teacher are referred to the following books and pamphlets, as the most useful and practical for these purposes:

The Great White Plague: Tuberculosis, by Dr. Edward O. Otis. 321 pages.

T. Y. Crowell \& Co., Publishers, New York. Price, \$r.oo.

Tuberculosis: A Preventable and Curable Disease, by Dr. S. Adolphus Knopf.

Fully illustrated. 394 pages. Moffat, Yard \& Co., Publishers, New York.

Price, $\$ 2.00$.

The Conquest of Consumption, by Dr. Woods Hutchinson. Illustrated. 138 pages. Houghton Mifflin Company, Publishers, Boston. Price, $\$ 1.00$. The Open-Air Treatment of Pulmonary Tuberculosis, by F. W. BurtonFanning. Illustrated. I 84 pages. Paul B. Hoeber, Medical Publisher, 69 East 59th St., New York. Price, \$1.50.

These four books may be found in public libraries, should be provided by local anti-tuberculosis associations, or may be ordered through any local bookseller.

Teachers may consult with profit Allen's Civics and Health, especially Chapter XXIV, "The Last Days of Tuberculosis." Ginn \& Company, Publishers, Boston. Price, $\$$ I.25.

A notable pamphlet, "The Cause and Prevention of Consumption," has been issued by the Illinois State Board of Health. Copies of the latest edition may be obtained by any resident of Illinois, without cost, by addressing the secretary at Springfield.

A most useful little pamphlet, "Tuberculosis and its Prevention," with suggestions to teachers, has been issued by the Massachusetts Board of Education. This will be sent gratis to teachers upon application at the statehouse, Boston.

For information on the subject of tuberculosis, sundry pamphlets issued by the Boston Association for Relief and Control of Tuberculosis may be obtained on application at the office of the association, 4 Joy Street, Boston, at a nominal price.

For information concerning a most admirable series of booklets on matters of health, including tuberculosis, correspondence is suggested with the Health-Education League, I 13 Devonshire St., Boston. These booklets are sold at a nominal price. 



\section{APPENDIX}

\section{EXPERIMENTAL WORK IN PHYSIOLOGY IN HIGHER SCHOOLS}

I. The Experimental Method of Instruction. Every experienced teacher knows that pupils gain a far better knowledge and keep up a livelier interest in any branch of science, if they are able to see with their own eyes and to do with their own hands that which serves to illuminate and illustrate the particular branch of science in which they are engaged.

The experimental method of instruction rivets the attention and arouses and keeps alive the interest of the young student; in fact, it is the only true method of cultivating a scientific habit of study.

2. Experimental Work in Physiology in Elementary Schools. Unlike other branches of science taught in elementary schools from the experimental point of view, the study of physiology has its limitations. The scope and range of such experiments is necessarily extremely limited compared with what may be done with the costly and elaborate apparatus of medical laboratories.

The study of anatomy and physiology is based upon the systematic and painstaking dissection of the dead human body and of the lower animals, together with experiments upon living animals. This plan of research and study very properly is not permitted in elementary school work. Experiments upon the living human body and the lower animals, now so generally depended upon in our medical and more advanced scientific schools, for obvious reasons can be performed only in a crude and quite superficial manner in high. and normal schools.

3. Importance of Experiments in Physiology in Higher Schools. While circumstances and regard for certain proprieties of social life forbid a range of experiments. in anatomy and physiology such as is 
permitted in other branches of science in secondary schools, it by no means follows that we are shut out altogether from this most important and interesting part of the study. However simple and crude the apparatus, the skillful and enthusiastic teacher has at his command a wide range of materials which can be profitably utilized for experimental instruction.

The subject-matter as set forth in the preceding chapters of this book should be mastered, of course, but at the same time the topics discussed should be illuminated and made more interesting and practical by the series of experiments given in connection with the several chapters, a goodly show of specimens, and a certain amount of microscopical work.

4. Costly Apparatus by no Means Necessary. It will be noticed that many of the experiments in this book can be performed with very simple and often crude and homemade apparatus. This plan has been rigidly followed by the author, first, because he fully realizes the limitations and restrictions of the subject; and secondly, because he wishes to emphasize the fact that expensive and complicated apparatus is by no means necessary to illustrate the great principles of anatomy and physiology.

In schools in which both the funds and the time for experimental work are limited, the zeal and ingenuity of teachers and students are often put to a severe test. Fortunately, a very little money and a great deal of ingenuity and patience will do much towards providing a working supply of apparatus.

5. Use of the Microscope. The appearance of the various structures and tissues of the human body as revealed by the microscope possesses a curious fascination for every observer, especially for young students. No one ever forgets the first look at a drop of blood, or the circulation of blood in a frog's foot as shown by the microscope.

For elementary class work a moderate-priced but well-made and strong instrument should be provided. If the school does not own a microscope, the loan of an instrument should be obtained for at least a few weeks from some person in the neighborhood.

To do thorough and satisfactory work in physiology in our higher schools a compound microscope is almost indispensable. Inasmuch as many of our best secondary schools are equipped with a microscope for use in other studies, notably botany, it is much less difficult 
than it was a few years ago to obtain this important help for the classes in physiology. ${ }^{1}$

6. Vivisection and Dissection. There should be no question at all concerning vivisection. In no shape or form should it be allowed in any grade of our schools. Nor is there any need of much dissection in the elementary grades. A few simple dissections which can be made with fresh beef-joints, and legs of chickens and turkeys, will never engender cruel or brutal feelings toward living things. A discreet teacher should rarely advise his pupils to dissect a dead cat, dog, frog, or any other animal. Instead of actual dissection, the pupils should examine specimens or certain parts previously dissected by the teacher, - as the muscles and joints of a sheep, the heart of an ox, the eye of a codfish, and so on. Even under these restrictions the teacher should rarely use the knife or scissors before the class to open up any part of the specimen.

Most teachers will find, however, even in schools of a higher grade, that the whole subject is fraught with many difficulties. A teacher's good sense and discretion are often put to a severe test to avoid unjust and senseless criticism, which is often easily aroused in any community.

7. Surface Anatomy and Landmarks of the Body. In our leading medical colleges the students are carefully and thoroughly drilled on a study of living models. The object is

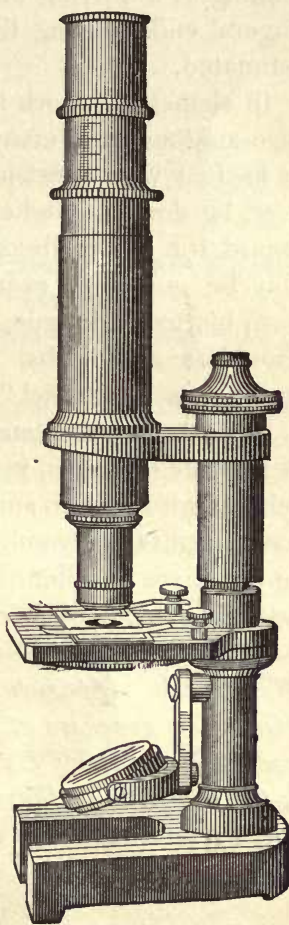

Fig. 176. A Compound Microscope.

1 For detailed suggestions in regard to the manipulation and use of the microscope the student is referred to any of the standard works on the subject. The catalogues of scientific-instrument makers generally furnish a list of the requisite materials or of handbooks which describe the use of the various microscopes of standard make.

For the names and addresses of firms that deal with microscopes and apparatus for experiments the reader is referred to the advertising pages of leading scientific or educational publications. 
to master by observation and manipulation what is known as surface anatomy and landmarks. Now while detailed work of this kind is not desirable in secondary schools, yet a limited amount of study along these lines is deeply interesting and profitable. The habit of looking at the living body with anatomical eyes and with eyes at our fingers' ends, during the course in physiology, cannot be too highly estimated.

In elementary work it is only fair to state that many points of surface anatomy and many of the landmarks cannot always be defined or located with precision. A great deal in this direction can, however, be done in higher schools with ingenuity, patience, and a due regard for the feelings of all concerned. For example, the student may be taught to examine the muscles and other parts of his own face, his teeth, tongue, and palate, and the bones and muscles of his shoulders and limbs. Two friends may thus work together, each serving as a "model" to the other."

8. Books for Collateral Reading in Experimental Work in Physiology. A number of books, prepared for the use of teachers and students in schools who wish to supplement the text-book with experimental work, have been recently published. Of these books the teacher is advised to use these excellent handbooks : Prudden's Dust and its Dangers and The Story of Bacteria (G. P. Putnam's Sons); Tracy's Handbook of Sanitary Information (Appleton \& Company); Woodhull's Homemade Apparatus (E. L. Kellogg \& Company); Bowditch's Hints for Teachers of Physiology (D. C. Heath \& Company); Peabody's Laboratory Exercises in Anatomy and Physiologv (H. Holt \& Co.) ; Brown's Physiology for the Laboratory (Ginn \& Company); and French's Manual of Dissection and Histology (J. B. Lippincott Company).

1 For a syllabus of a very brief course of study on the living model see Blaisdell's Practical Physiology, pp. 415-419. 


\section{GLOSSARY}

[Many words that are defined or explained as they occur in the text of this book. or the meaning of which is readily understood, have been omitted in this Glossary.]

Ab-do'men (Lat. $a b d o, a b d e r e$, to conceal). The largest cavity of the body, containing the liver, stomach, intestines, and other organs.

Ab-duc'tor (Lat. abducere, to draw from). A muscle which draws from the median line of the body or other median line.

Ab-sor'bent (Lat. absorbere, to suck up). An organ or part that absorbs; a lymphatic vessel.

Ab-sorp'tion. The process of sucking up nutritive or waste matters by the blood vessels or lymphatics.

Ac-com'mo-da'tion of the eye. The alteration in the shape of the crystalline lens, which adjusts the eye for near vision.

Ac-e-tab'u-lum (Lat. acetabulum, a small vinegar cup). The cup-shaped cavity of the innominate bone which receives the head of the femur.

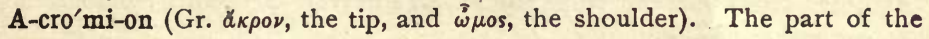
scapula forming the tip of the shoulder.

Ad-duc'tor (Lat. adducere, to draw to). A muscle which draws towards the median line of the body or other median line.

Af'fer-ent (Lat. ad, to, and ferre, to convey). Vessels or nerves carrying the contents or impulses towards the center.

Al-bu'men (Lat. albus, white). Formerly used as a synonym for proteid, now rarely used.

Al-bu'min (Lat. albus, white). A class of proteids, as egg-albumin, serumalbumin, etc.

Al-bu'mi-nu'ri-a. Presence of albumen in the urine.

Al-i-men'ta-ry (Lat. alimentum, food). Pertaining to aliment, or food.

Al-i-men'ta-ry ca-nal' (Lat. alimentum). The digestive tube from the lips to the end of the rectum.

Al'ka-li (Arabic al kali, soda-ash). Certain substances, such as soda, potash, and the like, which unite with acids to form salts. 
Al-ve'0-lus, pl. alveoli (Lat. alveolus, a little hollow). A small cavity, or socket, as the sockets for the teeth in the jawbone, the air sacs of the lungs, and the secreting recesses of certain glands.

A-mœ'ba (Gr. $\dot{a} \mu o \iota \beta \hat{\eta}$, a change). A single-celled, protoplasmic organism, which is constantly changing its form by protrusions and withdrawals of its substance.

A-mœ'boid. Like an amœba in form or in movement.

Am-pul'la (Lat. ampulla, a wine flask). The dilated part of the semicircular canals of the internal ear.

Am'y-lop'sin (Gr. a $\mu \nu \lambda o \nu$, starch, and $\delta \psi \iota s$, appearance). A ferment found in the pancreatic juice, which changes starch into sugar.

A-nab'o-lism (Gr. ávaßá $\lambda \epsilon \iota \nu$, to throw or build up). The process by which simpler elements are built up into more complex.

An'æs-thet'ic (Gr. åv, without, and ai $\sigma \theta \eta \sigma i a$, feeling). A substance which produces insensibility to pain or to touch, etc., as chloroform, ether, etc. An'ti-dote (Gr. a $v \tau i$, against, and $\delta \delta^{\prime} \delta \nu a \iota$, to give). A substance given to prevent or counteract the action of a poison.

An'ti-sep'tic (Gr. avti, against, and $\sigma \dot{\eta} \psi(s$, poison). A remedy or agent which prevents the development of bacteria, or prevents the growth of bacteria upon which putrefaction depends.

An'ti-tox'in (Gr. a $\nu \tau \ell$, against, and $\tau 0 \xi \iota \kappa \delta \nu$, poison). A substance which neutralizes the action of the toxins of bacteria. Antitoxins are used in the treatment of certain infectious diseases, like diphtheria.

An'trum (Lat. antrum, a cave). The cavity in the upper jaw.

Ap'o-neu-ro'sis (Gr. ámb, from, and $\nu \in \hat{v} \rho \circ \nu$, a nerve). A fibrous, membranous expansion of a tendon.

Ap'pa-ra'tus. Used to designate collectively organs which perform a certain function.

Ap-pen'di-ci'tis (Lat. appendix, and itis). Inflammation of the appendix vermiformis of the cæcum.

A'que-ous hu'mor (Lat. aqua, water). The watery fluid occupying the space between the cornea and crystalline lens of the eye.

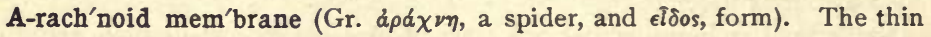
covering of the brain and spinal cord, between the dura mater and the pia mater.

Ar'bor vi'tæ. Literally, "the tree of life"; a name given to the tree-like appearance of a section of the cerebellum.

A-re'o-lar tis'sue (Lat. areola, a small space, dim. of area). Connective tissue containing small spaces.

Ar-tic'u-la'tion (Lat. articulus, a joint). The more or less movable union of bones, etc. ; a joint. 


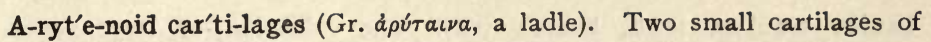
the larynx, resembling the mouth of a pitcher.

As-phyx'i-a (Gr. $\dot{a}$, without, and $\sigma \phi \dot{v} \xi \iota s$, the pulse). Suffocation. The suspension of vital phenomena when the lungs are deprived of oxygen.

As-sim'i-la'tion (Lat. $a d$, to, and similis, like). The conversion of food into living tissue.

A-stig'ma-tism (Gr. $\dot{a}$, without, and $\sigma \tau \ell \gamma \mu a$, a point). Irregular refraction of the eye, producing a blurred image.

At'ro-phy (Gr. $\dot{a}$, without, and $\tau \rho \circ \phi \dot{\eta}$, nourishment). Wasting of a part from lack of nutrition.

Ba-cil'lus (Lat. dim. of baculum, a staff). Microscopic, rod-shaped form of bacteria.

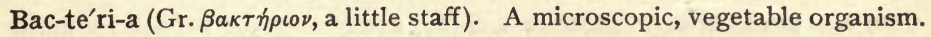

Bac-te'ri-cide (bacterium and Lat. caedere, to kill). An agent that destroys bacteria.

Bi-ol'o-gy (Gr. Blos, life, and $\lambda$ óyos, a discourse). The science of life.

Blad'der (Saxon bleddra, a bladder, a goblet). A bag, or sac, serving as a receptacle of some secreted fluid, as the gall bladder, etc.

Bright's dis-ease'. Disease of the kidneys, first described by Dr. Bright, an English physician.

Bron-chi'tis. Inflammation of the bronchial tubes.

Bur'sa. A small sac interposed between parts that move upon one another.

Cal'lus (Lat. callus, hardness). An excessive hardness of the skin caused by friction or pressure; the tissue which unites parts of a broken bone.

Cap'il-la-ry (Lat. capillus, hair). A minute vessel, as those that connect by a network the arteries and veins.

Cap'sule (Lat. capsula, a little chest). A receptacle, or bag.

Car'bon di-ox'ide. A gas produced in the respiration of animals, and in the decay or combustion of organic matter. Often called carbonic acid.

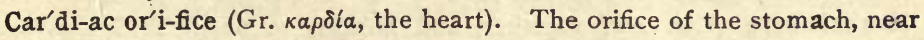
the heart.

Car'ron oil. A mixture of equal parts of linseed oil and lime water.

Car'ti-lage. Gristle. A tough but flexible connective tissue forming a part of the joints, air passages, nostrils, ears, etc.

Car'un-cle (lach'ry-mal) (Lat. caro, flesh). The small, red, conical-shaped swelling at the inner angle of the eye.

Ca'se-in (Lat. caseus, cheese). A proteid substance found especially in milk. The principal ingredient in cheese.

Ca-tarrh'. Inflammation of a mucous membrane. 
Cau'da e-qui'na (Lat., horse's tail). The collection of large nerves descending from the lower end of the spinal cord.

Cell (Lat. cella, a storeroom). One of the ultimate units of which all living bodies are composed. A granular mass of protoplasm containing a nucleus. Cer'e-bel'lum (Lat. dim. of cerebrum, the brain). The part of the brain lying below the cerebrum and above the pons and medulla oblongata.

Cer'e-brum. The brain proper, occupying the upper portion of the skull. Ce-ru'mi-nous (Lat. cerumen, ear wax). Pertaining to cerumen, or ear wax. Chlo'ral. A powerful drug and narcotic poison used to produce sleep.

Chlo'ro-form. A narcotic poison generally used by inhalation; of extensive use in surgical operations to produce anæsthesia.

Chon'drin (Gr. $\chi^{b v \delta \rho o s, ~ c a r t i l a g e) . ~ A ~ k i n d ~ o f ~ a l b u m i n o i d ~ r e s e m b l i n g ~ g e l a-~}$ tine obtained by boiling cartilage.

Chordæ ten-di'ne-æ. Tendinous cords,. connecting the papillary muscles of the heart with the auriculo-ventricular valves.

Cho'roid (Gr. $\chi 6 \rho \iota \nu$, skin, and $\epsilon i \delta o s$, form). The middle coat of the eyeball. Cil'i-a (Lat. pl. of cilium, an eyelash). Minute thread-like processes found upon the cells of the air passages and other parts.

Cil'ia-ry mus'cle. A small muscle of the eye which assists in accommodation.

Cir'cum-val'late (Lat. circum, around, and vallum, a rampart). The name given to certain papillæe of the tongue.

Co-ag'u-la'tion (Lat. coagulare, to curdle). The process by which a liquid like blood or milk clots, or solidifies.

Co'ca-ine. A bitter, white substance obtained from the leaves of coca, capable of producing local insensibility to pain when applied to the surface of mucous membranes or injected under the skin.

Coch'le-a (Lat. cochlea, a snail shell). The spiral cavity of the internal ear. Co-lum'næ car'ne-æ. Fleshy projections in the ventricles of the heart.

Co'ma (Gr. $\kappa \hat{\omega} \mu a$, lethargy). A deep stupor from which it is difficult or impossible to arouse a person.

Com'mis-sure (Lat. con, together, and mittere, to put). A bridge-like structure uniting similar parts.

Com'press. A pad or bandage applied directly to an injury.

Con'cha (Gr. $\kappa 6 \gamma \chi \eta$, a mussel shell). The shell-shaped portion of the external ear.

Con-ges'tion (Lat. con, together, and gerere, to bring). Abnormal collection of blood in a part or organ.

Con'junc-ti'va (Lat. con, together, and jungere, to join). A thin layer of mucous membrane which lines the eyelids and covers the front of the eyeball, thus joining the latter to the lids. 
Con-sump'tion (Lat. consumere, to consume). A wasting disease like tuberculosis, especially pulmonary tuberculosis.

Con-ta'gion (Lat. con, with, and tangere, to touch). The process by which a specific disease is communicated from one person to another, either by contact or by means of an intermediate agent. Also the specific germ, or virus, which causes a communicable disease.

Con'trac-til'i-ty (Lat. con, together, and trahere, to draw). The property of a muscle which enables it to draw its extremities closer together.

Con'vo-lu'tions (Lat. con, together, and volvere, to roll). Tortuous foldings, as those of the external surface of the brain.

Co-ör'di-na'tion. The manner in which several different organs of the body are brought into such relations with one another that their functions are performed in harmony.

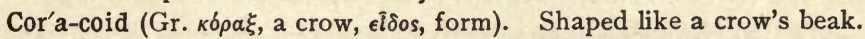

Cor'ne-a (Lat. cornu, a horn). The transparent horn-like substance which covers a part of the front of the eyeball.

Cor'o-na-ry (Lat. corona, a crown). A term applied to vessels and nerves which encircle a part or organ, as the coronary arteries of the heart.

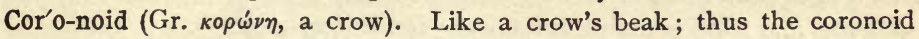
process of the ulna.

Cri'coid (Gr. kpikos, a ring, and $\epsilon i \delta o s$, form). A cartilage of the larynx resembling a seal ring in shape.

Crys'tal-line lens (Lat. crystallum, a crystal). One of the refractive media of the eye; a double-convex body situated in the front part of the eyeball.

Cu'mu-la-tive. The action from drugs which supervenes after the taking of several doses with little or no effect.

Cu'ti-cle (Lat. dim. of cutis, the skin). Scarf skin; the epidermis.

Cu'tis (Gr. $\sigma \kappa v \hat{\tau}$ 'os, a skin, or hide). The true skin, also called the dermis.

De-gen'er-a'tion (Lat. degenerare, to grow worse, to deteriorate). A morbid process in the structure of an organ by which its tissues are converted into some inert substance.

Deg'lu-ti'tion (Lat. deglutire, to swallow). The act of swallowing.

Den'tine (Lat. dens, dentis, a tooth). The hard substance which forms the greater part of a tooth; ivory.

De-o'dor-ant (Lat. de, without, and odorare, to smell). A substance which removes or conceals offensive odors.

Dex'trin (Lat. dexter, right). A soluble carbohydrate into which starch is converted by diastase or dilute acids or by dry heat.

Dex trose' (Lat. dexter, right). Grape sugar.

Di-as'to-le (Gr. $\delta i a \sigma \tau \lambda \lambda \epsilon \epsilon \nu$, to dilate). The relaxation of the heart. 
Dip'10-ē (Gr. $\delta \iota \pi \lambda_{0} \eta^{\prime}$, a fold). The spongy, osseous tissue between the dense outer and inner tables of the skull.

Dip'so-ma'ni-a (Gr. $\delta$ i $\psi a$, thirst, and $\mu a v i a$, madness). The uncontrollable desire for spirituous liquors.

Dis'in-fec'tants. Agents used to destroy the germs of disease, fermentation, and putrefaction.

Dis'lo-ca'tion (Lat. dislocare, to put out of place). An injury to a joint in which the bones are displaced or forced out of their sockets.

Dis-sec'tion (Lat. dis, apart, and secare, to cut). The cutting up of an animal in order to learn its structure.

Du'o-de'num (Lat. duodeni, twelve). The first division of the small intestines, about twelve fingers' breadth long.

Dys-pep'si-a (Gr. $\delta u_{s-}$, ill, and $\pi \dot{\epsilon} \pi \tau \epsilon \iota \nu$, to digest). Disturbed digestion.

Dysp-nœ'a (Gr. sús-, difficult, and $\pi \nu \epsilon \epsilon \iota \nu$, to breathe). Difficult breathing.

Ef'fer-ent (Lat. efferre, to carry out). Bearing or carrying outwards, as from the center to the periphery.

Ef-flu'vi-a (Lat. effuere, to flow out). Offensive odors coming from the body, and from decaying animal or vegetable substances.

El'e-ment (Lat. elementum). One of the simplest parts of which anything consists.

E-lim'i-na'tion (Lat. e, out of, and limen, liminis, a threshold). The act of expelling waste matters. Signifies literally "to throw out of doors."

E-met'ic (Gr. émerıkós, causing vomiting). An agent which causes vomiting.

E-mul'sion (Lat. emulgere, to milk). A preparation consisting of a liquid, usually water, containing an insoluble substance, as fat, in suspension.

E-nam'el (Fr. émail). Dense material covering the crown of a tooth.

En'do-lymph (Gr. $\epsilon \nu \delta o \nu$, within, and Lat. lympha, water). The fluid in the membranous labyrinth of the ear.

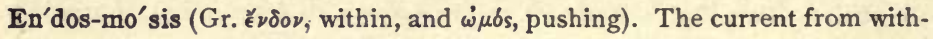
out inwards when diffusion of fluids takes place through a membrane.

En'do-the'li-um (Gr. $\epsilon^{\prime} \nu \delta o \nu$, within, and $\theta \eta \lambda \dot{\eta}$, nipple). The thin epithelium lining the blood vessels, lymphatics, and serous cavities.

En'zyme (Gr. $\epsilon^{\prime} \nu$, in, $\varsigma^{\prime}\langle\mu \eta$, leaven). Any ferment formed within the living organism. A chemical ferment, as distinguished from organized ferments, such as the yeasts. See Ferment.

Ep'i-dem'ic (Gr. $\epsilon \pi i$, upon, and $\delta \hat{\eta} \mu o s$, the people). A disease which affects large numbers, or which spreads over a wide area.

Ep'i-glot'tis (Gr. 'E $\pi l$, upon, and $\gamma \lambda \omega \tau \tau$ 's, the entrance to the windpipe). A leaf-shaped lid which covers the top of the larynx during the act of swallowing. 
Ep'i-lep'sy (Gr. $\dot{\epsilon} \pi i \lambda \eta \psi \iota s$, a seizure). A nervous affection accompanied by fits and sudden loss of consciousness.

E'ther (Gr. $a i \theta \eta \dot{\eta} \rho$, the pure, upper air). A narcotic poison. Its chief use is as an anæsthetic in surgical operations.

Eu-sta'chi-an tube (from an Italian anatomist named Eustachio). The tube which leads from the throat to the middle ear.

Ex-cre'ta (Lat. excernere, to separate). The refuse matter which is passed from the body in any form.

Ex-cre'tion (Lat. excernere, to separate). The separation from the blood of the waste matters of the body; also the materials excreted.

Ex'os-mo'sis (Gr. $\ddot{\xi} \xi \omega$, without, and $\dot{\omega} \theta \epsilon \epsilon \iota \nu$, to push). The current from within outwards when diffusion of fluids takes place through a membrane.

Ex-ten'sion (Lat. ex, out, and tendere, to stretch). The act of restoring a limb, etc., to its natural position after it has been flexed or bent; the opposite of flexion.

Fau'ces (Lat. fauces). The part of the mouth which opens into the pharynx. Fe-nes'tra (Lat.). Literally, "a window." Fenestra ovalis and fenestra rotunda, the oval and the round window; two apertures in the bone between the tympanic cavity and the labyrinth of the ear.

Fer'ment (Lat. fermentum). Any substance which in contact with another substance is capable of setting up changes (fermentation) in the latter, without itself undergoing much change. Ferments are classified into unorganized, or soluble, and organized, or living, ferments. See Enzyme.

Fer'men-ta'tion (Lat. fermentum, boiling). The process of undergoing an effervescent change, as by the action of yeast; in a wider sense, the change of organized substances into new compounds by the action of a ferment. It differs in kind according to the nature of the ferment.

Fi-bril'la (Lat.). A little fiber; one of the longitudinal threads into which a striped muscular fiber can be divided.

Fi'brin (Lat. fibra, a fiber). A proteid substance contained in the flesh of animals, and also produced by the coagulation of blood.

Fol'li-cle (Lat. dim. of follis, a money bag). A little pouch or depression, as the hair follicle.

Fo'men-ta'tion (Lat. fomentare, to keep warm). The application of heat and moisture to a part to relieve pain or reduce inflammation.

Fo-ra'men (Lat. forare, to pierce). A hole, or an aperture.

Fron'tal si'nus. A blind or closed cavity in the bones of the skull just over the eyebrows. 
Fu'mi-ga'tion (Lat. fumigare, to smoke). Disinfection by means of a vapor.

Func'tion (Lat. functio, a doing). The normal or special action of a part.

Gan'gli-on (Gr. $\gamma \dot{\alpha} \gamma \gamma \lambda \iota$ v, a knot). A collection of nerve cells.

Gel'a-tine (Lat. gelare, to congeal). An albuminoid substance which dissolves in hot water and forms a jelly on cooling.

Germ (Lat. germen, a sprout, bud). A portion of matter capable of developing into a living organism, - a micro-organism.

Ger'mi-cide (germ, and Lat. caedere, to kill). An agent which destroys germs, especially bacteria.

Gland (Lat. glans, an acorn). An organ consisting of one or more follicles and ducts, with numerous blood vessels interwoven.

Glot'tis (Gr. $\gamma \lambda \hat{\omega} \tau \tau i a$, the tongue). The space between the vocal cords.

Glu'cose'. A kind of sugar found in fruits, also known as grape sugar.

Gly'co-gen (Gr. $\gamma \lambda u \kappa u ́ s$, sweet, and $\gamma \in \nu \eta \dot{s}$, producing). A substance belonging to the carbohydrates, found especially in the liver; also known as animal starch.

Gust'a-to-ry (Lat. gustare, to taste). Belonging to the sense of taste.

Hæm'o-glo'bin (Gr. alua, blood, and Lat. globus, a globe or globule). A complex proteid substance which forms the principal coloring constituent of the red corpuscles of the blood.

Hem'i-sphere (Gr. $\dot{\eta} \mu l-$, half, and $\sigma \phi a \hat{\imath} \rho a$, a sphere). Half a sphere, the lateral halves of the cerebrum, or brain proper.

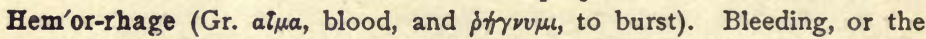
loss of blood.

He-pat'ic (Gr. $\dot{\eta} \pi \alpha \rho$, the liver). Pertaining to the liver.

He-red'i-ty (Lat. hereditas, heirship). The predisposition or tendency derived from one's ancestors to definite physiological actions or anatomical peculiarities.

Hi'lum, sometimes written hilus. A small fissure, notch, or depression, a term applied to the concave part of the kidney.

Ho'mo-ge'ne-ous (Gr. $\delta \mu \delta s$, the same, and $\gamma(\hat{t} v o s$, kind).. Of the same kind or quality throughout; uniform in nature, - the reverse of heterogeneous.

Hu'mor. The transparent contents of the eyeball.

Hy'a-line (Gr. va vos, glass). Glass-like, resembling glass in transparency.

Hy'dro-gen. An elementary gaseous substance, which, in combination with oxygen, produces water.

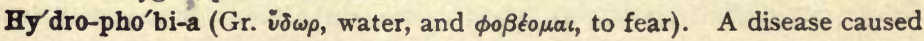
by the bite of a rabid dog or other animal. 


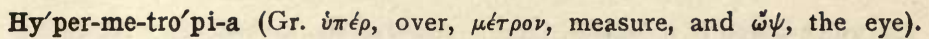
Farsightedness.

Hy-per'tro-phy (Gr. $i \pi \epsilon \rho$, over, and $\tau \rho \circ \phi \eta \dot{\eta}$, nourishment). Excessive growth; thickening or enlargement of any part or organ.

Im-mune' (Lat. immunis, free or exempt). Exempt from certain diseases by inoculation, by previous attack, or by nature.

In-ci'sor (Lat. incaedere, to cut into). Applied to the four front teeth of both jaws, which have sharp, cutting edges.

In'cus. An anvil; the name of one of the bones of the middle ear.

In'di-an hemp. The common name of Cannabis Indica, an intoxicating drug known as hasheesh and by other names in Eastern countries.

In-fec'tion (Lat. in, in, and facere, to make). The communication of disease from one body to another, or from one part to another part of the same individual (auto-infection). The material conveying the disease ; the disease-producing agent.

In-fe'ri-or ve'na ca'va. The vein carrying blood from the lower part of the body into the heart.

In'flam-ma'tion (Lat. in, in, and flammare, to flame). Tissue changes accompanied with redness or swelling of any part of the body, with heat and pain.

In-oc'u-la'tion (Lat. inoculare, to ingraft). The introduction of the germs of disease, generally through the skin, so as to produce the disease.

In-sal'i-va'tion (Lat. in, in, and saliva, spittle). The mingling of the saliva with the food during the act of chewing.

I'ris (Lat. iris, the rainbow). The thin muscular ring which lies between the cornea and crystalline lens, giving the eye its special color.

Jaun'dice (Fr. jaunisse, yellow). A disorder in which the skin, eyes, mucous membranes, and secretions assume a yellowish tint, due to the presence of bile pigments in the blood.

Ka-tab'o-lism (Gr. $\kappa a \tau a \beta a \lambda \lambda \epsilon \iota \nu$, to throw down). The process by means of which the more complex substances are rendered more simple and less complex. The opposite of anabolism.

Lab'y-rinth (Gr. $\lambda a \beta u ́ \rho \iota \nu \theta o s, a$ maze). The internal ear, so named from its many windings.

Lach'ry-mal, or lacrymal apparatus (Lat. lacrima, a tear). The organs for forming and carrying away the tears. 
La-ryn'go-scope (Gr. $\lambda \alpha \rho v \gamma \xi$, larynx, and $\sigma \kappa o \pi \epsilon \hat{\imath} v$, to behold). An instrument consisting of a small mirror which may be held in the throat, and a reflector to throw light on it, by which the interior of the larynx is brought into view.

Lens (Lat., a lentil). A piece of transparent glass or other substance so shaped as either to converge or disperse the rays of light.

Lig'a-ture (Lat. ligare, to bind). A thread of some material used in tying arteries or other parts.

Lymph (Lat. lympha, pure water). The watery fluid in the lymphatic vessels.

Mal'le-us (Lat. malleus, a hammer). The mallet; one of the small bones of the middle ear.

Me-a'tus (Lat. meare, to pass). A natural passage or canal.

Me-dul'la ob-lon-ga'ta. The "oblong marrow," also called the spinal bulb; that portion of the brain which lies upon the basilar process of the occipital bone.

Mei-bo'mi-an. A term applied to the small glands between the conjunctiva and tarsal cartilages, discovered by Meibomius.

Mem-bra'na tym'pa-ni. Literally, "the drum membrane"; the membrane separating the outer from the middle ear.

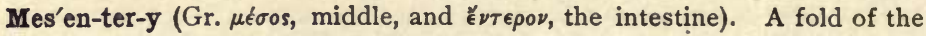
peritoneum, surrounding an intestine, especially the small intestine.

Me-tab'0-lism (Gr. $\mu \epsilon \tau a \beta 0 \lambda \eta$, change). The changes taking place in cells, whereby they become more complex and contain more force, or less complex and contain less force. The former is constructive metabolism, or anabolism; the latter, destructive metabolism, or katabolism.

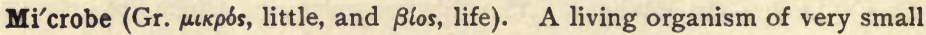
size - a micro-organism - either animal or vegetable.

Mol'e-cule (Lat. dim. of moles, a mass). The smallest portion of a substance which can retain the properties of the substance.

Mor-phol'o-gy (Gr. $\mu \circ \rho \phi \eta$, form, and $\lambda \delta$ oos, discourse). The science that treats of form or structure of organized beings.

Mo'tor (Lat. movere, to move). The name of the nerves which conduct to the muscles the stimulus which causes them to contract.

Mu'cous mem'brane. The thin layer of tissue which covers those internal cavities or passages which communicate with the external air.

Mu'cus. The thin glairy fluid secreted by mucous membranes.

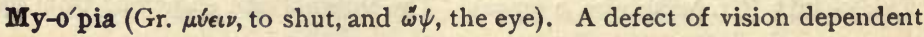
upon too great length of the eyeball, rendering distant objects indistinct; nearsightedness.

My'o-sin (Gr. $\mu \hat{v} s$, muscle). Chief proteid substance of muscle. 


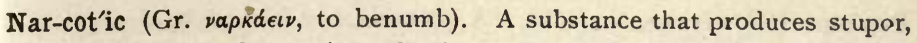
convulsions, and sometimes death.

Nic'0-tine. The poisonous alkaloid found in the leaves of the tobacco plant.

Nu-cle'o-lus (Lat. dim. of nucleus). A small body often found within the nucleus of a cell.

Nu'cle-us (Lat. nucleus, kernel). An essential part of a typical cell, often spherical and usually found near the center.

Nu-tri'tion (Lat. nutrire, to nourish). The processes by which the nourishment of the body is accomplished.

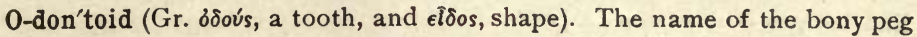
of the second vertebra, around which the first turns.

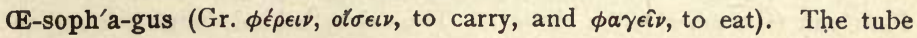
leading from the throat to the stomach; the gullet.

0-lec'ra-non (Gr. $\omega^{\prime} \lambda \epsilon \boldsymbol{\nu} \eta$, the elbow, and $\kappa \rho a v i o \nu$, the top of the head). A curved eminence at the upper and back part of the ulna.

Os-mo'sis (Gr. $\dot{\omega} \sigma \mu \delta s$, impulsion). Diffusion of liquids through membranes. Os'sa in-nom-i-na'ta, pl. of os innominatum (Lat.). The irregular or "unnamed" bones of the pelvis, so called on account of their nonresemblance to any known object:

0 'to-co'ni-a (Gr. oûs, an ear, and kovia, dust). Minute crystals of lime in the vestibule of the ear; also known as otoliths.

$0 \mathrm{x}-\mathrm{i}-\mathrm{da} \mathrm{a}^{\prime}$ tion (Gr. $\delta \xi \dot{v}$ s, sharp). The union of oxygen with other substances, as in combustion. The essential part of burning and of breathing.

Pa-cin'i-an cor'pus-cles (Pacini, an Italian physician). One of the forms of end organs for the sense of touch.

Pal'ate (Lat. palatum, the palate). The roof of the mouth, forming the hard palate, and the curtain at the back of the mouth, called the soft palate.

Pal'pi-ta'tion (Lat. palpitatio, a frequent or throbbing motion). A violent and irregular beating of the heart.

Pa-pil'læ (Lat., a nipple). The small elevations found on the skin and mucous membranes.

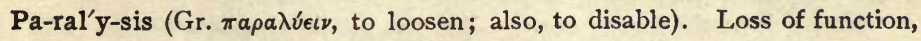
especially of motion or feeling.

Par'a-site (Gr. $\pi a \rho d$, near, and $\sigma \hat{\imath} \tau o s$, food). A plant or animal living upon or within another organism, called the host.

Pel'vis. Literally, "a basin"; the bony cavity at the lower part of the trunk. Pep'sin (Gr. $\pi \epsilon \epsilon \tau \epsilon \iota$, to cook). A ferment found in the gastric juice, and capable of digesting proteids in the presence of an acid. 
Pep'tone (Gr. $\pi \epsilon \pi \tau \epsilon$, to cook). A proteid body formed by the action of ferments on albumins or other proteids during gastric and pancreatic digestion.

Per'i-car'di-um (Gr. $\pi \epsilon \rho l$, about, and $k a \rho \delta i a$, heart). The sac enclosing the heart.

Per'i-os'te-um (Gr. $\pi \epsilon \rho l$, around, and $\delta \sigma \tau t o v$, a bone). A delicate membrane, which invests and nourishes the bones.

Per'i-stal'tic move'ments, or peristalsis (Gr. $\pi \epsilon \rho l$, round, and $\sigma \tau \epsilon \lambda \lambda \epsilon \iota \nu$, to send). The slow, wave-like movements of the stomach and intestines.

Per'i-to-ne'um (Gr. $\pi \epsilon \rho \iota \epsilon \in \epsilon \in \iota v$, to stretch around). The investing membrane of the stomach, intestines, and other abdominal organs.

Pha-lan'ges (Gr. $\phi \dot{\alpha} \lambda a \gamma \xi$, a body of soldiers closely arranged in ranks and files). The bones of the fingers and toes.

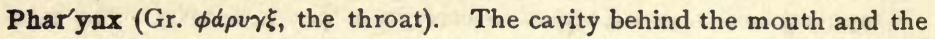
nose, leading to the gullet.

Pi'a ma'ter (Lat.). Literally, "the tender mother"; the innermost of the three coverings of the brain. It is thin and delicate; hence the name.

Pin'na (Lat., a feather or wing). External cartilaginous flap of the ear.

Plas'ma (Gr. $\pi \lambda a ́ \sigma \sigma \epsilon \iota \nu$, to mould). The fluid part of the blood and the lymph.

Pleu'ra (Gr. $\pi \lambda \epsilon v \rho \alpha$, the side, also a rib). A membrane covering the lung and lining the chest.

Plex'us (Lat. plectere, to braid). A network of vessels, nerves, or fibers.

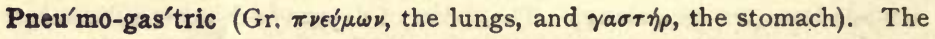
longest of the cranial nerves giving off branches to the lungs, the heart, the alimentary canal, and other parts ; also called the vagus, or wandering nerve.

Poi'son (Fr., from Lat. potio, a draught). A substance that when introduced into the body either destroys life or impairs seriously the function of one or more of its organs.

Pons Va-ro'li-i (Lat. pons, a bridge, and Varolius). The white fibers which form a bridge connecting the different parts of the brain, first described by Varolius.

Pop-li-te'al (Lat. poples, poplitis, the ham, the back part of the knee). The space behind the knee joint is called the popliteal space.

Por'tal vein (Lat. porta, a gate). The venous trunk formed by the veins coming from the stomach and the intestines. It carries the blood to the liver.

Pres'by $-0^{\prime}$ pi-a (Gr. $\pi \rho \epsilon \sigma \beta u s$, old, and $\dot{\omega} \psi$, the eye). A defect of the accommodation of the eye, caused by the hardening of the crystalline lens; the farsightedness of adults and aged persons. 
Proc'ess (Lat. procedere, processus, to proceed, to go forth). Any projection from a surface; also, a method of performance, a procedure.

Pro-na'tion (Lat. pronus, inclined forwards). The turning of the hand with the palm downwards.

Pro-na'tor. A muscle which turns the hand palm downwards.

Pro'te-ids (Gr. $\pi \rho \hat{\omega} \tau$ os, first, and $\epsilon i \delta o s$, form). A general term for the albuminous constituents of the body.

Pro'to-plasm (Gr. $\pi \rho \hat{\omega} \tau o s$, first, and $\pi \lambda \dot{\alpha} \sigma \sigma \epsilon \iota \nu$, to mould). The viscid material constituting the essential substance of living cells, upon which all the vital functions of the body depend.

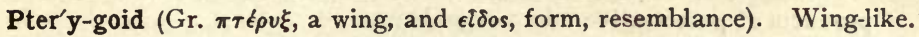

Pto'ma-ine (Gr. $\pi \tau \hat{\omega} \mu \alpha$, a dead body). One of a class of substances, resembling the vegetable alkaloids, formed during the decomposition of proteid. See Toxin.

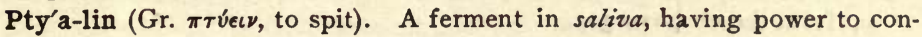
vert starch into sugar.

Pu'pil (Lat. pupilla). The central, round opening in the iris, through which light passes into the interior of the eye.

Pus (Gr. $\pi$ úos, foul). A yellowish white, creamy liquid produced by the process of suppuration. It consists mostly of cells floating in a liquid.

Py-æ'mi-a (Gr. $\pi \dot{v} o \nu$, pus, and aima, blood). A form of blood poisoning produced by the absorption into the blood of morbid matters usually originating in a wound or local inflammation.

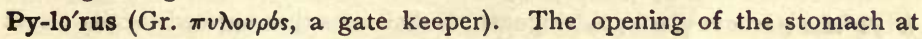
the beginning of the small intestine.

Re'flex (Lat. reflexus, turned back). Involuntary movements or secretion produced by an excitation traveling along a sensory nerve to a center, where it is turned back or reflected along motor or secretory nerves.

Res'pi-ra'tion (Lat. respirare, to breathe). The act of breathing in and breathing out air.

Ret'i-na (Lat. rete, a net). The innermost of the three tunics, or coats, of the eyeball, being an expansion of the optic nerve.

Ri'ma glot'ti-dis (Lat. rima, a chink or cleft). The opening of the glottis.

Roent'gen-rays, see X-rays.

Sar'co-lem'ma (Gr. $\sigma d \rho \xi$, flesh, and $\lambda \epsilon \mu \mu a$, a husk). The membrane which surrounds the contractile substance of a striped muscular fiber.

Scle-rot'ic (Gr. $\sigma \kappa \lambda \eta p b s$, hard). The tough fibrous outer coat of the eyeball. 
Scur'vy. A disease caused by use of improper food for a length of time, having prominent skin symptoms.

Se-ba'ceous (Lat. sebum, fat). Resembling fat; the name of the oily secretion by which the skin is kept flexible and soft.

Se-cre'tion (Lat. secernere, secretum, to separate). The process of separating from the blood some essential, important fluid, which fluid is also called a secretion.

Sem'i-cir'cu-lar ca-nals'. Three canals in the internal ear.

Sep'ti-cæ'mi-a (Gr. $\sigma \eta \pi \tau \iota k \delta s$, putrid, and al $\mu a$, blood). Blood poisoning, a form of poisoning resulting from the presence in the blood of the products of putrefactive micro-organisms.

Se'rum (Lat.). The clear, watery fluid which separates from the clot of the blood.

Spu'tum, pl. sputa (Lat. spuere, sputum, to spit). Matter which is coughed up from the air passages.

Sta'pes (Lat.). Literally, "a stirrup"; one of the small bones of the middle ear.

Ster'il-ize (Lat. sterilis, without power to produce seed). The destruction of micro-organisms, especially by heat. Commonly applied to the preparation of milk for infants and to surgical dressings.

Stim'u-lant (Lat. stimulare, to prick or goad on). An agent which causes an increase of activity in the body or in any of its parts without increasing its supply of energy.

Styp'tics (Gr. $\sigma \tau v \pi \tau \iota k \delta s$, astringent). Substances that applied locally arrest bleeding.

Sub-cla'vi-an vein (Lat. sub, under, and clavis, a key). A great vein, so called because it is situated underneath the clavicle, or collar bone.

Su-pe'ri-or ve'na ca'va (Lat., upper hollow vein). The great vein of the upper part of the body.

Syn-o'vi-a (Gr. $\sigma u ́ v$, with, and w'bv, an egg). The fluid secreted by the synovial membranes, which lubricates the joints; joint oil. It resembles the white of a raw egg.

Sys'to-le (Gr. $\sigma v \sigma \tau \epsilon \lambda \lambda \epsilon \iota \nu$, to contract). The contraction of the heart, by which the blood is expelled from that organ.

Tem'po-ral (Lat. tempus, time, and tempora, the temples). Pertaining to the temples; so called because the hair begins to turn white with age in that portion of the scalp.

Tet'a-nus (Gr. $\tau \in(\nu \in \iota \nu$, to stretch). A disease marked by persistent contractions of all or some of the voluntary muscles; those of the jaw are sometimes solely affected; it is then termed lockjaw. 
Thy'roid (Gr. avptos, a shield, and eîos, form). The largest of the cartilages of the larynx; its projection in front is called Adam's apple.

Tis'sue (Fr. tissu, from Lat. texere, to weave). Any substance or texture in the body formed of various elements, such as cells, fibers, blood vessels, etc., interwoven with each other.

To-bac'co (Indian tabaco, the tube, or pipe, in which the Indians smoked the plant). A narcotic plant used for smoking and chewing, and in snuff.

Toxin (Gr. $\tau 0 \xi \iota \kappa b \nu$, poison). A poison formed by bacteria, in both living tissues and dead substances; a poisonous ptomaine.

Tra'gus (Gr. $\tau \rho a$ ros, a goat). The eminence in front of the opening of the ear; sometimes hairy, like a goat's beard.

Tro-chan'ter (Gr. $\tau \rho \circ \chi \alpha \epsilon^{\prime} \nu$, to turn, to revolve). Name given to two projections on the upper extremities of the femur.

Tryp'sin (Gr. $\tau \rho$ i $\psi$ is, a rubbing). The ferment principle in pancreatic juice which converts proteid material into peptones.

Tu'ber-cle (Lat. tuberculum, a little lump). A pimple, swelling, or tumor; the specific lesion produced by the tubercle bacillus.

Tu-ber'cu-lo'sis (same derivation as tubercle). An infectious disease due to the bacillus tuberculosis discovered by Koch. The form of this disease with marked pulmonary symptoms is popularly known as consumption.

Tu'ber-os'i-ty (Lat. tuber, tuberis, a swelling, a protuberance).

Tur'bi-na'ted (Lat. turbinatus, from turbo, turbinis, a top). Formed like a top ; a name given to the bones in the outer walls of the nasal fossæ.

Tym'pa-num (Gr. $\tau \dot{u} \mu \pi \alpha \nu \circ \nu$, a drum). The cavity of the middle ear, resembling a drum in being closed by two membranes.

U're-a (Gr. oûpov, urine). Chief solid constituent of urine; nitrogenous product of tissue decomposition.

U-re'ter (Gr. oúprí $\rho$, a tube for the urine). The tube through which the urine is conveyed from the kidneys to the bladder.

U'vu-la (Lat. uva, a grape). The small pendulous body at the middle of the soft palate.

Vac'cine vi'rus (Lat. vacca, a cow, and virus, poison). The virus used in performing vaccination, now usually derived directly from heifers affected with cowpox.

Val'vu-læ con-ni-ven'tes (Lat. valvula, a small valve, and connivens, to bring close together). A name given to transverse folds of the mucous membrane in the small intestine.

Var'i-cose (Lat. varix, a dilated vein). Distended or enlarged, as a vein. 
Vas'cu-lar (Lat. vasculum, a little vessel). Pertaining to or possessing blood or lymph vessels.

Va'so-mo'tor (Lat. vas, a vessel, and movere, motum, to move). Causing motion to the vessels. Vasomotor nerves cause contraction and relaxation of the blood vessels.

Ve'næ ca'væ, pl. of vena cava. Literally, "hollow veins"; a name given to the two great veins which meet at the right auricle of the heart.

Ven'ti-1a'tion (Lat. ventilare, to fan). The process of replacing the foul or vitiated air in any room or confined space with air that is pure.

Ver'mi-form (Lat. vermis, a worm, and forma, form). Worm-shaped.

Ves'ti-bule (Lat. vestibulum, a porch). A portion of the internal ear, communicating with the semicircular canals and the cochlea.

Vil'li (Lat. villus, shaggy hair). Minute thread-like projections upon the internal surface of the small intestine.

Vi'rus (Lat., poison). The poison of an infectious disease, especially one found in the secretions or tissues of an individual or animal suffering from an infectious disease.

Vi'tal knot. Common name for that part of the medulla oblongata the destruction of which causes instant death; the respiratory center.

Vit're-ous (Lat. vitrum, glass). Having the appearance of glass; applied to the humor occupying the largest part of the cavity of the eyeball.

Viv'i-sec'tion (Lat. vivus, alive, and secare, to cut). Dissection of a living animal ; experimentation upon an animal while still alive.

Vo'cal cords. Two elastic bands or transverse folds of the larynx.

X-rays, or Roentgen-rays. The peculiar ether rays or waves discovered by Roentgen in 1895 . These rays penetrate substances like wood, the bodily tissues, and many other substances which are opaque to the light of the sun; extensively used in the diagnosis of surgical cases.

Zy-go'ma (Gr. §uyóv, a yoke). The arch formed by the malar bone and the zygomatic process of the temporal bone. 


\section{N D E X}

\begin{tabular}{|c|c|}
\hline & $\mathbf{P A C}$ \\
\hline Absorption . . . . . & \\
\hline by mouth and stomach & 120 \\
\hline by the intestines . & I 21 \\
\hline Accidents and emergencies & 302 \\
\hline chilles, Tendon of . . . & $5^{6}$ \\
\hline ir, made impure by breathing & 174 \\
\hline Necessity of pure & 175 \\
\hline Foul, effect of, on health & 176 \\
\hline cohol, Effect of, on bones & 46 \\
\hline Effect of, on muscularwork & 62 \\
\hline Effect of, on capacity for & \\
\hline physical exercise. & 77 \\
\hline Properties of . . . . & 90 \\
\hline Effects of small quantities & \\
\hline
\end{tabular}

of . . . . . . . 93 not a food. . . . 94 as a poison . . . . 95

Effect of, on gastric digestion . . . . . . 132

Effects of, on the liver . I 33

Effect of, on the blood . 156

Effect of,on the circulation 157

Effect of, on the heart . 158

Effect of, on respiration - I8I

Effect of, on pulmonary

diseases . . . . 182

Effect of, on kidneys . . 205

and the brain . . 230

Effect of habitual use of, upon brain. . . . 232

Self-control weakened by 232

Evil results of, inherited . 233

Alcohol, Effect of, on taste - $\mathbf{2 4 5}$

Effect of, on vision . . 263

Effect of, on throat and voice. . . . . 284

Alcoholic beverages . . . $.90,93$

fermentation . . . . 91

fermentation and bacteria 293

Anabolism defined . . . 5

Anatomy defined .. . . 6

Antidotes for poisons . . 315

Antitoxin treatment of disease 29I

Aorta and its branches . . 145

Apparatus, Question of . . . 318

Appendicitis . . . . . II 2

Arteries . . . . . . 145

Arytenoid cartilages . . . 278

Asphyxia . . . . . 3I I

Astigmatism . . . . . 256

Atmosphere, how made impure 174

Auditory canal . . . . . 265

Backbone .. . . . . $3^{\mathrm{I}}$

Bacteria, Nature of . . . 286

Action of . . . . 287

Disease-producing . . 288

Place of, in nature . . . 288

Disease-producing, in foods . . . . 289

Disease-producing, in soil 289 Access of, to body . . . 290

Diseases caused by . . . 290

Defense of body against . 29I 
Bacteria, Behavior of, within body . . . . . . 292

Behavior of, within wounds . . . . 292

and alcoholicfermentation 293 Bathing, Hints on . . . 197

Salt-water. . . . . 198

Baths, and bathing . . . 195

Hot . . . . . . 196

Cold. . . . . . . 196

Beverages, Fermented . . 92

Bicycle, Use of . . . . . 76

Bile . . . . . . . II 3

Biology defined . . . . 5

Bladder . . . . . . 204

Bleeding, from nose . . . 306

How to stop . . 304, 305

Blood, corpuscles . . . 136, 137

Physical properties of . . 136

Coagulation of . . . 137

Apparatus for circulation of . . . . . . 139

Effect of respiration upon $17 \mathrm{I}$

Gases of . . . . . I7 I

Blood vessels, Nervous control of . . . . . . ${ }^{152}$

Effect of alcohol on . . 157

connected with heart 143,144

Injuries to . . . . 303

Bodies, living, Main features of

our, Facts concerning.

Bone, Chemical composition of

Physical properties of .

Microscopic structure of .

Self-formative power of

Bones, uses of, The . . . . 43

Growth of, how modified . 44

Broken . . . . 45, 309

broken, Treatment for . $\quad 46$ Effect of alcohol on . . 46
PAGES

Bones, Effect of tobacco on . 47

Table of . . . . 48

Brain, as a whole. . . . 210

Weight of . . . . 211

Under surface of . . 21 2

Membranes of . . . 214

Reflex center in . . . 222

Effects of alcohol on . 230-232

Bronchial tubes . . . . 163

Burns or scalds . . . . 306

Capillaries . . . . . I 47

Carbohydrates . . . . . 9

Carpus . . . . . . 37

Cartilage. . . . . 19

Hyaline . . . . . 19

White fibro- . . . 19

Yellow fibro- . . . . 19

Thyroid . . . . 277

Arytenoid . . . . 278

Cricoid . . . . 278

Cells . . . . . . . Io

and the human organism II

Differentiation of . . I I I

Kinds of . . . . . . 12

Vital properties of . . . 13

Epithelial . . . . I 5

Nerve . . . . 207

Cerebellum . . . . . 212

Functions of . . . . 213

Cerebrum . . . . . 2 II

Convolutions of . . . 212

Chemical elements in the body 7

Chest, as air-tight chamber . 168

Chloral . . . . . . 234

Chloroform . . . . . 234

Choroid coat . . . 250

Chyle . . . . . . I 120

Chyme . . . . . 109

Cilia of air passages . . . 164 
Ciliary muscle . . . . 252

Circulation, Portal . . . I49

Pulmonary . . . . 147

Systemic . . . . . 148

Effect of alcohol on . . 157

Clavicle

Cleanliness, Necessity for . 195

Clothing, Use of . . . . 199

Precautions in use of . . 199

Suggestions for use of . 199

Effects of tight-fitting . 200

catching fire . . . 307

Coagulation of blood . . 137

Cocaine . . . . . 235

Coccyx . . . . . . 32

Cochlea . . . . . 268

Coffee. . . . . . 89

Colon . . . . . . . I1 2

Color-blindness . . . . 260

Condiments . . . . . 87

Conjunctiva . . . . $25^{8}$

Connective tissues . . . 16

with elastic fibers . . . I7

with white fibers . . 17

Consumption . . . 297, 317

Contraction, Object of . . 54

Contusions and bruises . 302

Cooking . . . . . 89

Coughing . . . . . 174

Cornea . . . . . 249

Corpuscles, Blood . . . 136

Red . . . . . 136

White . . . . . I 37

Cranial nerves . . . . 217

Cranium, Bones of . . . 27

Cricoid cartilage . . . 278

Crying. . . . . . 174

Crystalline lens . . . 252

Cuticle . . . . . . 187

Cutis vera, or true skin . . 186
Deglutition . . . . . . 104

Diaphragm . . . . . 165

Diet, Important articles of . 83

Too generous . . . 127

Digestion, Organs of . • 98

in small intestines . . . I 8

in large intestines . . I20

Effect of alcohol on . I 32, I 33

Diphtheria . . . . . 298

Disease, Means to avert dan-

ger from . . . . 295

Diseases, infectious and con-

tagious, Management of 297

Hints on nursing . . 30I

Disinfectants, Air and water as 296

Common . . . . 296

Disinfection . . . . . . 296

Dislocations . . . . . 45

Distilled liquors ' . . . 93

Drowning, Apparent . . . 3II

Method of treating . . 3 I $2^{2}$

Duct, Hepatic . . . . . II 4

Common bile. . . . II4

Cystic . . . . . II 4

Thoracic . . . . 123

Nasal . . . . 259

Duodenum . . . . . 109

Ear, External . . . . 264

Middle . . . . 265

Bones of the . . . 266

Internal . . . . 267

Practical hints on care of $27 \mathrm{I}$

Suggestions on care of $\quad 272$

Foreign bodies in . . 308

Eating, Practical points about 129

Eggs as food . . . . . 83

Elements, Chemical, in the body . . . . . 7

Endothelium . . . . 15 
PAGRS

Energy, Potential .

Kinetic .

Epidermis, or cuticle

Epiglottis . . . 104, 162

Epithelium . . . . . 14

Ciliated . . . . 15

Columnar . . . . I 15

Glandular . . . . 15

Squamous. . . . 15

Ether . . . . . . 234

Ethmoid bone . . . . 28

Eustachian tube . . . . 266

Excretion . . . . . . 184

Exercise, Physical . . . 66

Importance of . . . 66

Muscularcoördinationand 67

Effect of, on bodily temperature

Effect of, on circulation and digestion.

Effect of, on digestion . 68

Effect of, on personal appearance

Effect of excessive . 69,70

Amount of, required . . 73

Time for . . . . 74

Physical, in school . . . 76

Effect of alcohol and to-

bacco on capacity for . 77

Practical points about $\quad 77$

Experimental work in physiology

Importance of . . . 317 Expiration . . . . . 167 Eye . . . . . . 247

Inner structure of . . $25 \mathrm{I}$

Refractive media of . 253

Movements of . . . 257

Hints on care of . . 262

Hints on using . . . 262
Eye, how abused

Effect of tobacco and

alcohol on . . . 263

Foreign bodies in . . 309

Eyeball . . . . . . 248

Coats of . . . . 248

Eyelashes and eyebrows . . 258

Eyelids . . . . . . $25^{8}$

Face . . . . . . 28

Bones of the . . . . 29

Fainting . . . . . 310

Fats . . . . . . 9

and oils . . . . $8 \mathrm{r}$

Femur . . . . . 39

Fermentation, Alcoholic . • 91

Nature of . . . . 9I

Fibula . . . . . 39

Fish as food . . . . . $8_{4}$

Fits, Epileptic and hysterical . 310

Food, Necessity for . . . . 79

Waste made good by . $\quad 79,98$

Quantity of, as affected

by circumstances. . . 126

Quantity of, as affected

by occupation . . . 127

Need of variety of . . $\quad 128$

Foods, Classification of . . 80

Nitrogenous . . . . 80

Proteid. . . . . 80

Fatty . . . . . $8 \mathrm{r}$

Starch and sugar . . $8 \mathbf{I}$

Saline . . . . 82

Proteid vegetable . . . 84

Vegetable. . . . 84

Non-proteid animal . . 85

Non-proteid vegetable .85

Table of . . . . 130

Food materials, Table of . . 86

Foot . . . . . . 40 


\section{Index}

PAGES

Foramen magnum

27

Forearm. 36

Fractures, Different kinds of . 45 Framework, Body . . . . 2 I

Frontal bone . . . . . 27

Frost bites . . . . . 307

Fruits as food . . . . . 87

Gall bladder . . . . . II 4

Gastric glands . . . . 107

Gastric juice . . . . 108

Action of . . . . . 108

Glands . . . . . . 99

Salivary . . . . 102

Gastric . . . . . 107

Mesenteric . . . . I23

Lymphatic . . . . . 124

Ductless . . . . 125

Suprarenal . . . 125

Thymus . . . . 125

Thyroid . . . . 125

Sebaceous. . . . . 188

Lachrymal . . . 259

Glottis . . . . . 279

Hair, Growth of . . . . 189

Color of . . . . . 189

Structure of . . . . . 188

and nails, Care of . . 198

Hand .

as a marvel of mechanism . . . . . $3^{8}$

Haversian canals . . . . 25

Head, Bones of . . . . . 27

Hearing, Sense of . . . 263

Mechanism of . . . 269

Effect of tobacco and alcohol on . . . 272

Heart . . . . . . 140

Valves of .
Heart, Blood vessels connected with . . . . . 143, 144 Rhythmic action of . . 150 Impulse of . . . 150 Sounds of . . . . ${ }^{1} 5 \mathrm{I}$ Nervous control of . . I 5 I Effect of alcohol on . . 158 Effect of tobacco on . 158 Heat, Animal ... . . 178

Sources of . . . . 178

Hepatic lobules . . . . II3

duct . . . . . . II4

Hiccough . . . . . 174

Hip bones . . . . . . . 34

Histology defined . . . . 6

Humerus . . . . . 36

Hygiene defined . . . . 6

Hyoid bone. . . . 30, 277

Hypermetropia . . . . 255

Ileum . . . . . . . I Io

Infection, pulmonary, Dangers

of . . . . . . . 177

Influenza. • . . . . . 297

Injured, First aid to . . . 302

Inspiration . . . . . $: 167$

Intestine, Small . . . . . 109

Coats of small . . . . III

Digestion in small . . . 118

Large . . . . . . III

Iris and pupil . . . . 250

Jejunum . . . . . . i Io

Joints . . . . . . 40

Formation of . . 40

Different kinds of . . . 42

Katabolism defined . . . . 5

Kidneys . . . . . . $20 \mathrm{I}$

General structure of . . $20 \mathrm{r}$ 


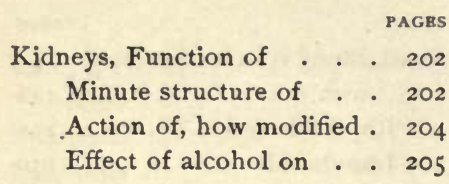

Labyrinth . . . . . 267

Lachrymal apparatus . . 258

bones . . . . . 29

glands . . . . . 259

caruncle . . . . 259

Lacteals . . . . . . 122

Landmarks of the body . . 319

Larynx . . . . . .162, 277

Leg, Bones of . . . . . 39

Lens, Crystalline . . . . 252

Levers in the body . . 57,58

Life, Incessant change of . . 4

Ligaments . . . . . 42

Limbs, Upper . . . . . 34

Lower . . . . $3^{8}$

Liver . . . . . . . 112

Lobules of ... . . II 3

Blood supply of. . . . II 5

Work done by . . . . II5

Formation of urea by . . 117

Glycogenic function of . 117

Effect of alcohol on . . 133

Long sight . . . . . 255

Lungs, General structure of . 165

Minute structure of . . 166

Effect of alcohol on . 181, 182

Lymph . . . . . . I 47

Lymphatics . . . . . . 124

Work done by . . . . 124

Malar bone . . . . . 29

Mastication . . . . . . 99

Maxillary, Superior . . . 29

Inferior . . . . 30

Meals, Suggestions about . . 128
PAGRS

Meats as food . . . . 83

Medulla oblongata . . . 215

Function of . . . 215

Membrane, Synovial . . . 57

Serous . . . . . 141

Membranes of brain . . . 214

Membranous sac . . . 268

Mesenteric glands . . . . 123

Mesentery . . . . I1 1 1 123

Metabolism defined . . . . 5

Metacarpal bones. . . . $3^{8}$

Metatarsal bones . . . . 40

Microscope, Use of . . . 318

Milk .. . . . . 83

Mineral foods . . . . 82

Morphology defined . . . 5

Mouth . . . . 99, 162

What may be seen in . 276

Movement, Mechanics of . . 57

Muscles, Kinds of . . . 49, 55

Microscopic structure of . 50

striated, Structure of . . 50

unstriated, Structure of . $5^{\mathrm{I}}$

unstriated, Action of . . 52

how named . . . . 55

of chest and back . . . 59

of head and neck . . . 59

of lower extremities . . $6 \mathrm{r}$

of shoulder and arm . . 61

Effect of alcohol on . . 62

Effect of tobacco on . . 63

Effect of exercise on . . 66

Review table of . . . 65

Muscular coördination . . . 67

contraction . . 52,54

movements . . . 70

fatigue..... . $7 \mathbf{I}$

sense . . . . . 241

Myopia . . . . . 255 
Nails . . . . . . 189

Care of . . . . 198

Nasal bones . . . . 29

duct . . . . . 259

Near sight . . . . . 255

Nerve cells . . . . 207

fibers . . . . 207, 208

cells and fibers, Function of . 209

Nerves, General structure of . 208

Cranial . . . . . 217

Cranial distribution and functions of . . . 217

Spinal . . . . . 2 I9

Motor . . . . 220

Sensory . . . . 220

Nervous system, General view of . . . . . . 206

compared to telegraph

system . . . . 209

Divisions of . . . 2 IO

Effect of alcohol on . 230

Effect of tobacco on . 235

Nitrogenous foods . . . 80

Non-proteid vegetable foods . 85

animal foods . . . 85

Nose, Bleeding from . . . 306

Foreign bodies in . . 308

Occipital bone . . . . 27

Esophagus . . . . . 104

Old sight . . . . . 254

Opium . . . . . 233

Poisonous effects of . 233

Victim of the, habit . 234

Optic nerve . . . . . 248

Organic compounds . . . 8

Oxidation . . . . 178

Pain, Sense of . . . . 242

Palate bones . . . . 29
Pancreas . . . . . . II7

Pancreatic juice . . . . 118

Papillæ, Kinds of . . . 242

Parietal bones . . . . 27

Patella . . . . . 40

Pelvis . . . . . . 34

Pepsin . . . . . . 108

Pericardium . . . . 140

Periosteum . . . . 23, 25

Peritoneum . . . . . III

Phalanges . . . . 38,40

Pharynx . . . . . 104

Physical exercise . . . 66

Physical exercises in school . 76

Practical points about $\quad 77$

Physiology defined . . 5, 5

in schools . . . . . . I

Lesșons taught by . . . 2

Experimental work in . 317

Pleura . . . . . . 165

Pneumogastric nerve . . I 52, 217

Poisoning, Treatment of . 313

Poisons . . . . . . 313

and their antidotes. . $3^{1} 3$

Practical points about . 3I4

common, Table of . . 315

Antidotes for. . . . 3I5

Prominent symptoms of . 315

Portal circulation . . . . I 49

Portal vein . . . . . . I1 3

Presbyopia . . . . . 254

Pressure, Where and how to

apply . . . . 304

Proteids . . . . . . 9,80

Proteid vegetable foods . . 84

Protoplasm . . . . . IO

Pulmonary artery . . . . 148

veins . . . . . 146

circulation . . . . 147

infection . . . . 177 


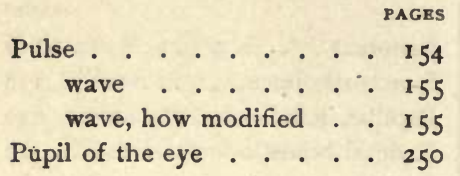

\section{Radius}

Receptaculum chyli .

Rectum

23

Reflex action, Importance of . 223

in spinal cord . . . 222

Reflex centers in the brain . 222

Renal secretion . . . . 204

Respiration, Nature and object of . . . . . . I6I

Essential step in . . $16 \mathrm{r}$

of the tissues. . . . I6I

Mechanism of . . . 168

Nervous control of . . . 169

Effect of, on the blood . I7 I

Effect of, on the air . . 172

Changes of air in . . I 73

Modified movements of . 174

Effect of alcohol on . . $18 \mathrm{r}$

Effect of tobacco on . . 182

artificial, Method of . . 312

Respirations, Frequency of . 168

Rest, for the muscles . . 72

Need of . . . . 227

Benefits of . . . 228

Retina . . . . . 250

Ribs . . . . . . 33

Sacrum . . . . . 32

Saline and mineral foods . . 82

Saliva . . . . . . 102

Salivary glands . . . 102

Salt as food . . . . . 88

Salts, Inorganic, in the body . 8

Scalds or burns . . . . 306

Scapula
Scarlet fever

PAGES

School, Physical exercises in . 76

Sclerotic coat . . . . 249

Secretion . . . . . . 99

Semicircular canals . . . 267

Semilunar valves . . . . 143

Sensation, Condition of . $\quad 238$

Sensations, General . . . 237

Sense, special, Organs of . $\quad 239$

organ, Essentials of $\cdot{ }^{2} 3^{8}$

Serous membranes . . . I4I

Sick room, Location and ar-

rangement of . . . 299

Ventilation of . . 298

Hints for . . . . 299

Additional hints for . 300

Helps for . . . . 300

Sighing ... . . . . 174

Sight, Sense of . . . . 247

Skating,swimming, and rowing 75

Skeleton . . . . . . 24

Study of . . . . 21

Review analysis of . . 48

Skin, General structure of . . 185

as complex organ . . 185

Color of . . . . . 188

regulator of temperature. $\quad 192$

Action of, how modified . 193

Absorbent powers of . . 194

Skull . . . . . . 27

Sutures of . . . 30

Sleep, a periodical rest . . . 228

Amount of, required . . 229

Practical rules about . . 229

Smell . . . . . . 245

and taste .... 246

Sense of . . . 246

Sneezing. . . . . 174

Sobbing . . . . . . . 174

Sounds, Articulate . . . 282 
PAGES

Special senses . . . . . 237

Speech . . . . . . 28 I

Sphenoid bone. . . . . 27

Spinal column . . . . . $3 \mathbf{I}$

Spinal cord . . . . . 218

Structure of .... . 218

Functions of . . . . 220

Reflex center in . . . $22 \mathrm{I}$

Reflex action of . . . 222

Spinal nerves . . . . . 219

Spleen . . . . . . 125

Sprains . . . . . . 44

Stammering . . . . . 283

Starches and sugars . . . $8 \mathrm{I}$

Sternum . . . . . . 34

Stomach . . . . . . 105

Coats of . . . . I07

Digestion in . . . 108

Strabismus . . . . . 258

Stuttering . . . . . 283

Sunstroke . . . . . 310

Suprarenal capsules . . . I25

Sutures of skull . . . . 30

Sweat . . . . . . . I9I

glands ... . . . . 189

Composition and quantity of . . . . . I9I

Visible . . . . . I9I

Secretion of, and nervous control . . . . 193

Number of, glands . . 190

Sympathetic system . . . 224

General functions of . . $\mathbf{2 2 6}$

Special functions of . . 226

Synovial membrane . . . 57

sheaths and sacs . . 57

Taste, Sense of . . . . 244

Effect of tobacco and alcohol on . . . . . .
Taste, Modifications of the sense of . . . 245

Tea . . . . . . . 89

Tear gland and tear passages 259

Tears . . . . . . . 260

Technical terms defined . . 5

Teeth . . . . . . . I00

Development of . . ror

Structure of . . . . IOI

Proper care of . . . 129

Hints about saving . . I 32

Temperature, Regulation of bodily . . . . . I79

Skin as a regulator of .180

Adjustment of . . . I8I

Sense of . . . . 242

Temporal bones . . . . 27

Tendon of Achilles . . . $5^{6}$

Tendons . . . . . 56

Thoracic duct . . . . 123

Throat . . . . . 276

Care of . . . . . 283

Effect of alcohol and to-

bacco on . . . 284

Foreign bodies in . . 308

Thymus gland . . . . I 25

Thyroid gland . . . . 125

cartilage . . . . 277

Tibia . . . . . . 39

Tissue, White fibrous . . . I7

Yellow elastic . . . I7

Adipose . . . . 18

Areolar . . . . . 18

Adenoid . . . . . 19

Tissues, Epithelial . . . . 14

Epithelial, classified . . 14

epithelial, Varieties of . . I5

Connective . . . . 16

Functions of . . . . 16

Tobacco, Effect of, on bones 47 
Tobacco, Effect of, on muscles

Effect of, on physical development .

Effect of, on digestion

Effect of, on the heart

Effect of, on the respiratory passages . .

Effect of, on mental abilities

Effect of, on the nervous system

Effect of, on taste .

Effect of, on vision .

Effect of, on hearing .

Effect of, on throat and voice

Tongue

as organ of taste . . 242

Touch, Organs of. . . . 240

Sense of . . . . 240

how educated . . . $24 \mathrm{I}$

Trachea . . ... . 163

Trunk, Bones of . . . . $3^{1}$

Tuberculosis . . . $\cdot 317-331$

a widespread and deadly disease . . . . 3 37

a very old disease . . 317 what it is . . . . $3^{18}$

Discovery of germ of . 318

Parts of body infected with . . . . 318

Growth and history of germ of .

as a contagious disease 319,320 how germs are scattered 320 Chief mode of communicating . . . 321

Danger in sputum of, 321,322 Early symptoms of . . 322 not inherited. . . 322
PAGES

Tuberculosis, in animals . $\quad 323$

Crusade against . . . . 323

Agencies at work in this crusade . . . . 324

Camps, open-air schools, and sanatoriums in treatment of . . . 325

Open-air treatment of . . 326

Education of general public in regard to . . . 327

Suggestions on protecting health . . $\cdot 327,328$

How school children may help in crusade against

328-330

Turbinated bones. . . . 29

Tympanum, Cavity of . . . 266

Typhoid fever . . . . 298

Ulna . . . . . . 36

Urine . . . . . . 204

Vaccination . . . . 295

Valve, Mitral . . . $\times 142$

Tricuspid . . . . 142

Valves, of the heart . . . 142

Semilunar. . . . 143

Vegetable foods . . . 84,85

Veins . . . . . 145

Flow of blood in . . 146

Ventilation, Object of . . 178

of sick room . . . . 298

Vermiform appendix . . . . II2

Vertebræ, Spinal . . . . 3I

Vestibule of ear .. . . . 267

Vision, Common defects of $254^{-258}$

Effect of tobacco on . . 263

Vivisection and dissection . . 319

Vocal cords . . . . . 278

Voice, Mechanism of . . 279 


\section{Index}

PAGES

PAGES

Voice, Factors in the production of . . . . . 280 Care of . . . . . 284 Effect of alcohol on . . 284 Effect of tobacco on . . 284

Walking, jumping, and running Waste, how made good by food . . . . 79,98 74 Waste material, Nature of $\quad . \quad 184$
Waste products, Elimination of $\quad \mathrm{I} 84$ Formation of . . . . . 184 Water, as food . . . . 82,88 Amount of, in various tissues . . . . 83 Need of pure . . . . 88 Whispering . . . . . 283 Yawning . . . . . . 174 


RETURN TO the circulation desk of any University of California Library

or to the

NORTHERN REGIONAL LIBRARY FACILITY

Bldg. 400, Richmond Field Station

University of California

Richmond, CA 94804-4698

ALL BOOKS MAY BE RECALLED AFTER 7 DAYS

- 2-month loans may be renewed by calling (510) 642-6753

- 1-year loans may be recharged by bringing books to NRLF

- Renewals and recharges may be made 4 days prior to due date

\section{DUE AS STAMPED BELOW JAN 052004}

DD20 15M 4-02 
QP36

$\bar{M} \quad 20 \%$

B59

1910

THE UNIVERSITY OF CALIFORNIA LIBRARY 
